\title{
Charakterisierung der konservierten Domänen des Transkriptionsfaktors N.t.BZI-1
}

\section{Dissertation}

zur Erlangung des Doktorgrades

der Mathematisch-Naturwissenschaflichen Fakultäten der Georg-August-Universität zu Göttingen

vorgelegt von

Markus Kuhlmann

aus Herford

Göttingen, 2002 


\section{D7}

Referentin : Frau Professorin Dr. Christiane Gatz Koreferentin: Frau PD Dr. Gertrud Lohaus

Tag der mündlichen Prüfung : 
für Alexandra 


\section{Das Gleiche lässt uns in Ruhe, aber der Widerspruch ist es, der uns produktiv macht.}




\section{INHALTSVERZEICHNIS}

A Zusammenfassung

B | Einleitung

1 | Transkriptionsfaktoren 2

2 Der bZIP-Transkriptionsfaktor BZI-1 4

3 Die Domänenstruktur von BZI-1 5

4 | BZI-1 reguliert die Auxin-abhängige Genexpression 10

5 | BZI-1 ist in Signalwege der pflanzlichen Pathogenabwehr eingebunden

6 | Zielsetzung der Arbeit

C | Material und Methoden

Geräte

Kits

Nucleinsäuren

Oligonucleotide

Plasmide

DNA-Fragment-Größenstandard

Enzyme

Pflanzen 
2 | $2 \quad$ Anzucht von Pflanzen 27

$2|2| 1 \quad$ Suspensionskultur 27

$2|2| 2 \quad$ Gewebekultur 27

2 | 2 | 2 Klimakammer/Gewächshaus 27

2 | 3 Molekulargenetische Methoden 28

2 2 3 | 11 Isolierung von Plasmid-DNA aus E.coli 28

2 2 3 | 2 Isolierung von Plasmid-DNA aus Agrobakterien 28

2 | 3 | 3 Isolierung von Gesamt-RNA aus Pflanzengewebe 28

2 | 3 | 4 Annealing von Oligonucleotiden 28

2 | 3 | 5 Konzentrations- und Reinheitbestimmung von Nukleinsäuren 28

$2|3| 6 \quad$ Agarosegelelektrophorese 28

2 2 3 | 7 Denaturierende Agarosegelelektrophorese von RNA 29

2 | 3 | 8 Isolierung von DNA-Fragmenten aus dem Agarosegel 29

2 | 3 |9 Restriktionsspaltung 29

$2|3| 10$ Ligation 29

$2|3| 11 \quad$ Polymerase-Ketten-Reaktion 30

2 | 3 | 12 Sequenzierung von Nucleinsäuren 30

2 | 3 | 13 Radioaktive Markierung von DNA-Fragmenten 30

$2|3| 13 \mid 1$ End-Markierung durch die Polynucleotidkinase 30

$2|3| 13 \mid 2$ Markierung durch die Klenow-Polymerase 30

2 | $4 \quad$ Konstruktion von verwendeten Plasmiden 31

2 | 4 | $1 \quad$ Plasmide zur Expression rekombinanter Proteine 31

$2|4| ⿰$\begin{tabular}{l|ll}
2 & Konstrukte zur Pflanzentransformation & 32
\end{tabular}

2 2 4 3 $3 \quad$ Konstrukte zur transienten Expression in Tabak-Protoplasten 32

$2 \mid 5 \quad$ Gentransfer 37

2 | 5 | $1 \quad$ Transformation in Escherichia coli 37

2 | 5 | 2 Transformation von Agrobakterium tumefaciens 37

2 2 5 | $3 \quad$ Stabile Transformation von Nicotiana tabacum 37

2 | 5 | 4 Transiente Transfektion von Nicotiana tabacum-Mesophyllprotoplasten 38

$2 \mid 6 \quad$ Biochemische Methoden 39

$2|6| 1 \quad$ Analyse auf RNA-Ebene (Northern-Blot) 39

$2|6| 1 \mid 1 \quad$ Transfer von RNA-Molekülen auf Nylon-Membranen 39

$2|6| 1 \mid 2$ Hybridisierung und Auswertung 39

$2|6| 2 \quad$ Analyse auf Proteinebene 40

2 |6 | 2 | 1 Expression und Aufreinigung von rekombinanten Proteinen 40

$2|6| 2 \mid 2$ Herstellung eines Antikörpers 40

2 |6 | 2 | 3 Präparation von pflanzlichen Gesamtproteinenextrakten 40

$2|6| 2 \mid 4 \quad$ Präparation von Proteinextrakten für den Kinase-Assay 41

$2|6| 2 \mid 5 \quad$ Präparation von pflanzlichen Kernextrakten 41

2 | 6 | 2 | 6 Bradford-Proteinbestimmung 41

2 | 6 | 2 | 7 Diskontinuierliche SDS-Polyacrylamid-Gelelektrophorese 41

2 |6 | 2 | 8 Coomassie-Protein-Färbung 42

2 |6 | 2 |9 Transfer von Proteinen auf PVDF-Membranen 42

2 |6 | 2 | 10 Immunologische Detektion 42

2 |6 | 2 | 11 Analyse der Phosphorylierung 43

2 | 6 | 2 | 12 Proteinasebehandlung von phosphorylierten Proteinen 43

2 |6 | 2 | 13 Gelretardationsanalysen (EMSA) 43

2 |6 | 2| 14 Reportergenassay 44

$2|6| 3 \quad$ Pathogenitätstests 44 
2 | 6 | 3 | 1 Infektion mit dem Tabak-Mosaic-Virus 44

2 | 6 | 3 | 2 Quantifizierung der bakteriellen Ausbreitung von Pseudomonas syringae 44

2 | 6 | 4 Quantifizierung der Blütengrößen 445

2 | 6 | 5 Fluoreszenzmikroskopische Analysen 45

$2|6| 6 \quad$ Konfokale Mikroskopie 45

D | Ergebnisse 46

1 Vorarbeiten zur Analyse von BZI-1 46

$1 \mid 1 \quad$ Expression rekombinanter Proteine 46

$1 \mid \begin{array}{lll}2 & \text { Herstellung des BZI-1-Antikörpers } & 48\end{array}$

1 | 3 Immunologischer Nachweis der rekombinanten BZI-1-Derivate 49

2 DNA-Bindung von BZI-1 51

2 | 1 Bindung von BZI-1 an das GH3-Promotorelement, die G/C-Box 51

2 | 2 Spezifität der BZI-1-DNA-Bindung durch die basische Domäne 55

3 | Phosphorylierungsstudie des BZI-1 Transkriptionsfaktors 57

3 | $1 \quad$ Phosphorylierung von BZI-1 nach Pathogenstimulus 57

3 | 2 Zuweisung der Phosphorylierungsstellen zu den

BZI-1-Proteindomänen 59

4 | Funktion der konservierten Domänen bei der zellulären

Lokalisierung von BZI-1 63

4 Konstruktion der GFP-Fusionsderivate 63

$4 \mid 2 \quad$ Zelluläre Verteilung der GFP-Fusionsproteine 65

5 | Analyse der Interaktion zwischen Domäne 1 und ANK1 73

5 | 1 In-vitro Nachweis der Interaktion zwischen BZI-1 und ANK1 73

5 | $2 \quad$ Transkriptionelle Regulation der ANK1-Expression nach Elicitierung 75

\begin{tabular}{l|lll}
5 & 3 & Lokalisierung des ANK1-GFP-Fusionsproteins
\end{tabular}

6 | Funktionale Analyse der BZI-1-Domänen 78

6 | 1 Expression von BZI-1-Deletionsderivaten in transgenen

Tabak-Pflanzen 78

6 | 2 Zelluläre Lokalisierung der BZI-1-Deletionsderivate in den Pflanzen 81

6 3 Veränderungen in den Pflanzen durch die Expression von

BZI-1-Derivaten $\quad 82$

6 6 3 | $1 \quad$ Veränderung der Blütengröße 83

6 6 3 | 2 Veränderung der Pollenmorphologie 85

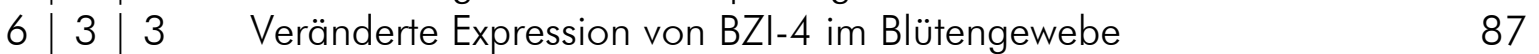

6 6 3 3 4 Veränderung im vegetativen Wuchs 88

6 6 3 3 5 Veränderung der auxinstimulierten Wurzelbildung 90

6 | 3 | $6 \quad \begin{aligned} & \text { Veränderung der Pathogenantwort durch Expression von } \\ & \text { BZI-1-Deletionsderivaten }\end{aligned}$ 
1 Expression von BZI-1-Deletionsderivaten in transgenen Pflanzen: Charakterisierung der konservierten Domänen

2 Die basische Domäne von BZI-1 vermittelt die Spezifität, die Domäne $\mathrm{N}$ moduliert die Bindung an ein G/C-Box-Promorelement des Auxin-responsiven GH3-Gens

3 Die Domänen N, 1, 2 und die basische Domäne sind an der Regulation des Kerntransportes beteiligt

4 Die Domänen N, 1, 4 und die basische Domäne von BZI-1 sind in Prozesse der Blütenbildung und Pollenentwicklung eingebunden

5 | BZI-1 ist durch Phosphorylierungsereignisse an der basischen Domäne und der Domäne 4 in Signalprozesse der Pathogenabwehr eingebunden

6 | Der Bereich der $\alpha$-helicalen Domäne 1 von BZI- 1 interagiert mit dem ANK1-Protein

7 | Ausblick

F | Literaturverzeichnis

1 | Aminosäuresequenz BZI-1

2 DNA Sequenz BZI-1

3 Aminosäuresequenz ANK1

4 DNA-Sequenz ANK1

5 Homologievergleich des ANK 1

6 Ausgemessene Blütenorgane

7 Detektion des Bakterienwachstums

8 Abkürzungen 


\section{A | Zusammenfassung}

Das Protein BZI-1 aus Nicotiana tabacum gehört zur Gruppe C der bZIPTranskriptionsfaktoren. Durch den Homologievergleich zu den verwandten Transkriptionsfaktoren CPRF2, bZIP63 und OHP1 aus Petersilie, Arabidopsis und Mais konnten die Proteindomänen $N, 1,2,3$ und 4, sowie die basische Domäne definiert werden. In der vorliegenden Arbeit sollte die Charakerisierung dieser Proteindomänen in den funktionalen Zusammenhängen erfolgen.

Es konnte durch die EMSA gezeigt werden, dass die DNA-Bindung durch die basische Domäne vermittelt wird. Als spezifisches cis-Element wird neben den G-Box und C-Box enthaltenden Elementen eine chimäre G/C-Box spezifisch gebunden. Die G/C-Box ist an der Regulation von Auxin-induzierbaren Genen wie der GH3 beteiligt. Durch die transgene Expression des BZI-1- $\Delta \mathrm{N}$-Derivates in Pflanzen zeigt sich eine reduzierte Auxin-Antwort.

Neben der DNA-Bindung vermittelt die basische Domäne zusätzlich den Kernimport des Transkriptionsfaktors. Durch die transiente Expression von BZI-1-GFP-Fusionsproteinen konnten ca. $80 \%$ des Proteins kernlokalisiert nachgewiesen werden. Die Domänen N, 1 und 2 sind an der Regulation der Kernlokalisation beteiligt. Der Kernimport wird durch die NLS in der basischen Domäne vermittelt.

Die durch das Hefe-System bekannte Interaktion zwischen dem Domäne 1-Bereich von BZI-1 mit dem ANK1-Protein wurde durch die EMSA-Analyse in vitro belegt. Die Expression des ANK1-Gen wird nach Pathogenstimulus transient negativ reguliert. Die Expression ist BZI-1 unabhängig. Das ANK1-Protein ist vorwiegend cytosolisch lokalisiert.

Durch eine serinspezifische Phosphorylierung nach Pathogenstimulus in den Bereichen der basischen Domäne und der Domäne 4 zeigt sich eine Einbindung von BZI-1 in pathogeninduzierte Signalübertragungen. Aufgrund der phänotypischen Abweichungen nach Infektion von BZI-1-Deletionsderivat-exprimierenden Pflanzen konnte die Beteiligung der Domänen N, 1, 4 und der DNA-bindenden Domäne in diesem Funktionszusammenhang belegt werden.

Durch Expression von BZI- $\Delta \mathrm{N}$-Derivaten traten verkürzte Blüten, missgebildete Pollen und molekular eine verringerte Expression des Gens für den interagierenden BZI-4-bZIPTranskriptionsfaktors auf. Die Domänen N, 1 und die DNA-bindende Domäne sind an der gewebe- und entwicklungsspezifischen Signalverarbeitung beteiligt. 


\section{B | Einleitung}

\section{1 | Transkriptionsfaktoren}

Um die Entwicklung einer Pflanze zu gewährleisten ist eine komplexe Genregulationen notwendig. Der Einfluss von biotischen und abiotischen Faktoren auf eine Pflanze erhöht zusätzlich diese Komplexität. Auf der transkriptionellen Ebene erfolgt in Eukaryoten eine Regulation durch ein Netzwerk unterschiedlicher DNA-bindender Proteine mit variierenden Affinitäten zu DNA-cis-Elementen. Diese Proteine werden als Transkriptionsfaktoren bezeichnet und besitzen einen modularen Aufbau (PTASHNE et al., 1989). So werden die Funktionen wie DNA-Bindung, transkriptionelle Aktivierung oder Interaktion mit anderen Proteinen über bestimmte, als Domänen bezeichnete Bereiche vermittelt. Die Analyse des Genoms der genetischen Modellpflanze Ackerschmalwand (Arabidopsis thaliana) zeigte bisher, dass ca. 5 \% der Gene für Transkriptionsfaktoren codieren (RIECHMANN \& RATCLIFFE, 2000). Von diesen sind bisher erst 10\% näher charakterisiert. Aufgrund ihrer strukturellen Besonderheiten werden diese transaktivierenden Proteine in unterschiedliche Klassen eingeteilt. Eine Übersicht über die wichtigsten Klassen der in Arabidopsis thaliana bekannten Transkriptionsfaktoren wurde 2000 von RIECHMANN \& RATCLIFFE zusammengefasst. Diese Einteilung enthält, gestaffelt nach der Anzahl der bekannten Vertreter die MYB-Faktoren; AP2/EREBP-Ëtylen REsponsives Bindendes Protein; NAC; bHLH-basic Helix Loop ㅂelix-Proteine; bZIP basic Zlpper-Proteine; HBProteine; Zink-finger-Proteine; MADS-Box-Proteine; WRKY-Faktoren und ARF-Auxin Response Faktoren.

Eine Gruppe dieser Transkriptionsfaktoren erhielt ihren Namen nach einer basischen DNAbindenden Region und einem Leucin-Zipper-Motiv (bZIP). Der "Leucin-Reißverschluss", oder Zipper (engl.) ist auf Aminosäureebene eine hydrophobe Region mit einer heptameren Wiederholung von Leucinen oder verwandten Aminosäuren. Durch diese Region können sich Proteine durch hydrophobe Wechselwirkungen zu funktionalen Homooder Heterodimeren zusammenlagern (LANDSCHULZ et al., 1988, MCKNIGHT, 1991).

Aufgrund der basischen Domäne und der benachbarten ZIP-Domäne in der Aminosäuresequenz wurde der in dieser Arbeit untersuchte Transkriptionsfaktor N.t.BZI-1 (N.t.-Nicotiana tabacum) als bZIP-Transkriptionsfaktor klassifiziert. Die DNA-Bindeaffinität 
der bZIP-Proteine ist für ACGT-Kernmotive am größten. Die Spezifität eines bZIPTranskriptionsfaktors für sein cis-Element hängt von den weiteren, das Kernmotiv umgebenden Nucleotiden ab (IZAWA et al., 1992). Durch die Interaktion mit einem anderen bZIP-Protein zu einem Heterodimer kann die Spezifität der Bindung an cis-Elementen verändert werden. In der mittlerweile gut untersuchten Modellpflanze Arabidopsis thaliana sind 75 Mitglieder der bZIP-Transkriptionsfaktor-familie beschrieben (JAKOBY et al., 2002). Diese Faktoren sind in die Signaltransduktion der Pathogen-, Licht- und Stressantwort eingebunden. Aber auch Entwicklungsprozesse, wie die Samenreifung und Blütenentwicklung werden von ihnen beinflusst. Die Fähigkeit der Genaktivierung kann durch unterschiedliche Mechanismen beeinflusst werden. So kann neben einer transkriptionellen Regulation der Menge des Transkriptionsfaktors auch die Aktivität eines Faktors gestevert werden (GBF1, KLIMCZAK et al., 1992). Der Zugang des Faktors zur DNA kann durch eine cytoplasmatische Retention eingeschränkt werden (GBF2, TERZAGHI et al., 1997). Eine Retention ist durch Maskierungen von Kernlokalisierungssignalen oder Komplexbildungen mit anderen Proteinen möglich. Neben einer Retention ist auch das aktive Ausschleusen aus dem Nucleus durch sogenannte Kernexportsequenzen bekannt (HOOD \& SILVER, 1999). Nicht zuletzt kann die Transaktivierung selbst durch Bindung von Cofaktoren oder posttranslationalen Modifikationen beeinflusst werden. Ein häufig anzutreffender Mechanismus in Sigaltransduktionswegen ist die Modifikation durch Phosphorylierung (z.B. GBF1, KLIMCZAK et al., 1992). Durch eine Phosphorylierung können Proteininteraktionen gelöst oder verändert werden und die Tertiärstruktur des Faktors modifiziert werden. Phosphorylierungen werden durch Kinasen vermittelt. Insbesondere im Rahmen der Pathogenantwort der Pflanze konnten Aktivierungen von Kinasen (Pto Serin/Threonin kinase, MARTIN et al., 1993; Calcium-dependent Proteinkinase- CDPK, ROMEIS et al., 1999, 2000, NUHSE et al., 2000) nachgewiesen werden. Ebenso besitzen auch Dephosphorylierungsereignisse Auswirkungen auf die Pathogenantwort. So kann durch eine Mutation von Kinasen die Resistenz erhöht werden (EDR1, eine MAPKKK, FRYE et al., 2001). Dies zeigt, dass die dynamischen Veränderungen im Phosphorylierungsstatus von Proteinen einen wichtige Rolle im frühen Stadium der pathogen-vermittelten Signalübertragung spielen. Dass auch die DNA-Bindeeigenschaft von Transkriptionsfaktoren durch den Phosphorylierungsstatus beeinflusst werden kann, wurde 1997 durch den Faktor G/HBF-1 belegt (DRÖGE-LASER et al., 1997). 


\section{2 | Der bZIP-Transkriptionsfaktor BZI-1}

Der in der vorliegenden Arbeit untersuchte Transkriptionsfaktor BZI-1 stammt aus Tabak (Nicotiana tabacum). Er wird aufgrund seiner Homologie der Gruppe C der bZIPTranskriptionsfaktor-Familie zugeordnet (JACOBI et al., 2002). Diese Einteilung begründet sich in Homologieeigenschaften bezüglich der basischen Domäne, des ZIP-Bereiches und der weiteren Domänenstrukturen zwischen Arabidopsis-bZIP-Trankriptiosfaktoren. Dieser Subfamilie gehören, aufgrund der Homologie, der konservierten Exon-Intron-Struktur und strukturellen Ähnlichkeiten auch CPRF-2 (Petroselinum crispum, WEISSHAAR et al., 1991) und OHP 1 und OHP 2 (Zea mays, PYSH et al., 1993) an. Der vergleichbare, aus dem Arabidopsis thaliana-Genom-Projekt bekannte Transkriptionsfaktor wird als bZIP63 bezeichnet (JAKOBY et al., 2002). Des Weiteren werden dieser Subfamilie die Faktoren aus monokotylen Pflanzen, BLZ-1 (Gerste; Hordeum vulgare, VICENTE-CARBAJOSA et al., 1998) und REB (Reis; Oryza sativa, NAKASE et al., 1997) zugeschrieben. Während dem CPRF-2 eine Funktion in der Lichtsignaltransduktion zugewiesen wird (HARTER et al., 1994), werden den beiden mit Opaque-2 interagierenden Faktoren OHP1 und OHP2 Funktionen im Bereich der Speicherproteinregulation zugeordnet (PYSH et al., 1993). Isoliert wurde BZI-1 ursprünglich als G-Box (CACGTG)- und H-Box III (CACCTACC)- bindender Faktor durch einen South-Western-Screen (DRÖGE-LASER et al., 1997). Dem, als G/HBF-1 bezeichneten, isolierten Protein fehlte der N-terminale Teil und es wurde fälschlicherweise der Sojabohne (Glycine max) zugewiesen. Nach Reisolierung aus einer Nicotiana tabacum cV. SR1 cDNA-Genbank (A. EICK, 1999) konnte das vollständige BZI-1 Protein isoliert werden und die genomische Exon-Intron-Struktur aufgeklärt werden. Das translatierte Protein besitzt eine Größe von 450 Aminosäuren und ein berechnetes Molekulargewicht von 48,4 kDa. Die Aminosäure- und DNA-Sequenz sind dem Anhang zu entnehmen ( $G|1, G| 2)$. Das Gen wird ubiquitär in der Pflanze exprimiert. Die Transkription unterliegt einer lichtabhängigen Regulation mit einer Verstärkung während der Nachtphase. Ca. 5 h nach Pathogenbefall (Pseudomonas syringae und TMV) wird die Transkription leicht verstärkt (HEINEKAMP et al., 2002). Es konnte an dem Protein eine Serin-spezifische Phoshorylierung und eine daraus resultierende verstärkte DNA-Bindung nach Pathogenbefall nachgewiesen werden (DRÖGELASER et al., 1997). 


\section{3 | Die Domänenstruktur von BZI-1}

Transkriptionsfaktoren besitzen einen modularen Aufbau (PTASHNE, 1988), das bedeutet, unterschiedliche Funktionen (wie z.B. DNA-Bindung, Transaktivierung oder Proteininteraktionen) werden durch Domänen mit charakteristischen Eigenschaften vermittelt. Aufgrund eines Homologievergleiches von N.t.BZI-1 mit verwandten Transkriptionsfaktoren lassen sich übereinstimmende Bereiche finden. Diese Bereiche werden aufgrund ihrer strukturellen Charakteristika und der evolutionären Konservierung als Domänen bezeichet. Ihnen werden aufgrund dieser Eigenschaften Funktionen zugeschrieben. Die folgende Abbildung B-1 zeigt die Zuordnung der Domänen im Vergleich zu den nah verwandten Faktoren CPRF-2 (Petroselinum crispum), bZIP63 (Arabidopsis thaliana), REB (Oryza sativa), BLZ-1 (Hordeum vulgare) OHP-1 und 2 (Zea mays) und die schematische Übersicht.

a

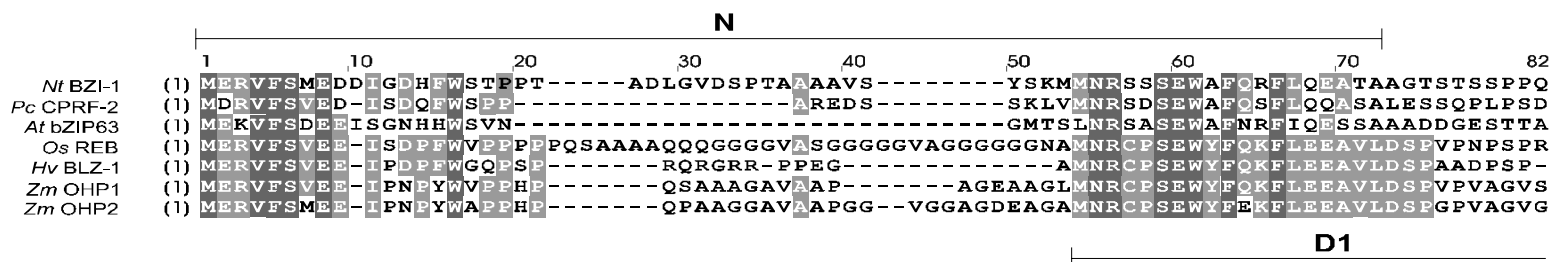

$$
83 \quad 90 \quad 100 \quad 110 \quad 120 \quad 130 \quad 140 \quad 160 \quad 164
$$

NtBZI-1 (70) PPTMTASSSSSSHQNDVVEIKDENLSIPNLNPSTALNSK ASSFGLAPPPNIAVDSE YOAFIRSQIHLACAAVALTRGKSL PC CPRF-2 (57) PVPVAG---DVKN--- -

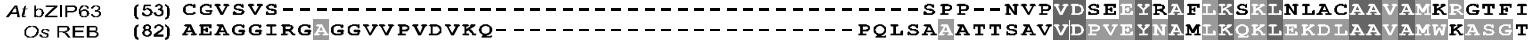
OS REB (18) AEAGGIRG G GVVPVDVKQ
HVBLZ-1 $\begin{array}{ll}Z m \text { OHP1 } & \text { (68) -R--GSVGAGVEAAERKTP-- } \\ \mathrm{Zm} \text { OHP2 } & \text { (73) -R--SSGQAGVEAAESKPL- - }\end{array}$ GAAAPASVS SVVDPVEYNAMLKQKLFHDLAAIA

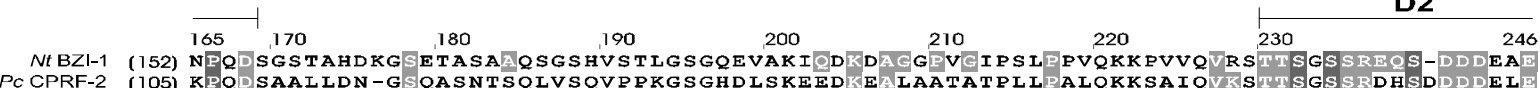
At bZIP63 (94)

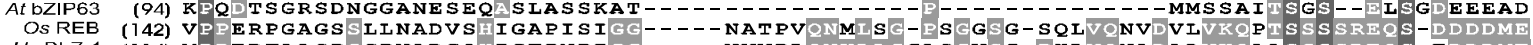
HVBLZ-1 (114) MPPERFAASP SCPNADGQHIGTINPI GG-----NVVPL ONKLACGASEVSG-PHLVENADALVKAASSSSREQS-EDDDME

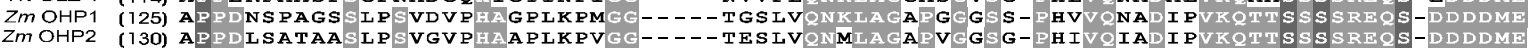
BD
ZIP

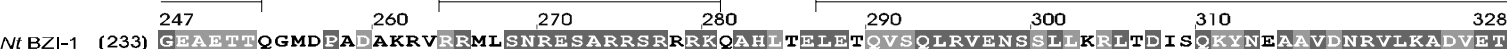
PC CPRF-2 (186) GETETIRNEDESDAKRVRRMISNRESARRSRRRKQAHMTEIETOVSOLRVENSSILKRITDISORYNDAAVDNRVIKADTET

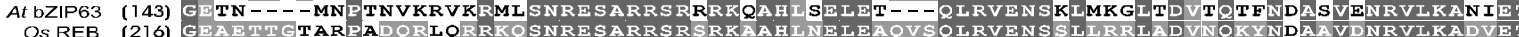

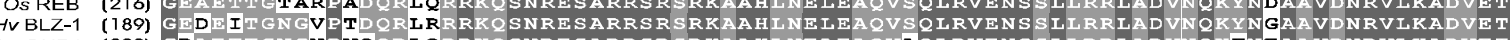

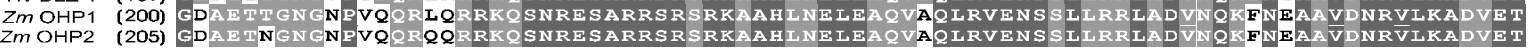
D3

D3

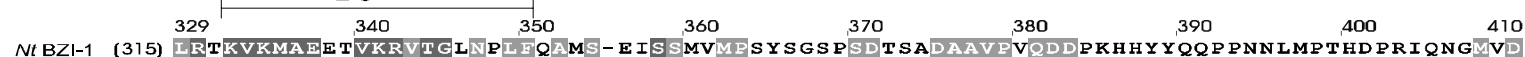

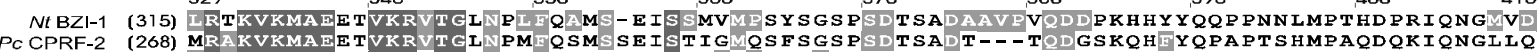
At bZIP63 (218) LRAKVKMAEETVKRLTGFNPM HNMPQIVSTVSLISETSN-OS REB (298) 


\begin{tabular}{|c|c|c|c|c|c|c|c|c|c|}
\hline \multicolumn{10}{|c|}{ Aminosäuren } \\
\hline 72 & 50 & 34 & 56 & 26 & 28 & 51 & 16185 & 58 & 2313 \\
\hline & & & & & & & 00 & & 00 \\
\hline $\mathrm{N}$ & & 1 & & $\|$ & Bas. & Leu cin-Zipper & $\left\|l_{a} \quad\right\|$ & & IV \\
\hline
\end{tabular}

Abb. B - 1: a. Homologievergleich der Transkriptionsfaktoren

$\mathrm{Nt} \mathrm{BZI-1} \mathrm{(Nicotiana} \mathrm{tabacum),} \mathrm{Pc} \mathrm{CPRF-2} \mathrm{(Petroselinum} \mathrm{crispum,} \mathrm{WEISSHAAR} \mathrm{et} \mathrm{al.,} \mathrm{1991),} \mathrm{At} \mathrm{bZIP63} \mathrm{(Arabidopsis}$ thaliana, JAkOBY et al., 2002), Os REB (Oryza sativa, YANG et al., 2001), Hv BLZ-1 (Hordeum vulgare, VICENTECARBAJOSA et al., 1998), Zm OHP1 (Zea mays, PYSH et al., 1993) und Zm OHP2 (Zea mays, PYSH, et al., 1993) mit Kennzeichnung der konservierten Bereiche: N: N-terminale Domäne; D1: Domäne 1;D2: Domäne 2; BD: basische Domäne; ZIP: Leucin-Zipper; D3: Domäne 3 und D4: Domäne 4. Die dunkel unterlegten Aminosäuren sind identisch. b. Schematische Domänenstruktur von N.t.BZI-1 abgeleitet aus dem Vergleich zu anderen Faktoren. N: N-terminale Domäne; I: Domäne 1;ll: Domäne 2; bas: basische Domäne; Leucin-Zipper: Leucin-Zipper; Illa und Illb: Domäne 3, (wobei Illb in a. nicht gekennzeichnet ist) und IV: Domäne 4

Durch den Aminosäuresequenzvergleich ließen sich neben der basischen DNA-bindenden Domäne und dem Leucinzipper fünf weitere konservierte Domänen definieren. Die Domäne $\mathrm{N}$ am $\mathrm{N}$-Terminus des Proteins besitz† einige Proline und damit Struktureigenschaften einer Aktivierungsdomäne (SCHWECHHEIMER et al., 1998, SRENGERHAUSSELS \& WEISSHAAR, 2000). Im verwandten Gerste (Hordeum vulgare)-Protein BLZ-1 konnte den 203 N-terminalen Aminosäuren (bis zur DNA-Bindedomäne) 85\% der Aktivierungseigenschaft des Gesamtproteins im Hefe-"two-hybrid"-System nachgewiesen werden. BLZ1 werden die Funktionen der Genaktivierung im Endosperm zugewiesen (VICENTE-CARBAJOSA et al., 1998). Für die Domäne $N$ von BZI- 1 belegen Daten aus dem Hefe-System die aktivierende Eigenschaft (STRATHMANN et al., 2001). Zusätzlich konnte eine ca. 2-fache Verstärkung der Reportergenaktivität in transienten Reportergenassays mit Mesophyll-Protoplasten duch die N-terminale Domäne von BZI-1 nachgewiesen werden (HEINEKAMP, 2002).

Die Domäne 1 (D1) weist eine Peptidsequenz auf, die in der Lage ist, eine $\alpha$-Helix zu formen. Diese könnte eine potentielle Protein-Protein-Interaktion ermöglichen. Durch eine Hefe-Interaktionsanalyse konnte das Protein ANK1 identifiziert werden (K. HORVAY, 2001). Die Interaktion konnte in dem Bereich zwischen den Domänen $\mathrm{N}$ und 2 des BZI-1-Proteins (Aminosäuren 73-241) eingegrenzt werden. Zusätzlich liegt in diesem Bereich eine potentielle SDPK-Phosphorylierungsstelle. 
Die strukturelle Besonderheit des interagierenden ANK1-Proteins stellten vier sogenannte Ankyrin-Repeats im C-terminalen Teil dar. Diese Ankyrin-Repeats erhalten ihren Namen von dem Ankyrin-Protein, das im Cytoskelett von menschlichen Erythrocyten entdeckt wurde (LUX et al., 1990). Von SEDWICK und SMERDON wurde 1999 die Konsensussequenz auf Aminosäureebene beschrieben. Ein Ankyrin-Repeat beinhaltet 33 Aminosäuren, wobei zwei $\alpha$-Helices auf beiden Seiten von je $2 \beta$-Faltblattstrukturen umgeben sind. In der folgenden Abbildung B-2 sind die Sekundär- und Tertiärsruktur der Ankyrindomänen abgebildet.

Sekundärstruktur :

D--G-TPLHLA---G---VV-LLL--GADVNA-

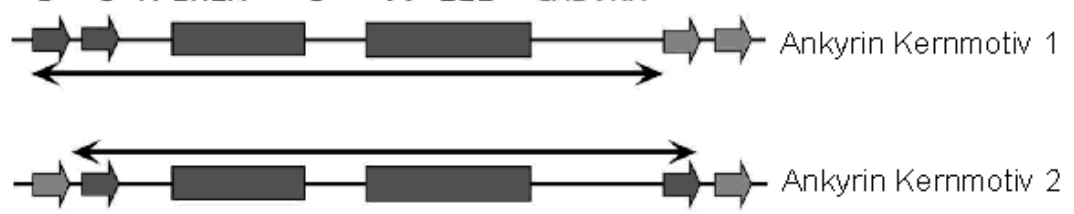

-G-TPLHLA---G---VV-LLL--GADVNA-D-
Tertiärstruktur :

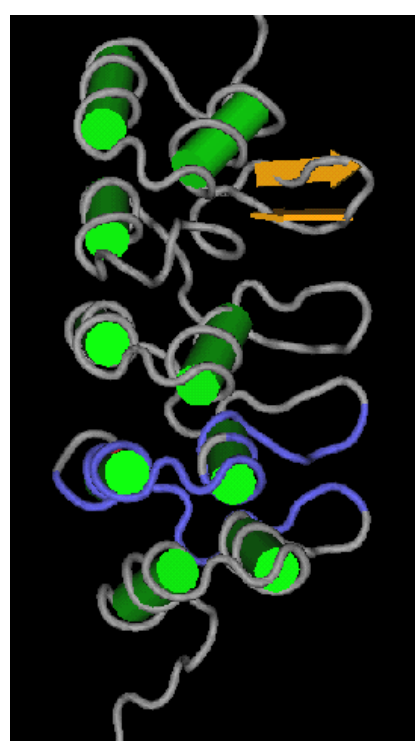

Abb. B - 2: Sekundär- und Tertiärstruktur von Ankyrin-Repeat-Domänen.

In der Sekundärstruktur ist die Konsensussequenz (SEDWICK and SMERDON, 1999) angegeben. Die Pfeile (rechts: orange) bezeichnen die $\beta$-Faltblattstrukturen, die Balken (rechts: grün) die $\alpha$-Helices. In der Abbildung der Sekundärstruktur werden 2 Ankyrin-Repeats dargestellt. In der Abbildung der Tertiärstruktur repräsentiert der blaue Bereich einen Ankyrinrepeat.

Den Ankyrin-Repeats wird insbesondere ein Funktion als Protein-Protein-InteraktionsDomäne zugeschrieben. Proteine mit Ankyrin-Repeats sind in allen Organismengruppen mit unterschiedlichsten Aufgaben verbreitet. Einige der bekanntesten Vertreter sind das Zellzyklus-regulierende CDC10p aus Hefe (Saccharomyces cerevisiae; OLIVER et al., 1992) und entwicklungsbiologisch relevante Transmembran-Rezeptoren wie Notch (Drosophila melanogaster, WHARTON et al., 1985) oder LIN-12 (Caenorhabditis elegans, GREENWALD et al., 1983). Ein weiteres regulatorisches Protein mit Inhibitoreigenschaften ist $I_{\kappa} B \alpha$. Dieses Protein bildet einen Komplex mit dem Transkriptionsfaktor NFאB, wodurch eine Maskierung einer Kernlokalisierungssequenz (NLS) erfolgt und die Inhibierung durch eine 
Cytoplasma-Retention des Komplexes bewirkt wird (JACOBS et al.,1998, HUXFORD et al., 1998). NFאB besitzt seine Funktion in der Signaltransduktion von inflammatorischen Prozessen. Ein weiteres Protein mit Ankyrin-Repeats aus der Pflanze (Arabidopsis thaliana) stellt das NPR 1 (non-expressor of PR-Genes)-Protein dar. Durch Mutanten konnte gezeigt werden, dass das Protein in die Salicylsäure-induzierte PR-Genexpression involviert ist. Es interagiert mit Mitgliedern der TGA/OBF Familie der bZIP-Transkriptionsfaktoren TGA 2 und 3 (mit TGA 5 und 6 schwach) aus Arabidopsis thaliana über den Ankyrin-Repeat (ZHOU et al., 2000). Eine entsprechende Interaktion verwandter Faktoren konnte auch in Tabak nachgewiesen werden (NIGGEWEG et al., 2000). In Arabidopsis thaliana sind zudem zwei ANK-homologe Proteine bekannt. Dies ist zum einen das ATPhos43 (Acc. Nr.: AAB86516). Das Gen dieses Proteins ist auf dem Chromosom 2 lokalisiert und das Protein wird nach Elicitierung phosphoryliert (PECK et al., 2001). Als zweites hochhomologes Protein konnte das AKR2 (Acc. Nr.: AAD10949 oder ARP2 Acc. Nr.: CAB54873 oder AFT-Protein Acc. Nr.: AAC33264) identifiziert werden. Das AKR2 wurde durch Interaktionen mit einem

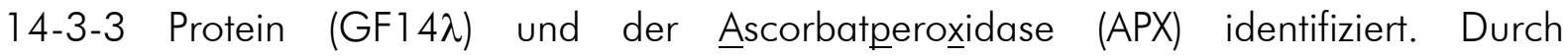
Verringerung der AKR2-Menge in planta konnte, aufgrund einer verstärkten Pathogenantwort und Resistenz, dem Protein eine Beteiligung in der Entwicklung der Pathogenantwort nachgewiesen werden (YAN et al., 2002).

Die Domäne 2 (D2) zeichnet sich durch relativ viele saure Reste aus. Eine Funktion als Aktivierungsdomäne konnte im Hefe-"two-hybrid"-System jedoch nicht nachgewiesen werden (STRATHMANN, 1999). Zentral befindet sich in diesem Bereich eine, zwischen allen Proteinen hoch konservierte, putative Caseinkinase-II-Phosphorylierungsstelle (-SDDD-, PINNA, 1997). Dem verwandten Protein CPRF-2 konnte eine lichtregulierte Translokation in den Kern nachgewiesen werden (KIRCHER et al., 1999). Als hierfür wichtige Domänen werden die Domänen 1 und 2 herausgestellt. Im Rahmen eines Modells wird eine cytosolische Retention des Proteins durch eine intra- oder intermolekulare Interaktion unter Beteiligung der Domäne 1 postuliert (KIRCHER et al.,1999).

Domäne 3 (D3) weist Ähnlichkeiten zu einer Domäne aus dem tierischen Transkriptionsfaktor MyoD auf. Für die entsprechende Domäne des CPRF-2 konnte durch Deletionsstudien eine Veränderung der Dimerstabilisierung postuliert werden (ARMSTRONG et al., 1992).

Die Domäne 4 weist zwischen den verwandten Faktoren ebenfalls eine hohe Ähnlichkeit auf. Hier liegen an exponierten Stellen ebenfalls einige Serine als potentielle 
Phosphorylierungsstellen. Für das vergleichbare Protein CPRF-2 konnte in der Cterminalen Hälfte (196-401 AA) ein lichtabhängiges Phosphorylierungsereignis durch eine 40 kDa schwere, cytosolische Kinase nachgewiesen werden (WELLMER et al, 1999).

Der Leucin-Zipper im mittleren Bereich des Proteins vermittelt die Dimer-Bildung von bZIPProteinen. Durch die Bildung von Homo- oder Heterodimeren kann die Spezifität der Bindung eines Transkriptionsfaktor-Komplexes an cis-Elemente in effektiver Weise reguliert werden. So kann zum Beispiel durch eine Mengenveränderung eines Faktors in unterschiedlichen Geweben die Zusammensetzung von Homo- und Heterodimeren verschoben werden. Für die bZIP-Transkriptionsfaktoren CPRF-1,-2 und -3 aus Petersilie (Petroselinum crispum) konnte gezeigt werden, dass diese bevorzugt Heterodimere bilden (ARMSTRONG et al., 1992). Der Faktor CPRF-4a zeigt ein selektives Heterodimerisierungsverhalten mit CPRF-1 und eine Homodimer-Bildung. Nicht jedoch mit dem BZI-1-verwandten Faktor CPRF-2 (KIRCHER et al., 1998). Des Weiteren konnten die Faktoren CPRF6 und CPRF7 als CPRF2-interagierende Proteine identifiziert werden (RUGNER et al., 2001).

In Hefe-Interaktionsversuchen konnten mit BZI-1 im Bereich des Leucinzippers interagierende Proteine isoliert werden. Die interagierenden Proteine sind relativ kleine Transkriptionsfaktoren mit langen Leucin-Zipper-Bereichen (9 heptamere LeucinWiederholungen). Sie wurden als BZI-2 (19,4 kDa), -3 (16,6 kDa) und -4 (15,6 kDa) bezeichnet (STRATHMANN et al., 2002). Aufgrund ihrer Größe und Homologien im basischenund Leucin-ZIP-Bereich werden sie der Gruppe $S$ zugeordnet (JAKOBY et al., 2002). Durch die Hefe-"two-hybrid"-Analyse zeigte sich ein bevorzugtes Heterodimerisierungsverhalten von BZI-1 mit diesen Gruppe S-Faktoren (STRATHMANN et al., 2001). Durch ein differenziertes Dimerisierungsverhalten mit den bezeichneten Faktoren lässt sich so ein diffiziles Signaltransduktionsnetzwerk mit der Verrechnung unterschiedlichster Umwelteinflüsse darstellen. Das interagierende BZI-2-Protein weist beispielsweise eine hohe Homologie und ein vergleichbares Expressionsmuster zu dem Saccharose-reprimierten und "sink"gewebespezifisch-exprimierten ATB2 (ROOK et al., 1998) aus Arabidopsis thaliana auf. BZI3 wird im vegetativen Bereich der Pflanze nur schwach exprimiert und die Expression ist ebenso wie bei dem verwandten bZIP-Transkriptionsfaktor TBZ17 (KUSANO et al.,1998) Kälte-induzierbar. BZI-4 weist durch seine gewebespezifische Expression und damit stamenspezifisch ermöglichte Heterodimerbildung mit BZI-1, auf die Verarbeitung von entwicklungsbiologisch wichtigen Signalen hin. 


\section{4 | BZI-1 reguliert die Auxin-abhängige Genexpression}

Wie in vorausgegangenen Arbeiten gezeigt werden konnte, führt die transgene Expression von BZI-1- $\Delta$ N-Derivaten und überaktivierenden VP16-BZI-1-Derivaten in Pflanzen zu Veränderungen im vegetativen Wuchs. Während die BZI-1- $\Delta \mathrm{N}$-Derivat-exprimierenden Pflanzen einen gestauchten Wuchs, vermehrte Seitensprosse und dunkelgrüne Blätter besaßen, zeigten die VP16-BZI-1-Derivat induziert exprimierenden Pflanzen einen letalen Phänotyp (HEINEKAMP, 2002). Die endogene Auxinkonzentration in den BZI-1- $\Delta$ N-Derivatexprimierenden Pflanzen zeigte keine Veränderung gegenüber den Wildtyp-Pflanzen. Durch die Analyse der Auxin-stimulierten Wuzelbildung von Blattexplantaten konnte auf eine Beteiligung des zu untersuchenden Transkriptionsfaktors in der Auxinsignalverarbeitung geschlossen werden. Das Pflanzenhormon Auxin reguliert die Zellelongation, die Zellteilung und die Differenzierung der Zellen (ABEL \& THEOLOGIS, 1996). Es ist beteiligt an der Ausbildung der Apikaldominanz, der tropistischen Ausrichtung, der Ausbildung von Seitenwurzeln, von vasculärem Gewebe und der Seneszenz von Blättern (MACDONALD, 1997). Aus dieser Vielzahl von Effekten ergibt sich auch die Komplexität der Auxinsignalverarbeitung und Einbindung von gewebe- und umweltspezifischen Einflüssen in den Auxinsignaltransduktionsweg. Auxin, oder Indol-3-Essigsäure (indole-3-acetic-acid, IAA) wird im Apikalmeristem der Pflanze synthetisiert. Aus dem Apex erfolgt ein unidirektionaler Transport durch das vasculäre System zu den basalen Geweben (PALME \& GÄLWEILER, 1999). Soweit mittlerweile aufgeklärt, erfolgt die Auxinsignalverarbeitung auf molekularer Ebene über kleine kurzlebige kernlokalisierte Aux/IAA-Proteine mit hoch konservierten Domänen (ABEL et al., 1994, WALKER \& ESTELLE, 1998). Über diese Domänen kann eine Interaktion und Regulation mit Auxin-responsiven Faktoren (ARF) erfolgen. Diese ARFs sind in der Lage an ARE oder AuxRE (Auxin-responsive Elemente) cis-Elemete mit der Consensus-Sequenz TGTCTC (ULMASOV et al., 1995) zu binden und die Expression spezifischer Gene zu regulieren. Die ARFs besitzen vier Domänen, von denen die erste Domäne im N-terminalen Bereich die DNA-Bindung vermittelt. Die zweite ist ein transaktivierender Bereich, dem im C-terminalen Teil des Proteins zwei ProteinInteraktionsdomänen folgen. Die eine vermittelt die Dimerisierung der ARFs untereinander, die andere die Bindung an die Aux/IAA-Proteine. Die Auxin-induzierten Gene entstammen unterschiedlichen Genfamilien und werden in unterschiedliche Gruppen eingeteilt. Die drei am besten charakterisierten Gruppen von Auxin-induzierbaren Genen sind die AUX/IAA- 
Gene (ABEL \& THEOLOGIS, 1996), die SAUR Gene und die GH3-Gene. Die biochemische Funktion der SAUR- und GH3-Gene ist bislang unbekannt. Die GH3-Genfamilie wurde zuerst in der Sojabohne (Glycine max) und weiterhin im Tabak (Nicotiana tabacum) und der Ackerschmalwand (Arabidopsis thaliana) identifiziert. Im Promotorbereich der G.m.GH3 konnten drei voneinander unabhängig funktionierende AuxRE entdeckt werden (ULMASOV et al., 1995). Zwei dieser Elemente, D1 und D4, enthalten ein TGTCTC-Motiv, welches an der Induktion der Transkription von GH3-Genen durch erhöhte Auxinmengen beteiligt ist (ULMASOV et al., 1995). Das dritte Auxin-responsive Element wird als El bezeichnet und enthält eine chimäre G/C-Box mit ACGT-Kernmotiv (LIU et al., 1994). Für den bZIP-Transkriptionsfaktor GBF2 aus der Sojabohne (Glycine max) konnte gezeigt werden, dass er in vitro an die G/C-Box bindet und in transienten Reportergenanalysen von Karotten (Daucus carota)-Protoplasten die Auxin-induzierbare Transkription des GH3Promotors reprimiert (LIU et al., 1997).

Da der in dieser Arbeit untersuchte Transkriptionsfaktor BZI-1 eine vergleichbare G-BoxSpezifität wie GBF2 besitzt und zudem ein Einfluss durch die transgene Expression des BZI1- $\Delta \mathrm{N}$-Derivates auf die auxininduzierte GH3-Expression nachzuweisen war (HEINEKAMP et al, 2002), stellt sich die Frage nach der Beteiligung von BZI-1 an der Regulation dieses Auxin-responsiven Promotorelementes.

\section{5 | BZI-1 ist in Signalwege der pflanzlichen Pathogenabwehr eingebunden}

Aufgrund der transkriptionellen Aktivierung von BZI-1 nach Pathogeninfektion (HEINEKAMP et al., 2002) und der Phosphorylierung von BZI-1- $\Delta$ N durch elicitierte Sojabohnen-ZellkulturExtrakte (DRÖGE-LASER et al., 1997) liegt eine Beteiligung des untersuchten Transkriptionsfaktors in der Signaltransduktion der Pathogenantwort nahe. Pflanzen können durch Pathogene wie Viren, Bakterien und Pilze existenziell bedroht werden. Im Laufe der Evolution haben Pflanzen verschiedene Mechanismen zur Abwehr von pathogenen Mikroorganismen entwickelt. So sind sie gegen die meisten potentiellen Pathogene widerstandsfähig und es existieren jeweils nur einige wenige Wirt-Pathogen Beziehungen, in denen sich das Pathogen ausbreiten kann (EBEL \& MITHÖFER, 1998). Bei einer Pathogenattacke wird nach dem Eindringen des Pathogens durch Zellwand und Cuticula ein Abwehrmechanismus in der Pflanze ausgelöst, der auf der Erkennung des angreifenden Pathogens beruht. Diese Interaktion wird durch das Zusammenwirken von pflanzlichen Resistenz-Gen-(R)-Produkten und bakteriellen avirulenz-(avr-)Faktoren 
ausgelöst. Eine Modellvorstellung geht hier von einer Ligand-Rezeptor-ähnlichen Interaktion aus, die eine Signalkaskade auslöst. Als Ligand wirken auf Seiten des Pathogens sogenannte Elicitoren. Dies sind Produkte von avirulenz-Genen, einzelner Pathogenbestandteile, sekretierter Produkte, oder sogar in frühen Phasen der Infektion produzierte pflanzliche Zellwandfragmente (EBEL \& SCHEEL, 1997). Durch die Interaktion zwischen dem Rezeptor und dem Elicitor "erkennt" die Pflanze das avirulente Pathogen und es folgt die Gen-für-Gen-Antwort mit der Folge der wirtspezifischen Resistenz (HAMMONDKOSACK \& JONES, 1996). Wird die Interaktion gestört, oder fehlt eine Komponente in diesem System, so kann eine verzögerte oder ausbleibende Abwehrantwort der Pflanze die Folge sein. In diesem Fall vermehrt sich das virulente Pathogen schneller als der suszeptible Wirt es abwehren kann. Ob die Pflanze resistent oder suszeptibel (empfänglich) für ein Pathogen ist, hängt von der zeitlichen Erkennung des Pathogens und dem folgenden schnellen Aktivieren der Abwehrmechanismen ab. Ziel der induzierten Pflanzenabwehr ist es, das eindringende Pathogen direkt zu bekämpfen, die Ausbreitung zu verhindern und die Pflanze auf weitere potentielle Angriffe vorzubereiten. Als erste Reaktion auf das Eindringen eines Pathogens konnte lokal eine Erhöhung von reaktiven Saverstoff-Spezies (ROS) nachgewiesen werden (SUTHERLAND, 1991, LAMB \& DIXON, 1997). Diese ROS können einerseits als "second messenger" in die Signalkaskade zur Induktion von schützenden Proteinen einfließen, anderseits direkt toxisch auf die eindringenden Pathogene wirken. Durch die reaktiven Saverstoff-Spezies kann zusätzlich eine Quervernetzung von Zellwandproteinen erfolgen, welche den Angriff von pilzlichen Enzymen erschwert (BRADLEY et al., 1992). Neben dieser Akkumulation von ROS, die auch als "oxidative burst" bezeichnet wird, laufen Signalkaskaden mit unterschiedlichen Auswirkungen ab. Auf molekularer Ebene konnten Aktivierungen von G-Proteinen und Proteinkinasen (BLUMWALD et al., 1998) gezeigt werden. Die Modifikation von Proteinen durch Phoshorylierung oder Dephosphorylierung ist ein wesentlicher Teil von schnellen Signalverarbeitungen. Durch diese Phosphatübertragung im Rahmen der Signaltransduktion kommt es zur Aktivierung von Transkriptionsfaktoren und damit zur Induktion von Schutz- und Abwehrgenen. So konnte die Anhäufung von Zell-entgiftenden Glutathion-S-transferasen, $\mathrm{H}_{2} \mathrm{O}_{2}$ produzierenden Peroxidasen oder Proteinaseinhibitoren beobachtet werden. Als antimikrobiell wirksame Substanzen werden auch Phytoalexine in verstärktem Maß produziert (DIXON et al., 1983, DIXON \& HARRISON, 1990, PAIVA et al., 1991). Dies geschieht durch eine verstärkte Regulation von sekundären Stoffwechselwegen. Als beteiligte Enzyme 
seien hier exemplarisch, die nach Pathogeninduktion transkriptionell induzierte Phenylammoniumlyase (PAL, DIXON et al., 1983) und die Sesquiterpenecyclase (YIN et al., 1997) genannt. Durch die verstärkte Expression der PAL werden Resourcen in den Phenylpropanstoffwechselweg (PPP) geleitet, an dessen Ende in einigen Fällen die Produktion von Phytoalexinen oder Lignin steht. Die Sesquiterpenecyclase (5-eppiaristolochene synthase: EAS, FACCHINI \& CHAPELL, 1992) ist ein zentrales Enzym, welches durch den Ringschluss von trans,trans-Farnesyldiphosphat zu bizyklischem 5-epiAristolochen die Produktion des Phytoalexins Capsidiol (VÖGELl et al., 1988) mitsynthetisiert. Nach diesen schnellen Reaktionen der Pflanze auf Pathogene, die sich im Bereich von Minuten bis Stunden bewegen, kommt es zu weiteren mittelfristigen Abwehrreaktionen am Ort der Infektion. Als sichtbarer Effekt treten nach 8 - 24 Stunden am Infektionsort nekrotische Läsionen auf. In dieser Hypersensitiven Reaktion (HR; AGRIOS, 1988) wird ein lokal begrenzter, programmierter Zelltod ausgelöst (LAM et al., 2001), der zusammen mit den anderen Abwehrmechanismen die Ausbreitung der pathogenen Organismen verhindert. Parallel werden im infizierten Blatt die sogenannten PR(Pathogenesis-Related-)-Proteine synthetisiert (KOMBRINK \& SOMSSICH, 1997). Zu diesen zählen neben Glucanasen, Chitinasen / Lysozymen einige weitere antimikrobiell wirksame Substanzen (STINTZI et al., 1993). Neben der lokalen Abwehr bildet die Pflanze auch eine Art "erhöhte Bereitschaft" in den nicht infizierten Bereichen aus. Diese erhöhte Resistenz wird als SAR (ㅁystemic Aquired Resistance, systemisch erworbene Resistenz; ROSS, 1961) bezeichnet und zeichnet sich molekular in der Expression von PR-Genen aus (WARD et al., 1991). Hierdurch ist die Pflanze gegen weitere Sekundärinfektionen durch andere Pathogene besser geschütz† (RYALS et al., 1996). Die SAR bildet sich ca. 1 - 2 Wochen nach der Erstinfektion aus und hält ca. 4 - 6 Wochen an. Als ein wichtiges Signalmolekül, das zur Ausprägung der SAR und Expression von PR-Genen beiträgt, konnte die Salicylsäure (SA) identifiziert werden (Übersicht: MURPHY et al., 1999, KLESSIG \& MALAMY, 1994). In infizierten Blättern kann eine Steigerung der Salicylsäuremenge um das 20 - 50-fache nachgewiesen werden. In Pflanzen ohne Salicylsäure (durch Expression einer bakteriellen Salicylathydroxylase, nahG) kann sich hingegen keine SAR entwickeln (DELANEY et al., 1994). So konnte in in vivo-labelingExperimenten ein weiterer Transport von Salicylsäure durch die infizierten Gewebe gezeigt (SHULAEV et al., 1995), aber die Funktion als mobiles, SAR-auslösenden Signals nicht eindeutig belegt werden. Im Bereich des Signalweges konnten bisher einige Faktoren charakterisiert werden. So interagiert die SA mit SA-bindenden Proteinen mit 
nachfolgenden Phosphorylierungsereignissen (SIPK, SA-induzierte Proteinkinase, ZHANG \& KLESSIG, 1991). Des Weiteren ist die essentielle Bedeutung eines Ankyrin-Domänenbeinhaltenden Proteins in der Signalkette (NPR-1) gezeigt worden. Es konnten auch auf Promotorebene Salicylsäure-responsive cis-Elemente identifiziert werden (as-1-Element, QIN et al., 1994). Die Signalverarbeitung, die zur Ausprägung der SAR führt, wird zusätzlich durch Jasmonsäure und Ethylen (PIETERSE \& VAN LOON, 1999) beeinflusst. Ebenso gibt es aber einige Pathogen-stimulierte Gene, deren Expression Salicylsäure- und Ethylenunabhängig verläuft.

Diese Ergebnisse zeigen ein komplexes Netzwerk mit vielen zusätzlichen, zu verarbeitenden Seiteneinflüssen, welches die unterschiedlichen Abwehrmechanismen der Pflanze auslöst. Auch die Auxin-Homöostase ist ein wichtiger Punkt für die korrekte Pathogen-ausgelöste Signalkaskade zur Pflanzenabwehr. So konnte ein Regulator (DTH9-Detachment-Mutante Nr.9) für ein Auxin-inhibiertes Gen einer anionischen Peroxidase (CEVI-1) isoliert werden (MAYDA et al., 2000a). In dth9-Pflanzen konnte neben der Insensitivität gegenüber exogen appliziertem Auxin eine verstärkte Suszeptibilität der Pflanzen gegenüber Pathogenen verzeichnet werden. In diesen Auxin-insensitiven Arabidopsis thaliana dth9-Mutanten kann so die durch Pathogene verstärkte, aber Salicylsäure-unabhängige Expression einer Peroxidase (CEVI-1) beeinflusst werden (MAYDA et al., 2000b). Dies zeigt eine molekulare Verknüpfung der Auxin- und SA-unabhängigen Pathogenantwort über ein als DTH9 bezeichneten Regulator.

Durch die vergleichbare Auxin-Insensitivität in den BZI-1- $\Delta$ N-exprimierenden Tabakpflanzen und der nachgewiesenen transkriptionellen und posttranslationalen Aktivierung von BZI-1 nach Pathogeninduktion stellt sich die Frage nach dem Zusammenhang dieser Funktionen und der Beteiligung der einzelnen Domänen von BZI-1 bei der Erfüllung dieser Aufgaben. 


\section{6 | Zielsetzung der Arbeit}

Durch den Vergleich der verwandten Transkriptionsfaktoren konnten die konservierten Domänen des Transkriptionsfaktors BZI-1 definiert werden. Da Transkriptionsfaktoren einen modularen Aufbau besitzen, ist davon auszugehen, dass die einzelnen Domänen spezifische Aufgaben im Verlauf der Aktivität von BZI-1 übernehmen. Ziel dieser Arbeit ist es diesen Domänen die spezifischen Funktionen zuzuweisen.

Mit Hilfe von in vitro-Analysemethoden soll der Einfluss der Domänen auf die DNABindung des BZI-1-Transkriptionsfaktors untersucht werden. Hierbei soll die Spezifität der basischen Domäne für DNA-cis-Elemente und die Funktionen der weiteren Domänen in diesem Zusammenhang untersucht werden.

Durch einen Kinase-Assay sollen Phosphorylierungsereignisse als posttranslationale Modifikationen nach unterschiedlichen Stimuli nachgewiesen werden. Durch eine Grobkartierung der Phosphorylierungsstellen kann so möglicherweise eine Funktionszuweisung an die Domänen erfolgen.

Eine Charakterisierung der Funktion der Domäne 1 ist möglicherweise durch eine weitere Analyse der Interaktion mit ANK1 möglich. Es soll aufgeklärt werden, ob die detektierte Interaktion eine funktionale Beteiligung an der Translokation des BZI- 1 in den Kern besitz† oder die DNA-Bindung beeinflusst.

Die Funktion der putativen Kernlokalisierungssequenz in der basischen Domäne und eventuelle Einflüsse der anderen Domänen sollen durch transiente Expressionstudien von BZI-1 -GFP-Fusionsproteinen in Tabakmesophyll-Protoplasten analysiert werden.

Um die komplexen Zusammenhänge im Rahmen der Pathogenantwort und dem damit verbundenen Einfluss der Auxin-Signaltransduktion zu verstehen, sollen transgene Pflanzen hergestellt und die Funktion des Transkriptionsfaktors BZI-1 in planta analysiert werden. Durch die unterschiedlichen phänotypischen Veränderungen der BZI- 1- $\Delta \mathrm{N}$-exprimierenden Pflanzen war ein System zur Analyse von Doppeldeletionsderivaten vorhanden. Durch die zusätzlich eingefügten Domänendeletionen soll durch die Revertierung des Phänotyps in den unterschiedlichen Funktionszusammenhängen ein Nachweis der Relevanz der einzelnen Domänen in planta zu führen sein. Als Funktionszusammenhänge sollen die Auxin-Antwort, die Blütenentwicklung und Pollenbildung und die Pathogenantwort charakterisiert werden. 


\section{C | Material und Methoden}

\section{1 | Material}

\section{1|1 Geräte}

\begin{tabular}{|c|c|c|}
\hline Gerät & Modell & Hersteller/Lieferant \\
\hline Autoklav & 3870 ELV & Tuttnaver \\
\hline Automatische Pipetten & $2,20,200,1000$ & Gilson \\
\hline Biofuge & pico & Heraeus \\
\hline Bioimager (Phosphoimager) & BAS-1000 & Fuji \\
\hline Digitalkamera & Coolpix & Nikon \\
\hline Elektroporationsapparatur & $\begin{array}{l}\text { Gene pulser® II } \\
\text { Pulse Controller Plus }\end{array}$ & BioRad \\
\hline Elektroelutionsapparatur & Elutrap (Schleicher und Schuell) & Werkstatt der Universität \\
\hline Fluorometer & CytoFluorll Plate Reader & PerSeptive \\
\hline Fluoreszenzmikroskop & Axiovert 35 & Zeiss \\
\hline Geldokumentationsanlage & & MWG Biotech \\
\hline Gelelektrophoresekammer & & Werkstatt der Universität \\
\hline Gelelektrophoresekammer(PAGE) I & V 15-17 & GIBCO BRL \\
\hline Gelelektrophoresekammer(PAGE) II & Joey $^{\mathrm{TM}}$ \#JGC-4 & AGS \\
\hline Geltrockner & Phero-Temp & Biotec-Fischer \\
\hline Gefriertruhe $-80^{\circ} \mathrm{C}$ & C54285 & New Brunswick Scientific \\
\hline Handmonitor & Contamat & Eberline \\
\hline Heizblock & & Boekel Scientific \\
\hline Heizrührer & RCT basic & IKA Labortechnik \\
\hline Hybridisierungsofen & & Bachhofer \\
\hline Hybridisierungswasserbad & Belly Dancer & Sorvall \\
\hline Inkubationsschränke & & WTC binder; Memmert \\
\hline Kühlzentrifuge & Sorvall RC 5B Plus & DuPont \\
\hline Laserscanningmikroskop & LSM-510 & Zeiss \\
\hline Netzgerät & E 323 & Benedikt Heinemann \\
\hline Netzgerät & EC 105 & EC Apparatus Corporation \\
\hline PCR-Gerät, MiniCycler ${ }^{\mathrm{TM}}$ & PTC- 150 & MJ Research, USA \\
\hline Peristaltikpumpe & Cyclo 1 & Roth \\
\hline $\mathrm{pH}-$ Meter & HI 9321 & Hanna Instruments \\
\hline Photometer & Unikon 720 LC & Kontron \\
\hline RNA-/DNA-Calculator & GeneQuant II & Pharmacia \\
\hline Scanner & ScanJet $4 c$ & Hewlett Packard \\
\hline Sequenzanalyseanlage & ABI PRISM 310 & Perkin-Elmer \\
\hline Speed vac Konzentrator & SK $100 \mathrm{H}$ & Sarvant \\
\hline Spektralphotometer & Novaspek Biochrom & LKB \\
\hline Spektralphotometer für Microtiterplatten & MRX & Dynex \\
\hline Sterilbank & Microflow Laminar W. & Nunc \\
\hline Szintillationsmessgerät & & raytest Isootopenmessgeräte $\mathrm{GmbH}$ \\
\hline Tischzentrifuge & Biofuge pico & Heraeus Christ \\
\hline Tischzentrifuge, gekühl† & 5403 & Eppendorf \\
\hline Ultraschallgerät & Soniprep 150 & Scientific Instruments \\
\hline Ultrazentrifuge & Centrikon T-1065 & Kontron \\
\hline \multirow[t]{2}{*}{ Rotoren } & TFT 30.58 & \\
\hline & TFT 65.13 & \\
\hline UV-Transilluminator & FLX-20 M & Vilber Lourmat \\
\hline Vortex & L46 & Labinco BV \\
\hline Wasseraufbereitungsanlage & Option 4, Maxima & ELGA \\
\hline Zählkammer & Fuchs-Rosenthal & Brand \\
\hline Zentrifuge & UJ3S & Christ \\
\hline
\end{tabular}




\section{1 |2 Verbrauchsmaterialien}

\begin{tabular}{|c|c|}
\hline Produkt & Hersteller/Lieferant \\
\hline Bradford-Reagenz & Roth \\
\hline Dialysemembranen & Millipore \\
\hline Elektroporationsküvetten & BioRad \\
\hline 3MM-Fließpapier & Whatman \\
\hline Gläser für Pflanzensterilkultur & Weck \\
\hline Glasmaterialien: Flaschen, Pasteurpipetten, Erlenmeyerkolben & Brand, Schott \\
\hline Glaskugeln (2 mm Durchmesser) & Roth \\
\hline Kunststoff-Einwegmaterial & Biozym; Eppendorf; Greiner; Roth \\
\hline Micro Spin ${ }^{\mathrm{TM}}$ G25 Column & Amersham \\
\hline Miracloth & Calbiochem \\
\hline NiNTA® - Resin & Qiagen \\
\hline Nylon-Membran Nytran ${ } \mathrm{N}^{+}$ & Schleicher und Schuell \\
\hline Parafilm M & American National Can ${ }^{\mathrm{TM}}$ \\
\hline Polyacrylamid (PAA)-Mix: 30 \% PAA + Bisacrylamid (37,5: 1) & Roth \\
\hline Polyacrylamid (PAA)-Mix: 40 \% PAA + Bisacrylamid (19: 1) & Roth \\
\hline PVDF-Membran Immobilon ${ }^{\mathrm{TM}}-\mathrm{P}$ & Millipore \\
\hline Röntgenfilm Entwickler LX24 & Kodak \\
\hline Röntgenfilm Fixierer AL4 & Kodak \\
\hline Röntgenfilme Cronex 4, Cronex 10T & DuPont \\
\hline Sephadex G50 & Pharmacia \\
\hline
\end{tabular}

\section{$1 \mid 3$ Chemikalien}

\begin{tabular}{|c|c|}
\hline Chemikalien & Hersteller/Lieferant \\
\hline Agar Bacteriological & Life Technologies \\
\hline Agarose SeaKem LE & Biozym \\
\hline Ampicillin & AGS \\
\hline Ameisensäure & Roth \\
\hline Antipain & SERVA \\
\hline Aprotinin & Sigma \\
\hline Ammoniumperoxodisulfat (APS) & Biometra \\
\hline Bactopeptone & Difco \\
\hline 6-Benzylaminopurin (6-BAP) & Sigma \\
\hline$\beta$-Mercaptoethanol & Roth \\
\hline Bovine-Serum-Albumin (BSA) & Serva \\
\hline Bromphenol-Blau & Roth \\
\hline Cefotaxim & Duchefa \\
\hline Coomassie Brilliant Blve G-250 & Bio-Rad \\
\hline Cyanbromid & Roth \\
\hline 2,4-Dichlorphenoxyessigsäure (2,4-D) & Sigma \\
\hline Diethylpyrocarbonat (DEPC) & Roth \\
\hline Dimethylsulfoxid (DMSO) & Sigma; Roth \\
\hline N,N-Dimethylformamid (DMF) & J.T. Baker Chemicals B. V. \\
\hline dNTPs & $\mathrm{MBI}$; Roth \\
\hline$\alpha-{ }^{32} \mathrm{P}$ dATP; $800 \mathrm{Ci} / \mathrm{mmol}$ & Hartmann Analytic \\
\hline$\alpha-^{32} \mathrm{P}$ dCTP; $800 \mathrm{Ci} / \mathrm{mmol}$ & Hartmann Analytic \\
\hline$\gamma-{ }^{32} \mathrm{P}$ dATP; $800 \mathrm{Ci} / \mathrm{mmol}$ & Hartmann Analytic \\
\hline Dithiothreitol (DTT) & Sigma \\
\hline Ethylendiamintetraacetat (EDTA) & AppliChem \\
\hline Ethidiumbromid (EłBr) & Roth \\
\hline Formaldehyd & Roth \\
\hline Formamid & Fluka \\
\hline Gamborg's B5-Medium & Duchefa \\
\hline HEPES & Roth \\
\hline Hygromycin & Duchefa \\
\hline
\end{tabular}




\begin{tabular}{|c|c|}
\hline Chemikalien & Hersteller/Lieferant \\
\hline Imidazol & Sigma \\
\hline Isopropylthiogalactosid (IPTG) & BioTech Trade \\
\hline Kanamycin & Sigma \\
\hline Kinetin & Sigma \\
\hline Leupeptin & Serva \\
\hline Linsmeier und SkoogMedium & Duchefa \\
\hline Magermilchpulver & Glücksklee \\
\hline 2-[N-Morpholino]ethansulfonsäure (MES) & Sigma \\
\hline Methylumbelliferon (4-MU) & Sigma \\
\hline Methylumbelliferyl- $\beta$-D-Glucoronid (MUG) & Duchefa \\
\hline MOPES & Sigma \\
\hline Murashige und Skoog Medium & Duchefa \\
\hline$\alpha$-Naphthalinessigsäure (NAA) & Sigma \\
\hline Natriumhydroxid ( $\mathrm{NaOH})$ & Merck \\
\hline Natriumazid & Sigma \\
\hline Natriumhypochlorid & Roth \\
\hline Nonidet P-40 & Fluka \\
\hline organische Lösungsmittel (Alkohole etc.) & Merck; Roth \\
\hline Pepstatin A & $\mathrm{BIOMOL}$ \\
\hline Phenol & AppliChem \\
\hline Phenylmethansulfonylchlorid (PMSF) & Fluka \\
\hline PIPES & Roth \\
\hline Polydesoxyinosin-desoxycytidylsäure (Polydl/dC) & Sigma \\
\hline Ponceau & Sigma \\
\hline Rifampicin & Duchefa \\
\hline Salze für Puffer etc. & AppliChem; Merck \\
\hline Salzsäure (HCl) & Merck \\
\hline Sodiumdodecylsulfat (SDS) & Roth \\
\hline Select Agar & Life Technologies \\
\hline Select Yeast Extract (Hefeextrakt) & GIBCO BRL \\
\hline Spermin Tetrahydrochlorid & Sigma \\
\hline Spermidin & Sigma \\
\hline TEMED & BIORAD, Roth \\
\hline Triton X-100 & Roth \\
\hline Trypton & Oxoid \\
\hline Tween-20 & Roth \\
\hline X-Gal & BioTechTrade \\
\hline X-Gluc & Roth \\
\hline Xylencyanol FF & Roth \\
\hline
\end{tabular}

\section{$1 \mid 4$ Kits}

Kit

BigDye $^{\mathrm{TM}}$ Terminator Cycle Sequencing Ready Reaction Kit Enhanced Chemiluminescence ${ }^{\mathrm{TM}}$ Kit (ECL)

Enhanced Chemiluminescence ${ }^{\mathrm{TM}}$ Plus Kit $\left(\mathrm{ECL}^{+}\right)$

Megaprime $^{\mathrm{TM}}$ DNA Labelling Systems

pGEM ${ }^{\circledR}-T$ Vector Systems

Qiagen Plasmid-Preparations Kit (Midi/Maxi)

QIAprep Spin Miniprep Kit

QIAquick Gel Extraction Kit

RNeasy Plant Mini Kit
Hersteller/Lieferant

Perkin-Elmer

AmershamPharmacia

AmershamPharmacia

AmershamPharmacia

Promega

Qiagen

Qiagen

Qiagen

Qiagen 


\section{1 |5 Nucleinsäuren}

\section{$1|5| 1$ Oligonucleotide}

Die Oligonucleotide wurden nach Vorgabe der Basensequenz von der Firma Pharmacia Biotech oder MWG synthetisiert und in lyophilisierter Form geliefert.

\begin{tabular}{|c|c|c|}
\hline Oligonucleotid & Sequenz $5^{\prime} \rightarrow 3^{\prime}$ & Verwendung \\
\hline OL20 & GAT CGA AGA AAG CAG GCC CAT CTG ACA GAA C & Deletion BD-BZII \\
\hline OL21 & TC GAG TTC TGT CAG ATG GGC CTG CTT TCT TC & Deletion BD-BZII \\
\hline OL33 & CT AGA TGT GGA ACT CAA GGC AGG GGA GAG CAA TAA G & Deletion D4-BZI1 \\
\hline OL34 & TC GAC TTA TTG CTC TCC CC T GCC TTG AGT TCC ACA T & Deletion D4-BZI1 \\
\hline OL35 & CT AGC AAG CTT CAA GGC ATG & Deletion D2-BZII \\
\hline OL36 & ATC CAT GCC TTG AAG CTT G & Deletion D2-BZI1 \\
\hline mkANK2 & CCA TGG ACC TGC AGA ACA ACA CAT CTT TCT C & ANK \\
\hline mkANK3 & AGA TCT GAA TTC ATG TCT GAG GGA GAG AAA & ANK \\
\hline pAK4 & GCG GAG CAG ATA GCG AAA GAT C & Sequenzierung ANK1 \\
\hline pAK2 & GGT GCT ACC TCT TCC GCA ATA CCT & Sequenzierung ANK1 \\
\hline Uni & AGG GTT TTC CCA GTC ACG TT & Sequenzierung \\
\hline Rev & GGA AAC AGC TAT GAC CAT G & Sequenzierung \\
\hline GFP1 & CAA CCA TTA CCT GTC CAC AC & Sequenzierung \\
\hline GFPII & TTC AGG GTC AGC TTG CCG TAG G & Sequenzierung \\
\hline $\mathrm{P} 40$ & GCC GGT ACC TCC ACT TCA TCT C & Sequenzierung D1 \\
\hline P47 & GAT TCT CAT CCT TGA TCT CCA CGA CGT C & Sequenzierung $N$ \\
\hline P49 & CTC TAC AGC TCA CGA CAA AGG ATC AGA G & Sequenzierung D2 \\
\hline P50 & CAA CCA GTG GTT CAT CTA GAG AGC AAT CTG & Sequenzierung BD \\
\hline P80 & GGA AGA TCT ATA TGG AGC GGG TCT TCT CCA TGG & BZII \\
\hline P81 & СCT AGA TCT CTC TGC TCT CCC CTG CCT TGA CTT C & BZII \\
\hline G-Box for & AAT TCT CCC TTA TTC CAC GTG GCC ATC CGG & GRA \\
\hline G-Box rev & CTA GTC CGG ATG GCC ACG TGG AAT AAG GGA & GRA \\
\hline G-mut for & AAT TCT CCC TTA TTC CAC TGT GCC ATC CGG A & GRA \\
\hline G-mut rev & CTA GTC CGG ATG GCA CAG TGG AAT AAG GA & GRA \\
\hline GH3-Box for & $\begin{array}{l}\text { AAT TCG AGA ACT TTT GCT GAC GTG GCG ACA CAT CTG GAC } \\
\text { CCA }\end{array}$ & GRA \\
\hline GH3-Box rev & $\begin{array}{l}\text { C TAG TGG GTC CAG ATG TGTCGC CAC GTC AGC AAA AGT } \\
\text { TCT CG }\end{array}$ & GRA \\
\hline GH3-mut for & $\begin{array}{l}\text { AAT TCG AGA ACT TTT GCT TTC GAT TTG ACA CAT CTG GAC } \\
\text { CCA }\end{array}$ & GRA \\
\hline GH3-mutrev & $\begin{array}{l}\text { C TAG TGG GTC CAG ATG TGT CAA GTC GAA AGC AAA AGT TCT } \\
\text { CG }\end{array}$ & GRA \\
\hline C-Box for & AAT TCT CCC TTA TCT GAC GTC AGC ATC CGG A & GRA \\
\hline C-Box rev & CT AGT CCG GAT GCT GAC GTC AGA TAA GGG AG & GRA \\
\hline C-mut for & AAT TCT CCC TTA TCT GAC TGT AGC ATC CGG A & GRA \\
\hline C-mut rev & AT AGT CCG GAT GCT ACA GTC AGA TAA GGG AG & GRA \\
\hline CA-I & GTG TTG CAC GTG ATA CTC ACC TAC CCT ACT TCC TAT CCA & GRA \\
\hline CA-II & TGG ATA GGA AGT AGG GTA GGT GAG TAT CAC GTG CAA CAC & GRA \\
\hline as- 1 for & $\begin{array}{l}\text { GAA TTC ACT GAC GTA AGG GAT GAC GCA CAA TCC CAC TAG } \\
T\end{array}$ & GRA \\
\hline as- 1 rev & A CTA GTG GGA TTG TGC GTC ATC CCT TAC GTC AGT GAA TTC & GRA \\
\hline
\end{tabular}

Die Schmelztemperatur der Oligonucleotide wird gemäß der Formel von BOLTON und McCARTHY, 1962 berechnet:

$$
\mathrm{T}_{\mathrm{m}}\left[{ }^{\circ} \mathrm{C}\right]=69,3+0,41 \times(\% \mathrm{GC})-(650 / \mathrm{n})
$$

wobei $n=$ Anzahl der Basen und $T_{m}=$ Schmelztemperatur 


\begin{tabular}{|c|c|c|}
\hline Bezeichnung & Beschreibung & Referenz \\
\hline pANK-GFP & $\begin{array}{l}\text { pHBTL-sGFP-Derivat, ANK-GFP-Fusionsprotein zur } \\
\text { transienten Expression, } \mathrm{Amp}^{r}\end{array}$ & diese Arbeit \\
\hline pGAD-ANK & $\begin{array}{l}\text { Hefe-Expressionsvektor mit ANK- } \\
\text { Aktivierungsdomänenfusion, Amp }\end{array}$ & $\begin{array}{l}\text { K. HORVAY, } \\
\text { Diplomarbeit } 2000\end{array}$ \\
\hline pGAD-BZI2 & $\begin{array}{l}\text { Hefe-Expressionsvektor mit BZI2 (BZII -interagierender } \\
\text { N.t.bZIP TKF)-Aktivierungsdomänenfusion, Amp }{ }^{r}\end{array}$ & STRATHMANN et al., 2001 \\
\hline pGAD-BZI3 & $\begin{array}{l}\text { Hefe-Expressionsvektor mit BZI3 (BZI1 -interagierender } \\
\text { N.t.bZIP TKF)-Aktivierungsdomänenfusion, Amp }{ }^{r}\end{array}$ & STRATHMANN et al., 2001 \\
\hline pGAD-BZI4 & $\begin{array}{l}\text { Hefe-Expressionsvektor mit BZI4 (BZII -interagierender } \\
\text { N.t.bZIP TKF)-Aktivierungsdomänenfusion, } \mathrm{Amp}^{r}\end{array}$ & STRATHMANN et al., 2001 \\
\hline pBinHygTX & $\begin{array}{l}\text { pBinHyg-Derivat (Becker, 1991), enthält Fragment aus dem } \\
\text { TX-Promotor und pAocs, mcs; Hygr in Pflanzen; Kan' in } \\
\text { Bakterien }\end{array}$ & GATZ et al., 1992 \\
\hline pBinGHHA & $\begin{array}{l}\text { pBinHygTx-Derivat mit N.t.bzi-1 ohne N-terminus mit 5' } \\
\text { fusionierter HA-tag-Sequenz }\end{array}$ & $\begin{array}{l}\text { T. HEINEKAMP, } \\
\text { Diplomarbeit, } 1997\end{array}$ \\
\hline pBinantiGH & $\begin{array}{l}\text { pBinHygTx-Derivat, enthält ein 677bp-Antisense-Fragment d } \\
\text { g/hbf-1, Kan }{ }^{r}\end{array}$ & $\begin{array}{l}\text { M. KUHLMANN, } \\
\text { Diplomarbeit, } 1998\end{array}$ \\
\hline pBluescriptlIKS & $\begin{array}{l}\text { Sequenziervektor mit uni-, rev-Primerbindestellen; } \\
\text { Ampr }\end{array}$ & Clontech \\
\hline $\mathrm{pBZI} 1 \Delta \mathrm{N}$ & $\begin{array}{l}\text { pUCA7Tx-Derivat, enthält das N.t.bzi- } 1 \text { ohne N-Terminus, } \\
\text { Amp }^{r}\end{array}$ & $\begin{array}{l}\text { M. KUHLMANN, } \\
\text { Diplomarbeit, } 1998\end{array}$ \\
\hline $\mathrm{pBZI} 1-\Delta \mathrm{NHA} \Delta \mathrm{D} 2$ & $\begin{array}{l}\text { Derivat des pUCA7Tx, enthält das im Bereich der Domäne } \\
\text { D2 deletierte N.t.bzi-1 ohne N-Terminus, mit fusioniertem } \\
\text { HA-tag; Amp }\end{array}$ & $\begin{array}{l}\text { M. KUHLMANN, } \\
\text { Diplomarbeit, } 1998\end{array}$ \\
\hline $\mathrm{pBZI} 1-\Delta \mathrm{N} \Delta \mathrm{BD}$ & $\begin{array}{l}\text { Derivat des pUCA7Tx, enthält das im Bereich der basischen } \\
\text { Domäne deletierte N.t.bzi-1 ohne N-Terminus, Amp }{ }^{r}\end{array}$ & $\begin{array}{l}\text { M. KUHLMANN, } \\
\text { Diplomarbeit, } 1998\end{array}$ \\
\hline $\mathrm{pBZI} 1-\Delta \mathrm{NHA} \Delta \mathrm{D} 4$ & $\begin{array}{l}\text { Derivat des pUCA7Tx, enthält das im Bereich der Domäne } \\
\text { D4 deletierte N.t.bzi-1 ohne N-Terminus mit fusioniertem } \\
\text { HA-tag; Ampr }\end{array}$ & $\begin{array}{l}\text { M. KUHLMANN, } \\
\text { Diplomarbeit, } 1998\end{array}$ \\
\hline pBZII & pUCA7Tx-Derivat, enthält das N.t.bzi-1, Amp ${ }^{r}$ & T.HEINEKAMP, 2001 \\
\hline $\mathrm{pBZI} 1 \mathrm{HA}$ & $\begin{array}{l}\text { pUCA7Tx-Derivat, enthält das N.t.bzi-1 ohne N-terminus } \\
\text { mit einer } 5 \text { ' fusionierten HA-tag-Sequenz, Amp }{ }^{r}\end{array}$ & $\begin{array}{l}\text { T. HEINEKAMP, } \\
\text { Diplomarbeit, } 1997\end{array}$ \\
\hline pBZII-GFP & $\begin{array}{l}\text { pHBTL-sGFP-Derivat, BZI 1 -GFP-Fusionsprotein zur } \\
\text { transienten Expression, Amp }{ }^{r}\end{array}$ & diese Arbeit \\
\hline $\mathrm{pBZI} 1 \Delta \mathrm{N}-\mathrm{GFP}$ & $\begin{array}{l}\text { pHBTL-sGFP-Derivat, BZI1 } \Delta \text { N-GFP-Fusionsprotein zur } \\
\text { transienten Expression, Amp }{ }^{r}\end{array}$ & diese Arbeit \\
\hline $\mathrm{pBZI} 1 \Delta \mathrm{D} 1-\mathrm{GFP}$ & $\begin{array}{l}\text { pHBTL-sGFP-Derivat, BZI1 } \Delta \text { D 1-GFP-Fusionsprotein zur } \\
\text { transienten Expression, Amp }\end{array}$ & diese Arbeit \\
\hline $\begin{array}{l}\mathrm{pBZI} 1 \Delta \mathrm{N} \Delta \mathrm{D} 1- \\
\text { GFP }\end{array}$ & $\begin{array}{l}\text { pHBTL-sGFP-Derivat, BZI 1 } \Delta \mathrm{N} \Delta \mathrm{D} 1 \text {-GFP-Fusionsprotein zur } \\
\text { transienten Expression, } \mathrm{Amp}^{r}\end{array}$ & diese Arbeit \\
\hline $\mathrm{pBZI1} \triangle \mathrm{D} 2-\mathrm{GFP}$ & $\begin{array}{l}\text { pHBTL-sGFP-Derivat, BZI1 } \Delta \text { D2-GFP-Fusionsprotein zur } \\
\text { transienten Expression, Amp }\end{array}$ & diese Arbeit \\
\hline $\begin{array}{l}\mathrm{pBZI} 1 \Delta \mathrm{N} \Delta \mathrm{D} 2- \\
\text { GFP }\end{array}$ & $\begin{array}{l}\text { pHBTL-sGFP-Derivat, BZI 1 } \Delta \mathrm{N} \Delta \mathrm{D} 2-\mathrm{GFP}-\text { Fusionsprotein zur } \\
\text { transienten Expression, } \mathrm{Amp}^{r}\end{array}$ & diese Arbeit \\
\hline pBZII $\triangle B D-G F P$ & $\begin{array}{l}\text { pHBTL-sGFP-Derivat, BZI1 } \Delta \text { BD-GFP-Fusionsprotein zur } \\
\text { transienten Expression, Amp }{ }^{r}\end{array}$ & diese Arbeit \\
\hline $\begin{array}{l}\mathrm{pBZI} 1 \Delta \mathrm{N} \Delta \mathrm{BD}- \\
\text { GFP }\end{array}$ & $\begin{array}{l}\text { pHBTL-sGFP-Derivat, BZI } 1 \Delta \mathrm{N} \Delta \mathrm{BD} \text {-GFP-Fusionsprotein zur } \\
\text { transienten Expression, } \mathrm{Amp}^{r}\end{array}$ & diese Arbeit \\
\hline $\mathrm{pBin} B Z I 1 \Delta N \Delta \mathrm{BD}$ & $\begin{array}{l}\text { Derivat des pBinHygTx, enthält das N.t.bzi-1 ohne N- } \\
\text { Terminus mit deletierter basischer Domäne, } \mathrm{Kan}^{r}\end{array}$ & $\begin{array}{l}\text { M. KUHLMANN, } \\
\text { Diplomarbeit, } 1998\end{array}$ \\
\hline $\begin{array}{l}\text { pBinBZI 1 - } \\
\Delta \mathrm{NHA} \Delta \mathrm{D} 1\end{array}$ & $\begin{array}{l}\text { Derivat des pBinHygTx, enthält das N.t.bzi-1 ohne N- } \\
\text { Terminus mit deletierter Domäne D1 und fusioniertem HA- } \\
\text { tag, Kan }{ }^{r}\end{array}$ & $\begin{array}{l}\text { M. KUHLMANN, } \\
\text { Diplomarbeit, } 1998\end{array}$ \\
\hline
\end{tabular}




\begin{tabular}{|c|c|c|}
\hline $\begin{array}{l}\mathrm{pBinBZI} 1- \\
\Delta \mathrm{NHA} \Delta \mathrm{D} 2\end{array}$ & $\begin{array}{l}\text { Derivat des pBinHygTx, enthält das N.t.bzi-1 ohne N- } \\
\text { Terminus mit deletierter Domäne D2 und fusioniertem HA- } \\
\text { tag, } \mathrm{Kan}^{r}\end{array}$ & $\begin{array}{l}\text { M. KUHLMANN, } \\
\text { Diplomarbeit, } 1998\end{array}$ \\
\hline $\begin{array}{l}\mathrm{pBinBZI} 1- \\
\Delta \mathrm{N} \Delta \mathrm{BD}\end{array}$ & $\begin{array}{l}\text { Derivat des pBinHygTx, enthält das N.t.bzi-1 ohne N- } \\
\text { Terminus mit deletierter basischer Domäne und fusioniertem } \\
\text { HA-tag, Kan }\end{array}$ & $\begin{array}{l}\text { M. KUHLMANN, } \\
\text { Diplomarbeit, } 1998\end{array}$ \\
\hline $\begin{array}{l}\mathrm{pBinBZI} 1- \\
\Delta \mathrm{NHA} \triangle \mathrm{D} 4\end{array}$ & $\begin{array}{l}\text { Derivat des pBinHygTx, enthält das N.t.bzi- } 1 \text { ohne N- } \\
\text { Terminus mit deletierter Domäne D4 und fusionietem HA- } \\
\text { tag, } \mathrm{Kan}^{r}\end{array}$ & $\begin{array}{l}\text { M. KUHLMANN, } \\
\text { Diplomarbeit, } 1998\end{array}$ \\
\hline pCS2 & $\begin{array}{l}\text { pBluescript II KS-Derivat mit CS2 (N.t.Chalconesynthase)- } \\
\text { Promotor, Amp }\end{array}$ & DREWS et al., 1992 \\
\hline pCHS-GFP & $\begin{array}{l}\text { mAV4 5' -GFP-derivat, CHS(Petroselinum crispum)- } \\
\text { mGFP4-Fusion unter Kontrolle des 35S-Promotors mit nos- } \\
\text { Terminator, Ampr }\end{array}$ & HAASEN et al., 1999 \\
\hline pEAS4 & $\begin{array}{l}\text { pBluescript II SK-Derivat mit EAS4 (N.t.5-epi aristochene } \\
\text { synthase) cDNA-Insert(1835bp) mit 188bp UTR, Amp }{ }^{r}\end{array}$ & YIN et al., 1997 \\
\hline pET28a $(+)$ & Expressionsvektor mit T7-Promoter und lac-Operator; Kan ${ }^{r}$ & Novagen \\
\hline pGEM-T & $\begin{array}{l}\text { pGEM-5Zf(+)-Derivat, EcoRV-linearisiert, } 3^{\prime} \text {-dT- } \\
\text { Überhänge zur Klonierung und Sequenzierung von PCR- } \\
\text { Produkten, Amp }\end{array}$ & Promega \\
\hline pGEM-ANK & pGEM-Derivat mit ANK PCR-Produkt & diese Arbeit \\
\hline pHBT-L & $\begin{array}{l}\text { pUC 18-Derivat, enthält zusätzlich eingefügte Schnittstellen } \\
\text { zwischen HBT-Promotor und nos-Terminator, Amp }{ }^{r}\end{array}$ & $\begin{array}{l}\text { K. NICKOLOV, } \\
\text { unveröffentlicht }\end{array}$ \\
\hline pHBT-sGFP & $\begin{array}{l}\text { pUC18-Derivat, enthält den chimären HBT-Promotor, } \\
\text { sGFP-S65T-Gen, nos-Terminator zur transienten } \\
\text { Expression, Amp }\end{array}$ & $\begin{array}{l}\text { K. NICKOLOV, } \\
\text { unveröffentlicht }\end{array}$ \\
\hline pRanBPla-GFP & $\begin{array}{l}\text { mAV4 5'-GFP-derivat, RanBPla (A.thaliana)-mGFP4- } \\
\text { Fusion unter Kontrolle des 35S-Promotors mit nos- } \\
\text { Terminator, Amp }\end{array}$ & HAASEN et al., 1999 \\
\hline pNES-CHS-GFP & $\begin{array}{l}\text { mAV4 5'-GFP-derivat, CHS mit N-terminalerNES und C- } \\
\text { terminaler-mGFP4-Fusion unter Kontrolle des 35S- } \\
\text { Promotors mit nos-Terminator, Amp }\end{array}$ & HAASEN et al., 1999 \\
\hline pN12BZI1-GFP & $\begin{array}{l}\text { pHBTL-sGFP-Derivat, BZI 1-N-Terminus (Domäne N-1-2)- } \\
\text { GFP-Fusionsprotein zur transienten Expression, Ampr }\end{array}$ & diese Arbeit \\
\hline pPRla & $\begin{array}{l}\text { pUC57-Derivat mit } 531 \text { bp PRla(Nicotiana tabacum) PCR- } \\
\text { Fragment, Amp }\end{array}$ & $\begin{array}{l}\text { CUTT et al., } 1988 \\
\text { Plasmid von M. Dröge }\end{array}$ \\
\hline pl6.1 & $\begin{array}{l}\text { pET28a-Derivat, enthält ein Fusionsgen aus der His-tag- } \\
\text { Sequenz und N.t.bzi-1 ohne N-Terminus; Kan }{ }^{r}\end{array}$ & DRÖGE-LASER et al., 1997 \\
\hline $\mathrm{p} 16 . \Delta \mathrm{N} \Delta \mathrm{D} 1$ & $\begin{array}{l}\text { pET28a-Derivat, enthält ein Fusionsgen aus der His-tag- } \\
\text { Sequenz und N.t.bzi-1 ohne N-Terminus und Domänel; } \\
\text { Kan }^{r}\end{array}$ & DRÖGE-LASER et al., 1997 \\
\hline pl6. $\Delta \mathrm{N} \Delta \mathrm{BD}$ & $\begin{array}{l}\text { pET28a-Derivat, enthält ein Fusionsgen aus der His-tag- } \\
\text { Sequenz und N.t.bzi-1 ohne N-Terminus und basische } \\
\text { Domäne; Kan }\end{array}$ & diese Arbeit \\
\hline pl6.BZII & $\begin{array}{l}\text { pET28a-Derivat, enthält ein Fusionsgen aus der His-tag- } \\
\text { Sequenz und N.t.bzi-1; } \mathrm{Kan}^{r}\end{array}$ & diese Arbeit \\
\hline p1 1.24 & $\begin{array}{l}\text { pQE30 Derivat (Qiagen), enthält ein Fusionsgen aus der } \\
\text { His-tag-Sequenz und N.t.bzi-1 ohne N-Terminus; Amp }{ }^{r}\end{array}$ & DRÖGE-LASER et al., 1997 \\
\hline pl6BZI1- $\Delta N \Delta B D$ & $\begin{array}{l}\text { pET28a-Derivat, enthält ein Fusionsgen aus der His- } \\
\text { tag-Sequenz und N.t.bzi- } 1 \text { ohne N-Terminus } \Delta B D ; A m p r\end{array}$ & $\begin{array}{l}\text { M. KUHLMANN, } \\
\text { Diplomarbeit, } 1998\end{array}$ \\
\hline pUCA7Tx & pUC-Derivat mit TX-Promotor, pAocs, mcs; Amp ${ }^{r}$ & GATZ et al., 1992 \\
\hline pUC18 & $\mathrm{pMBl}, \mathrm{lac} Z, \mathrm{Amp}^{\mathrm{r}}$ & {$[\mathrm{LO9136}]$} \\
\hline pUC19 & pUC18-Derivat mit invertierter mcs, Amp ${ }^{r}$ & {$[\mathrm{LO9137}]$} \\
\hline pUC19pGH3 & $\begin{array}{l}\text { PUC19-Derivat mit GH3-Promotor (Glycine max.) , 5' -UTR, } \\
\text { GUS-Fusion, Amp }{ }^{r}\end{array}$ & GUILFOYLE et al., 2001 \\
\hline $\begin{array}{l}\text { pKSBZI } 1-\Delta \mathrm{N} \\
\mathrm{HA} \triangle \mathrm{D} 4\end{array}$ & $\begin{array}{l}\text { Derivat des pBlueskriptKS, enthält das N.t.bzi-1 ohne N- } \\
\text { Terminus mit deletierter Domäne D4 und fusioniertem HA- } \\
\text { tag, Ampr }\end{array}$ & diese Arbeit \\
\hline
\end{tabular}


1|5|3 Hybridisierungssonden

\begin{tabular}{|c|c|c|}
\hline Gen & Fragment & Plasmid \\
\hline ANK1 - N.t.Ankyrin & EcoRI - BamHI - 513 bp-Fragment & pANK-GFP \\
\hline BZI-1 - N.t.bZIP-TKF 1 & Xhol - Nhel - 459 bp-Fragment & pBZII \\
\hline BZI-2 - N.t.bZIP-TKF 2 & Xbal - Accl - 512 bp komplettes Gen & pGAD-BZI2 \\
\hline BZI-3 - N.t.bZIP-TKF 3/TBZF & Xbal - Accl - 349 bp Fragment & pGAD-BZI3 \\
\hline BZI-4 - N.t.bZIP-TKF 4 & Xbal - Accl - 485 bp-Fragment & pGAD-BZI4 \\
\hline CHS - N.t.Chalkonesynthase & Xbal - Pstl - 1 kb - Fragment & pCS2 \\
\hline EAS4- N.t.Sequiterpenecyclase & Clal- Xhol - 1647 bp-Fragment & pEAS4 \\
\hline PRla- N.t.Pathogenisis related P. la & EcoRI - BamHI - 531 bp-Fragment & pPRla \\
\hline
\end{tabular}

1 | 5 | 4 DNA-Fragment-Größenstandard

Marker

RNA Größen-Standard Low Range

$\lambda$ DNA Pstl gespalten

pUC19-DNA Hpall gespalten

DNA Größen-Standard Marker X

\section{1 | 6 Proteine}

\section{$1|6| 1$ DNA-modifizierende Enzyme}

Enzyme

alkalische Phosphatase

T4-DNA-Ligase

Klenow-Polymerase

Klenow-Polymerase exo

Restriktionsenzyme

AmpliTaq ${ }^{\circledR}$ DNA Polymerase, FS

$1|6| 2$ Enzyme

Enzyme

Cellulase Onozuka R-10

Lysozym

Lyticase

Macerocym R-10

Restriktionsenzyme

RNase A (DNAse frei)

V8-Protease

\section{$1|6| 3$ Protein-Größenstandard}

Protein-Standards

SeeBlue ${ }^{\mathrm{TM}}$ Pre-Stained Standards

BenchMark ${ }^{\mathrm{TM}}$ Prestained Protein Ladder

Mark $12^{\mathrm{TM}}$ Wide Range Protein Standard

1 | 6 |4 Antikörper

Antikörper

$\alpha$-BZI1, polyklonal aus Kaninchen

$\alpha-H M G, \quad$ polyklonal aus Kaninchen

$\alpha$-His, polyklonal aus Kaninchen

$\alpha-H A$, polyklonal aus Kaninchen

$\alpha$-rabbit lg, polyklonal aus Esel,

Meerettichperoxidase gekoppelt
Hersteller/Lieferant

GIBCO BRL Life Technol.

laborintern

laborintern

Boehringer

Hersteller/Lieferant

Boehringer

Boehringer

MBI-Fermentas

$\mathrm{MBI}$-Fermentas

MBI-Fermentas, Gibco BRL, NEB

ABI Prism ${ }^{T M}$

Hersteller/Lieferant

Serva

Serva

Sigma

Serva

Pharmacia, Boehringer, NEB

Qiagen

Serva

Hersteller/Lieferant

Novex

GibcoBRL

Novex

Hersteller

diese Arbeit

GUPTA, et al., 1999

BioScience

Santa Cruz

Amersham 


\section{1 |7 Organismen}

\section{$1|7| 1$ Mikroorganismen}

\begin{tabular}{|c|c|c|}
\hline Stamm & Eigenschaften & Herkunft \\
\hline E. coli S17.1 & pro, res', mod $^{+}$ & SIMON et al., 1983 \\
\hline E. coli $\mathrm{DH} 5 \alpha$ & $\begin{array}{l}\text { F-, gyrA96(Nalr), recA1, relA1, thi-1, hsd'R17 } \\
\text { (rk-mk+), glnV44, deoR, D (lacZY A-argF) } \\
\text { U169 [p80dD(lacZ)M15 }\end{array}$ & HANAHAN et al., 1983 \\
\hline E. coli XL1Blue & $\begin{array}{l}\operatorname{rec} A 1 \text {, end } A 1 \text {, gyrA96, hsdR17, supE44, lac, } \\
{\left[F^{\prime} \text { proAB, laclq } Z M 15, \operatorname{Tn} 10\left(\text { tet }^{r}\right)\right] \text {, thi }}\end{array}$ & BULLOCK et al., 1987 \\
\hline E.coli Bl21 & $\mathrm{F}^{-}$, dcm, ompT, $\mathrm{lac}^{-}, \mathrm{Met}^{+}, \mathrm{r}_{\mathrm{B}}^{-}, \mathrm{m}_{\mathrm{B}}^{-}, \mathrm{gal}, \mathrm{kan}^{\mathrm{r}}$ & STUDIER \& MOFFAT, 1986 \\
\hline A. tumefaciens LBA 4404 & $\mathrm{pAL} 4404, \mathrm{Sm}^{\mathrm{R}}$ & HOKEMA et al., 1983 \\
\hline $\begin{array}{l}\text { Pseudomonas syringae } \\
\text { pv.pisi / tabacci }\end{array}$ & & YUCEL et al., 1989 \\
\hline TMV & & NIGGEWEG, 1999 \\
\hline
\end{tabular}

\section{$1|7| 2$ Pflanzen}

Die Pflanzen für die stabilen Transformationen entstammen dem Kultivar Xanthi nc (NN). Verwendet wurden drei parallele Linien mit unterschiedlichen Reportergen-Konstrukten (8.xxx: pchs8-gus; 15.xxx: pchs15-gus; p.xxx: ppal-gus). Die Pflanzen zur Präparation der Mesophyllprotoplasten entstammten dem Kultivar SNN.

\section{1 | 8 Medien}

\section{$1|8| 1$ Bakterienmedien}

LB-Medium (LURIA-BERTANI BROTH; SAMBROOK et al., 1989)

$\begin{array}{ll}\text { Trypton } & 10 \mathrm{~g} / \mathrm{l} \\ \text { Hefe-Extrakt } & 5 \mathrm{~g} / \mathrm{l} \\ \mathrm{NaCl} & 5 \mathrm{~g} / \mathrm{l}\end{array}$

Einstellen des pH-Wertes auf 7,4 Auffüllen mit $\mathrm{H}_{2} \mathrm{O}$ ultra pure auf 1 I

Für ein Festmedium $12 \mathrm{~g}$ Bacteriological Agar/l Medium zusetzen.

Autoklavieren $\left(15 \mathrm{~min}, 120^{\circ} \mathrm{C}, 1,2 \mathrm{bar}\right)$.

Agrobakterium-Minimal-Medium (AMM) (SAMBROOK et al, 1989)

\section{$20 \times$ T-Puffer}

$\begin{array}{ll}\mathrm{K}_{2} \mathrm{HPO}_{4} & 210 \mathrm{~g} \\ \mathrm{KH}_{2} \mathrm{PO}_{4} & 90 \mathrm{~g}\end{array}$

$20 \times$ T-Salze

$\begin{array}{ll}\mathrm{MgSO}_{4} \times 7 \mathrm{H}_{2} \mathrm{O} & 4 \mathrm{~g} \\ \mathrm{CaCl}_{2} & 0,2 \mathrm{~g} \\ \mathrm{FeSO}_{4} & 0,1 \mathrm{~g} \\ \mathrm{MnCl}_{2} & 0,04 \mathrm{~g} \\ \mathrm{NH}_{4} \mathrm{Cl} & 20 \mathrm{~g} \quad \text { mit } \mathrm{H}_{2} \mathrm{O} \text { auf } 1 \mathrm{I} \text { auffüllen }\end{array}$

AMM

$20 \times$ T-Puffer $\quad 50 \mathrm{ml}$

$20 \times$ T-Salze $\quad 50 \mathrm{ml}$

Glucose $\quad 5 \mathrm{~g}$

mit $\mathrm{H}_{2} \mathrm{O}$ ultra pure auf 1 I auffüllen

Für ein Festmedium $12 \mathrm{~g}$ Bacteriological Agar/l Medium zusetzen.

Autoklavieren (15 min, $120{ }^{\circ} \mathrm{C}, 1,2 \mathrm{bar}$ ) 
King's B Medium (KING et al., 1954)

$\begin{array}{ll}\begin{array}{l}\text { Peptose Peptone \#3 } \\ \text { (Difco 0122) }\end{array} & 20 \mathrm{~g} \\ 87 \% \text { Glycerol } & 11,5 \mathrm{ml} \\ \mathrm{K}_{2} \mathrm{HPO}_{4} \times 3 \mathrm{H}_{2} \mathrm{O} & 1,96 \mathrm{~g} \\ \mathrm{MgSO}_{4} \times 7 \mathrm{H}_{2} \mathrm{O} & 1,5 \mathrm{~g}\end{array}$

Einstellen des pH-Wertes auf 7,2 Mit $\mathrm{H}_{2} \mathrm{O}$ ultra pure auf 1 I auffüllen

Für ein Festmedium $12 \mathrm{~g}$ Bacteriological Agar/l Medium zusetzen.

Autoklavieren $\left(15 \mathrm{~min}, 120^{\circ} \mathrm{C}, 1,2 \mathrm{bar}\right)$

YEB-Medium (SAMBROOK et al., 1989)

$\begin{array}{ll}\text { Beefextrakt } & 10 \mathrm{~g} \\ \text { Hefe-extrakt } & 2 \mathrm{~g} \\ \text { Pepton } & 5 \mathrm{~g} \\ \text { Saccharose } & 5 \mathrm{~g} \\ \mathrm{MgSO}_{4} & 2 \mathrm{mM}\end{array}$

Einstellen des $\mathrm{pH}$-Wertes auf 7,0

Mit $\mathrm{H}_{2} \mathrm{O}$ ultra pure auf $1 \mathrm{I}$ auffüllen

\section{1|8|2 Pflanzenmedien}

MS-Medium (MURASHIGE \& SKOOG, 1962)

\begin{tabular}{|c|c|c|c|}
\hline $\begin{array}{l}\text { Murashige \& Skoog Medium } \\
\text { Oder }\end{array}$ & \multicolumn{3}{|l|}{$4,59 \mathrm{~g}$} \\
\hline $20 \times$ Makroelemente & $50 \mathrm{ml}$ & $\begin{array}{l}\mathrm{NH}_{4} \mathrm{NO}_{3} \\
\mathrm{KNO}_{3} \\
\mathrm{CaCl}_{2} \times 2 \mathrm{H}_{2} \mathrm{O} \\
\mathrm{MgSO}_{4} \times 7 \mathrm{H}_{2} \mathrm{O} \\
\mathrm{KH}_{2} \mathrm{PO}_{4}\end{array}$ & $\begin{array}{l}33,0 \mathrm{~g} / 1 \\
38,0 \mathrm{~g} / 1 \\
8,8 \mathrm{~g} / 1 \\
7,4 \mathrm{~g} / 1 \\
3,4 \mathrm{~g} / 1\end{array}$ \\
\hline $200 \times$ Eisen-EDTA & $5 \mathrm{ml}$ & $\begin{array}{l}\mathrm{Na} \text { EDTA } \times 2 \mathrm{H}_{2} \mathrm{O} \\
\mathrm{FeSO}_{4} \times 7 \mathrm{H}_{2} \mathrm{O}\end{array}$ & $\begin{array}{l}7,45 \mathrm{~g} / \mathrm{l} \\
5,57 \mathrm{~g} / \mathrm{l}\end{array}$ \\
\hline $200 \times$ Mikroelemente & $5 \mathrm{ml}$ & $\begin{array}{l}\mathrm{H}_{3} \mathrm{BO}_{3} \\
\mathrm{MnSO}_{4} \times 4 \mathrm{H}_{2} \mathrm{O} \\
\mathrm{ZnSO}_{4} \times 7 \mathrm{H}_{2} \mathrm{O} \\
\mathrm{KJ} \\
\mathrm{Na}_{2} \mathrm{MoO}_{4} \times 2 \mathrm{H}_{2} \mathrm{O} \\
\mathrm{CuSO}_{4} \times 5 \mathrm{H}_{2} \mathrm{O} \\
\mathrm{CoCl}_{2} \times 6 \mathrm{H}_{2} \mathrm{O}\end{array}$ & $\begin{array}{l}1,24 \mathrm{~g} / \mathrm{l} \\
4,46 \mathrm{~g} / \mathrm{l} \\
1,72 \mathrm{~g} / \mathrm{l} \\
166 \mathrm{mg} / \mathrm{l} \\
50 \mathrm{mg} / \mathrm{l} \\
5 \mathrm{mg} / \mathrm{l} \\
5 \mathrm{mg} / \mathrm{l}\end{array}$ \\
\hline $200 \times$ Vitamine & $5 \mathrm{ml}$ & $\begin{array}{l}\text { Nicotinsäure } \\
\text { Pyridoxin } \mathrm{HCl} \\
\text { Thiamin } \mathrm{HCl} \\
\text { Glycin } \\
\text { myo-Inositol }\end{array}$ & $\begin{array}{l}100 \mathrm{mg} / \mathrm{l} \\
100 \mathrm{mg} / \mathrm{l} \\
20 \mathrm{mg} / \mathrm{l} \\
400 \mathrm{mg} / \mathrm{l} \\
20 \mathrm{~g} / \mathrm{l}\end{array}$ \\
\hline Sucrose & $30 \mathrm{~g}$ & & \\
\hline
\end{tabular}

Mit $\mathrm{H}_{2} \mathrm{O}$ ultra pure auf 1 I auffüllen Mit $\mathrm{KOH}$ auf $\mathrm{pH}$ 5,8 einstellen Zugabe von 7,4 g Select Agar/I Medium Autoklavieren (15 min, $120^{\circ} \mathrm{C}, 1,2 \mathrm{bar}$ )

Zugabe von Antibiotika aus sterilfiltrierten Stammlösungen nach Abkühlen des Mediums auf ca $60{ }^{\circ} \mathrm{C}$
Cefotaxim
$500 \mathrm{mg} / \mathrm{l}$
(Stammlsg.: $250 \mathrm{mg} / \mathrm{ml}$ )
Hygromycin $30 \mathrm{mg} / \mathrm{l}$
(Stammlsg.: $30 \mathrm{mg} / \mathrm{ml}$ ) 
LS-Medium (LINSMAIER \& SKOOG, 1962) für sterile Suspensionskulturen

Linsmaier und Skoog Medium

Saccharose

\section{$4,4 \mathrm{~g}$}

$30 \mathrm{~g}$

Lösen der Substanzen und Einstellen des pH-Wertes auf 5,8 mit $\mathrm{KOH}$

Auffüllen auf 1 I mit Millipore- $\mathrm{H}_{2} \mathrm{O}$

autoklavieren, Zugabe von $1 \mu \mathrm{M}$ 2,4-D aus einer Stammlösung von 1,1 mg/ml in 50 \% EłOH

\section{B5-Infektionsmedium}

Gamborgs B5-Infektionsmedium 3,71 g

$\mathrm{NH}_{4} \mathrm{NO}_{3} \quad 250 \mathrm{mg}$

MES $\quad 500 \mathrm{mg}$

Sucrose $\quad 30 \mathrm{~g}$

Lösen der Substanzen und Einstellen des pH-Wertes auf 5,8 mit $\mathrm{KOH}$

Auffüllen auf 1 I mit Millipore- $\mathrm{H}_{2} \mathrm{O}$

autoklavieren

Medium für die Blattscheibentransformation

Murashige \& Skoog Medium 4,59 $\mathrm{g}$

Glucose $\quad 16 \mathrm{~g}$

Lösen der Substanzen und Einstellen des $\mathrm{pH}$-Wertes auf 5,7 mit $\mathrm{KOH}$

Select Agar

$7,4 \mathrm{~g}$

Auffüllen mit Millipore- $\mathrm{H}_{2} \mathrm{O}$ auf 1 I

Autoklavieren

Zugabe der Antibiotika nach Abkühlen des Mediums auf $60^{\circ} \mathrm{C}$

Zugabe der Pflanzenhormone

6-Benzylaminopurin (6-BAP) $\quad 1 \mathrm{mg} / \mathrm{l} \quad$ (Stammlsg. $1 \mathrm{mg} / \mathrm{ml} \mathrm{E†OH}$ )

1 -Naphtylessigsäure (NAA) $\quad 0,1 \mathrm{mg} / \mathrm{l}$

(Stammlsg. $1 \mathrm{mg} / \mathrm{ml} \mathrm{EłOH)}$

\section{1 | 9 Zusätze}

\begin{tabular}{llll} 
Zusatz & Stocklösung $[\mathrm{mg} / \mathrm{ml}]$ & \multicolumn{2}{l}{ Endkonzentration [mg/l] } \\
\hline Ampicillin & 100 in $\mathrm{H}_{2} \mathrm{O}$ & 100 & (f. E.coli-medien) \\
Cefotaxim & 500 in $\mathrm{H}_{2} \mathrm{O}$ & 250 & (f. Pflanzenmedien) \\
Hygromycin & 30 in $\mathrm{H}_{2} \mathrm{O}$ & 30 & (f. Pflanzenmedien) \\
IPTG & 23,8 in DMF & 50 & (f. E.coli-medien) \\
Kanamycin & 50 in $\mathrm{H}_{2} \mathrm{O}$ & 50 & (f. E.coli-medien) \\
& & 150 & (f. A.tum-medien) \\
Rifampicin & 10 in Methanol & 100 & (f. P.syr-medien) \\
X-Gal & 20 in DMF & 40 & (f. E.coli-medien)
\end{tabular}




\section{1 | 10 Standardlösungen und Puffer}

\begin{tabular}{|c|c|}
\hline BPB (Bromphenolblau) & $\begin{array}{l}10 \mathrm{ml} \mathrm{TBE} \\
80 \mathrm{ml} \text { Glycerin (87 \%) } \\
250 \mathrm{mg} \text { BPB-Pulver }\end{array}$ \\
\hline Ethidiumbromidbad & $0,5 \mu \mathrm{g}$ Ethidiumbromid $/ \mathrm{ml} \mathrm{H}_{2} \mathrm{O}$ \\
\hline $\mathrm{NaAc}$ & $\begin{array}{l}\text { 0,3M (pH 7,5): } 2,46 \mathrm{~g} \mathrm{NaAc}(\mathrm{M}=82,03 \mathrm{~g} / \mathrm{mol}) \\
+100 \mathrm{ml} \text { Aqua bidest. }\end{array}$ \\
\hline $\mathrm{Pl}$ & $\begin{array}{l}50 \mathrm{mM} \text { Tris- } \mathrm{HCl}, \mathrm{pH} 8,0 \\
10 \mathrm{mM} \text { EDTA } \\
100 \mu \mathrm{g} / \mathrm{ml} \mathrm{RNaseA}\end{array}$ \\
\hline P2 & $\begin{array}{l}200 \mathrm{mM} \mathrm{NaOH} \\
1 \% \mathrm{SDS}\end{array}$ \\
\hline P3 & 2,55 M KAc, pH 5,5 \\
\hline $1 \times P B S$ & $\begin{array}{ll}70 \mathrm{mM} & \mathrm{NaCl} \\
1,35 \mathrm{mM} & \mathrm{KCl} \\
0,75 \mathrm{mM} & \mathrm{KH} 2 \mathrm{PO} 4 \\
4,05 \mathrm{mM} & \mathrm{Na} 2 \mathrm{HPO} 4, \mathrm{pH} 7,4\end{array}$ \\
\hline PCl-Mix (Phenol-Chloroform-Isoamylalkohol) & $\begin{array}{l}250 \mathrm{ml} \text { Phenol } \\
250 \mathrm{ml} \text { Chloroform } \\
10,4 \mathrm{ml} \text { Isoamylalkohol } \\
\text { mind. } 1 \text { h auf dem Rührer mischen }\end{array}$ \\
\hline QBT & $\begin{array}{l}750 \mathrm{mM} \mathrm{NaCl} \\
50 \mathrm{mM} \mathrm{MOPS} \\
15 \% \mathrm{EtOH} \\
0,15 \% \text { Triton } \times 100, \mathrm{pH} \mathrm{7,0}\end{array}$ \\
\hline QC & $\begin{array}{l}1 \mathrm{M} \mathrm{NaCl} \\
50 \mathrm{mM} \mathrm{MOPS} \\
15 \% \mathrm{EtOH}, \mathrm{pH} 7,0\end{array}$ \\
\hline QF & $\begin{array}{l}1,25 \mathrm{M} \mathrm{NaCl} \\
50 \mathrm{mM} \mathrm{MOPS} \\
15 \% \mathrm{E \dagger OH}, \mathrm{pH} 8,2\end{array}$ \\
\hline RNase & $10 \mathrm{mg}$ RNase $/ \mathrm{ml} \mathrm{H}_{2} \mathrm{O}\left(20 \mathrm{~min}, 100^{\circ} \mathrm{C}\right)$ \\
\hline SSC $20 x$ & $\begin{array}{l}3 \mathrm{M} \mathrm{NaCl} \\
0,3 \mathrm{M} \mathrm{Na} \text {-Citrat }\end{array}$ \\
\hline STE & $\begin{array}{ll}8 \% & \text { Sucrose (Saccharose) } \\
50 \mathrm{mM} & \text { Tris-HCl, } \mathrm{pH} 8,0 \\
50 \mathrm{mM} & \text { EDTA in Wasser }\end{array}$ \\
\hline STET & $\begin{array}{ll}8 \% & \text { Sucrose (Saccharose) } \\
50 \mathrm{mM} & \text { Tris-HCl, } \mathrm{pH} 8,0 \\
50 \mathrm{mM} & \text { EDTA in Wasser } \\
0,1 \% & \text { Triton } \mathrm{X}-100\end{array}$ \\
\hline $50 \times T A E$ & $\begin{array}{l}242 \mathrm{~g} \text { Tris } \\
57,1 \mathrm{ml} \text { Aceticacid } \\
100 \mathrm{ml} \text { EDTA 0,5M, pH 8,0 ad } 11\end{array}$ \\
\hline 10xTBE-Puffer & $\begin{array}{ll}1 \mathrm{M} & \text { Tris/ } \mathrm{HCl}(\mathrm{pH} 8,2) \\
0,83 \mathrm{M} & \text { Borsäure } \\
0,1 \mathrm{M} & \text { EDTA }\end{array}$ \\
\hline TE-Puffer & $\begin{array}{l}10 \mathrm{mM} \text { Tris/HCl } \\
1 \mathrm{mM} \text { EDTA, pH 8,0 }\end{array}$ \\
\hline
\end{tabular}




\section{2 | Methoden}

\section{2|1 Anzucht von Mikroorganismen}

\section{$2|1| 1$ Anzucht von TMV}

Die Anzucht und Isolierung des TMV-Virus erfolgte aus Tabakblattgewebe nach YALPANI et al., 1991.

\section{2|1|2 Anzucht von E.coli}

Die Anzucht der E. coli - Bakterien erfolgt auf LB-Festmedium, bzw. in LB-Flüssigmedium bei $37^{\circ} \mathrm{C}$ ü.N. Die angeimptten Flüssigmedien in Reagenzgläsern werden im Roller inkubiert (SAMBROOK et al., 1989). Flüssigkulturen im Erlenmeyerkolben werden nach Überimpfen aus einer Vorkultur im Luftschüttler bei 250 rpm inkubiert. Die Bakteriendichte wird photometrisch bei $600 \mathrm{~nm}$ gemessen, wobei der Wert 0, leinem Titer von $2 \times 10^{7}$ Zellen entspricht. Zur Selektion wird dem Medium ein entsprechendes Antibiotikum zugesetzt. Zur Differenzierung inserttragender Plasmide kann das Ausplattieren auch auf X-Gal/IPTG erfolgen. Bei einem geeigneten Stamm (XL1-Blue) und einem entsprechenden Plasmid kommt es zur $\alpha$-Komplementation und es kann ein Blau/Weiß-Screening vorgenommen werden. Die Konservierung der Stämme erfolgt in $15 \%$ Glycerin-versetztem LB-Medium bei $-80^{\circ} \mathrm{C}$.

\section{2| 1 |3 Anzucht von Agrobakterien}

Die Anzucht der A. tumefaciens - Bakterien erfolgt in Agrobakterien-Minimal-Medium (fest und flüssig) oder in LB-Medium (fest und flüssig). Die Inkubation erfolgt bei $28{ }^{\circ} \mathrm{C}$ für 3 Tage. Die Inkubation der Flüssigmedien erfolgt im Roller. (SAMBROOK et al., 1989). Zur Selektion wird dem Medium das entsprechende Antibiotikum zugesetzt. Die Konservierung der Stämme erfolgt bei $-80^{\circ} \mathrm{C}$ in Glycerinkulturen.

\section{2| 1 |4 Anzucht von Pseudomonaden}

Die Anzucht der P. syringae - Bakterien erfolgt in King's B-Medium (KING et al., 1954) bei $28{ }^{\circ} \mathrm{C}$ für 2 Tage. Die Inkubation der Flüssigmedien erfolgt im Roller. Zur Selektion wird dem Medium das entsprechende Antibiotikum zugesetzt. Für Pflanzeninfektionen werden die Bakterien aus der ü.N.-Kultur erneut in frisches Medium überimpft. Die Aufbewahrung der Stämme erfolgt in sterilem Leitungswasser bei $4{ }^{\circ} \mathrm{C}$.

\section{2|2 Anzucht von Pflanzen}

\section{$2|2| 1$ Suspensionskultur}

Die Anzucht der BY-2 (Bright Yellow-2)-Tabak (Nicotiana tabacum)-Suspensionskulturen erfolgt in Linsmaier und Skoog-Flüssigmedium in $100 \mathrm{ml}$ Erlenmeyerkolben unter Lichtausschluss bei $26{ }^{\circ} \mathrm{C}$ auf einem Schüttler mit $120 \mathrm{rpm}$. Für die Subkultivierung werden wöchentlich, im gleichen Rhythmus $3 \mathrm{ml}$ Kultur in $27 \mathrm{ml}$ frisches Medium transferiert. Dem Medium wird jeweils frisch 2,4-D und NAA zugesetzt.

\section{$2|2| 2$ Gewebekultur}

Die Tabakpflanzen werden unter sterilen Bedingungen auf 2MS-Festmedium in Gläser kultiviert. Die Anzucht erfolgt in Klimakammern oder -schränken bei $24{ }^{\circ} \mathrm{C}$ am Tag und $22{ }^{\circ} \mathrm{C}$ in der Nacht, wobei der Licht/Dunkel-Rhythmus $16 \mathrm{~h}: 8 \mathrm{~h}$ beträgt. Die Subkultivierung erfolgt durch Abtrennen und überführen der vegetativen Spitze auf frisches Medium. Die Blattexplanate auf den Hormonmedien werden unter den gleichen Bedingungen inkubiert. Für die Präparation von Mesophyllprotoplasten werden SNN-Tabakpflanzen in weitbauchigen Schmuckformgläsern auf modifieziertem 2-MS-Medium mit zusätzlich 0,5 g/l MES angezogen.

\section{$2|2| 3$ Klimakammer/Gewächshaus}

Die Kultivierung der Pflanzen bis zur Blüte erfolgt unter unsterilen Bedingungen in Erde bei $22{ }^{\circ} \mathrm{C}$ am Tag und $19{ }^{\circ} \mathrm{C}$ in der Nacht, bei einer relativen Lufffeuchtigkeit von $85 \%$ in einem Licht-Dunkel-Rhythmus von $16 \mathrm{~h}$ : 8 h. Als Erde wird zum Aussetzen Frühstdorfer Torf Typ P (Pikier), zum Umtopfen Frühsdorfer Torf Typ $T$ (Topf) verwandt. Die Samenproduktion erfolgte im Gewächshaus unter Umweltbedingungen. 


\section{2|3 Molekulargenetische Methoden}

\section{$2|3| 1$ Isolierung von Plasmid-DNA aus E.coli}

Zur schnellen Präparation von Plasmid-DNA zu alamytischen Zwecken wird eine modifizierte alkalische Lyse der Bakterien (LE GOUILL et al., 1994) vorgenommen. 1,5 ml einer stationären E.coli-Kultur werden pelletiert $\left(3^{\prime}, 5000 \mathrm{rpm}\right)$ und die Zellen nach Dekantieren des Überstandes in $100 \mu \mathrm{l} \mathrm{P1}$ resuspendiert. Die Lyse der Bakterien erfolgt im alkalischen Milieu durch Zugabe von $200 \mu \mathrm{l} \mathrm{P2}$ und $150 \mu \mathrm{l}$ Chloroform. Nach 1' Inkubation wird zur Neutralisation $150 \mu \mathrm{l}$ P3 zugegeben, der Ansatz gevortext und die Präzipitate durch Zentrifugation $\left(2^{\prime}, 15000 \mathrm{rpm}, 4^{\circ} \mathrm{C}\right)$ sedimentiert. Die obere, wässrige Phase wird zur Fällung der DNA mit 2,5 Volumen Ethanol $\left(-20^{\circ} \mathrm{C}\right)$ gemischt und $2^{\prime}, 15000 \mathrm{rpm}, 4{ }^{\circ} \mathrm{C}$ zentrifugiert. Die pelletierte DNA wird mit $70 \%$ Ethanol gewaschen und für $10^{\prime}$ bei $37^{\circ} \mathrm{C}$ getrocknet. Die gewonnene DNA wird in $20 \mu \mathrm{l} \mathrm{EB}$ oder $\mathrm{H}_{2} \mathrm{O}$ gelöst und kann zur Restriktionsanalyse eingesetzt werden.

Für Sequenzierreaktionen wird hochreine DNA mit Hilfe des QIAprep Spin Miniprep-Kits isoliert. Das Prinzip entspricht dem der o.g. Lyse.

Präparative Mengen DNA mit hohem Reinheitsgrad werden mit Hilfe der Midi-und Maxi-Kits der Firma Qiagen präpariert. Die Durchführung erfolgt den Herstellerangaben gemäß.

\section{$2|3| 2$ Isolierung von Plasmid-DNA aus Agrobakterien}

Zur Isolation von binären Vektoren aus Agrobakterien wird $10 \mathrm{ml}$ einer stationären Kultur pelletiert $\left(20^{\prime}\right.$,

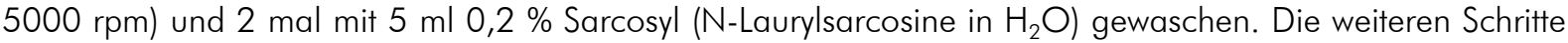
erfolgen mit Hilfe des QIAprep Spin Miniprep-Kits nach Herstellerangaben. Zur Elution der DNA wird der EB auf $70{ }^{\circ} \mathrm{C}$ erhitzt und von dem Eluat $1 / 3$ zur Restriktionsanalyse eingesetzt.

\section{$2|3| 3$ Isolierung von Gesamt-RNA aus Pflanzengewebe}

Zur RNA-Präparation wird der Rneasy-Plant Mini-Kit der Firma Qiagen verwendet. Die Aufarbeitung erfolgt mit Hilfe des Herstellerprotokolls. Zur Extraktion wird der $\beta$-ME ( $\beta$-Mercaptoethanol) versetzte RLT-Puffer verwendet. Eingesetzt werden $150 \mathrm{mg}$ Material. Zur Erhöhung der Ausbeute wird der Durchfluss der ersten Eluation ein zweites Mal auf die Säule appliziert und zentrifugiert.

\section{2|3|4 Annealing von Oligonucleotiden}

Nach 10' Kochen der komplementären Oligonucleotide zur Auflösung von Sekundärstrukturen erfolgt das Annealen durch langsames Senken der Temperatur. Die Temperatur wird jeweils in 15' Inkubationsschritten von $65^{\circ} \mathrm{C}$, auf $37{ }^{\circ} \mathrm{C}$, auf RT bis schließlich auf $4{ }^{\circ} \mathrm{C}$ herabgesetzt. Eingesetzt werden je $1 \mathrm{nmol}$ der Oligonucleotide in einem Reaktionsvolumen von $20 \mu \mathrm{l}$.

\section{$2|3| 5$ Konzentrations und Reinheitbestimmung von Nukleinsäuren}

Zur Konzentrationsbestimmung wird der GeneQuant II der Firma Pharmacia verwendet. Da man die Absorption von Nucleinsäuren in einer wässrigen Lösung im UV-Bereich bei $260 \mathrm{~nm}$ messen kann, lässt sich hierdurch die Konzentration der DNA bestimmen. Das Absorptionsmaximum bei dieser Wellenlänge wird durch die Anregung des $\pi$-Elektronensystems in den Heterocyclen der Basen hervorgerufen. Bei einer Schichtdicke von $1 \mathrm{~cm}$ entspricht somit eine OD260 von 1,0 einer Nucleinsäure-Konzentration von 50 $\mu \mathrm{g} / \mathrm{ml}$ bei dsDNA und $40 \mu \mathrm{g} / \mathrm{ml}$ bei RNA. Im Vergleich zur Absorption bei der Wellenlänge $280 \mathrm{~nm}$, bei der die aromatischen Seitenketten von Proteinen angeregt werden, lässt sich nun der Quotient aus der Absorption der Wellenlängen 260/280 nm als ein Maß für den Reinheitsgrad der DNA- oder RNApräparation darstellen.

Der Reinheitgrad sollte idealerweise zwischen 1,7 und 2,0 liegen. Gemessen werden 1:100 Verdünnungen der Präparationen.

\section{$2|3| 6$ Agarosegelelektrophorese}

Die elektophoretische Auftrennung von DNA für analytische und präparative Zwecke erfolgt in horizontalen Agarosegelen mit 1x TAE oder 1x TBE. Für DNA-Moleküle im Größenbereich von 500 bp - 1,4 kb werden Gele mit einer Agarosekonzentration von 1-0,7\% (w/v) verwendet. Für die Auftrennung kleinerer DNAFragmente wird ein HEC-Gel $(0,7 \%$ Hydroxyethylcellulose in $1 \%$ Agarose in $1 \times$ TAE) verwendet (PERLMANN \& HAVORSON, 1987). Die zu analysierende DNA wird in 10x Probenpuffer (67\% Saccharose, 50mM EDTA, pH8 
0,42\% w/v BPB) aufgenommen und auf das Gel aufgetragen. Zur Abschätzung der Fragmentgrößen wird jeweils ein entsprechender Fragmentgrößenstandard mit auf das Gel aufgetragen. Aufgrund der negativ geladenen Phosphatgruppen innerhalb der DNA-Moleküle wandern diese nach Anlegen des elektrischen Feldes mit einer Stromstärke von $90-120 \mathrm{~V}$ in Richtung der Anode. Zur Detektion wird das Gel nach dem Lauf im EłBr-Bad gefärbt, das nicht in der DNA interkalierende EłBr im Wasserbad aus dem Gel ausgeschwemmt, die angefärbten Banden auf dem Transilluminator bei 302 nm illuminiert und mit Hilfe der Geldokumentationsanlage dokumentiert.

\section{2|3|7 Denaturierende Agarosegelelektrophorese von RNA}

Um die elektrophoretische Größenauftrennung von RNA-Molekülen zu ermöglichen muss die Elektrophorese unter denaturierenden Bedingungen stattfinden, da sonst die Sekundärstrukturen das Laufverhalten beeinflussen. Die Elektrophorese findet in einem Formaldehyd-haltigen Agarosegel (1 \% w/v Agarose, 5,5\% v/v Formaldehyd in 1x MEN-Puffer, $200 \mathrm{mM}$ MOPS, $50 \mathrm{mM} \mathrm{NaAc}, 10 \mathrm{mM}$ EDTA, pH 7,0 mit $\mathrm{NaOH}$ ) wobei 1x MEN als Laufpuffer dient. Die je $8 \mu \mathrm{g}$ der RNA-Proben werden auf das gleiche Volumen abgeglichen und mit 2,5x Probenpuffer (2,5x MEN, 5,55 \% v/v Formaldehyd, $48 \%$ deionisiertes Formamid, $10,44 \%$ v/v Glycerin,0,5 \% EłBr, 0,001 \% v/v BPB-Lösung) versetzt. Die Denaturierung der Proben erfolgt bei $65^{\circ} \mathrm{C}$ für 10'. Bis zum Auftragen der Proben werden diese auf Eis gehalten. Die Elektrophorese erfolgt bei $120 \mathrm{~V}$ bis die BPB-Bande 2 - $3 \mathrm{~cm}$ vom unteren Gelrand entfernt ist. Die Kontrolle und Dokumentation der RNA erfolgt am UV-Transilluminator mit Hilfe der Geldokumentationsanlage.

\section{$2|3| 8$ Isolierung von DNA-Fragmenten aus dem Agarosegel}

Für die Isolierung von DNA-Fragmenten aus Agarosegelen wird der QIAquick Gel Extraction Kit von Qiagen verwendet. Die Aufreinigung erfolgte nach dem Protokoll des Herstellers.

\section{$2|3| 9$ Restriktionsspaltung}

Doppelsträngige DNA kann mit Hilfe von Restriktionsendonucleasen des Typs II sequenzspezifisch gespalten werden. Die Enzyme erkennen palindromische Sequenzen und es entstehen je nach Enzym 3'- oder 5'überhängende ("sticky") oder glatte ("blunt") Enden. Die optimalen Reaktionsbedingungen werden durch die entsprechenden 10x Puffersysteme eingestellt:
Puffer $\mathrm{B}^{+}: \quad 10 \mathrm{mMTris}-\mathrm{HCl}(\mathrm{pH} 7,5) ; 10 \mathrm{mM} \mathrm{MgCl} 2 ; 0,1 \mathrm{mg} / \mathrm{ml} \mathrm{BSA}$
Puffer $\mathrm{G}^{+}: \quad 10 \mathrm{mMTris}-\mathrm{HCl}(\mathrm{pH} 7,5) ; 10 \mathrm{mM} \mathrm{MgCl}_{2} ; 50 \mathrm{mM} \mathrm{NaCl} ; 0,1 \mathrm{mg} / \mathrm{ml} \mathrm{BSA}$
Puffer $\mathrm{O}^{+}: \quad 50 \mathrm{mMTris}-\mathrm{HCl}(\mathrm{pH} 7,5) ; 10 \mathrm{mM} \mathrm{MgCl} 2 ; 100 \mathrm{mM} \mathrm{NaCl} ; 0,1 \mathrm{mg} / \mathrm{ml} \mathrm{BSA}$
Puffer $\mathrm{R}^{+}$: $\quad 10 \mathrm{mMTris}-\mathrm{HCl}(\mathrm{pH} 8,5) ; 10 \mathrm{mM} \mathrm{MgCl} ; 100 \mathrm{mM} \mathrm{KCl} ; 0,1 \mathrm{mg} / \mathrm{ml} \mathrm{BSA}$
Puffer $\mathrm{Y}^{+}: \quad 33 \mathrm{mMTris-Acetat}(\mathrm{pH} 7,9) ; 10 \mathrm{mM} \mathrm{MgAc} ; 66 \mathrm{mM} \mathrm{KAa} ; 0,1 \mathrm{mg} / \mathrm{ml} \mathrm{BSA}$

Die Menge an einzusetzendem Enzym errechnet sich aus folgender Formel:

$U_{\min }=\frac{b p[\lambda \text {-DNA }] \times \text { Schnittstellen }[D N A]}{\text { Schnittstellen }[\lambda \text {-DNA }] \times b p[D N A]}$

wobei bp $[\lambda]=48500$ und $u$ [unit] die Enzymmenge beschreibt, die $1 \mu \mathrm{g} \lambda$-DNA innerhalb von 60' vollständig verdaut.

\section{$2|3| 10$ Ligation}

Die Verknüpfung zweier DNA-Fragmentenden geschieht mit Hilfe der T4-DNA-Ligase. Die Ligase katalysiert unter ATP-Verbrauch eine Phosphodiesterbindung zwischen benachbarten 5'-Phosphat- und 3'-OHGruppen. Für die Konstruktion von Plasmiden wird 50 fmol linearisierte Vektor-DNA und entsprechend, in 10-100 fachen molaren Überschuss, das zu inserierende Fragment eingesetzt. Die Reaktion erfolgt im Ligase-Puffer (40 mM Tris-HCl; 10 mM MgCl $; 10$ mM DTT; 0,5 mM ATP; pH 7,8) mit 4 u T4-DNA-Ligase bei RT für $4 \mathrm{~h}$. 


\section{2|3|11 Polymerase-Ketten-Reaktion}

Mit Hilfe der Polymerase-Kettenreaktion ("polymerase chain reaction", PCR, MULLIS \& FALOONA, 1987) können unter Verwendung zweier gegenläufiger Primer spezifische Sequenzen eines DNA-Templats mittels einer DNA-Polymerase selektiv amplifiziert werden.

Die als Matrize dienende Template-DNA wird zunächst denaturiert. Nach der Anlagerung der Primer an die komplementären Sequenzen der DNA-Einzelstränge synthetisiert die hitzestabile Taq-DNA-Polymerase in einer Primer-Verlängerungsreaktion komplementäre DNA-Stränge an der DNA-Matrize. Dieser Zyklus aus Denaturierung, Primeranlagerung (Annealing) und DNA-Synthese (Elongation) wird 25-35 mal wiederholt.

Ein Standard-Ansatz enthält Matrizen-DNA (10 ng), je 10 pmol der Primer, dNTPs (0,2 mM je Nucleotid) und 2,5 u Taq-Polymerase in Taq-Puffer $\left(20 \mathrm{mM}\right.$ Tris-HCl, pH 8,55, 1,5 mM MgCl$\left.; 16 \mathrm{mM}_{2}\left(\mathrm{NH}_{4}\right)_{2} \mathrm{SO}_{4}\right)$. Die Amplifikation wird in einem Thermocycler mit folgendem Beispiel-Programm vorgenommen:

\begin{tabular}{|c|c|c|c|c|c|}
\hline & & Erste Denaturierung & $4^{\prime}$ & $94^{\circ} \mathrm{C}$ & \\
\hline & & Annealing & $30^{\prime \prime}$ & $50-72^{\circ} \mathrm{C}$ & (Primer $T_{m}$ ) \\
\hline l & & Elongation & & $\begin{array}{l}1^{\prime} / \mathrm{kb} \\
77^{\circ} \mathrm{C}\end{array}$ & $72^{\circ} \mathrm{C}$ \\
\hline
\end{tabular}

Die Schmelztemperatur $T_{m}$ eines Primers errechnet sich nach folgender Formel :

$\mathrm{T}_{\mathrm{m}}\left[{ }^{\circ} \mathrm{C}\right]=69,3+0.41 \cdot(\% \mathrm{GC})-(650 / \mathrm{n})$

\section{$2|3| 12$ Sequenzierung von Nucleinsäuren}

Die DNA-Sequenzierung erfolgt mit Hilfe des BigDye ${ }^{T M}$ Terminator Cycle Sequencing Ready Reaction Kits von Perkin Elmer. Das Prinzip der Sequenzierung beruht auf der Kettenabbruchmethode nach SANGER et al., 1977. Hier befindet sich in einem Ansatz zur Amplifikation der DNA nur ein Primer, wodurch diese linear abläuft. Neben den 4 Desoxynucleotiden befinden sich auch vier mit verschiedenen Fluoreszenzfarbstoffen markierte Didesoxynucleotide zur Termination der Polymerisation in dem Ansatz. Die durch die Amplifikation entstehenden, unterschiedlich großen und markierten Fragmente können nun mit Hilfe des Analysegerätes (Kapillarsequenzer ABI Prism 310 von Applied Biosystems) über eine Kapillarmatrix aufgetrennt und detektiert werden.

Für die Reaktion der linearen PCR werden 170 fmol Plasmid-DNA, 5 pmol Primer und $2 \mu$ l RR-Mix in einem Endvolumen von $10 \mu \mathrm{l}$ eingesetzt. Die Reaktion im Thermocycler besteht aus 25 Zyklen mit 10', Denaturierung bei $95^{\circ} \mathrm{C}, 5^{\prime \prime}$ Annealing bei $50{ }^{\circ} \mathrm{C}$ und $4^{\prime}$ bei $60{ }^{\circ} \mathrm{C}$ Elongation. Die Fragmente werden durch eine Ethanol-Fällung von den nicht eingebauten Nucleotiden abgetrennt und in TSR (Template Suppression Reagent, Perkin Elmer) aufgenommen. Nach dem Denaturieren können sie in das Analysegerät appliziert werden. Die gewonnenen Rohdaten werden mit Hilfe des Chromas-Programms ausgewertet.

\section{2|3| 13 Radioaktive Markierung von DNA-Fragmenten}

\section{2|3|13|1 End-Markierung durch die Polynucleotidkinase}

Für die radioaktive Markierung von Oligonucleotiden wird das Enzym Polynucleotidkinase verwendet. Die PNK überträgt das $\gamma$-ständige radioaktive Phosphat $\left(\mathrm{P}^{32}\right)$ auf das synthetische Oligonucleotid. Der Reaktionsansatz enthält: 2 pmol Oligonucleotide, 10x Kinase-Puffer für die forward reaction, MBI (zum Austausch von Phosphaten an isolierten DNA-Fragmenten der Puffer für die exchange reaction, MBI), $10 \mathrm{u}$ T4-Polynucleotidkinase und $25 \mu \mathrm{Ci} \gamma$-[P(2)]ATP (Hartmann SCP-401 in einem Reaktionvolumen von $10 \mu \mathrm{l}$ verwendet. Der Ansatz wird $1 \mathrm{~h}$ bei $37^{\circ} \mathrm{C}$ inkubiert. Anschließend werden die komplementären Oligonucleotide, wie unter 2.3.4 beschrieben, annealt. Das radioaktiv markierte Fragment wird nun mittels Gelfiltration über Micro Spin ${ }^{\top M}$ G25 Column der Firma Pharmacia über eine Sephadexmatrix aufgereinigt. Nach der Aufreinigung wird das Fragment auf ein Volumen von 600-800 $\mu$ l verdünnt und je Ansatz $4 \mu$ lca. $25 \mathrm{fmol}$ mit 200-300 cpm) eingesetzt.

\section{$2|3| 13 \mid 2$ Markierung durch die Klenow-Polymerase}

Für die Herstellung radioaktiv markierter Hybridisierungssonden wird ein DNA Fragment nach Restriktionsspaltung aus einem Agarosegel elviert. Die Markierungsreaktion erfolgt nach der Random-PrimeLabelling-Methode nach FEINBERG \& VOGELSTEIN, 1983, bei der Hexanucleotide zufälliger Sequenz an die Matrizen-DNA binden: Die annealten Hexanucleotide dienen dann als Primer für die Neusynthese eines komplementären Stranges durch die Klenow-Polymerase unter Einbau von radioaktiven Nucleotiden. Die verwendete Klenow-Polymerase ist modifiziert, so dass sie keine Exonucleaseaktivität (exo') mehr besitzt. Die Markierungsreaktion wird mit Hilfe des Megaprime ${ }^{T M}$ DNA labelling system Kits von Amersham Pharmacia vorgenommen. Die Durchführung erfolgt nach dem Protokoll des Herstellers. 


\section{2|4 Konstruktion von verwendeten Plasmiden}

Zur Analyse des BZI-1 Transkriptionsfaktors wurden Plasmide für unterschiedlichste Zwecke hergestellt. Diese dienten der Expression unterschiedlicher Deletionsderivate in E.coli zur Gewinnung rekombinanten Proteins, außerdem zur Herstellung transgener Pflanzen durch den Agrobakterien vermittelten Gentransfer und schließlich zur transienten Expression von Proteinen in Tabak-Mesophyll-Protoplasten.

\section{2|4| 1 Plasmide zur Expression rekombinanter Proteine}

Für die Expression von rekombinanten Proteinen wurden die unterschiedlichen Deletionsderivate in den pET28a eingebracht. Die Derivate p16.1 und p16.4D1 wurden freundlicherweise in Vorexperimenten von W. Dröge-Laser konstruiert. Das Plasmid p16.1 enthält das BZI-1 mit deletiertem N-Terminus bis zu der Kpnl-Schnittstelle. Am N-terminalen Ende befindet sich die Fusion mit dem His ${ }^{\circledR}$-tag. Die Transkription startet am T7-Promotor unter der Kontrolle des lac-Operons. Sie stoppt am T7-Terminator. Das Plasmid p16. $\mathrm{D} 1$ enthält das im Bereich der Domäne 1 deletierte $\Delta \mathrm{N}$-Derivat des BZI-1. Die Deletion der Domäne erfolgte durch eine Restriktion mit dem Enzym Dral und eine folgende Religation des Vektors. Die Überprüfung der Plasmide wurde mitlles Restriktionsanalyse vorgenommen.

Für die Herstellung des Gesamtproteins wurde der N-terminale Bereich des BZI-1- $\Delta \mathrm{N}$ zwischen den BamHIRestriktionsschnittstellen ausgetauscht. Das 731 bp große BamHI-Fragment aus dem pNGH (HEINEKAMP, 2002) wurde in den Restvektor hineinligiert. Die korrekte Orientierung konnte durch einen Kpnl und Sall Doppelverdau bestätigt werden. Zusätzlich wurde die Fusion mit dem His ${ }^{\circledR}$-tag und der korrekte Austausch durch eine Sequenzierung des Überganges mit dem Primer P47 bestätigt. Der Vektor wurde als p16.BZI1 bezeichnet.

Zur Herstellung des Derivates mit der Deletion im DNA-bindenden Bereich des Proteins wurde der in der voausgegangenen Diplomarbeit (KUHLMANN, 1998) hergestellte Vektor pUCA7Tx $\triangle B D$ verwandt. Das BZI-1$\triangle N \triangle B D$-gen wurde mit einem Kpnl und Sall Doppelverdau geschnitten und das 1242 bp-große Fragment aus dem Gel eluiert. Der p16.1 wurde mit denselben Enzymen geöffnet und der Restvektor ebenfalls aus dem Gel eluiert. Nach der Ligation der Fragmente konnte die Kontrolle des Produktes durch eine BamHI Restriktion erfolgen, da durch die Deletion der DNA-bindenden Domäne die BamHI Erkennungsstelle mitdeletiert wurde. Zusätzlich erfolgte eine Sequenzierung des Produktes mit dem Primer P50 um Mutationen auszuschließen. Der konstruierte Vektor wurde als p16.ABD bezeichnet. Zur erleichterten Übersicht ist im Anschluss das Klonierschema der Konstrukte abgebildet.

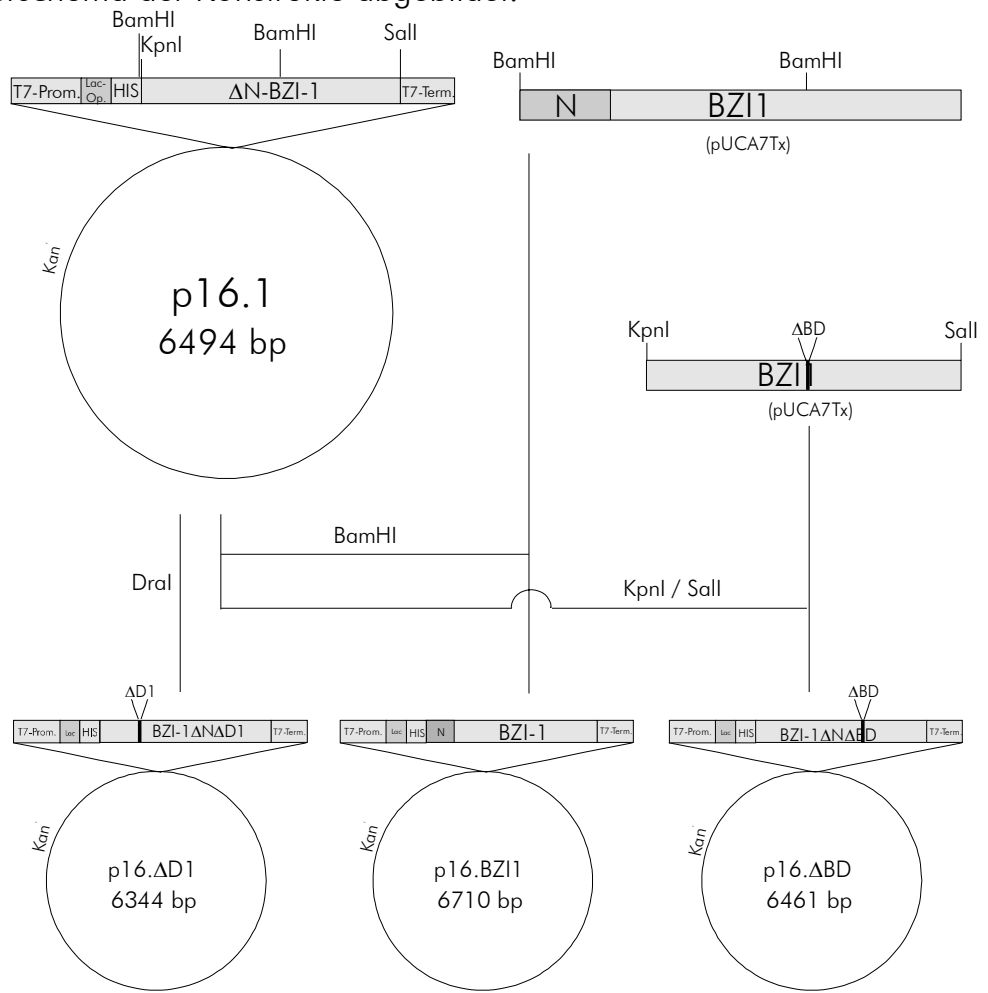

Abb. C - 1: Klonierschema der Konstrukte zur Expression der BZI-1-Derivate in E.coli.

p16.:Expressionsvektor basierend auf dem pET28a; Kan': Kanamycin-Resistenz; T7-Prom.: T7-Promotor; lac.-Op.: LacOperon; T7-Term.: T7-Terminator; N: Domäne N, D1: Domäne1; BD: basische Domäne; $\Delta$ : Deletion; Bral, BamHl,Kpnl, Sall: Restriktionsenzyme; bp: Basenpaare. 


\section{$2|4| 2$ Konstrukte zur Pflanzentransformation}

Zur Einbringung von Genen in Ganzpflanzen wird der Agrobakterien vermitteltem Gentransfer verwendet. Hierfür wurden die erwünschten Gene in einen binären Vektor, den pBINHygTx gebracht. Dieser Vektor kann in E.coli verändert werden und ist ebenso in den Agrobakterien in der Lage sich zu replizieren.

Die BZI-1 überexprimierenden Pflanzenlinienen wurden von T. Heinekamp konstruiert, getestet (HEINEKAMP, 2002) und zur Verfügung gestellt. Ebenso die Linien, die das $\mathrm{HA}^{\circledR}$-markierte $\Delta \mathrm{N}$-Deletionsderivat exprimieren (HEINEKAMP, 1998).

Die Herstellung der Konstrukte, die die Doppeldeletionsderivate BZI-1- $\Delta \mathrm{N} \Delta \mathrm{D} 2, \Delta \mathrm{N} \Delta \mathrm{BD}$ und $\Delta \mathrm{N} \Delta \mathrm{D} 4$ trugen wurden im Rahmen der Vorarbeiten in meiner Diplomarbeit 1998 beschrieben (p25 $\Delta$ D2; p25 BDD; p25 DD4). Die Einbringung der Mutationen erfolgte im pUCA7Tx-Vektor unter Herausschneiden der Domänen mittels spezifischer Enzyme und unter Einbringung synthetischer Oligonucleotide. Die korrekten Produkte wurden abschließend mittels Sequenzierung kontrolliert.

Die Konstruktion des p25. $\Delta \mathrm{N} \Delta \mathrm{D} 1$ erfolgte durch einen Austausch des Kpnl-Sall-Fragmentes vom p16. $\Delta \mathrm{D} 1$ in den p25. $\triangle B$ D. Der Austausch wurde über eine Restriktionsanalyse vorgetestet und mit Hilfe von Sequenzierungen mit den Primern P40 und P50 verifiziert.

Die Herstellung der BZI-7antisense-Linien erfolgte mit Hilfe des pBinanti, dessen Konstruktion ebenfalls erstmals in meiner Diplomarbeit beschrieben ist. Dieser enthält ein $\mathrm{pBINHygTx-Derivat} \mathrm{mit} \mathrm{dem} \mathrm{invertierten}$ Xhol-Sall-Fragment des BZI-7 Gens.

\section{2|4|3 Konstrukte zur transienten Expression in Tabak-Protoplasten}

Um eine vergleichbare Expressionsstärke der unterschiedlichen Derivate in den Mesophyll-Protoplasten zu garantieren wurden die Konstrukte unter Kontrolle des 35S-Promotors in den pHBTL-Vektor eingebracht. Zur Untersuchung des Kernimports oder der Verteilung der Proteine in der Zelle, erfolgte eine C-terminale Fusionierung mit dem GFP. Um eine Fusion des zu untersuchenden Proteins mit dem GFP herzustellen wurde das BZI-1 Gen mit den Primern P80 und P81 durch eine PCR amplifiziert und so N-terminal durch den Primer P80 eine Bglll- und eine Ncol-Schnittstelle eingefügt. Am C-terminalen Ende, an dem die Fusion mit dem GFP-Gen vollzogen werden sollte, wurden eine Xbal- und Bg/ll-Schnittstelle eingefügt. Das 1372 bp große PCR-Produkt wurde aus dem Gel eluiert und in den pGEM-T zum pGEM-BZI1 hineinligiert. In diesem Zwischenkonstrukt konnte durch Sequenzierungen mit uni- und rev-Primern eine Leserastermutation nach 102 bp nachgewiesen werden, die durch den Austausch des 1230 bp Sall-Nhel-Fragmentes aus dem pBZII korrigiert werden konnte. Das korrekte Produkt wurde als pGEM-BZIIX (exchange) bezeichnet. Das BglllFragment konnte nun in den BamHI-geöffneten pHBTL hineinligiert werden. Der entstandene Vektor pHBTLBZI1-GFP hatte eine Größe von 5617 bp und nach erfolgter Restriktionsanalyse konnte die Sequenzierung die fehlerfreie Fusion mit dem GFP bestätigen. Das folgende Klonierschema soll noch einmal den Ablauf der Konstruktion verdeutlichen. 


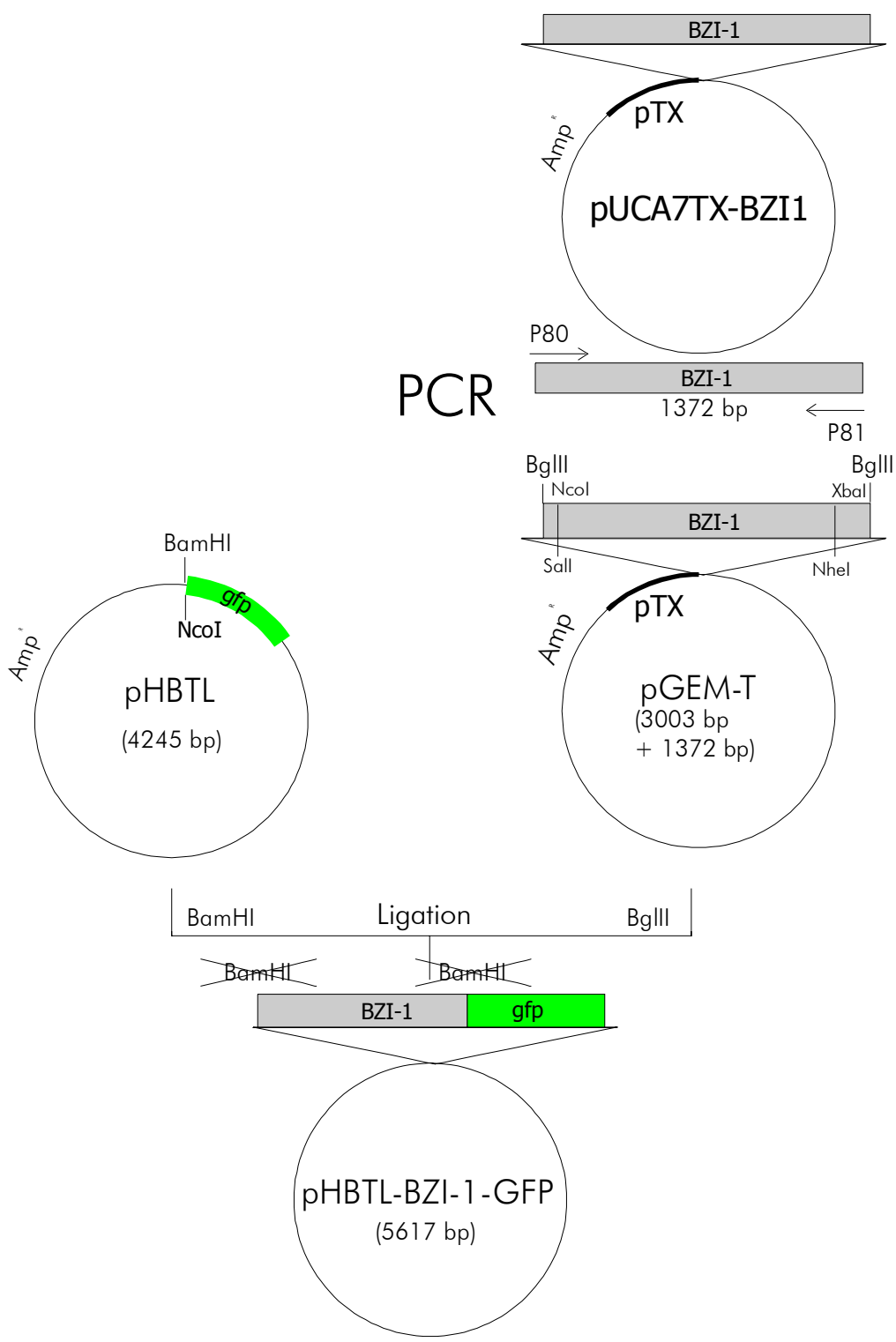

Abb. C - 2: Klonierschema zur Konstruktion des pHBTL-BZI-1-GFP.

pHBTL: Vektor zur transienten Expression in Protoplasten; pGEM-T: Vektor zur Amplifikation von PCR-Konstrukten; BZI-1: N.t.BZI-1; gfp: Grün fluoreszierendes protein; PCR: Polymerase-ketten-reaktion; P80, P81: Primer; BamHI, Bgll, Ncol, Nhel, Sall: Restriktionsenzyme, Ampr: Ampicillinresistenz; bp: Basenpaare.

Zur Einbringung der Deletionen wurden die Zwischenkonstrukte zur Konstruktion der Pflanzentransformationsvektoren verwendet (pUCA7Tx $\Delta \mathrm{N} \Delta \mathrm{D} 1$, $\mathrm{pUCA7T} x \Delta \mathrm{N} \Delta \mathrm{D} 2$ und $\mathrm{pUCA7T} x \Delta \mathrm{N} \Delta \mathrm{BD}$ ). Die deletionstragenden Bereiche wurden mit Hilfe der Restriktionsenzyme Kpnl und Nhel ausgetauscht. Der Vektor pHBTL-BZI 1-GFP wurde hierfür Kpnl und Nhel geöffnet, wobei das BZI-1-Fragment, wie auch der beidseits Kpnl-geschnittene N-terminus entfernt wurden. Die Größen der einzelnen Fragmente sind dem nachfolgenden Klonierschema zu entnehmen. Die entstandenen Konstrukte trugen nun die Doppeldeletionsderivate fusioniert an das GFP. Die entstandenen Konstrukte wurden als pHBTL- $\triangle N \Delta D 1$ BZI1-GFP, pHBTL- $\Delta N \Delta D 2-B Z I 1$-GFP und pHBTL- $\triangle N \Delta B D-B Z$ I1-GFP bezeichnet. Diese Doppelmutanten entsprachen somit den in den Pflanzen exprimierten Proteinen. Die Vektoren wurden durch Restriktionsanalysen und Sequenzierungen (Primer D1: P40, D2: P49 und BD: P50) analysiert. 


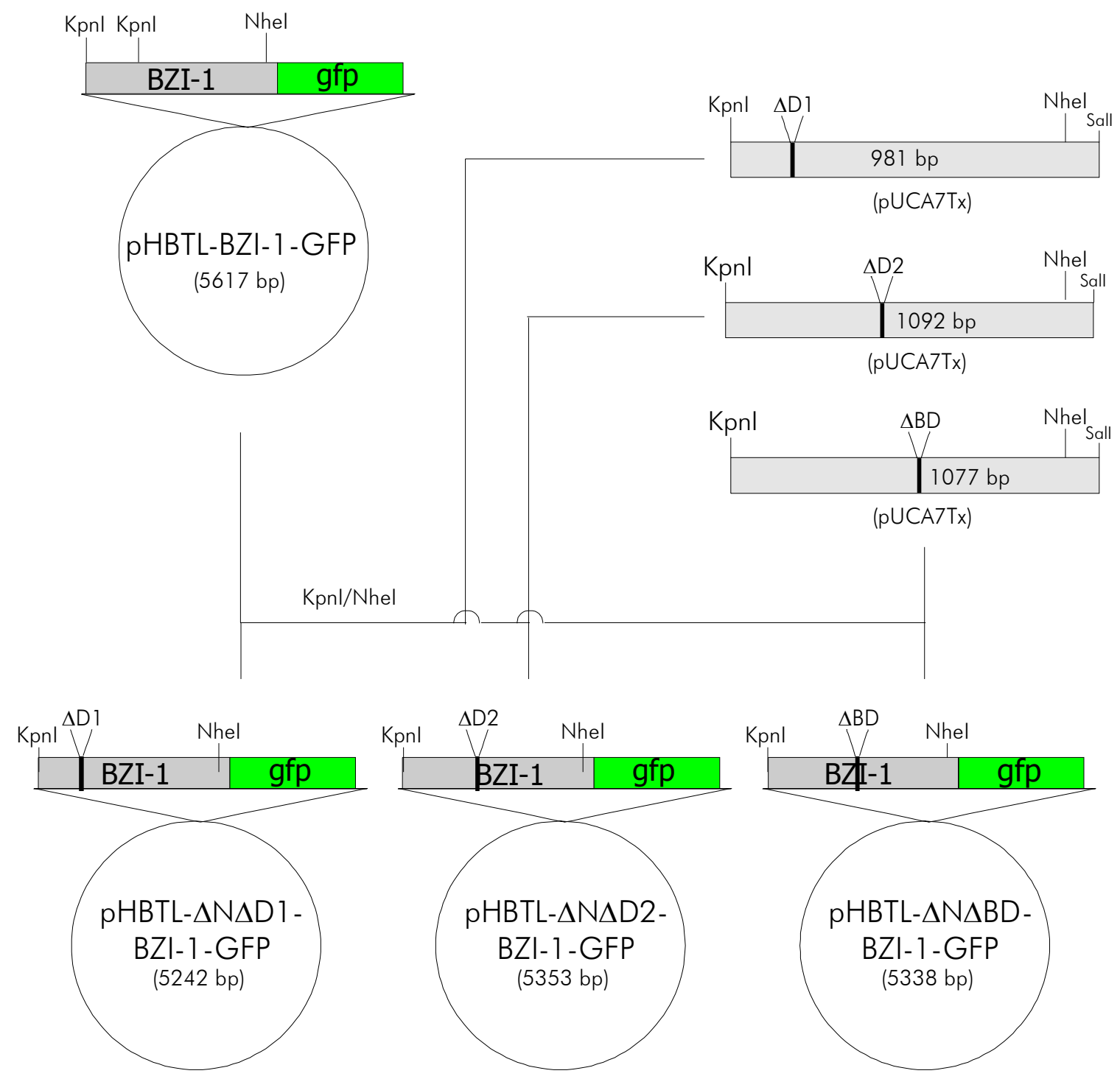

Abb. C - 3: Klonierschema zur Konstruktion der Plasmide pHBTL- $\Delta$ N $\Delta$ D1-BZI-1-GFP/ pHBTL- $\Delta$ N $\Delta$ D2-BZI-1-GFP und pHBTL- $\triangle \mathrm{N} \Delta \mathrm{BD}-\mathrm{BZI}-1$-GFP.

pHBTL: Vektor zur transienten Expression in Protoplasten; pUCA7Tx: Vektor zur Amplifikation von Zwischenkonstrukten; N: Domäne N; D1: Domäne1; BD: basische Domäne; $\Delta$ : Deletion; BZI-1: N.t.-BZl-1; gfp: Grün fluoreszierendes Protein, Kpnl, Nhel, Sall: Restriktionsenzyme; bp: Basenpaare.

Die Konstruktion des Deletionsderivates im Bereich der Domäne N, wurde durch eine Restriktion mit dem Enzym Kpnl durchgeführt. Durch die anschließende Religation entstand das pHBTL- $\Delta$ N-BZI1-GFP. Der entstandene Vektor wurde standardmäßig mittels Restriktionsanalyse und Sequenzierung (Primer P47) getestet.

Zum Anfügen des N-Terminus an die Doppeldeletionsderivate wurden zwei unterschiedliche Strategien gewählt. Der Übersicht dient das folgende Klonierschema. Für das Anfügen an das Deletionsderivat $\triangle \mathrm{D} 1$ wurde der N-Terminus des BZI-1 durch das Enzym Aatl mit einem Teil des pHBTL aus dem pHBTL-BZI 1-GFP in den ebenso geöffneten Vektor pHBTL- $\triangle N \Delta$ D 1-BZI 1 -GFP zum pHBTL- $\triangle$ D 1-BZI 1-GFP hineinligiert.

In die beiden weiteren Deletionsderivaten $\triangle \mathrm{D} 2$ und $\triangle \mathrm{BD}$ wurde der $\mathrm{N}$-Terminus mit Hilfe der Enzyme Eco255I und NgoMIV hineinligiert. Die entstandenen Vektoren wurden als pHBTL- $\triangle$ D2-BZI1-GFP und pHBTL- $\triangle$ BD-BZI1-GFP bezeichnet. 


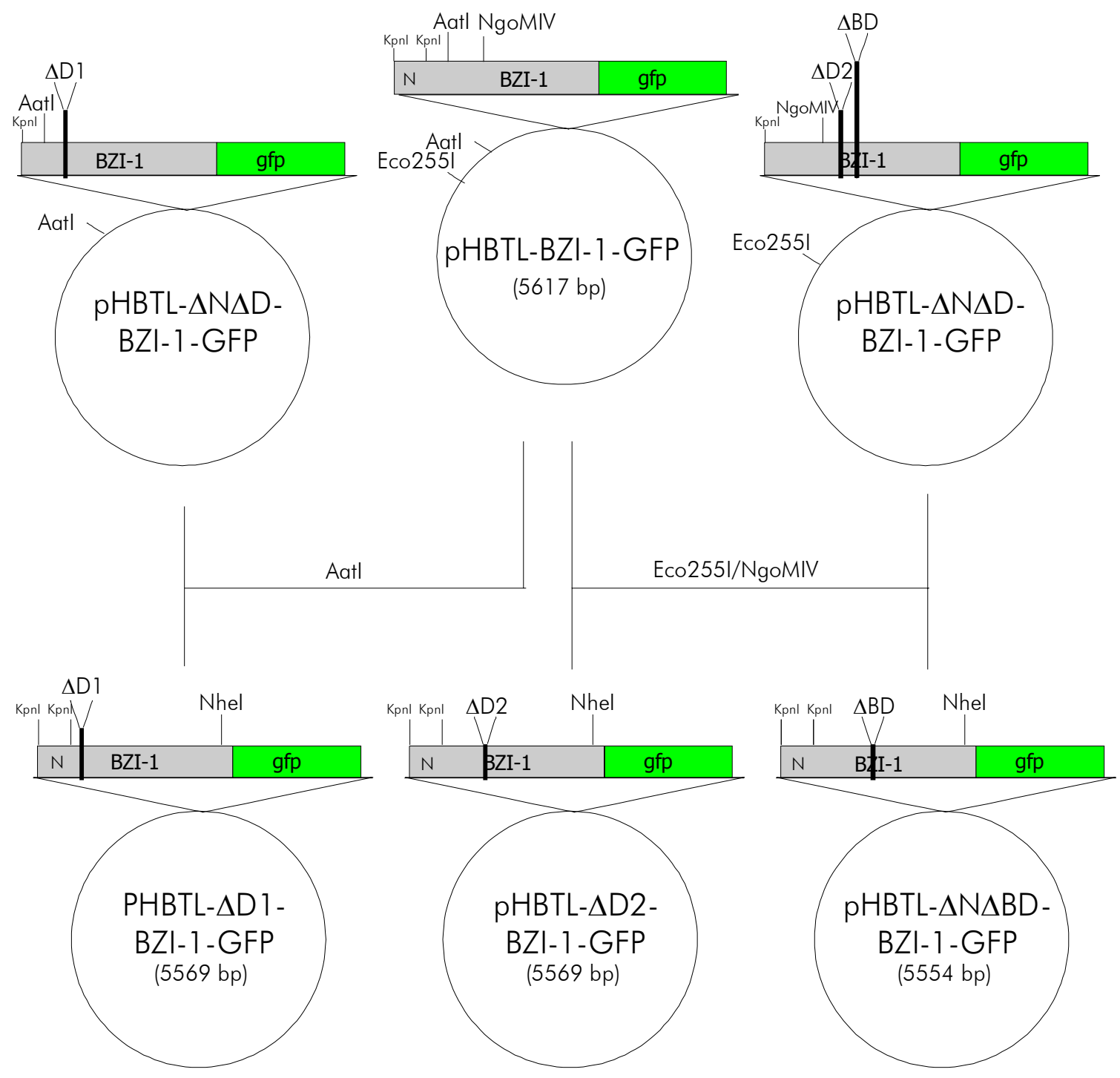

Abb. C - 4: Klonierschema zur Konstruktion der Plasmide pHBTL- $\triangle$ D 1-BZI-1-GFP/ pHBTL- $\triangle$ D2-BZI-1-GFP und pHBTL$\triangle \mathrm{BD}$-BZI-1-GFP

pHBTL: Vektor zur transienten Expression in Protoplasten; pUCA7Tx: Vektor zur Amplifikation von Zwischenkonstrukten; N: Domäne N; D1: Domäne 1; BD: basische Domäne; $\Delta$ :Deletion; BZI-1: N.t.-BZI-1; gfp: Grün fluoreszierendes Protein, Aatl, Eco255I, Kpnl, NgoMIV, Nhel: Restriktionsenzyme; bp: Basenpaare.

Zur weiteren Analyse der Domänenfunktion wurde der N-terminale Bereich des BZI-1 bis zur basischen Domäne an das GFP fusioniert. Hierfür wurden der pHBTL und der pBZI-1-HBTL durch Ndel und BamHI fragmentiert und das 1080 bp große Domäne N-, 1- und 2- umfassende Teilstück des BZI-1 in den pHBTL hineinligiert. Das entstandene Produkt wurde als pHBTL-N12-GFP bezeichnet und standardmäßig überprüft (Sequenzierung mit GFPII). 
Zur Analyse des ANK1-Proteins wurde es ebenfalls N-terminal an das GFP fusioniert. Hierfür wurde es mit den Primern mkANK3 und mkANK2 aus dem Hefevektor pGAD-ANK (K. HORVAY, 2000)amplifiziert und Cterminal eine Ncol-Restriktionsschnittstelle eingefügt. Das PCR-Produkt wurde in den pGEM-T Vektor hineinligiert und durch Sequenzierungen überprüft. Nach der Kontrolle wurde das ANK1-tragende Fragment mittels Ncol aus dem pGEM-ANK gespalten und in den ebenso geöffneten pHBTL hineinligiert. die Orientierung wurde mit Hilfe des Enzyms BamHI getestet und die Übergänge sequenziert. Die Klonierstrategie kann zusätzlich dem Schema entnommen werden. Der fertiggestellte Vektor wurde als pHBTL-ANK bezeichnet.
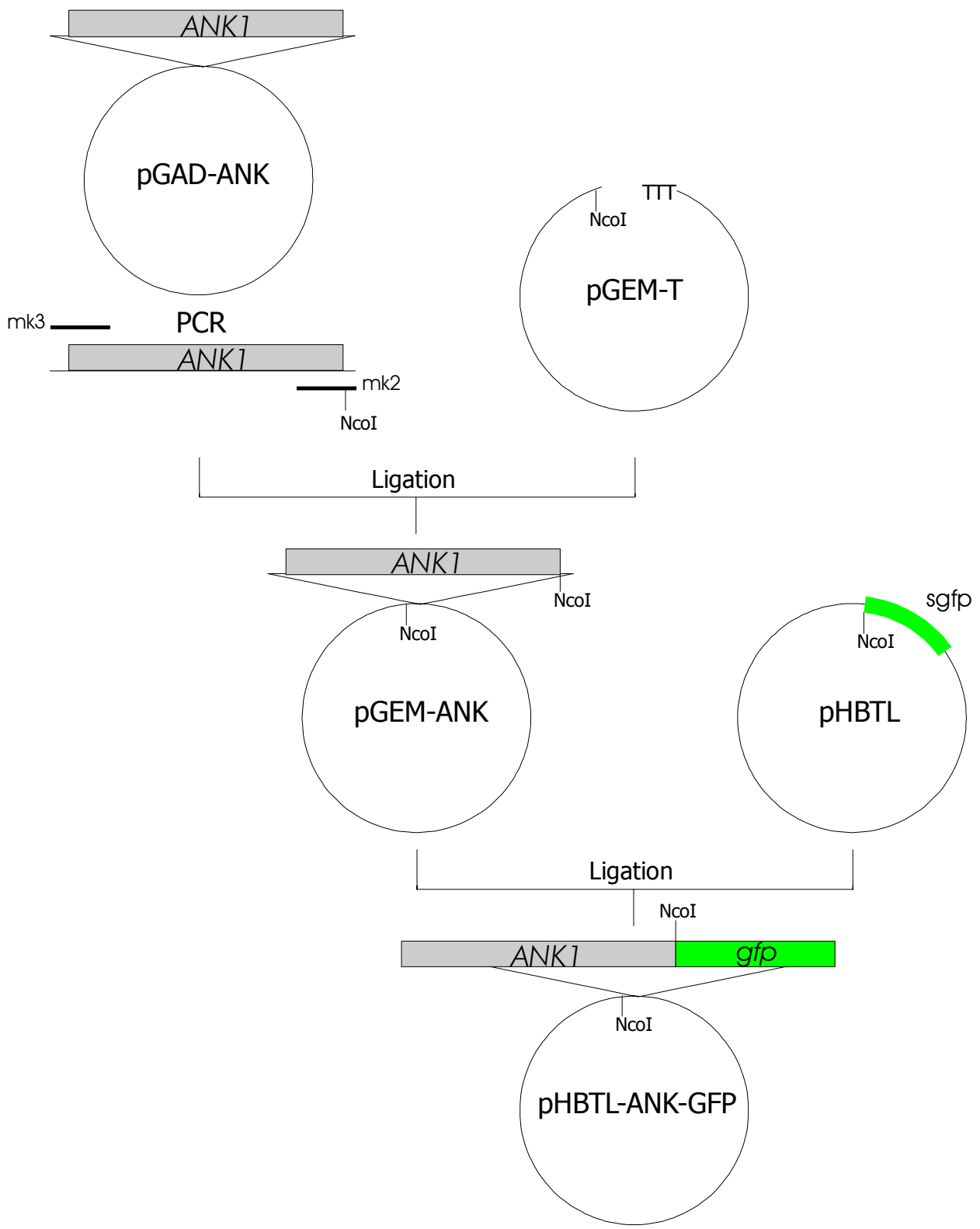

Abb. C - 4: Klonierschema zur Konstruktion des pHBTL-ANK-GFP.

pHBTL: Vektor zur transienten Expression in Protoplasten; pGEM-T: Vektor zur Amplifikation von PCR-Konstrukten; ANK: N.t.ANK1; gfp: Grün fluoreszierendes Protein; PCR: Polymerase-ketten-reaktion; mk2, mk3: Primer; Ncol: Restriktionsenzym, Ampr: Ampicillinresistenz; bp: Basenpaare. 


\section{2|5 Gentransfer}

\section{2|5|1 Transformation von Escherichia coli}

Um E.coli - Zellen kompetent zur Aufnahme vom DNA zu machen, wird das modifizierte Verfahren von INOUE et al., 1990, verwendet. Hierbei wird eine Vorkultur von einer frisch ausgestrichenen Platte angelegt und diese am nächsten Tag in $300 \mathrm{ml} \mathrm{SOC}-M e d i u m$ verdünnt. Die Kultur wächst bei einer Temperatur von $37^{\circ} \mathrm{C}$ bis zu einer $\mathrm{OD}_{600}$ von 0,2 - 0,25 in einem Luftschüttler. Das weitere Wachstum, bis $\mathrm{OD}_{600} 0,4-0,5$ erfolgt bei $18{ }^{\circ} \mathrm{C}$. Die Zellen werden werden durch Zentrifugation $\left(4000 \mathrm{rpm}, 4{ }^{\circ} \mathrm{C}\right)$ geerntet und in $90 \mathrm{ml} \quad 4{ }^{\circ} \mathrm{C}$ gekühltem Transformationspuffer (10 mM PIPES, $15 \mathrm{mM} \mathrm{CaCl}$, $250 \mathrm{mM} \mathrm{KCl}, \mathrm{pH}$ 6,7, $55 \mathrm{mM} \mathrm{MnCl}$ ) resuspendiert. Nach 15' Inkubation erfolgt der nächste Zentrifugationsschritt und das Resuspendieren in $30 \mathrm{ml} 4{ }^{\circ} \mathrm{C}$ Transformationspuffer. Danach erfolgt der zweimalige Zusatz von je $1050 \mu$ LMSO, wobei die Zellen nach jeder Zugabe 5' auf Eis inkubiert werden. Die auf diese Weise hergestellten chemisch kompetenten Zellen werden nun zu je $200 \mu \mathrm{l}$ aliquotiert, in flüssigem $\mathrm{N}_{2}$ eingefroren und können so bei $-80{ }^{\circ} \mathrm{C}$ gelagert werden. Die zu erwartende Transformationseffizienz dieser Methode liegt bei $10^{7} \mathrm{ycfu} / \mathrm{g}$ DNA.

Die chemisch kompetenten Zellen werden langsam auf Eis aufgetaut und mit der zu transformierenden DNA gemischt. Nach 30' Adaptionszeit auf Eis erfolgt der Hitzeschock bei $42{ }^{\circ} \mathrm{C}$ für $3^{\prime}$. Die Zellen werden $5^{\prime}$ auf Eis inkubiert, mit $800 \mu \mathrm{l} \mathrm{SOC-Medium} \mathrm{versetzt} \mathrm{und} 60^{\prime}$ bei $37^{\circ} \mathrm{C}$ im Roller regeneriert. Falls eine Selektion auf Ampicillin erfolgt, sollte die Regenerationszeit auf 45' verkürzł werden. Die transformierten Zellen werden in unterschiedlichen Verdünnungen auf Selektionsmedium ausplattiert und ü.N. bei $37^{\circ} \mathrm{C}$ inkubiert.

\section{2|5|2 Transformation von Agrobacterium tumefaciens}

Die Transformation von Agrobacterium tumefaciens - Zellen mit DNA erfolgt mittels Elektroporation (DOWER et al., 1988). Es wird eine ü.N. Kultur der Bakterien in YEB-Medium verwendet und in $250 \mathrm{ml}$ Medium verdünnt. Nachdem die Kultur bei $28{ }^{\circ} \mathrm{C}$ eine $\mathrm{OD}_{600}$ von 0,5 erreicht hat wird sie durch Zentrifugation $\left(5^{\prime}\right.$, $5000 \mathrm{rpm}$ ) geerntet und die Zellen werden $3 \mathrm{mal}$ in $4{ }^{\circ} \mathrm{C}$ sterilem $\mathrm{H}_{2} \mathrm{O}$ gewaschen. Das Pellet wird in $1 \mathrm{ml}$ $15 \%$ Glycerin resuspendiert, zu je $50 \mu \mathrm{l}$ aliquotiert und in flüssigem $\mathrm{N}_{2}$ eingefroren. Die kompetenten Zellen können bis zur Verwendung bei $-80^{\circ} \mathrm{C}$ gelagert werden.

Zur Elektroporation werden die Zellen auf Eis aufgetaut, mit der zu transformierenden DNA versetzt und in eine Elektroporationsküvette (Elektrodenabstand $2 \mathrm{~mm}$ ) überführt. Die Transformation erfolgt im Elektroporator bei einer Stromstärke von 2,5 kV, Kapazität von $25 \mu \mathrm{F}$ und Widerstand von $400 \Omega$. Die Zellen werden nach der Elektroporation mit $1 \mathrm{ml} \mathrm{SOC}$-Medium versetzt und $1 \mathrm{~h}$ bei $28{ }^{\circ} \mathrm{C}$ regeneriert. Nach der Regeneration werden die Zellen auf Selektionsmedium ausplattiert und $2-3$ Tage bei $28^{\circ} \mathrm{C}$ inkubiert.

\section{$2|5| 3$ Stabile Transformation von Nicotiana tabacum}

Sämtliche im Rahmen dieser Arbeit erstellten transgenen Pflanzen entstanden mit Hilfe des Agrobacterium tumefaciens-vermittelten Gentransfers. Eine Pflanze bildet bei Befall mit dem Bodenbakterium A. tumefaciens Tumore, die sogenannten Wurzelhalsgallen. A. tumefaciens besitzt durch sein Ti-Plasmid (Tumorinduzierendes Plasmid) die Fähigkeit, eigenes genetisches Material (Transfer-DNA, T-DNA) in verletzte Pflanzenzellen zu transferieren und in deren Genom einzubauen. Die T-DNA wird durch zwei "border"Sequenzen begrenzt. Nur die zwischen den border-Sequenzen liegende DNA wird ins Pflanzengenom transferiert. Durch die auf der T-DNA lokalisierten Gene produziert die Pflanzenzelle Phytohormone, die ein tumorartiges Wachstum des Gewebes hervorrufen, sowie Opine, die von den Agrobakterien als N- und CQuelle genutz† werden. Durch bestimmte Veränderungen dieses Gentransfersystems ist es nun möglich, mit Hilfe von Agrobakterien Pflanzenzellen gezielt mit ausgewählten Genen zu transformieren. Dabei bedient man sich heute des binären Vektorsystems (HOEKEMA et al., 1984). Die für den DNA-Transfer notwendigen Funktionen werden auf zwei Plasmide getrennt. Der gesamte T-DNA-Bereich des Ti-Plasmids wurde deletiert - damit ist es nicht mehr tumorinduzierend -, besitzt aber weiterhin die Fähigkeit, T-DNA in die Pflanze zu transferieren. Die vir-(Virulenz) Funktion liegt in dem verwendeten Stamm LBA 4404 auf dem Plasmid pAL4404. Eine modifizierte T-DNA wird auf einem kleinen zweiten Plasmid zur Verfügung gestellt. Dabei kann die DNA zwischen den border-Sequenzen durch Fremdgene mit einem Selektionsmarker (z.B. Resistenz gegen die Antibiotika Hygromycin oder Kanamycin) ausgetauscht werden. Durch Infektion von Pflanzengewebe mit diesen gentechnisch veränderten Agrobakterien kann man einzelne transgene Pflanzenzellen erzeugen, die sich unter geeigneten Hormonbedingungen zunächst zu Kallusgewebe und schließlich zu neuen Pflanzensprossen entwickeln. Durch Regeneration auf antibiotikahaltigem Medium ist 
eine Selektion der transformierten Pflanzenzellen durch den Selektionsmarker auf der modifizierten T-DNA möglich.

Für die Transformation werden Blätter von in Sterilkultur gewachsenen Pflanzen verwendet. Die Mittelrippe wird entfernt und die Blätter in $2 \mathrm{~cm}^{2}$ große Stücke zerteilt. Die Blattstücke werden mit $200-400 \mu \mathrm{l}$ einer 2 Tage-Kultur der Agrobakterien im Dunklen bei RT in B5-Infektionsmedium kokultiviert. Nach 3 Tagen werden die Blattstückchen mit sterilem $\mathrm{H}_{2} \mathrm{O}$ gründlich gewaschen und auf sterilem Filterpapier getrocknet. Die Blattscheiben werden anschließend auf das Pflanzenmedium mit Hormonen (1 mg/l 6-Benzylaminpurin und 0,1 mg/l 1-Naphtylessigsäure) zur Sprossildung in Petrischalen ausgebracht. Zur Selektion der transgenen Zellen ist dem Medium Hygromycin zugesetzt. Das Wachstum der Agrobakterien wird durch Cefotaxim unterdrückt. Nach gelungener Sprossbildung werden die Sprosse auf hormonfreies MS-Selektionsmedium überführt und weiterkultiviert.

\section{2|5|4 Transiente Transfektion von Nicotiana tabacum-Mesophyll-Protoplasten}

Für eine vorübergehende Expressionsanalyse kann Plasmid-DNA durch Elektroporation in TabakMesophyllprotoplasten eingebracht werden (LEBORGNE-CASTEL et al., 1999). Diese Methode ermöglicht die Lokalisation von GFP-Fusionsproteinen im Zellraum oder die Analyse von Genaktivitäten mit Hilfe von Reportergenkonstrukten und unterschiedlichen Effektoren.

Zur Gewinnung der Mesophyllprotoplasten werden Nicotiana tabacum - Pflanzen Kultivar SNN in MSMedium mit MES angezogen. Jeweils ein Blatt wird an der Unterseite in Abständen von $1 \mathrm{~mm}$ angeritzt und nach dem Entfernen der Mitelrippe auf $7 \mathrm{ml}$ Enzymlösung aus 0,4 \% Macerocym und 0,8 \% Cellulase in TEX-Puffer (3.05 g/l Gamborg's B5-Medium, 0,5 g/l MES, 0,75 g/l CaCl $\left({ }^{*} \mathrm{H} 2 \mathrm{O}\right), 0,25 \mathrm{~g} / \mathrm{I} \mathrm{NH}_{4} \mathrm{NO}_{3}, 0,4$ $\mathrm{M}$ Saccharose, $\mathrm{pH}$ 5,7 mit $\mathrm{KOH})$ mit der Blattunterseite nach unten, in einer Petrischale aufgebracht. Der Verdau der Zellwandbestandteile erfolgt bei $25^{\circ} \mathrm{C}$ ü.N im Dunkeln. Durch leichtes Klopfen lassen sich die Protoplasten aus den Blattrümmern und der Cuticula lösen. Zur Abtrennung der großen, unverdauten Blattfragmente werden die Protoplasten durch ein $125 \mu \mathrm{m}$ Drahtsieb gefiltert. Um die vitalen Protoplasten zu gewinnen, wird der Ansatz nun $20^{\prime}$ bei $60 \mathrm{~g}$ in einer ungebremsten Zentrifuge mit Ausschwingrotor ohne Auslaufbremse zentrifugiert. Der Unterstand wird mit Hilfe einer Pasteurpipette und Peristaltikpumpe abgezogen und verworfen. Die Protoplasten schwimmen aufgrund ihrer geringeren Dichte an der Oberfläche des Puffers. Die Protoplasten werden dreimal mit je $25 \mathrm{ml}$ Elektroporationspuffer $(2,4 \mathrm{~g} / \mathrm{l} \mathrm{HEPES}, 6 \mathrm{~g} / \mathrm{K} \mathrm{KCl}$, $0,6 \mathrm{~g} / \mathrm{l} \mathrm{CaCl}_{2}, 0,4 \mathrm{M}$ Saccharose, $\mathrm{pH}$ 7,2 mit $\mathrm{KOH}$ ) pro $50 \mathrm{ml}$-Greinerröhrchen gewaschen. Die Zentrifugationsschritte werden bei $100 \mathrm{~g}$ für einmal 10' und zweimal 5' vorgenommen. Vor der letzten Zentrifugation werden die Protoplasten vereinigt und die Zelldichte mit Hilfe der Fuchs-RosenthalZählkammer bestimmt. Die anschließende Resuspension erfolgt mit dem entsprechenden Volumen Elektroporationspuffer auf eine Konzentration von $4 \times 10^{6}$ Protoplasten $/ \mathrm{ml}$. Es sollten sich durch diese Methode pro hinreichend mit Blättern gefüllter Petrischale ca. 2 - 3 Transformationsansätze gewinnen lassen. Für die Elektroporation werden $0,5 \mathrm{ml}$ der Protoplastensuspension mit max. $50 \mu \mathrm{g}$ DNA (mit Elektroporationspuffer auf $100 \mu \mathrm{l}$ aufgefüllt) in eine Elektroporationsküvette mit $4 \mathrm{~mm}$ Elektrodenabstand überführt. Nach 5' Inkubation erfolgt die Elektroporation mit Hilfe des Elektroporators bei einer Stromstärke von $160 \mathrm{~V}$ und Kapazität von $900 \mu \mathrm{F}$. Bei gelungener Elektroporation sollte sich ein Zeitfaktor für den Stromfluss von 30 ms ergeben. Die elektroporierten Zellen werden anschließend für 30' erschütterungsfrei regeneriert und mit $2 \mathrm{ml} \mathrm{TEX-Puffer} \mathrm{ü.N.} \mathrm{bei} 25^{\circ} \mathrm{C}$ im Dunkeln inkubiert. Je nach Art der Analyse stehen die Protoplasten nun zur weiteren Verarbeitung bereit. 


\section{2|6 Biochemische Methoden}

\section{2|6|1 Analyse auf RNA-Ebene (Northern-Blot)}

Zur Analyse der Genexpression auf transkriptioneller Ebene muss die pflanzliche RNA zunächst aus den Zellen präpariert und anschließend mittels des Northern-Blot-Verfahrens (SAMBROOK et al., 1989) untersucht werden. Die zu analysierende RNA wurde durch die denaturierende Agarosegelelektrophorese der Größe nach aufgetrennt. In diesem Verfahren wird die RNA durch einen Kapillarstrom des Puffers auf eine Nylonmembran übertragen und fixiert. In diesem Zustand kann die Membran sofort zur Hybridisierung eingesetzt oder über mehrere Monate aufbewahrt werden.

\section{2 |6 | 1 | 1 Transfer von RNA-Molekülen auf Nylon-Membranen}

Nach der Elektophorese wird die RNA aus dem denaturierenden Agarosegel mittels Kapillarblot auf eine Nylonmenbran (Hybond $\mathrm{N}^{+}$von Amersham) übertragen. Der Aufbau des Blots erfolgt gemäß der Abbildung luftblasenfrei, wobei die Membran vorsichtig in einem Arbeitsschritt auf das Gel aufgebracht wird.

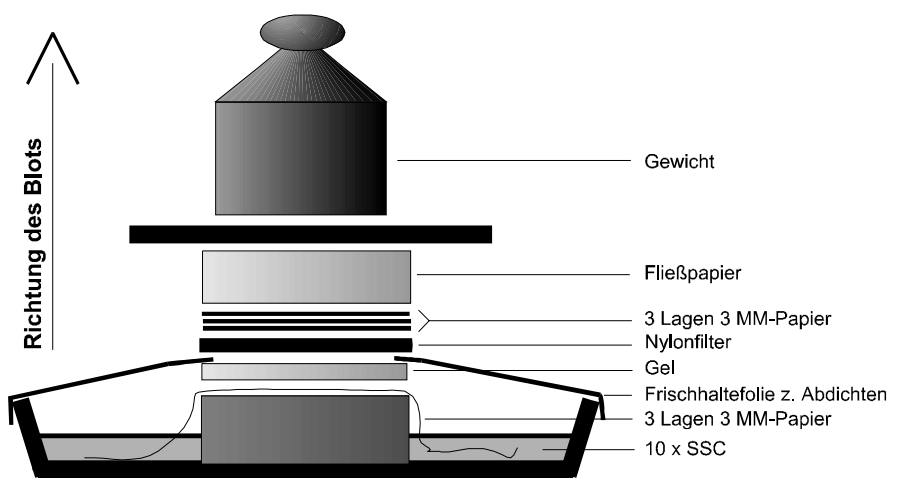

Abb. C - 5: Aufbau eines Northern Blots.

Nach mindestens $14 \mathrm{~h}$ ist die Übertragung vollzogen und der Blot kann abgebaut werden. Zur Kontrolle wird der Transfer auf dem UV-Transilluminator überprüft und die RNA durch eine Inkubation von $2 \mathrm{~h}$ bei $80{ }^{\circ} \mathrm{C}$ kovalent auf der Menbran gebunden.

\section{$2|6| 1 \mid 2$ Hybridisierung und Auswertung}

Durch Behandlung der Membran mit radioaktiv markierten, einzelsträngigen DNA-Sonden lassen sich komplementäre RNA-Transkripte auf der Membran lokalisieren. Die Spezifität, mit der die Sonde an die RNA bindet, ist abhängig von der Salzkonzentration und der Temperatur. Bei hoher Salzkonzentration und niedriger Temperatur isł die Stabilität unspezifischer DNA-RNA-Hybride größer als in Lösungen niederer Salzkonzentration und höherer Temperatur. Durch die Absenkung der Salzkonzentration in den Waschlösungen erhöht man die Stringenz. Bei einer detektierbaren Strahlung auf dem Filter von ca. $100 \mathrm{cps}$ ist der Filter auswertbar. Die Methode ist modifiziert nach $\mathrm{CHURCH}$ und GILBERT, 1984. Die zu analysierende Membran wird in einer Hybridisierungsröhre $30^{\prime}$ bei $65^{\circ} \mathrm{C}$ in einer Hybridisierungslösung $(0,5 \mathrm{M} \mathrm{Na-}$ Phosphatpuffer, $1 \mathrm{mM}$ EDTA, 7 \% SDS) inkubiert. Die Sonden-DNA wird $10^{\prime}$ bei $100{ }^{\circ} \mathrm{C}$ denaturiert und $5^{\prime}$ auf Eis inkubiert. Nach der Zugabe der Sonden-DNA in ca. $10 \mathrm{ml}$ Hybridisierungslösung in der Hybridisierungsröhre erfolgt die Hybridisierung bei $65{ }^{\circ} \mathrm{C}$ ü.N. im Roller. Zur Abtrennung unspeziefisch gebundener Sonden-DNA wird die Membran zweimal mit 2 x SSC (20x SSC: M NaCl, 0,3 M Na-Citrat) / $0,1 \%$ SDS und einmal mit $1 \times$ SSC/0,1\% SDS und optional mit 0,5x SSC $/ 0,1 \%$ SDS für 15' - 30' gewaschen. Für den Nachweis der Radioaktivität wird die Membran in Folie eingeschweißt und mit einem IPScreen exponiert. Die Daver der Exposition hängt von der Menge der nachweisbaren Radioaktivität ab. Die Auswertung erfolgt mit Hilfe des Bioimagers (BAS-1000 von Fuji). Zur Quantifizierung werden die Programme PCBAS®2.09 und TINA®2.0 der Firma raytest verwendet. Die Normalisierung der detektierten Signale wird über den Vergleich mit der dokumentierten EłBr-Färbung der RNA erreicht. 


\section{2|6|2 Analyse auf Proteinebene}

\section{$2|6| 2 \mid 1$ Expression und Aufreinigung von rekombinanten Proteinen}

Zur Expression der rekombinanten Proteine in E. coli wird das BL21/pET-System von NOVAGEN verwendet. Das zu exprimierende Gen steht im pETmcs-Vektor unter die Kontrolle des T7 RNA-Polymerase Promotors, dessen Expression durch die Bindung der T7 RNA-Polymerase initiiert wird. Das Gen für die T7 RNAPolymerase liegt auf der DNA des lysogenen Phagen DE3 in dem Wirtstamm BL21 und steht unter der Kontrolle des IPTG-induzierbaren lacUV5-Promotors. Die Expression des rekombinanten Proteins ist somit durch IPTG induzierbar. Die Zellen werden nach der Epression durch Zyklen von Einfrieren und Auftauen lysiert. Die in E. coli exprimierten Proteine werden über den N-terminal angehängten $\mathrm{HIS}^{\circledR}$-taq mittels NiNTAMatrix aufgereinigt.

$200 \mathrm{ml}$ LB-Flüssigmedium mit Ampicillin werden mit 0,4 ml ü. N.-Kultur des transgenen BL21 DE3-Stammes angeimpft, und die Kultur bei $37^{\circ} \mathrm{C}$ unter Schütteln $(250 \mathrm{rpm})$ bis zu einer $\mathrm{OD}_{600}=0,6$ angezogen. Im Anschluss wurde die Kultur in zwei parallele Ansätze aufgeteilt und in einem Ansatz die Expression des Transkriptionsfaktors durch die Zugabe von 0,8 mM IPTG induziert. Die Kulturen wurden $3 \mathrm{~h}$ bei $37^{\circ} \mathrm{C}$ unter Schütteln weiter inkubiert und anschließend die $\mathrm{OD}_{600}$ bestimmt. Zum Aufschluss der $E$. coli - Zellen wurden $50 \mathrm{ml}$ der Kulturen in der Biofuge bei $5000 \mathrm{rpm}$ für $5^{\prime}$ sedimentiert und das Pellet in $5 \mathrm{ml}$ Lysepuffer $(50 \mathrm{mM}$ $\mathrm{NaH}_{2} \mathrm{PO}_{4}, \mathrm{pH}$ 8,0, $300 \mathrm{NaCl}, 10 \mathrm{mM}$ Imidazol) resuspendiert. Der Aufbruch der Zellen erfolgt durch dreimaliges Einfrieren und Wiederauftauen des Extraktes. Gegebenenfalls lassen sich die Zellen zusätzlich durch eine Ultraschallbehandlung für 30" lysieren. Die Aufreinigung des rekombinanten Proteins aus dem Lysat erfolgt mit Hilfe der NiNTA ${ }^{\circledR}$-Matrix von Qiagen. Die mit dem heptameren Histidinrepeat versehenen Proteine bilden mit dem Nickel der Matrix eine Chelatbindung, die durch das Imidazol im Rahmen der Aufreinigung kompetitiv verdrängt werden. Die Aufreinigung erfolgt über eine Säule, wobei das Säulenvolumen dem Probevolumen entspricht. Zu Beginn der Aufreinigung wird die Säule mit 1 Volumen Lysepuffer equilibriert. Anschließend wird das Lysat appliziert und mit 2 Volumen Waschpuffer $(50 \mathrm{mM}$ $\mathrm{NaH}_{2} \mathrm{PO}_{4}, \mathrm{pH}$ 8,0, $300 \mathrm{NaCl}, 20 \mathrm{mM}$ Imidazol) gewaschen. Die Elution des Proteins erfolgt mit 1 Volumen Elutionspuffer (50 mM NaH${ }_{2} \mathrm{PO}_{4}, \mathrm{pH} 8,0,300 \mathrm{NaCl}, 100 \mathrm{mM}$ Imidazol). Die Säulendurchläufe werden fraktioniert aufgefangen, der Proteingehalt mittels der Bradford-Proteinbestimmung ermittelt und auf einem Coomassie gefärbten SDS-Gel überprüft. Für kleine Volumina lässt sich diese Methode auch im BatchVerfahren durchführen.

\section{$2|6| 2 \mid 2$ Herstellung eines Antikörpers}

Zur Herstellung des polyklonalen Antikörpers werden $2 \mathrm{mg}$ rekombinantes BZI- 1- $\Delta \mathrm{N} \Delta \mathrm{BD}$-Protein hergestellt, über den $\mathrm{His}^{\circledR}$-tag angereinigt und zusätzlich über ein SDS-Gel aufgereinigt. Die durch eine CoomassieFärbung sichtbar gemachte Bande mit dem rekombinanten Protein wird aus dem PAA-Gel ausgeschnitten und mittels Elektroelution (modifiziert nach HARRINGTON, 1990) in einer Elektroelutionsapparatur des Typs Elutrap (Nachbau Schleicher und Schuell) mit Elutionspuffer (25 mM Tris, $192 \mathrm{mM}$ Glycin, pH 8,5) bei 100 $\checkmark 36 \mathrm{~h}$ eluiert. Die Menge des elvierten Proteins konnte im Vergleich zum BSA-Standard abgeglichen werden. Das Eluat kann direkt für die Immunisierung des Kaninchens verwendet werden. Die Immunisierung wird von der Firma BioScience in Göttingen vorgenommen. Zur Auswahl des geeigneten Kaninchens werden die Präimmunseren von 8 Kaninchen in Western Blot Analysen in den Verdünnungen 1:100 und 1:400 getestet. Es wird das Kaninchen ausgewählt welches die geringste Reaktion auf $30 \mu \mathrm{g}$ Gesamtzellextrakt aus Pflanzen und keine Reaktion auf $1 \mu \mathrm{g}$ des rekombinanten BZI-1- $\Delta \mathrm{N} \Delta \mathrm{BD}$-Proteins zeigt. Zur Immunisierung werden dem Kaninchen (Deutscher Riese) $1 \mathrm{mg}$ rekombinantes Protein subkutan appliziert und die ersten Seren nach 1 und 2 Wochen abgenommen. Nach drei Wochen erfolgt eine zweite Injektion mit Proteinlösung $(1 \mathrm{mg})$ und ein drittes Testserum wird nach 4 Wochen entnommen. Die finale Serumabnahme erfolgte nach 6 Wochen. Die Immunseren werden mittles Western Blot auf ihre Einsatzfähigkeit getestet. Hierfür werden Verdünnungsstufen der Seren von 1:400, 1:800, 1:1250, 1:1500, 1:2500 und 1:5000 in Western Blot Analysen getestet. Für alle weiteren Analysen wird das Serum der 4., finalen Abnahme 1:1250 (

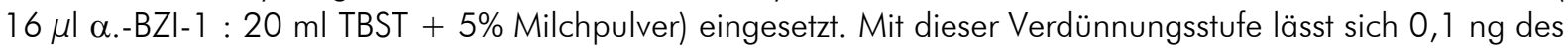
rekombinanten Proteins in der Western Blot Analyse nachweisen.

\section{$2|6| 2 \mid 3$ Präparation von pflanzlichen Gesamtprotein-Extrakten unter denaturierenden Bedingungen}

Das Blattgewebe wird unter $\mathrm{N}_{2}$ (liq.) aufgemörsert, 50 - 200 mg des Pulvers im gefrorenen Zustand in ein Eppendorfgefäß eingewogen, mit der dreifachen Menge (w/v) Harnstoffextraktionspuffer (4 M Harnstoff, $16,6 \%$ (v/v) Glycerin, $5 \%$ (v/v) $\beta$-Mercaptoethanol, 5 \% (w/v) SDS, 0,5 \% (w/v) Bromphenolblau)

aufgenommen, gevortext und bei $65^{\circ} \mathrm{C}$ für $10^{\prime}$ inkubiert. Nach $5^{\prime}$ Inkubation werden die Eppendorfgefäße mehrmals invertiert. Anschließend wird der Rohextrakt 15' bei 15000 rpm und RT zentrifugiert um Zelltrümmer und DNA abzutrennen. ${ }^{2} / 3$ Volumen des Überstandes werden in ein neves Eppendorfgefäß 
überführt. Die Proteinextrakte werden bis zur weiteren Verwendung bei $-80^{\circ} \mathrm{C}$ gelagert. Vor Auftragung in der SDS-PAGE werden die $5^{\prime}$ bei $65^{\circ} \mathrm{C}$ inkubiert. Die Proben können direkt auf das Gel appliziert werden.

\section{$2|6| 2 \mid 4$ Präparation von denaturierten pflanzlichen Kernextrakten (modifiziert nach PRAT, et al., 1989, NIGGEWEG, 1999)}

Alle Schritte der Prozedur finden, soweit nicht anders angegeben bei $4{ }^{\circ} \mathrm{C}$ statt. 6 - $10 \mathrm{~g}$ Blattgewebe werden unter Kühlung mit $\mathrm{N}_{2}$ (liq.) im Mixer zu einem homogenen Pulver zerkleinert und in $40 \mathrm{ml}$ Puffer 1A (1 M Hexylenglykol, 0,25 M Saccharose, 20mM TAPES, pH 8,5 bei $25^{\circ} \mathrm{C}, 10 \mathrm{mM} \mathrm{MgCl} 2,0,15 \mathrm{mM}$ Spermin, 0,5 mM Spermidin, 0,6\% (v/v) Nonidet P-40, frisch dazu $80 \mathrm{mM} \beta$-Mercaptoethanol) resuspendiert. Durch anschließende Filtration durch zwei Lagen Miracloth werden größere Zelltrümmer von der Organellensuspension abgetrennt. Eine nachfolgende Zentrifugation (SS34, 1100 rpm, 2' 40') trennt verbleibende Zelltrümmer und Stärke ab. Der Überstand wird in frische $50 \mathrm{ml}$ Röhrchen überführt und erneut zentrifugiert (SS34, $2000 \mathrm{rpm}, 3^{\prime}$ ), um die Zellkerne zu pelletieren. Der verbleibende Überstand wird verworfen und das Kernpellet mit einem Haarpinsel in $8 \mathrm{ml}$ Puffer 0,5A (0,5 M Hexylenglykol, 0,25 M Saccharose, $20 \mathrm{mM}$ TAPES, pH 8,5 bei $25^{\circ} \mathrm{C}, 10 \mathrm{mM} \mathrm{MgCl}$, 0,15 mM Spermin, 0,5 mM Spermidin, 0,6 \% (v/v) Nonidet P-40, frisch dazu $80 \mathrm{mM} \beta$-Mercaptoethanol) resuspendiert. Die Kernpelletierung wird insgesamt viermal durchgeführt, um die Kerne von den leichteren Chloroplasten zu trennen. Das letzte Kernpellet wurde anstatt in 0,5 A in $350-450 \mu$ Harnstoff-Extraktionspuffer aufgenommen, gründlich durch Verrühren und vortexen gemischt und für $10^{\prime}$ bei $60^{\circ} \mathrm{C}$ im Wasserbad inkubiert. Durch anschließende Ultraschallbehandlung 30" wird die hochmolekulare DNA fragmentiert und somit die Lösung weniger viskos. Eine abschließende Zentrifugation (15000 rpm, RT, 10') trennt die Membranfragmente der Zellkerne ab. Der verbleibende Überstand wurde in neve Eppendorfgefäße überführt. Die Proteinkonzentration wird mithilfe eines SDS-PAA-Gels und einer anschließenden Coomassie-Färbung abgeglichen und zur Western Blot Analyse eingesetzt.

\section{$2|6| 2 \mid 5$ Präparation von Proteinextrakten für den Kinase Assay}

Für den Kinase Assay werden 150 mg abgenutschte Tabak-Suspensionskulturen oder ausgestochenes Blattgewebe nach der Ernte unter $\mathrm{N}_{2}$ (liq.) im Mörser homogenisiert und im gleichen Volumen Kinase-Puffer aufgenommen. Der Extrakt wird bei $13000 \mathrm{rpm}, 10^{\prime}$ bei $4{ }^{\circ} \mathrm{C}$ zentrifugiert und der Überstand in ein neues Eppendorfgefäß überführt. Die Proteinkonzentration wird mittels Bradford-Proteinbestimmung ermittelt und $30 \mu \mathrm{g}$ pro Kinaseansatz eingesetzt.

\section{$2|6| 2 \mid 6$ Bradford-Proteinbestimmung}

Die Bestimmung der Proteinkonzentration nach BRADFORD, 1976 beruht auf der Verschiebung des Absorptionsmaximums bei der photometrischen Analyse von Coomassie Brilliant Blue G250 von $465 \mathrm{~nm}$ nach $595 \mathrm{~nm}$ nach Bindung an die Aminogruppen von Proteinen. Ein adäquates Volumen 0,5-5 $\mu \mathrm{l}$ wird in eine Vertiefung einer 96-well-Mikrotiterplatte vorgelegt und mit 1:4 $\mathrm{H}_{2} \mathrm{O}$ verdünntem Bradford-Reagenz (Roth) auf $200 \mu \mathrm{l}$ aufgefüllt. Nach 5' Inkubation bei RT wird die $\mathrm{OD}_{595}$ mit Hilfe des Spektralphotometers (MRX Dynex Plate Reader) bestimmt. Die Proteinkonzentration kann mit Hilfe einer, mit einem BSA-Standard $(0,1,4$,und $8 \mu \mathrm{g})$ erstellten Eichgerade ermittlet werden.

\section{2|6|2 7 Diskontinuierliche SDS-Polyacrylamid-Gelelektrophorese}

Durch die diskontinuierliche Sodiumdodecylsulfat(SDS)-Polyacrylamid-Gelelektrophorese(PAGE) werden Proteine in ihrer denaturierten Form der Größe nach durch die Polyacrylamidgel-Matrix nach Anlegen eines elektrischen Feldes aufgetrennt (modifiziert nach LAEMMLI, 1970). Für die Polacrylamid-Gelelektophorese wird das AGS-Gelsystem eingesetzt. Die Porengröße der Polyacrylamid-Matrix kann durch das Verhältnis der Acrylamid-Konzentration zur Konzentration des Quervernetzers N-N-Methylenbisacrylsäureamid bestimmt werden. Die radikalische Polymerisation erfolgt nach Zugabe von Ammoniumpersulfat (APS) und wird durch $\mathrm{N}, \mathrm{N}, \mathrm{N}^{\prime}, \mathrm{N}^{\prime}$-Tetramethylethylendiamin (TEMED) katalysiert. Für die optimale Auftrennung der nachzuweisenden Proteine mit einer Größe von ca. 50 - $65 \mathrm{kDa}$ wird ein $10 \%$ iges Trenngel $(10 \% \mathrm{w} / \mathrm{v})$ $\mathrm{N}, \mathrm{N}^{\prime}$-Methylenbisacrylamid (19:1), 0,4 M Tris-HCl, pH 8,8, 0,1 \% (w/v) SDS, 0,1 \% (v/v) TEMED und 0,1 \% (w/v) APS) verwendet. Nach dem Gießen des Trenngels wird zur Oberflächenglättung mit Isobutanol oder optional bei höherprozentigen Gelen mit $\mathrm{H}_{2} \mathrm{O}$ überschichtet. Zur gleichmäßigen Auftrennung der Proteine wird, nach Abgießen des Überstandes auf dem Trenngel, ein Sammelgel $\left(5 \%\right.$ (w/v) $\mathrm{N}^{\prime} \mathrm{N}^{\prime}$ Methylenbisacrylamid (19:1), $125 \mathrm{mM}$ Tris- $\mathrm{HCl}, \mathrm{pH}$ 6,8, 0,1 \% (w/v) SDS, 0,2 \% (v/v) TEMED und 0,1 \% (w/v) APS) mit den Probeauftragstaschen gegossen. Vor dem Autragen werden die Proteinextrakte mit SDSProbenpuffer ( $2 x$ : 0,2 M Tris, $15 \%(v / v)$ Glycerin, $6 \%$ (w/v) SDS, $10 \%(v / v) \beta$-Mercaptoethanol und $0,05 \%(\mathrm{w} / \mathrm{v}) \mathrm{BPB}$ ) versetzt, $5^{\prime}$ bei $100{ }^{\circ} \mathrm{C}$ denaturiert und aufgetragen. Die Elektrophorese erfolgte in Laufpuffer $(25 \mathrm{mM}$ Tris, $190 \mathrm{mM}$ Glycin und 0,1 \% (w/v) SDS) ca. 30' bei $90 \mathrm{~V}$ zum Durchlaufen der 
Proteine durch das Sammelgel und anschließend bei $120 \mathrm{~V}$ bis die BPB-Bande das unter Ende des Gels erreicht hat. Zur Bestimmung der Molekulargewichte wird auf jedes Gel ein Proteingrößenstandard (Prestained Protein Ladder, BenchMark ${ }^{\mathrm{TM}}$ ) mitaufgetrennt.

\section{$2|6| 2 \mid 8$ Coomassie-Protein-Färbung}

Um Proteinbanden in SDS-PAGE-Gelen sichtbar zu machen lassen sich diese mit dem Farbstoff Coomassie Brilliant Blue G-250 anfärben. Hierfür wird das Gel 30' in der Fixierlösung (25 \% (v/v) Isopropanol, 10 \% (v/v) Essigsäure) geschwenkt. Nach Verfärbung der BPB-Bande ins Gelbliche wird das Gel in der Färbelösung (0,006 \% (w/v) Coomassie Brilliant Blue G-250, 10 \% (v/v) Essigsäure) 30' - 60' inkubiert. Die Entfärbung des Gel erfolgt in dem Entfärbebad (10\% (v/v)Essigsäure) unter wiederholtem Wechsel der Lösung für mehrere Stunden. Optional kann der Vorgang durch kurzes Erwärmen in der Mikrowelle beschleunigt werden.

\section{$2|6| 2 \mid 9$ Transfer von Proteinen auf PVDF-Membranen}

Um Proteine aus SDS-PAGE-Gelen immunologisch oder radioaktiv detektieren zu können, müssen diese auf einen Trägerfilter (PVDF oder Nitrocellulose) übertragen werden. Eine einfache, effektive Methode stellt der nach KYHSE-ANDERSEN, 1984 modifizierte Semi-dry Blot (Western Blot) dar. Hierfür wird eine PVDF-Membran in Gelgröße mit Methanol aktiviert und in Transferpuffer (192 mM Glycin, 25 mM Tris, 20 \% (v/v) Methanol, $0,01 \%$ (w/v) SDS) equilibriert, ebenso wie jeweils 6 Lagen Whatmann-Papier. Der Aufbau der Apparatur erfolgt analog der folgenden Abbildung.

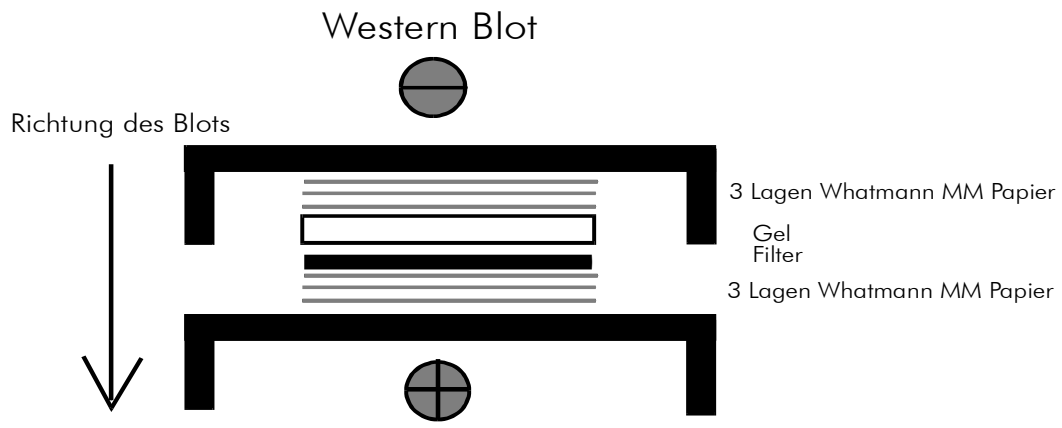

Abb. C - 6: Aufbau eines Western Blots.

Der Transfer erfolgt durch das Anlegen einer Spannung zwischen den Graphitplatten bei einer konstanten Stromstärke von $140 \mathrm{~mA}$ pro Gel $\left(2 \mathrm{~mA} / \mathrm{cm}^{2}\right.$ Gelfläche). Der erfolgreiche Transfer kann durch eine vorübergehende Anfärbung der Proteine auf der Membran mit Ponceau S-Färbelösung $(0,25 \%(\mathrm{w} / \mathrm{v})$ PonceauS, 40 \% (v/v) Methanol, 15 \% (v/v) Essigsäure) sichtbar gemacht werden. Die Membran lässt sich durch TBS wieder vollständig entfärben.

\section{2|6|2|10 Immunologische Detektion}

Die Immunodetektion erfolgt mittels zweier Antikörper, wobei der Primärantikörper das zu detektierende Protein erkennt und der Sekundärantikörper, der mit dem Enzym Peroxidase gekoppelt ist, spezifisch an den Primärantikörper bindet. Die an den zweiten Antikörper gebundene Peroxidase katalysiert die Oxidation des Substrates Luminol. Bei dieser Reaktion kommt es zu einer Chemilumineszenz, die durch Belichtung eines Röntgenfilms nachgewiesen werden kann. Die Oberfläche der Membran wurde zu Beginn der Detektion mit unspezifischen Proteinen durch eine $2 \mathrm{~h}$ Inkubation mit TBS-T (Tris-buffered Saline; $50 \mathrm{mM}$ Tris, $150 \mathrm{mM}$ $\mathrm{NaCl}, \mathrm{pH} 7,4$ mit $\mathrm{HCl}$ mit 0,1 \% Tween-20) mit 5 \% Magermilchpulver abgesättigt. Die Inkubation mit dem Primärantikörper ( $\alpha$-BZI-1/ $\alpha$-HMG/ $\alpha$-His:1:1250) erfolgt ebenfalls für $2 \mathrm{~h}$ in $20 \mathrm{ml}$ TBS-T mit $5 \%$ Magermilch. Der unspezifisch gebundene Antikörper wird durch dreimaliges 10' waschen mit TBS-T entfernt. Vor der Inkubation mit dem Sekundärantikörper erfolgt ein erneutes $1 \mathrm{~h}$ Blocken der Membran mit TBS-T mit $5 \%$ Milchpulver. Der Sekundärantikörper $\alpha$-rabbit lg HRPgekoppelt wird 1:5000 verdünnt in $20 \mathrm{ml}$ TBS-T mit $5 \%$ Milchpulver eingesetzt. Zur Entfernung des unspezifisch gebundenen Antikörpers wird die Membran mit $5 \times 5^{\prime}$ mit TBS gewaschen. Alle Inkubation erfolgten bei RT auf dem Schütller. Zum indirekten Nachweis der Proteine wird der ECL (EnhancedChemiluminescence) oder $\mathrm{ECL}^{+}$-Kit der Firma Amersham verwendet. Der Nachweis basiert auf der Umsetztung des Substrates Luminol durch die an den 2. Antikörper gekoppelte Peroxidase unter Emittierung von Licht. Dieses wird durch die Exposition auf einem Röntgenfilm (Cronex 10T) dokumentiert. Die Entwicklung des Films erfolgte 5' im Entwickler-Bad (LX24, Kodak), 5' Stop-Bad und 5' Fixier-Bad (AL4, Kodak) 


\section{$2|6| 2 \mid 11$ Analyse der Phosphorylierung (Kinase Assay)}

Die Untersuchung von Kinaseaktivitäten in Pflanzengeweben nach Pathogeninfektion wird in vitro durch die Übertragung von radioaktivem Phosphat auf das rekombinant hergestellte Protein $\triangle \mathrm{NBZI}$ - 1 vorgenommen. Die zu untersuchenden Suspensionskulturen werden durch wöchentliches Überführen in frisches Medium synchronisiert und 3 Tage nach dem letzten Überführen in neues Medium zu je $5 \mathrm{ml}$ in 6-Well-Platten (Nunc) oder in $100 \mathrm{ml}$ Erlenmeyerkolben aufgeteilt. Zur Induktion werden die Pseudomonaden (P.syringae pv.pisi) in einer Vorkultur 2 Tage bei $28{ }^{\circ} \mathrm{C}$ vorinkubiert und 1 Tag vor der Infektion in frisches Medium überführt. Es werden zur Induktion $5 \times 10^{7} \mathrm{cfu}$ der Pseudomonaden/ml Suspensionskultur eingesetzt. Die Bakteriendichte wird bei einer $\mathrm{OD}_{600}$ bestimmt. Die zu untersuchenden Blätter werden mit einer ebenso konzentrierten Bakteriensuspension mit einer Spritze ohne Nadel von der Unterseite inokuliert. Die Kontrollen werden mit sterilem Leitungswasser inokuliert. Es werden jeweils Gewebe zu den Zeitpunkten 0, 15, 30, 45 und 60' nach Infektion untersucht. Das gesamte für die Untersuchung genutzte Gewebe wird infiziert. Im Kontrollgewebe erfolgt eine Inokulation mit $\mathrm{H}_{2} \mathrm{O}$. Die Infektionsstellen werden mit einem $\varnothing 3 \mathrm{~cm}$ Korkbohrer ausgestochen. Für die weitere Analyse werden die Proteinextrakte wie o.g. aufgearbeitet und je $30 \mu \mathrm{g}$ Protein für einen Ansatz eingesetzt. Das rekombinante Protein wird über die NiNTA-Matrix angereinigt und auf Dialysemembranen gegen Kinasepuffer $3 \mathrm{~h}$ bei $4{ }^{\circ} \mathrm{C}$ dialysiert. Die $30 \mu \mathrm{g}$ Proteinextrakt werden mit $1 \mu \mathrm{g}$ rekombinantem Protein und $1 \mu \mathrm{l} \gamma$-P ${ }^{32}$-ATP $15^{\prime}$ bei RT in einem Volumen von $30 \mu \mathrm{l}$ inkubiert. Das Volumen der Probe wird auf $60 \mu \mathrm{l}$ mit Kinasepuffer erhöht und das überschüssige $\gamma$ - ${ }^{32}$ ATP mittels Gelfiltration durch Sephadex G25-Säulen in Kinasepuffer abgetrennt. $20 \mu \mathrm{l}$ der Probe werden auf ein SDS-PAGE-Gel aufgetragen. Die Proteine werden mittels Semi-Dry-Blot auf eine Nitrocellulosemembran übertragen und mit Hilfe eines IP-Screens und des Bioimagers (BAS-1000 von Fuji) und der Programme PCBAS 2.09 und TINA ${ }^{\circledR} 2.0$ der Firma raytest ausgewertet.

\section{$2|6| 2 \mid 12$ Proteinasebehandlung von phosphorylierten Proteinen}

Zur Grobkartierung von Phosphorylierungsstellen können die radioaktiv markierten Proteine durch Proteinasen spezifisch gespalten werden und die Fragmente ihrer Größe nach im SDS-PAG-Gel aufgetrennt werden. Auf diese Weise lassen sich durch Analyse der Fragmentmuster bei unterschiedlichen Proteinasebehandlungen die Phosphorylierungsstellen auf bestimmte Bereiche des Proteins festlegen. So wird das zu analysierende Protein durch Cyanbromid spezifisch hinter jedem Methionin (M-X), durch Ameisensäure zwischen jeder Asparaginsäure und einem Prolin(D-P) und durch die V8-Endoproteinase GluC Hinter jeder Glutaminsäure (E-X) gespalten. Zur Spaltung des Proteins wird die radioaktiv detektierbare Bande aus der Membran ausgeschnitten, zerkleinert und mit 0,1 M Cyanbromid in Methanol überschichtet. Zur weiteren Analyse wird der Ansatz dreigeteilt. Die Aliquots werden in der Speedvac bis zur Tocknung eingedampft und in $10 \mathrm{ml}$ PBS aufgenommen. Ein Aliquot wird mit $10 \%$ Ameisensäure und ein Aliquot mit $1 \mu \mathrm{l}$ V8-Proteinase versetzt ü.N. bei RT inkubiert. Die gespaltenen Fragmente werden auf einem $15 \%$ SDSPAGE-Gel aufgetragen, mittels Semi-Dry-Blot auf eine Nitrocellulosemembran übertragen und mit Hilfe eines IP-Screens und des Bioimagers (BAS-1000 von Fuji) und der Programme PCBAS ${ }^{\circledR} 2.09$ und TINA ${ }^{\circledR} 2.0$ der Firma raytest das Spaltungsmuster ausgewertet.

\section{$2|6| 2 \mid 13$ Gelretardationsanalysen (EMSA)}

DNA-Fragmente, an die Proteine gebunden sind, zeigen in einem nativen Polyacrylamidgel ein anderes Laufverhalten als ungebundene DNA. Der DNA-Proteinkomplex wandert aufgrund seines höheren Molekulargewichts langsamer, verglichen mit einem proteinfreien Fragment. Diese Verzögerung (lat. retardere) wird auch als "Shiff" bezeichnet. Man kann sich dieses Phänomen zunutze machen um spezifische Bindungen von Proteinen an DNA-Fragmente zu charakterisieren. Hierzu wir das Fragment radioaktiv markiert und in einem geeigneten Puffer mit einem Proteinextrakt inkubiert. Nach abgeschlossener Elektrophorese kann das Gel getrocknet werden und eine Autoradiographie vorgenommen werden um das Bandenmuster auszuwerten. Die Bindereaktion eines Ansatztes erfolgt in einem Volumen von $20 \mu \mathrm{l}$. Dieses setzł sich zusammen aus $4 \mu \mathrm{l}$ Puffer $\mathrm{F}+, 2 \mu \mathrm{l}$ Puffer $\mathrm{D}, 4 \mu \mathrm{l}$ radioaktiv markierten ds Oligonucleotiden (25 fmol), $2 \mu \mathrm{l}$ pdldC $(1 \mu \mathrm{g} / \mu \mathrm{l}), 2 \mu \mathrm{l}$ rekombinantem Protein oder $6 \mu \mathrm{l}$ Proteinextrakt und $\mathrm{H}_{2} \mathrm{O}$, wobei das Proteinvolumen gegebenenfalls mit BSA $(1 \mathrm{mg} / \mathrm{ml})$ abgeglichen wird. Die Bindereaktion erfolgt $30^{\prime}$ bei RT und die Proben werden auf das native PAGE-Gel $\left(10 \mathrm{ml} 30 \%\right.$ PAA-Mix, $60 \mathrm{ml} \mathrm{H} \mathrm{H}_{2} \mathrm{O}, 3,5 \mathrm{ml}$ 10x TBE, $400 \mu \mathrm{l}$ APS, $40 \mu$ TEMED) aufgetragen. Als Laufpuffer dient 0,5 x TBE. Zur Kontrolle des Gellaufes wird die Spur des freien Fragmentes mit BPB-Mix versetzt. Die Elektrophorese erfolgt bis die BPB-Bande ca. 4/5 des Gels durchlaufen hat. Zur Detektion wird das Gel auf einem Geltrockner $45^{\prime}$ bei $80{ }^{\circ} \mathrm{C}$ unter Unterdruck getrocknet und mit Hilfe eines IP-Screens und des Bioimagers (BAS-1000 von Fuji) und der Programme $\mathrm{PCBAS}^{\circledR} 2.09$ und $\mathrm{TINA}^{\circledR} 2.0$ der Firma raytest ausgewertet. 


\section{$2|6| 2 \mid 14$ Reportergenassay}

Die $\beta$-Glucuronidase (GUS) ist das Genprodukt des gus-Reportergens. Das Enzym GUS ist in der Lage $\beta$ Glucuronide in D-Glucuronsäuren und einen aglyconischen Rest zu spalten. Setzł man das künstliche Substrat 4-Methylumbeliferyl- $\beta$-D-Glucuronid (4-MUG) ein, so erhält man nach der Hydrolyse das fluoreszierende Molekül Methylumbeliferon (MU). Durch die Stärke der Fluoreszenz in den Ansätzen lässt sich die umgesetzte Menge MU quantifizieren und die Aktivität der GUS bestimmen. Die Anregung des MU erfolgt bei $360 \mathrm{~nm}$, die Messung der Emission bei $460 \mathrm{~nm}$.

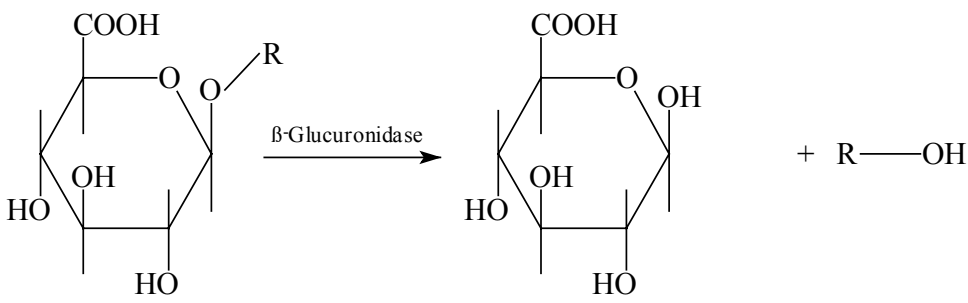

Abb. C - 7: Umsetzung des Substrates durch die $\beta$-Glucuronidase.

R: Methylumbeliferon (MU) oder Glucuronid; Spaltung der $\beta$-glucurosidischen Bindung.

Unter der Kontrolle eines entsprechenden Promotors, kann auf diese Weise die Expression eines Gens unter dem Einfluss eines trans-Elementes oder unter diversen Umwelteinflüssen detektiert werden. Es werden für den GUS-Assay entweder $100 \mathrm{mg}$ Blattgewebe oder entsprechend aufgearbeitete Mesophyllprotoplasten eingesetzt. Die Mesophyllprotoplasten werden 5' bei $1000 \mathrm{~g}$ zentrifugiert, die abgestorbenen, sedimentierten Zellen werden mit einer Pasteurpipette und Peristaltikpumpe entfernt. Die Protoplasten werden mit 10 fachem Volumen $250 \mathrm{mM} \mathrm{NaCl}$ versetzt und bei $1200 \mathrm{~g}$ sedimentiert. Das Pellet wird in $100 \mu \mathrm{l}$ GUSExtraktionspuffer $\left(50 \mathrm{mM} \mathrm{NaPO}_{4}, \mathrm{pH}\right.$ 7,0, $10 \mathrm{mM}$ EDTA, 0,1 \%Triton X-100, 0,1 \% Sarcosyl, frisch dazu $0,05 \% \beta$-Mercaptoethanol) aufgenommen. Die Proben werden in einer 96-well Mikrotiterplatte mit $100 \mu \mathrm{l}$ 4 mM MUG (in DMF gelöst) versetzt und bei $37^{\circ} \mathrm{C} 30^{\prime}$ vorinkubiert. Nach der Vorinkubation wird die Hälfte des Ansatztes mit GUS-Stop-Puffer $\left(0,2 \mathrm{M} \mathrm{Na}_{2} \mathrm{CO}_{3}\right.$ in $\left.\mathrm{H}_{2} \mathrm{O}\right)$ versetzł und die andere Hälfte über einen definierten Zeitraum $\left(60^{\prime}\right)$ bei $37{ }^{\circ} \mathrm{C}$ weiterinkubiert. Nach der vorgegebenen Zeit wird auch dieser Ansatz durch die Zugabe von $100 \mu \mathrm{l}$ GUS-Stop-Puffer abgestoppt. Die Fluoreszenz wird mit Hilfe des CytoFluorll Plate Reader von PerSeptive bei einer Anregung von $360 \mathrm{~nm}$ die Emission bei $460 \mathrm{~nm}$ gemessen. Als Standard werden 50 pmol MU (200 $\mu$ von 250 nM MU in GUS-Stop-Puffer) in ein well der zu messenden Mikrotiterplatte pipettiert. Die GUS-Aktivität wird nach der Formel

$$
A_{G U S}[U]=\frac{\Delta F \times 50_{p m o l ~ M U}}{T[m i n] \times \text { mg Protein } \times F_{50 \text { pmol MU }}}
$$

berechnet. $\Delta \mathrm{F}$ ist die Differenz der Fluoreszenz zu Beginn der Reaktion und am Ende. $T$ ist die Dauer der Reaktion in min. $A_{G U S}$ ist die errechnete rel. GUS-Aktivität in Units.

\section{$2|6| 2 \mid 15$ Pathogenitätstests}

\section{$2|6| 2|15| 1$ Infektion mit dem Tabak-Mosaic-Virus}

Zur Infektion mit TMV wird das Phagenlysat auf ein mit Carborundum versetztes Stück Zellstoff getropft und gleichmäßig sanft die Blattoberfläche berieben. Es werden komplett expandierte Blätter im unteren Drittel der Pflanzen infiziert. Die Infektion erfolgte wie bei YALPANI et al., 1991 beschrieben.

\section{$2|6| 2|15| 2$ Quantifizierung der bakteriellen Ausbreitung von Pseudomonas syringae}

Zur Bestimmung der Verbreitung von Pathogenen innerhalb einer Pflanze kann man die Miroorganismen wieder isolieren und ihr Wachstum titern, indem man die Kolonieenzahl der Bakterien auf einem semiselektiven Medium auszählt; modifiziert nach KNOCHE et al., 1987. Zur Quantifizierung des Bakterienwachstums werden von den Pseudomonaden ü.N.-Vorkulturen angezogen, diese neu überimpft und bis zu einer $\mathrm{OD}_{600}$ von 1,0 kultiviert. Die Kultur wird abzentrifugiert (5000 rpm, 5', RT) und 3 mal mit sterilem Leitungswasser gewaschen. Die Pseudmonaden werden auf eine Dichte von $1 \times 10^{5} \mathrm{cfu} / \mathrm{ml}$ verdünnt und zur Kontrolle in Verdünnungsstufen auf King's B-Medium ausplattiert. Die Pflanzen werden mit einer 1 $\mathrm{ml}$ Spritze ohne Nadel von der Blattunterseite in eine Fläche mit $\varnothing 0,5 \mathrm{~cm}$ inokuliert. Das Volumen einer 
Inokulation betrug ca. $10 \mu \mathrm{l}$. Es werden jeweils 5 Infektionsstellen mit einem Korkbohrer $\varnothing 1 \mathrm{~cm}$ ausgestochen, in $1 \mathrm{ml}$ sterilem Leitungswasser aufgemörsert und in einer Probe vereinigt. Das Bakterienwachstum wird zu den Zeitpunkten $0,48 \mathrm{~h}$ und $96 \mathrm{~h}$ nach Infektion aufgenommen. Die aufgemörserten Proben werden jeweils kurz gevortext und und in 1:10 Verdünnungsschritten in einer Verdünnungsreihe auf King's B-Medium ausplattiert. Es erwies sich als praktikabel die Verdünnungs-Stufen $10^{0}-10^{-5}$ auszuplattieren. Es werden pro Pflanze jeweils Doppelbestimmungen an zwei unterschiedlichen Blättern durchgeführt und jeweils zwei Pflanzen der gleichen Linien parallel getestet. Die Platten werden 2 - 3 Tage bei $28{ }^{\circ} \mathrm{C}$ inkubiert und die Anzahl der Kolonien ausgezählt. Es werden die Zahlen der gleichen Linien gemittelt und die Standardabweichung ermittelt.

\section{$2|6| 2 \mid 16$ Quantifizierung der Blütengrößen}

Zur Quantifizierung der Blütengrößen werden vollständig entfaltete Blüten von Erdkulturpflanzen aus der Klimakammer verwendet. Die Größen werden mit Hilfe eines Lineals bestimmt, wobei die Größe der Gesamtblüte vom Blütenboden bis zur oberen Wölbung der Petalen bestimmt wird. Die Länge der Stamen wird vom Blütenboden bis zur oberen Kante des Pollensackes bestimmt. Zur Bestimmung der Stempellänge (Pistill) wird die Blüte aufpräpariert. Der Stempel wird direkt über dem Fruchtknoten abgebrochen und von der Bruchstelle bis zur Spitze ausgemessen. Die gemessenen Werte werden gemittelt und die Standardabweichung ermittelt.

\section{$2|6| 2 \mid 17$ Fluoreszenzmikroskopische Analysen}

Das GFP (GrünFluoreszierendes Protein), welches ursprünglich aus der Qualle Aequorea victoria stammt, wird in dieser Arbeit in einer modifizierten Form als eGFP S65T (CUBITT, et al., 1995) eingesetzt. Der Aminosäureaustausch im Chromophor bewirkt eine ca. 35fache Steigerung der sichtbaren Fluoreszenz, eine Verlangsamung des Ausbleichens und eine leichte Verschiebung der Anregung von 470 nm zu 488 nm. Das Protein emittiert das Licht bei einer Wellenlänge von $511 \mathrm{~nm}$. Die Verteilung des GFP-Fusionsproteine in den Mesophyllprotoplasten wird mit Hilfe des Fluoreszenzmikroskops detektiert. Die Protoplasten werden $24 \mathrm{~h}$ nach der Elektroporation 5', $100 \mathrm{~g}$ in der ungebremsten Zentrifuge mit Aussschwingrotor zentrifugiert und der Unterstand mit einer Pasteurpipette abgezogen. Die Fluoreszenz wird mit Hilfe des Zeiss Axiovert 35 Fluoreszenzmikroskops bei 200x und 400x Vergrößerung analysiert und photographisch dokumentiert.

\section{$2|6| 2 \mid 18$ Konfokale Mikroskopie}

Die wie unter 2.6.2.16 aufgearbeiteten Mesophyllprotoplasten werden mit Hilfe eines Laserscanning Miroskops LSM-510 der Firma Zeiss unter Trennung der Grün- und Rot-Kanäle zur Differenzierung der Chloroplasten- und der GFP-Fluoreszenz. Da die Rotfluoreszenz bei entsprechender Intensität in den Grünbereich "überstrahlt" lässt sich mit Hilfe dieser Technik die Lokalisation der GFP-Fusionsproteine sehr effizient und artefakffrei durch die entsprechend Wahl der Parameter (Pinhole $\approx 100$ ) analysieren. 


\section{D | Ergebnisse}

\section{1 | Vorarbeiten zur Analyse von BZI-1}

Zur Charakterisierung der Funktion der konservierten BZI-1-Domänen in vitro wurden unterschiedliche BZI-1 Derivate rekombinant in E.coli hergestellt. Diese sollten einerseits der Analyse der in vitro - DNA-Bindung des Transkriptionsfaktors dienen, andererseits als Substrat für in vitro Phosphorylierungsstudien dienen. Mit Hilfe der rekombinanten Proteine wurde ein polyklonaler Antikörper gegen das BZI-1-Protein hergestellt. Durch den Antikörper soll die Analyse der Funktion von BZI-1 in planta (Zelluläre Lokalisation, Analyse transgener Linien) ermöglicht werden.

\section{1| 1 Expression rekombinanter BZI-1-Derivate}

Zur Analyse der DNA-Bindespezifität, Proteinphosphorylierung und Herstellung eines polyklonalen Antikörpers wurden unterschiedliche BZI-1-Deletionsderivate exprimiert. Die Expression erfolgte im pET-Expressionssystems. Es werden das BZI-1-Gesamtprotein und die Deletionsderivate $\mathrm{BZI} 1-\Delta \mathrm{N}, \mathrm{BZI}-1-\Delta \mathrm{N} \Delta \mathrm{D} 1, \mathrm{BZI}-1-\Delta \mathrm{N} \Delta \mathrm{BD}$ exprimiert (zur Übersicht: Abbildung 1).

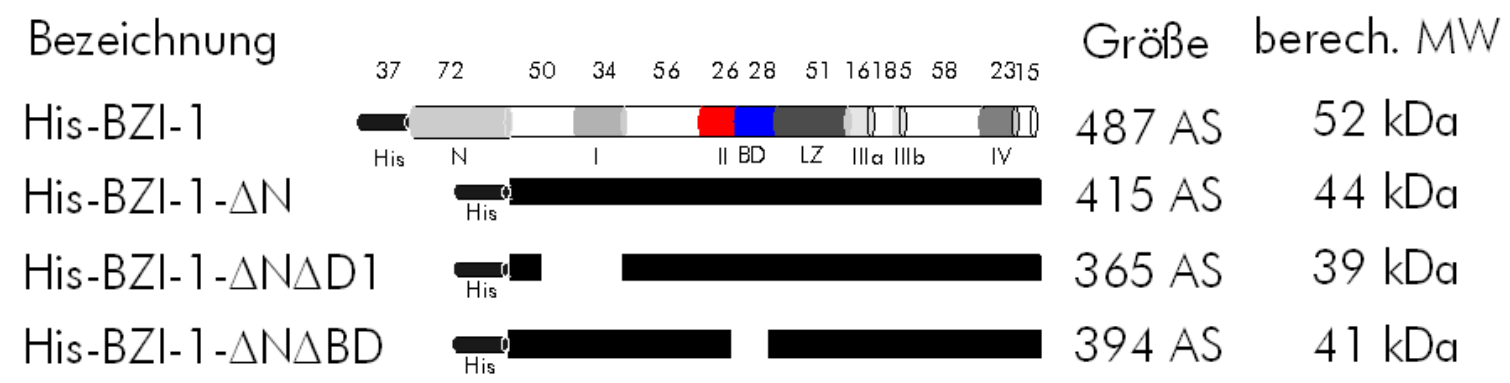

Abb. D - 1: Schematische Übersicht der rekombinanten BZI-1-Derivate.

Die Übersicht zeigt die 4 konstruierten $H i s{ }^{\circledR}$-tag-Fusionsproteine. Innerhalb des His ${ }^{\circledR}$-BZI-1-Proteins werden die Domänen schematisch dargestellt. Die deletierten Bereiche der Derivate wurden ausgespart. Die Größe der Proteine wird in Aminosäuren (AS) angegeben, das berechnete Molekulargewicht in Kilo-Dalton (kDa); His: His-tag, N: Domäne N; I: Domäne 1, II: Domäne 2, BD: basische Domäne, LZ: Leuzin-Zipper, Illa+b: Domäne 3, IV: Domäne 4, $\Delta$ : Deletion.

Das zu exprimierende Gen wird so in den multiplen-klonier-Bereich (mcs) des Vektors eingebracht, dass eine Translationsfusion mit dem His-tag ${ }^{\circledR}$ entsteht. Die korrekte Fusion des His-tag ${ }^{\circledR}$ im 5'-Bereich wurde durch eine Sequenzierung bestätigt. Durch den His-tag ${ }^{\circledR}$ werden die Fusionsproteine um 37 Aminosäuren vergrößert. Nach der Transformation der 
Plasmide in den E.coli BL21-Stamm wurden die optimalen Expressionsbedingungen für die einzelnen Proteine getestet. Es wurden jeweils die Menge an Induktor, die Inkubationstemperatur während der Expression und die Expressionsdaver variiert. Es zeigte sich, dass bei einer Induktion der Expression mit 0,8 mM IPTG und einer Inkubation bei RT nach $3 \mathrm{~h}$ die optimale Ausbeute an rekombinatem Protein zu erhalten war. Bei einer Ausdehnung der Inkubationszeit nahmen die Abbauprodukte des zu exprimierenden Proteins durch Proteolyse zu stark zu. In allen Expressionsstudien zeigte sich eine größere Ausbeute der Deletionsderivate im Gegensatz zum Gesamtprotein. Das His ${ }^{\circledR}$-tag-Epitop am N-Terminus des rekombinanten Proteins kann durch den spezifischen His ${ }^{\circledR}$-Antikörper detektiert werden. Die erfolgreiche Expression wurde durch Coomassie-gefärbte SDSPAGE-Gele und Immunodetektion getestet (exemplarisch für His ${ }^{\circledR}-B Z I 1-\Delta N$ Abb. D-2). Nach der Expression erfolgte die Aufreinigung durch eine Affinitätschromatographie über die NiNTA-Matrix. Der Säulendurchlauf wird fraktioniert aufgefangen und die Fraktionen werden mit Hilfe der Bradford-Proteinbestimmung auf ihren Proteingehalt getestet. Eine exemplarische Aufreinigung des in E.coli exprimierten $\mathrm{His}^{\circledR}-\mathrm{BZI} 1-\Delta \mathrm{N}$-Derivates ist in Abbildung D-2 zu sehen.
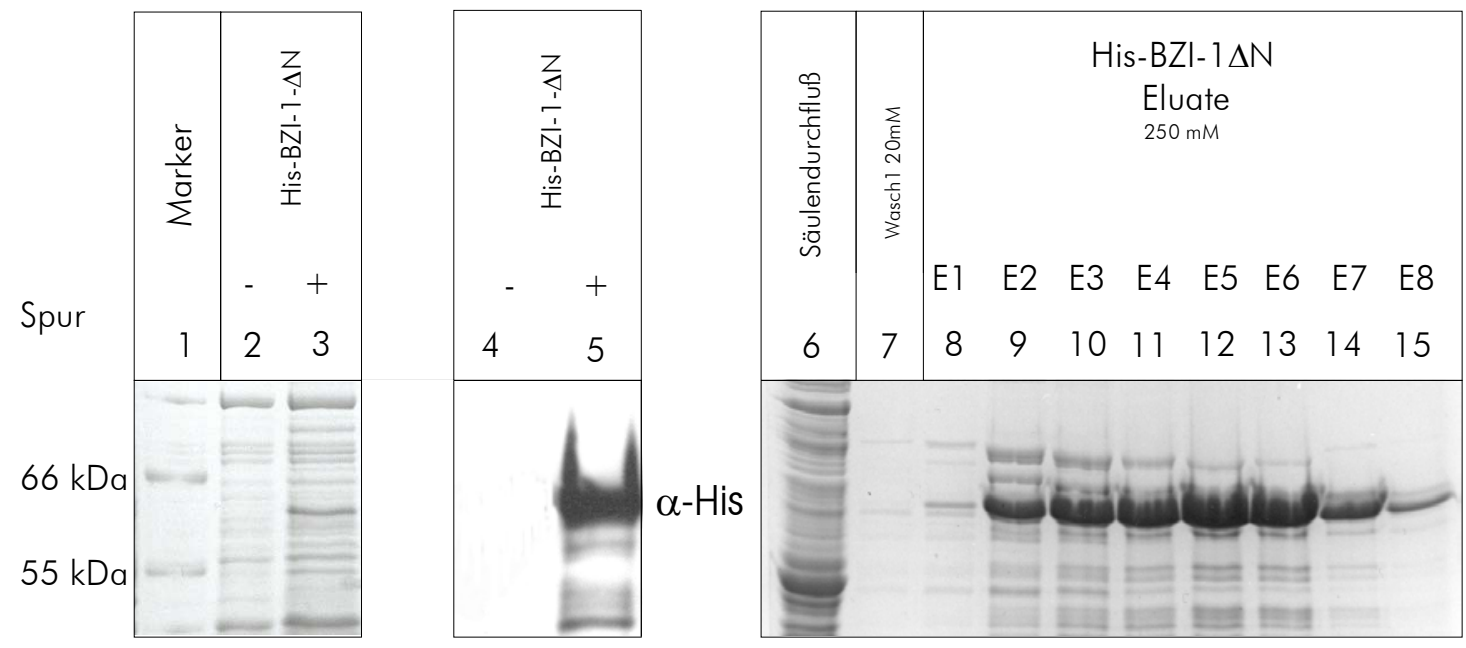

Abb. D - 2: Expression des His ${ }^{\circledR} \mathrm{BZI}-1-\Delta \mathrm{N}$ und exemplarische Aufreinigung des His ${ }^{\circledR} \mathrm{BZI}-1-\Delta \mathrm{N}$ Proteins. Spur 1-3: Coomassie gefärbte 8\% PAGE-Gele. Spurl: Marker, Spuren 2+3: Expression der Proteine His ${ }^{\circledR}$ BZI-1- $-\Delta \mathrm{N}$ ohne (-) IPTG und mit (+) 0,8 mM IPTG nach 3 h Expressionszeit bei RT; Spuren 4+5 Immunodetektion mit dem HisAntikörper 1:1250, sek. Antikörper 1:5000; Spur 4: uninduzierter His ${ }^{\circledR} B Z I-1-\Delta N-B a k t e r i e n e x t r a k t, 3 h$ RT; Spur 5: 0,8 mM IPTG induzierter His ${ }^{\circledR}$ BZI-1- $\Delta \mathrm{N}$-Bakterienextrakt, 3 h RT; Spuren 6-15: exemplarische Aufreinigung des His ${ }^{\circledR}$ BZI-1$\triangle \mathrm{N}$ durch eine $\mathrm{NiNTA}^{\circledR}$-Säulenchromatographie. Spur 6: 1.Säulendurchlauf; Spur 7: Waschfraktion mit 20 mM Imidazol; Spur 8-15: fraktioniert aufgefangene Eluatfraktionen (E) mit $250 \mathrm{mM}$ Imidazol eluiert. 


\section{1 | 2 Herstellung des BZI-1-Antikörpers}

Das erste im Rahmen dieser Arbeit hergestellte Protein, das His ${ }^{\circledR}$-BZl-1- $\Delta \mathrm{N} \Delta \mathrm{BD}$-Derivat wurde im mg-Maßstab quantitativ exprimiert. Das ausgewählte Derivat ließ sich, vermutlich aufgrund der fehlenden putativen DNA-Bindedomäne, am effizientesten expimieren. Die Aufreinigung erfolgte zunächst affinitätschromatographisch und anschließend über ein SDS-PAGE. Das durch eine Coomassiefärbung detektierte $\mathrm{His}^{\circledR}-\mathrm{BZI}-1-\Delta \mathrm{N} \Delta \mathrm{BD}$-Derivat wurde aus dem Gel durch eine Elektroelution herauspräpariert und zur Immunisierung eines Kaninchens eingesetzt. Für Immunodetektionen wurde das Serum der 4. Blutentnahme eingesetzt. Um die untere Nachweisgrenze des Antikörpers auszutesten wurde eine SDS-PAGE durchgeführt und unterschiedliche Verdünnungen des rekombinanten His ${ }^{\circledR}$-BZI-1-Derivates aufgetragen.

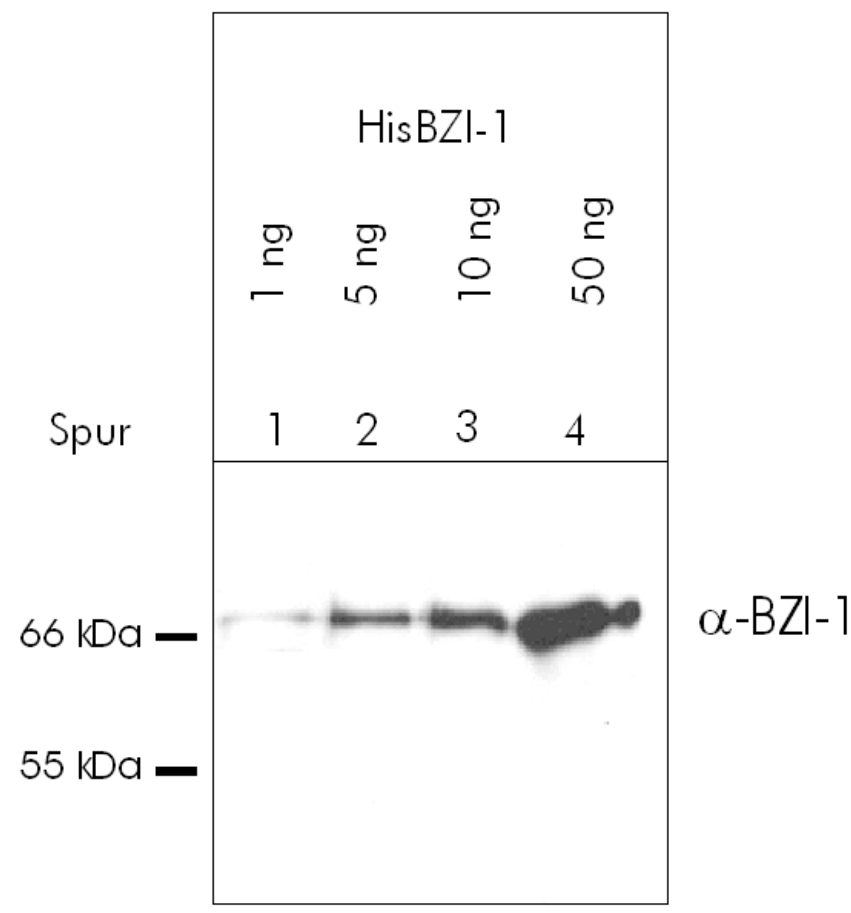

Abb. D - 3: Spezifität des $\alpha$-BZI-1 -Antikörpers.

Immunologische Detektion des rekombinant exprimierten $\mathrm{His}^{\circledR} \mathrm{BZI}-1$ nach Aufreinigung mit dem $\alpha$-BZI-1-Antikörper. Prim. AK: 1:1250; Sek. AK: 1:5000 Spur 1: 1 ng, Spur 2: 5 ng, Spur 3: 10 ng und Spur 4: 50 ng His ${ }^{\circledR}$-BZI-1-Protein.

Wie in Abbildung D-3 ersichtlich, lässt sich mit der ausgetesteten und standardmäßig eingesetzten Verdünnung des primären Antikörpers von 1:1250 unter Verwendung des 4. Serums eine Menge von 1 ng gerade noch nachweisen. Mit steigender Menge an eingesetztem Protein steigt die Intensität der Detektion. 


\section{1 | 3 Immunologischer Nachweis der rekombinanten BZI-1-Derivate}

Um die Spezifität der aufreinigten Proteine zu protokollieren, werden die Fraktionen zusätzlich durch eine Immunodetektion mit dem $\alpha$-BZI-1 getestet. Hierbei lassen sich auch proteolytische Abbauprodukte des rekombinanten Proteins nachweisen. Abbildung D-4 zeigt eine immunologische Detektion einer Proteinaufreinigung des His ${ }^{\circledR}$-BZI- 1- $\Delta$ N Proteins mit Hilfe des hergestellten $\alpha$-BZI-1 Antikörpers.

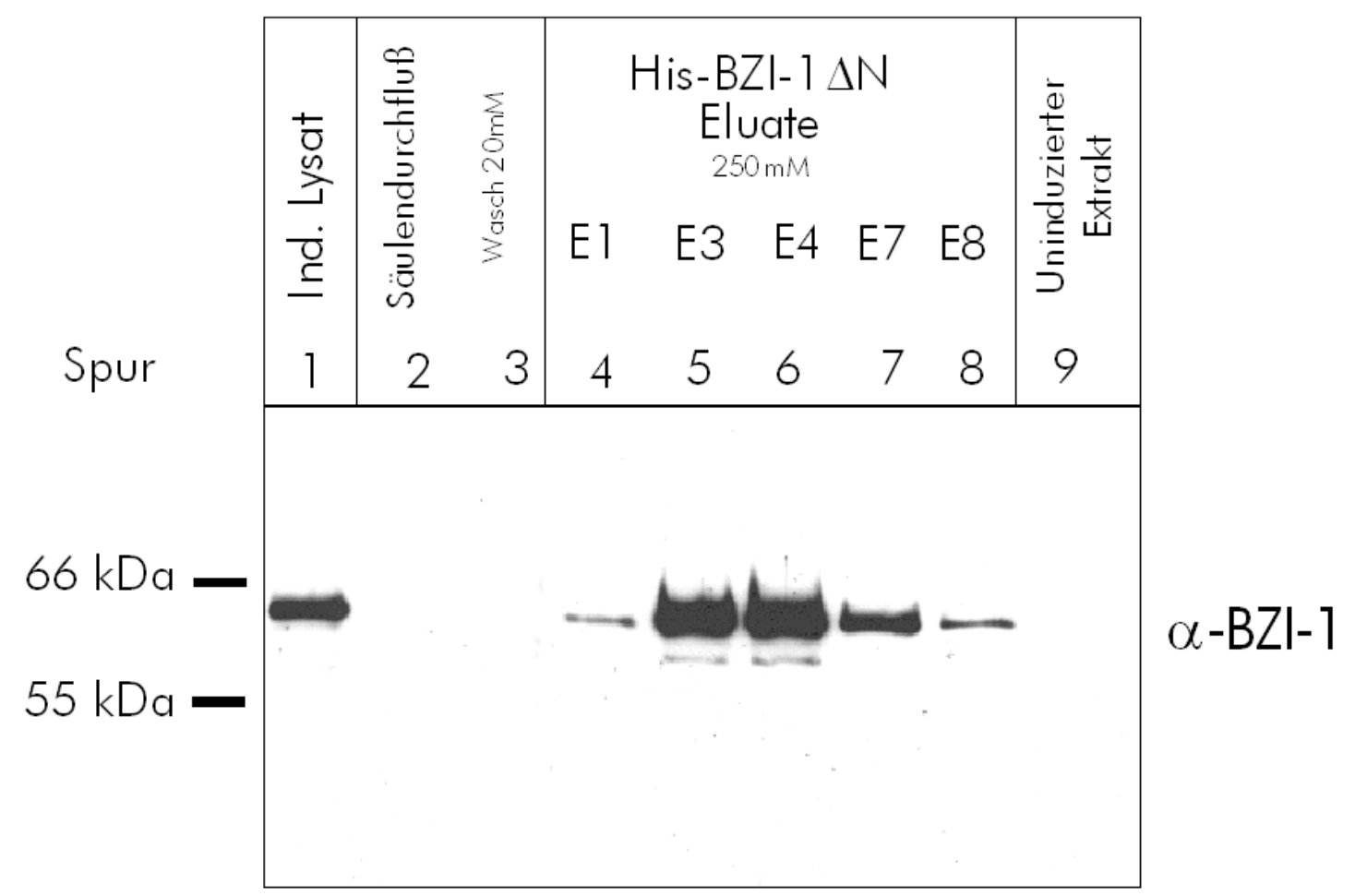

Abb. D - 4: Immunodetektion des $\mathrm{His}^{\circledR} \mathrm{BZI}-1-\Delta \mathrm{N}$ Proteins nach der Aufreinigung.

Immunologische Detektion des His ${ }^{\circledR}$ BZI-1- $\Delta$ N Proteins in den Fraktionen nach einer NiNTA®-Säulenchromatographie mit Hilfe des $\alpha$-BZl-1-Antikörpers. Spur 1: Positivkontrolle induzierter Bakterienextrakt 3 h, RT, lysiert; Spur 2: 1.Säulendurchfluss; Spur 3: Waschfraktion mit $20 \mathrm{mM}$ Imidazol Spur 4-8: fraktioniert aufgefangene Eluatfraktionen (E) mit 250 mM Imidazol eluiert; Spur 9: Negativkontrolle uninduzierter Bakterienextrakt 3 h, RT, lysiert.

Die Western Blot - Analyse bestätigt, dass durch die Affinitätschromatographie die rekombinanten Proteine effektiv aufgereinigt werden konnten und nur sehr wenig immunologisch nachweisbare Abbauprodukte die Extrakte $\left(\mathrm{His}^{\circledR}-\mathrm{BZI}-1-\Delta \mathrm{N}\right.$ und $\mathrm{His}^{\circledR}$-BZI- 1 $\triangle \mathrm{N} \triangle \mathrm{BD}$ ) kontaminieren. In Abbildung $\mathrm{D}-5$ sind die aufgereinigten und auf $10 \mathrm{ng}$ abgeglichenen rekombinanten Proteine zu sehen. 


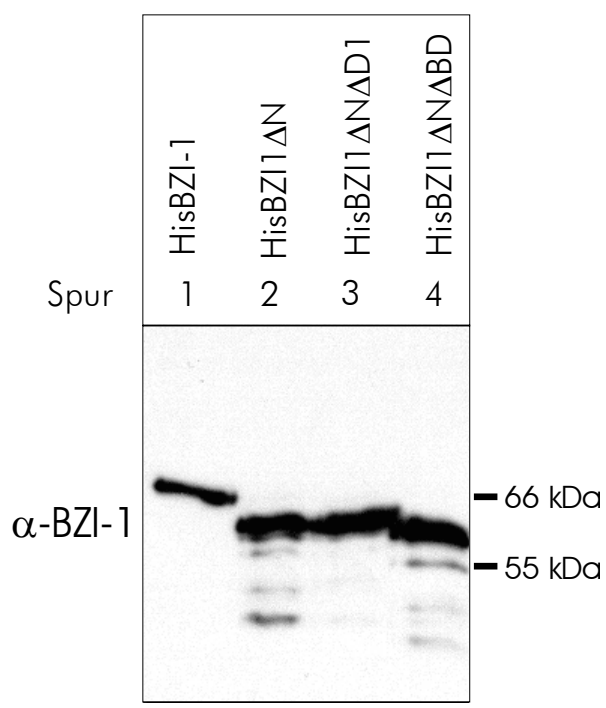

Abb. D - 5: Größenvergleich der BZI-1-Derivate.

Immunologische Detektion der rekombinant exprimierten $\mathrm{His}^{\circledR} \mathrm{BZI}-1$-Derivate (10 ng) nach Aufreinigung mit dem $\alpha$-BZI1-Antikörper. Spur 1: His ${ }^{\circledR}$-BZI-1; Spur 2: His ${ }^{\circledR}-\mathrm{BZI}-1-\Delta \mathrm{N}$-Derivat; Spur 3: His ${ }^{\circledR}$-BZI-1- $\Delta \mathrm{N} \Delta \mathrm{D} 1$-Derivat; Spur 4: His ${ }^{\circledR}$-BZI$1-\Delta \mathrm{N} \Delta \mathrm{BD} ;$ Spur 5: Marker.

Alle untersuchten Proteine zeigten ein verzögertes Laufverhalten im Gel im Vergleich zu ihren berechneten Molekulargewichten. Insbesondere das Doppeldeletionderivat His ${ }^{\circledR}$-BZI1- $\Delta \mathrm{N} \Delta \mathrm{D} 1$ fiel durch ein abweichendes Laufverhalten auf. Die Vollständigkeit des hergestellten Konstruktes konnte durch zusätzliche Sequenzierungen der Fusionsübergänge und der deletierten Bereiche bestätigt werden. Mit Hilfe dieser rekombinant hergestellten Proteine konnten nun die BZI-1 DNA-Bindeeigenschaften untersucht werden. 


\section{2 | DNA-Bindung von BZI-1}

Eine wichtige Eigenschaft eines Transkriptionsfaktors isł seine Fähigkeit ein spezifisches DNA-Element zu erkennen und daran zu binden. Für bZIP-Transkriptionsfaktoren wie BZI-1 wurde bereits gezeigt, dass sie allgemein ACGT-Core-Motive erkennen (IZAWA et al., 1993). Für das BZI-1- $\Delta \mathrm{N}$-Derivat konnte bereits gezeigt werden, dass es in vitro an G-BoxElemente des Chalkonsynthase 15-Promotors der Bohne (Phaseolus vulgaris) bindet (HEINEKAMP et al., zur Veröffentlichung eingereicht; DRÖGE-LASER et al., 1997). Ein entsprechendes G-Box-Element ist auch aus dem ppal2-Promotor bekannt (HATTON et al., 1995). Eine Regulation der Tabak Chalkonsynthase- und Phenylammoniumlyasegene durch BZI-1 in planta konnte jedoch nicht gezeigt werden (HEINEKAMP et al., 2002). Für das orthologe Protein CPRF-2 aus Petersilie konnte überdies hinaus eine Bindung an die C-Box und GBox in vitro und in vivo nachgewiesen werden (WEISSHAAR et al., 1991; FELDBRÜGGE et al., 1996; SCHINDLER et al., 1992).

\section{2| 1 Bindung von BZI- 1 an das GH3-Promotorelement, die G/C-Box}

Nach Analyse von Auxin-induzierbaren Genen konnten wir in den BZI-1- $\Delta \mathrm{N}$ exprimierenden transgenen Linien das verringert exprimierte GH3-Gen finden (HEINEKAMP et al., zur Veröffentlichung eingereicht). Um die mögliche Bindung von BZI-1 an diesem Promotor molekular zu belegen und damit ein spezifisches cis-Element zu identifizieren, wurde ein Promotorfragment isoliert und für Gelretardationsanalysen (EMSA:

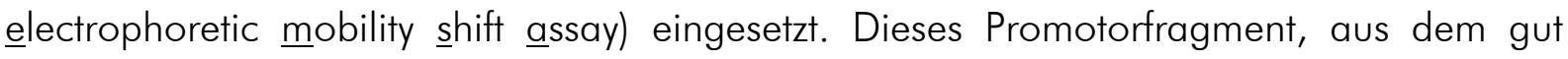
analysierten GH3-Promotor aus der Sojabohne (Glycine max), enthält eine chimäre G/CBox. Eine Bindung des BZI-1 an diesen Teil des Promotorelementes erschien einerseits aufgrund der Sequenzähnlichkeiten zu den bisher getesteten Promotorelementen wahrscheinlich. Auf der anderen Seite deutet der negative Einfluss der BZI-1- $\Delta$ N-Derivate in den transgenen Pflanzen auf eine transkriptionelle Regulation der GH3-Expression hin. Um die Bindung nachzuweisen wurde ein synthetisches Oligo mit dem Bereich der chimären G/C-Box hergestellt, welches im Folgenden als GH3-Oligo bezeichnet wird. Abbildung D-6 zeigt die Position und Sequenz des Oligonucleotids im GH3Promotorkontext. Das konstruierte Oligonucleotid entspricht der ursprünglichen Promotorsequenz und enthält das charakterisierte El-Element (LIU et al., 1997). Es besitz† eine Größe von 37 bp und stellt den GH3-Promotorbereich von -215 bis -178 bp 
stromaufwärts der TATA-Box dar. Die beiden Auxin-responsiven cis-Elemente D1 und D4 (ULMASOV et al., 1995) sind nicht Teil des Oligos, sondern verdeutlichen die Lage des E1Elementes im Promotorkontext.

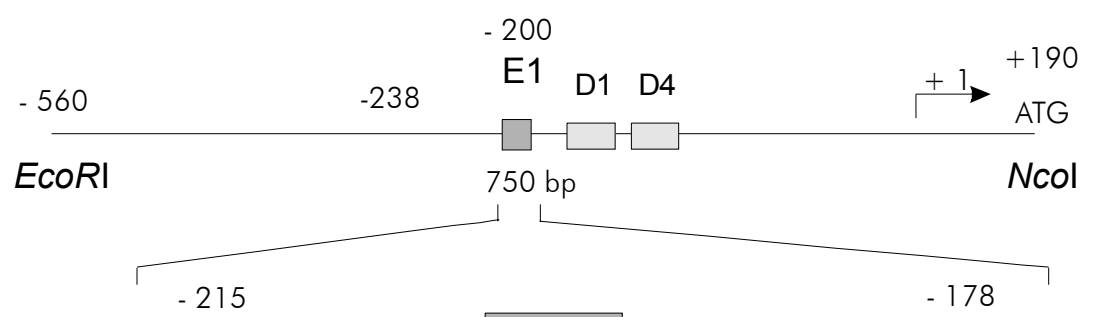

GH3-G/C-box GCTCTTGAAAACGA CTGCAC CGCTGTGTAGACCTGGGTGATC

G/C-box mut GCTCTTGAAAACGA aag Cta aac TGTGTAGACCTGGGTGATC

Abb. D - 6: Sequenz und Lage des eingesetzten Oligos im GH3-Promotorkontext. Die Abbildung beschreibt den GH3-Promotor mit den von LIU et al., 1997 und ULMASOV et al., 1995 bezeichneten DNA-cis-Elementen E1, D1 und D4. Die dunkel unterlegten Basenpaare bezeichnen die G/C-Box, die im Fall des G/Cmut in den Bereichen der kursiv und klein herausgestellten Buchstaben mutiert ist.

Wie aus Abbildung D-7 ersichtlich, ist das Homodimer des His ${ }^{\circledR}-\mathrm{BZI}-1-\Delta \mathrm{N}$-Proteins in der Lage an das GH3-Oligo zu binden. Um eine verlässliche Aussage über die eingesetzten Proteinmengen machen zu können, wurde der aufgereinigte Proteinextrakt über ein SDSGel mit Hilfe einer Coomassiefärbung gegen einen $1 \mu \mathrm{g} / \mu \mathrm{l}$ BSA-Standard abgeglichen.

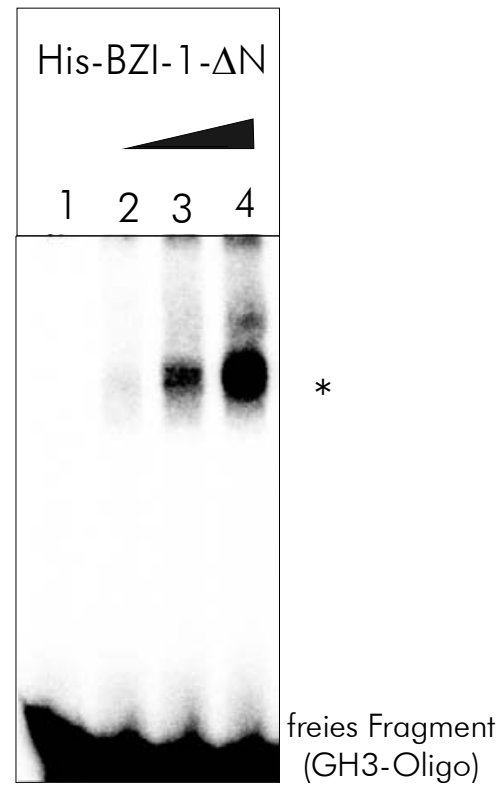

Abb. D - 7: Spezifität der DNA-Bindeaktivität in Abhängigkeit von der Proteinmenge.

Die Bindeaktivität des His ${ }^{\circledR} \mathrm{BZI}-1-\Delta \mathrm{N}$-Proteins in Abhängigkeit zur eingesetzten Menge des Proteins an das GH3-Oligo: Spur 1 : 0 ng ; 2 : 50 ng; 3: 100 ng und 4 : 200 ng Protein, ${ }^{*}$ retardierter BZI-1-DNA-Komplex. 
Es entsteht ein DNA-Proteinkomplex, dessen Signal mit der eingesetzten Proteinmenge korreliert. Bei einer im Überschuss vorhandenen Menge an Protein (200 ng) erscheint unter den eingesetzten Bindebedingungen eine stärker retardierte Bande etwas oberhalb der prominenten Bande. Möglicherweise handelt es sich hierbei um Proteinmultimere, die über den $\mathrm{His}^{\circledR}$-tag komplexieren können.

Um die Spezifität der BZI-1 Bindung an die chimäre G/C-Box des GH3-Oligos nachzuweisen wurde ein Kompetitionsassay mit dem GH3-Oligo und dem vergleichbaren, im Bereich der G/C-Box mutierten Oligo vorgenommen. Das Ergebnis dieser Kompetitionsstudie ist in Abbildung D-8 zu sehen.

Als optimal detektierbare Menge konnte aus den gewonnenen Ergebnissen des vorangehenden Versuches 200 ng rekombinantes Protein eingesetzt werden. Es wurde jeweils ein 1:100- und 1:200-fachen Überschuss unmarkiertes GH3-Box Fragment oder mutiertes G/C-Box-Element zugegeben.

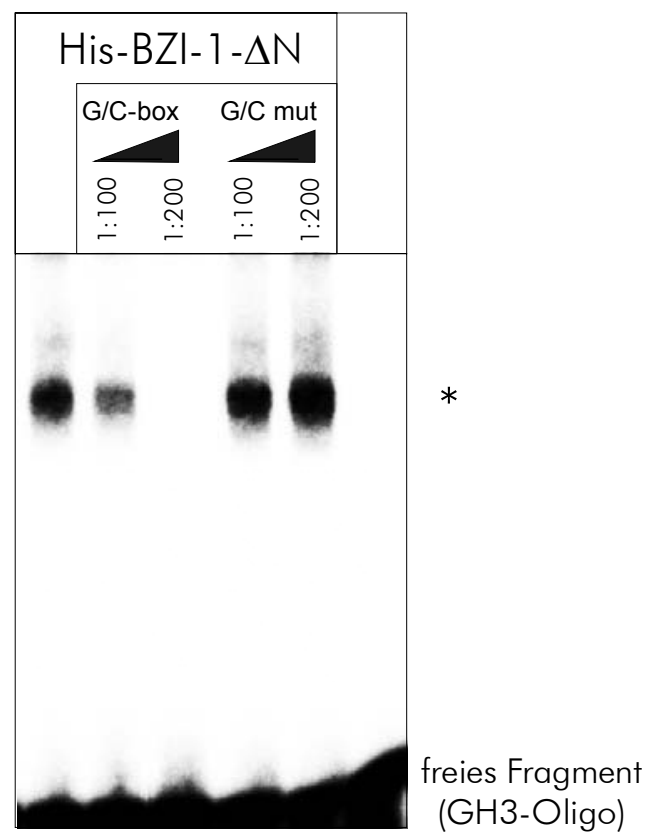

Abb. D-8: G/C-Box Spezifität der DNA-Bindeaktivität.

Kompetitionsanalyse der DNA-Bindung von $\mathrm{His}^{\circledR} \mathrm{BZI}-1-\Delta \mathrm{N}$ an die G/C-Box. Die radioaktiv markierten Fragmente wurden durch Zugabe von unmarkierten G/C-Box und G/C-mut Fragmenten im molaren Verhältnis 1:100 und 1:200 kompetitiert. His ${ }^{\circledR}$ BZI-1- $-\Delta$ N-rekombinantes His ${ }^{\circledR}$ BZI-1- $\Delta$ N-Protein (200ng); G/C-Box: GH3-Oligo; G/C-mut: im Bereich der G/C-Box mutiertes GH3-Oligo; * retardierter BZI-1 -DNA-komplex.

Die erste Spur zeigt das Signal der unkompetitierten Bindung des Proteins an das G/CBox tragende Fragment. Durch die Kompetition mit dem unmarkierten GH3-Oligo sieht man die Abnahme des detektierbaren Komplexes im Vergleich zur nicht kompetitierten 
Bindung des BZI-1. Durch die Kompetition mit dem mutierten G/C-Oligo lässt sich kein Einfluss auf die DNA-Bindung erkennen. Das hier verwendete Oligo trägt die gleichen Randsequenzen wie das radioaktiv markierte, ist jedoch im Bereich des cis-Elementes mutiert (Abbildung D-6). Durch diesen Ansatz lässt sich als spezifisches DNA-Bindemotiv von BZI-1 als G/C-Box mit einer DNA-Sequenz GACGTG beschreiben.

Um die Affinität der BZI-1-DNA-Bindung an die G/C-Box gegenüber einem allgemein bZIP-bindenden Element mit ACGT-Kernmotiv vergleichen zu können, wurde das as-1 Element (Sequenz: TGACGTAA) verwendet. Des Weiteren wurde die Affinität des BZI-1 zu den palindromischen C- (Sequenz: CCACGTGG) und G- (Sequenz: TGACGTCA) Boxen verglichen. Die Ergebnisse dieser Analyse sind in Abbildung D-9 zu sehen.

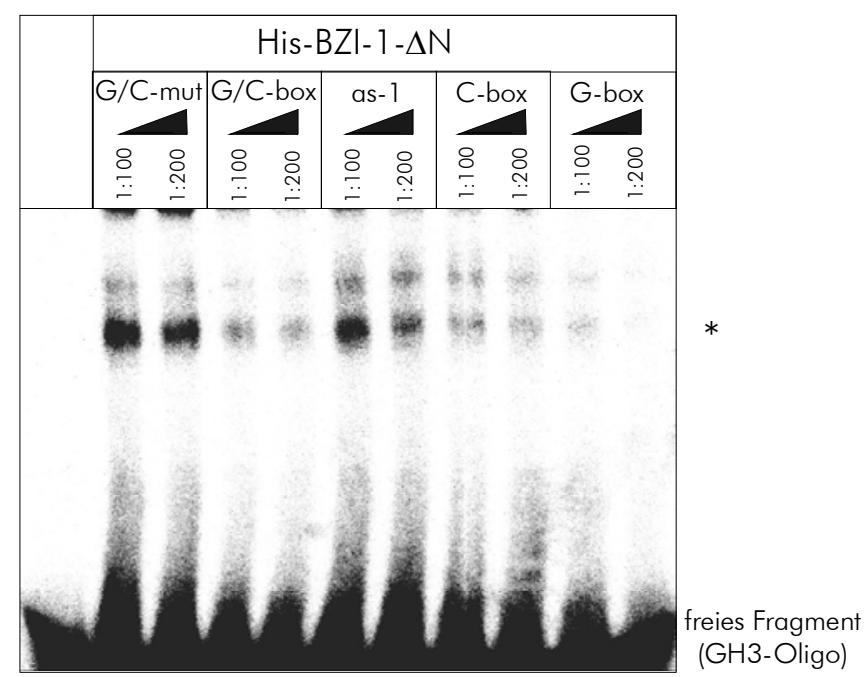

Abb. D - 9: Spezifität der DNA-Bindung von His ${ }^{\circledR} B Z I-1-\Delta N$ an unterschiedliche DNA-Elemente.

Kompetitionsanalyse der DNA-Bindung von $\mathrm{His}^{\circledR} \mathrm{BZI}-1-\Delta \mathrm{N}$ an die G/C-Box. Die radioaktiv markierten Fragmente wurden durch Zugabe von unmarkierten Fragmenten im molaren Verhältnis 1:100 und 1:200 kompetitiert. Zur Kompetition eingesetzte DNA-Fragmente: G/C-mut; G/C-Box; as-1-Element, C-Box und G-Box. His ${ }^{\circledR} B Z I-1-\Delta N$ : rekombinantes His ${ }^{\circledR}$ BZl- $1-\Delta$ N-Protein (200ng);

Zum Vergleich der Bindung an die cis-Element-tragenden DNA-Fragmente wurden diese im 100- und 200-fachen molaren Überschuss als Kompetitoren zugesetzt. Das as-1Fragment wurde freundlicherweise von S. Krawczyk zur Verfügung gestellt. Dieses Element trägt ein für TGA-Faktoren spezifisches as-7-cis-Element mit einen ACGT-Kernmotiv. Wie schon von IZAWA et al.,1992 gezeigt, variiert die Spezifität der DNA-Bindung in Abhängigkeit von den eingesetzten Faktoren. Durch den Einsatz eines 200-fachen Überschusses zeigt sich eine leichte Kompetition. Diese beruht auf der schwachen Verdrängung durch das as1-Element, woraus die hohe Spezifität des BZI-1 für das G/C-Element erkennbar wird. Durch die C- und G-Box zeigt sich ebenfalls eine hohe Spezifität des BZI-1 für diese cis- 
Elemente. Hier erfolgt eine starke Kompetition der unmarkierten Fragmente gegenüber der radioaktiv markierten G/C-Box. Da die G/C-Box in dem GH3-Oligo direkt den GH3Promotorbereich widerspiegelt, kann hier eine direkte Interaktion des BZI-1-Proteins mit einem Promotorelemtent eines putativen Zielgens verknüpft werden. Diese nachgewiesene Interaktion isł ein wichtiger Punkt der Entschlüsselung der Signalverarbeitung. In dem verwendeten in vitro Analysesystem steht hier nun die Bindung an die entdeckte G/C-Box in dem GH3-Oligo neben den bisher bekannten Interaktionen des BZI-1-Proteins mit der C- und G-Box.

\section{2|2 Spezifität der BZI-1-DNA-Bindung durch die basische Domäne}

Die Bindung der unterschiedlichen rekombinanten Proteine an das GH3-Oligo ist in Abbildung D-10 zu sehen.

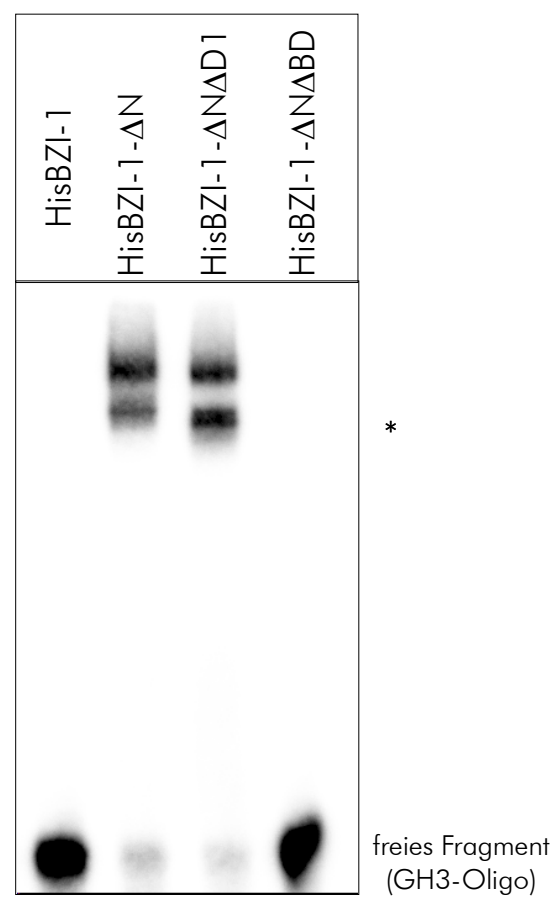

Abb. D - 10: EMSA (electrophor. mobility shift assay) der Bindung von BZI-1-Deletionsderivate an das GH3-Oligo.

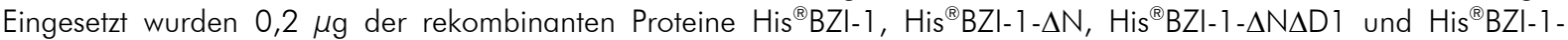
$\triangle N \triangle B D$. Das eingesetzte radioaktiv markierte DNA-Fragment ist das in Abb. D-6 beschriebene GH3-Oligo. Das Sternchen bezeichnet die spezifischen Bindeaktivitäten.

Da das rekombinant hergestellte $\mathrm{His}^{\circledR}$-BZI-1 durch die eingeschränkte Expression nach der Aufreinigung in einer geringen Konzentration vorlag, zeigte sich keine nachweisbare Bindefähigkeit an das cis-Element. Um zu testen, ob die verminderte Bindung durch die geringe bakterielle Expression des His ${ }^{\circledR}$-BZI-1 begründet war, wurde zur Kontrolle in vitro- 
translatiertes BZI-1 für die Bindestudie eingesetzt. Für das BZI-1-in vitro-Translatat konnte ebenfalls keine DNA-Bindung nachgewiesen werden. Die Abbildung D-10 zeigt, dass die Deletionsderivate mit den Deletionen der Domänen $\mathrm{N}$ und 1 das cis-Element gut binden. Durch die relativ große Menge eingesetzten Proteins zeigt sich auch in dieser Gelretardationsanalyse der zweite, oben beschriebene, stärker retardierte Komplex. Das rekombinant hergestellte $\mathrm{His}^{\circledR}-\mathrm{BZI}-1-\Delta \mathrm{N} \Delta \mathrm{BD}$ ist nicht in der Lage an DNA-zu binden. Mit Hilfe dieser Deletionsstudien lässt sich die DNA-Bindefähigkeit des BZI-1-Proteins auf die basische Domäne zurückführen. Durch die Deletion von 21 Aminosäuren im Bereich von 256-277 Aminosäuren des BZI-1 wird somit die DNA-Bindeeigenschaft des Transkriptionsfaktors unterbunden. 


\section{3 | Phosphorylierungsstudie des BZI-1 Transkriptionsfaktors}

Das BZI-1- $\Delta$ N-Derivat wird in vitro durch einen Extrakt elicitierter Sojabohnenzellen phosphoryliet. Die detektierte Phosphorylierung ist Serin-spezifisch. Durch Infektion mit dem avirulenten Pseudomonasstamm P. syringae pv. glycinea ist diese schnelle, transiente Phosphorylierung nach $2 \mathrm{~h}$ nachweisbar (DRÖGE-LASER et al., 1997). Es stellten sich die Fragen, ob BZI-1 im homologen Tabaksystem ebenfalls phosphoryliert wird und in welchen Domänen des Proteins die Serin-spezifische Phosphorylierung erfolgt. Hierfür wurden im ersten Schritt Tabaksuspensionskulturen mit dem avirulenten Stamm Pseudomonas syringae pv. pisi induziert und in einem in vitro-Kinase-Assay die Aktivität der Extrakte zu unterschiedlichen Zeitpunkten nach Induktion getestet. Des Weiteren wurden, um in vivo Phosphorylierungsereignisse zu detektieren, Inokulationen mit den Pseudomonaden am Blattgewebe vorgenommen und wie oben beschrieben die Kinaseaktivität ermittelt. Außerdem wurde die Phosphorylierung mit Hilfe spezifischer Proteasen grob kartiert, so dass eine Eingrenzung auf die spezifischen Domänen erfolgen konnte.

\section{3| 1 Phosphorylierung von BZI-1 nach Pathogenstimulus}

Die Phosphorylierung als posttranslationale Modifikation ist ein weit verbreiteter Mechanismus der Signalverarbeitung und -weiterleitung. Um die Phosphorylierung des Transkriptionsfaktors nachzuweisen, wurde ein in vitro-Kinaseassay verwendet. Dafür wurden native Proteinextrakte hergestellt, deren Kinaseaktivität getestet werden sollte. Die Ansätze wurden mit rekombinant hergestelltem His ${ }^{\circledR}-\mathrm{BZI}-1-\Delta \mathrm{N}$ Protein inkubiert. Nur für die spätere Kartierung wurde zusätzlich His ${ }^{\circledR}$-BZI- 1- $\Delta \mathrm{N} \Delta \mathrm{BD}$ verwendet. Unter Anwesenheit von radioaktivem $\gamma$ - $\mathrm{P}^{32}$-ATP kann das markierte Phospat nun durch eine aktive Kinase aus dem Extrakt auf das rekombinante Protein übertragen werden. Es erfolgten auch zusätzliche Versuche mit unterschiedlichen Stimuli. So konnte durch Licht- oder AuxinInduktion keine Phosphorylierung des BZI-1 Proteins durch die Extrakte nachgewiesen werden (Daten nicht gezeigt). Nach Zugabe eines Pathogenstimulus hingegen war eine Phosphorylierung nachweisbar.

Zur Untersuchung der Kinaseaktivität in Tabak-Suspensionskulturen wurden Suspensionskulturen des Pflanzenkultivars Xanthi verwendet. Die Induktion der Suspensionskulturen erfolgte durch den avirulenten Bakterienstamm P. syringae pv. pisi. 
Die erfolgreiche Induktion der Pflanzenantwort wurde durch einen Northern Blot und die Expression des Pflanzenabwehrgens EAS4 überprüft (Abbildung D-11).

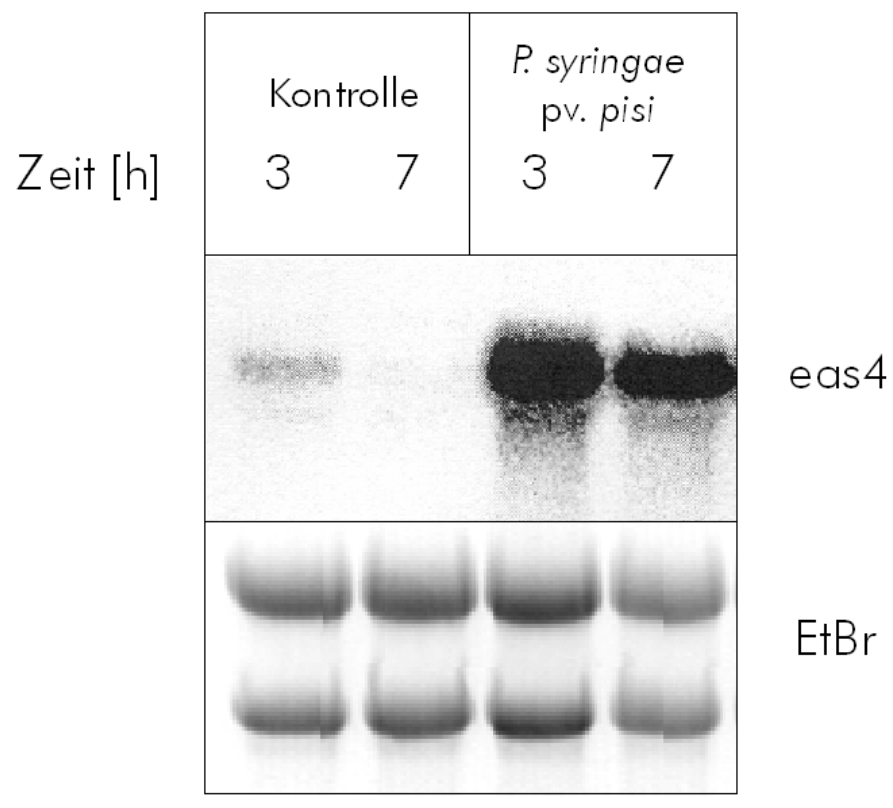

Abb. D-1 1: Nachweis der ausgelösten Pathogenantwort in P. syringae pv. pisi infizierten Suspensionskulturen Northern Blot-Analyse der Sesquiterpencyclase-Expression nach Pathogen-Induktion. Aufgetragen wurde $8 \mu \mathrm{g}$ RNA von Suspensionskulturen. Die Probentnahme erfolgte 3 und 7 Stunden nach Induktion. Induktion mit Kontrolle : steriles Leitungswasser; $P$. syringae pv. pisi : $5 \times 10^{7}$ cfu. Sonde: eas4 :Sesquiterpencyclase. Zur Kontrolle sind die Ethidiumbromid-gefärbten RNA-präparationen ( $\mathrm{E}+\mathrm{Br}$ ) abgebildet.

Die Ansätze wurden im Dunklen inkubiert. Die Extrakte wurden anschließend mit dem rekombinanten Protein BZI-1- $\Delta \mathrm{N}$ inkubiert und analysiert. Abbildung D-12 zeigt die transiente radioaktive Markierung des rekombinanten Proteins nach der Infektion.

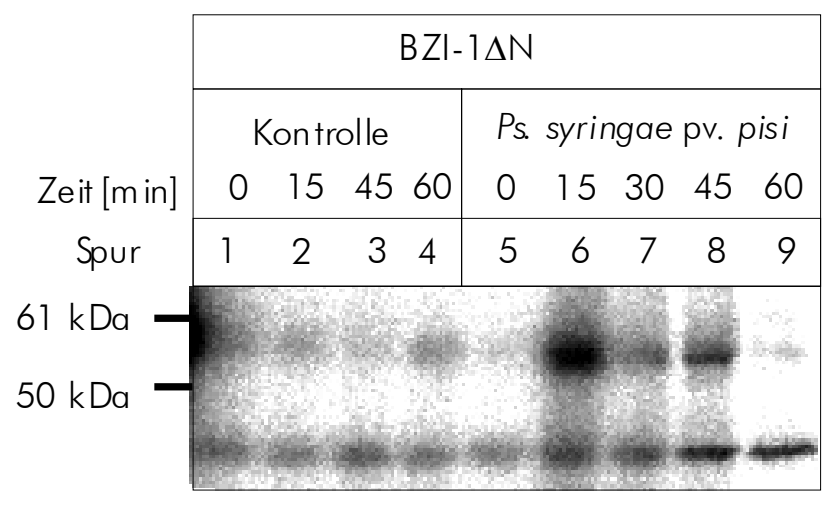

Abb. D - 12: in vitro-Phosphorylierung von $\mathrm{His}^{\circledR} \mathrm{BZI}-1-\Delta \mathrm{N}$ durch Extrakte von Ps. syringae pv. pisi infizierten Suspensionskulturen

Kinase-Assay von infizierten Suspensionskulturextrakten mit His ${ }^{\circledR} \mathrm{BZI}-1-\Delta \mathrm{N}$-Protein gelelektrophoretisch über ein $8 \%$ PAGE-Gel aufgetrennt. Die Proben zeigen die Kinaseaktivität 0, 15, 30, 45 und 60 Minuten nach der Zugabe der Bakterien/Kontroll-Extrakte. Pro Spur wurde $1 \mu \mathrm{g} \mathrm{His}{ }^{\circledR} \mathrm{BZI}-1-\Delta \mathrm{N}$ als Phosphorylierungssubstrat eingesetzt. Der Größenstandard in kDa-Kilodalton ist am linken Bildrand abgebildet. 
Unterhalb der 50 kDa-Markerbande ist eine radioaktiv markierte Bande sichtbar, die in sämtlichen Spuren auftritt. Hierbei handelt es sich vermutlich um ein pathogen- und substratunabhängiges Phosphorylierungsereignis der Extrakte, da sie in allen Spuren in unveränderter Stärke bestehen bleibt und auch nicht mit der Zugabe des rekombinanten Proteins korrelliert. 15 Minuten nach der Induktion zeigt sich ein starker Anstieg der Kinaseaktivität in den Extrakten. Die detektierte Bande besitzt, verglichen mit dem Marker, eine Größe von ca. 58 kDa. Sie entspricht damit der Größe des eingesetzten rekombinanten Proteins. Das BZI-1-Protein wird somit transient innerhalb von ca. 15 - 45 Minuten nach Infektion posttranslational durch eine Phosphorylierung modifiziert. Diese Phosphorylierung konnte durch andere Stimuli wie UV-Bestrahlung (3 min Transilluminator), Hitze $\left(3 \mathrm{~min}, 37^{\circ} \mathrm{C}\right)$ oder Elicitierung durch hairpin $(1,2 \mathrm{M})$ nicht gezeigt werden. Eine Kontrolle der Kinaseaktivität des Bakterienstammes zeigte ebenfalls keine Kinaseaktivität (Daten nicht gezeigt).

Um die in planta-Kinaseaktivität zu testen, wurde das Experiment am Blattgewebe von Ganzpflanzen in Erdkultur wiederholt. In dem Blattgewebe war ein entsprechendes Phosphorylierungsereignis nachweisbar. Die transiente Kinaseaktivität war im gleichen Zeitraum von 15 - 45 Minuten nach Infektion detektierbar.

\section{3|2 Zuweisung der Phosphorylierungsstellen zu den BZI-1-Proteindomänen}

Durch eine Zuweisung der Phosphorylierungsstelle zu einer BZI-1-Proteindomäne ergibt sich möglicherweise ein neuer Hinweis auf die Funktion des Proteins. Deshalb wird die, im oben beschriebenen etablierten Suspensionskultursystem nachweisbare Phosphorylierung im Protein kartiert. Da für das BZI-1- $\Delta \mathrm{N}$ durch ein in vivo-labeling mit anschließender Hydrolyse bekannt war, dass die Phosphorylierung Serin-spezifisch ist (DRÖGE-LASER et al., 1997), konnten die weiteren Analysen auf die im Protein liegenden Serine eingegrenzt werden. Insgesamt kommen im 450 AS-großen BZI-1 58 Serine vor.

\begin{tabular}{l|l} 
BZI-1 Domänen & Anzahl Serine \\
\hline Domäne N & 11 \\
Domäne 1 und 2 & 28 \\
basische Domäne & 7 \\
Domäne 4 & 3 \\
restliche Bereiche & 9 \\
\hline Gesamt & 58
\end{tabular}

Tabelle D - 1: Überblick über die Serin-Verteilung innerhalb der BZI-1-Proteindomänen. 
Zur Übersicht ist die Verteilung der Serine auf die Proteindomänen in der Tabelle D-1 aufgeführt. Durch in silico-Analysen (NetPhos 2.0) konnte im mittleren Bereich der Domäne 2 die Aminosäuresequenz SDDD als typische Caseinkinase-Erkennungsstelle identifiziert werden. Diese in silico-Analyse sagte eine Erkennung durch die Kinase mit einer statistischen Wahrscheinlichkeit von 99\% aufgrund der umgebenden Aminosäuren voraus. Im Bereich der basischen Domäne konnte für das Serin in der Sequenz NRESARR ebenfalls eine statistische Kinase-Erkennungswahrscheinlichkeit von 99\% ermittelt werden. Zur Grobkartierung der Phosphorylierungsstellen wurde der oben beschriebene KinaseAssay mit einer in Vorversuchen positiv getesteten Probe (45 min nach Infektion einer Suspensionskultur) im dreifachen Ansatz durchgeführt. Als Substrat dienten jeweils das $\mathrm{His}^{\circledR}-\Delta \mathrm{N}-\mathrm{BZI}-1$-Protein und das His ${ }^{\circledR}-\Delta \mathrm{N} \Delta \mathrm{BD}-\mathrm{BZI}-1$-Protein. Für die Kartierung wurde das Protein $\mathrm{His}^{\circledR}-\Delta \mathrm{N}-\mathrm{BZI}-1$ zunächst mit Cyanbromid und danach mit Ameisensäure beziehungsweise der Endoproteinase V8 verdaut. Es ergaben sich durch die Cyanbromidspaltung zwei radioaktiv markierte Banden, die separat voneinander durch die Ameisensäure- und V8-Spaltung weiteranalysiert wurden. Das $\mathrm{His}^{\circledR}-\Delta \mathrm{N} \Delta \mathrm{BD}-\mathrm{BZI}-1$ Protein wurde zum direkten Vergleich mit dem $\mathrm{His}^{\circledR}-\Delta \mathrm{N}-\mathrm{BZI}-1$ ausschließlich mit Cyanbromid (CNBr) gespalten.

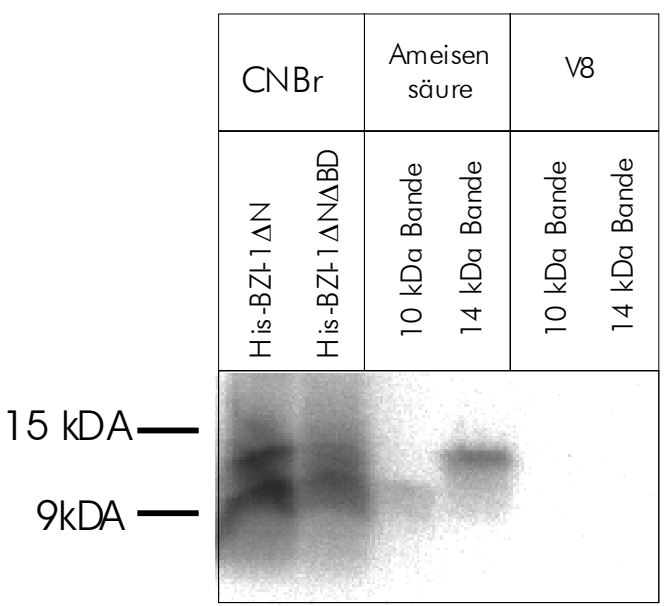

Abb. D - 13 Kartierung der Phosphorylierungsstellen.

Spaltung der phosphorylierten $\mathrm{His}^{\circledR}-\mathrm{BZI}-1-\Delta \mathrm{N}$ und $\mathrm{His}^{\circledR}{ }^{\circledR}-\mathrm{BZI}-1-\Delta \mathrm{N} \Delta \mathrm{BD}$-Proteine mit Cyanbromid (CNBr), der einzelnen $\mathrm{His}^{\circledR}$-BZI-1- $\Delta \mathrm{N}$-Fragmente mit Cyanbromid und Ameisensäure (Ameisensäure) und Cyanbromid und V8-Endoproteinase (V8). Übersicht über die entstehenden Fragmente und Zuordnung der Fragmente zu den Proteindomänen. N-N-term. Domäne, I- Domäne 1, I-Domäne 2, Bas.-basische Domäne, IIla+b-Domäne 3 und IV-Domäne 4. AS-Anzahl Aminosäuren. Die Scheren versinnbildlichen das Zerlegen der Fragmente. P-mögliche Phosphorylierungsstellen (groß: statistisch >95\% Wahrscheinlichkeit der Phosphorylierung). 
Abbildung D-13 zeigt das komplexe Spaltungsmuster nach dem proteolytischen Verdau. Es ergeben sich nach der CNBr-Behandlung zwei Banden, in den Größen von ca. 10 und 14 kDa. Dies weist erstmals auf mindestens zwei unterschiedliche Phosphorylierungsereignisse hin.

Da das Cyanbromid Proteine spezifisch hinter jedem Methionin schneidet, ergeben sich 11 unterschiedlich große Fragmente des His ${ }^{\circledR}-\Delta \mathrm{N}$-BZI-1-Proteins (zur Übersicht Abbildung D-14).

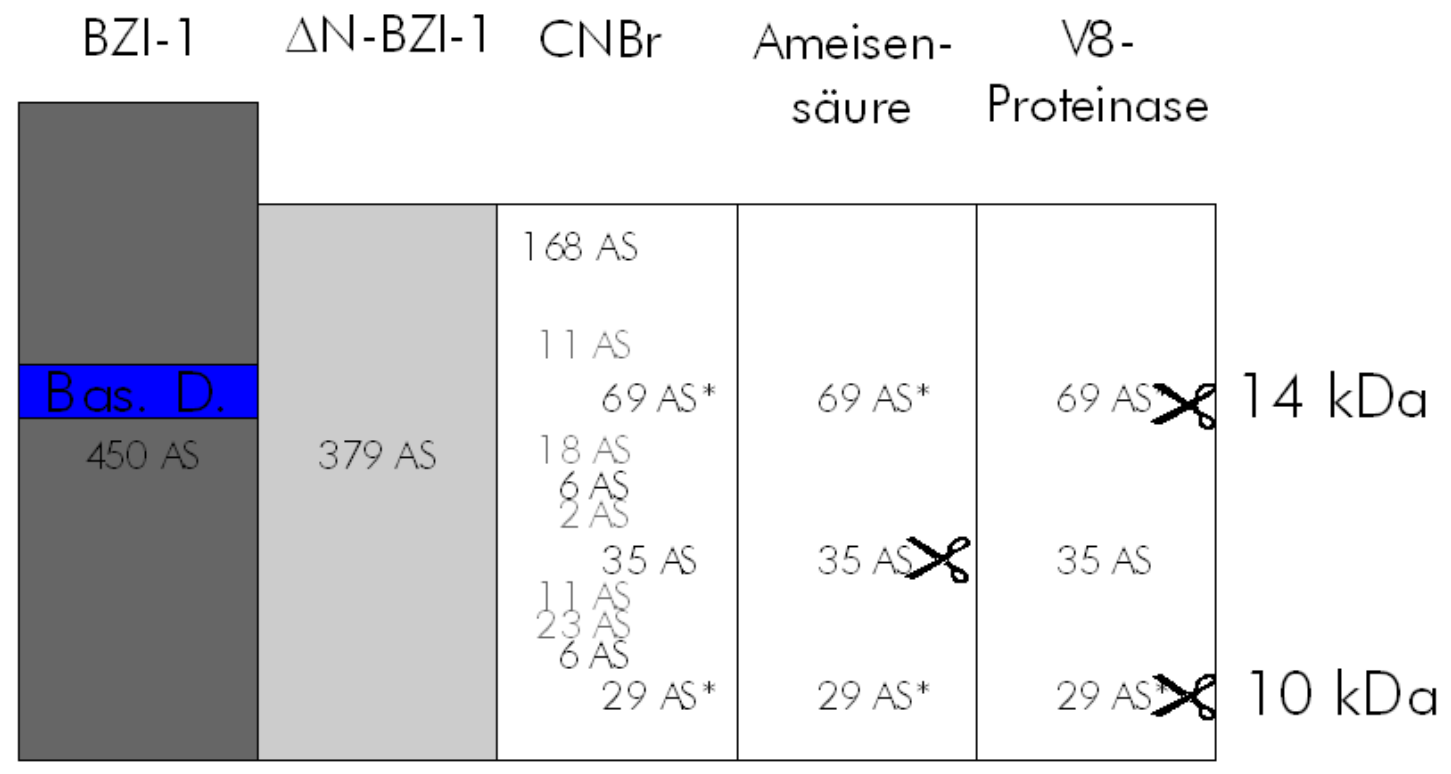

Abb. D - 14: Proteolytisch entstehende BZI-1-Fragmente.

Spaltung der phosphorylierten His ${ }^{\circledR}$-BZI-1- $\Delta$-Proteine mit Cyanbromid (CNBr), der einzelnen Fragmente mit Cyanbromid und Ameisensäure (Ameisensäure) und Cyanbromid und V8-Endoproteinase (V8). Übersicht über die entstehenden Fragmente nach der Cyanbromid- (CNBr-), Ameisensäure- und V8-Spaltung. AS-Anzahl Aminosäuren. Die Scheren versinnbildlichen das Zerlegen der Fragmente. BZI-1: N.t.BZI-1, Bas. D.: basische Domäne, N: Domäne N, $\Delta$ : Deletion.

Der C-terminale Teil der basischen Domäne wird duch den CNBr-Verdau in ein 69 ASgroßes Fragment zerteilt. Dies entspricht einer Größe von umgerechnet ca. 14 kDa und findet sich im Gel in der oberen Bande wieder. Dies weist auf eine Phosphorylierung in dem Bereich der basischen Domäne hin. Diese Bande ist im phosphorylierten und gespaltenen $\mathrm{His}^{\circledR}-\Delta \mathrm{N} \Delta \mathrm{BD}$-BZI-1-Protein nicht nachweisbar. Daraus kann man auf eine Phosphorylierung von einem der 5 Serine in der DNA-Binderegion oder Kernlokalisierungssequenz schließen.

Im C-terminale Teil des Proteins lässt sich das zweite Phosphorylierungsereignis auf das 29 AS-große Fragment aus der Domäne 4 begrenzen. Das durch die Cyanbromidbehandlung entstehende 10 kDa Peptid lässt sich durch die folgenden Spaltungen als 29 AS-großes 
Fragment identifizieren. Durch den Verdau mit der Ameisensäure, die spezifisch zwischen den Aminosäuren Asparaginsäure und Prolin (D-P) schneidet, wird das 10 kDa markierte Fragment nicht beeinflusst. Da das 35 AS-große Fragment jedoch durch die Ameisensäurebehandlung zerlegt wird, entspricht das radioaktiv markierte $10 \mathrm{kDa}$ Fragment dem 29 AS-großen Bereich, welcher einen Teil der Domäne 4 beinhaltet. Durch die Spaltung mit der V8-Proteinase (E-X-spezifische Spaltung) sind die markierten Peptide nicht mehr nachweisbar. Aufgrund der Glutaminsäuren in den Peptiden des 69 ASFragmentes und des 29 AS-Fragmentes werden diese in nicht mehr nachweisbare Bruchstücke zerlegt. (Das 35 AS große Fragment enthält keine Glutaminsäure.) Diese Spaltung weist ebenso darauf hin, dass es sich bei der unteren Bande um das 29 AS große Fragment handelt. Die Abbildung D-14 zeigt eine Übersicht der entstehenden Proteinfragmente. Die Lage der Phosphorylierungsstellen innerhalb des BZI-1 Proteins wird durch Abbildung D-15 verdeutlicht.

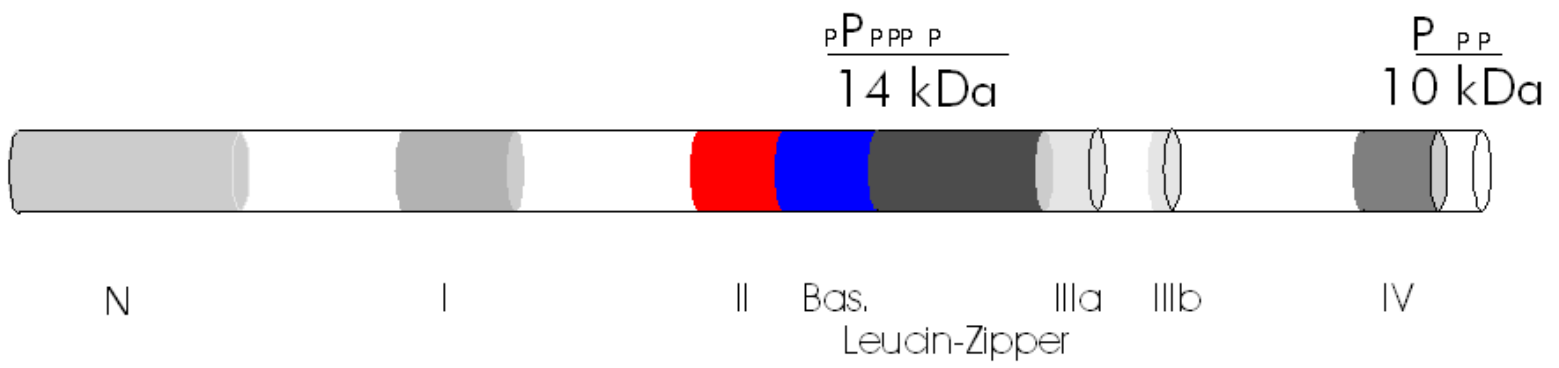

Abb. D - 15: Lage der Phosphorylierungsstellen im BZI-1-Protein.

Zuordnung der Fragmente zu den Proteindomänen. N-N-term. Domäne, I- Domäne 1, II-Domäne 2, Bas.-basische Domäne, Illa+b-Domäne 3 und IV-Domäne 4. kDa-Molekulargewicht der Peptide. P-mögliche Phosphorylierungsstellen (groß: statistisch >95\% Wahrscheinlichkeit der Phosphorylierung).

In diesem Bereich der Domäne 4 liegen 3 potentiell phosphorylierbare Serine. Dem ersten Serin in diesem Bereich (QRVASLEHL) wird in silico die statistische Wahrscheinlichkeit einer Erkennung durch eine Kinase von 98\% (NetPhos 2.0) zugeschrieben.

Die Ergebnisse zeigen, dass mindestens zwei pathogeninduzierte Phosphorylierungsereignisse im Bereich der basischen Domäne/Leucin-Zippers und im C-terminalen Bereich der Domäne 4 stattfinden. 


\section{4 | Funktion der konservierten Domänen bei der zellulären Lokalisierung von}

\section{BZI- 1}

Im Bereich des Kerntransportes wurde für den homologen Faktor CPRF-2 aus Petroselinum crispum ein Phytochrom-abhängiges Modell entwickelt (KIRCHER et al., 1999). In der vorliegenden Arbeit soll die Lokalisierung des Trankriptionsfaktors BZI-1 auf der zellulären Ebene detektiert werden. Den hierfür wichtigen Domänen soll die Funktion von Erkennungssequenzen für den Import oder einer Retention zugewiesen werden. Hierfür wurden BZI-1-GFP-Fusionen hergestellt, deren Lokalisierung im transienten Expressionssystem untersucht wurde. Aufgrund der großen Anzahl der zu testenden Konstrukte war es nicht praktikabel transgene Pflanzen herzustellen. Als Kontrolle wurden cytoplasmatische, kernlokalisierte und gleichverteilte, aus der Literatur bekannte ProteinGFP-Fusionen verwandt (HAASEN et al., 1999). Zur besseren Detektion und Unterscheidbarkeit der Autofluoreszenz phenolischer Substanzen wurde das eGFP verwendet. Das eGFP besitzt den Vorteil einer Verschiebung des Anregungsbereiches nach $488 \mathrm{~nm}$ und eine verstärkte Intensität und verminderte Ausbleichung gegenüber dem GFP. Durch die veränderte Anregungswellenlänge wird die Autofluoreszenz der phenolischen Substanzen in den Protoplasten verringert. Zudem konnte durch die verstärkte Fluoreszenz die Überstrahlung durch die Chloroplastenfluoreszenz aus dem Rotbereich vermindet werden.

\section{4|1 Konstruktion der GFP-Fusionsderivate}

Zur Analyse der Lokalisierung wurden die in Abbildung D-16 aufgeführten Konstrukte hergestellt. Die transiente Expression der Fusionsproteine stand unter Kontrolle des CaMV35S-Promotors. Das GFP wurde zur Kontrolle als gleichverteiltes Protein ohne besondere Lokalisierungssequenz gewählt. Das eGFP-Protein besteht aus 260 Aminosäuren $\cong 27$ kDa). Das GFP liegt somit unterhalb der Kernporenausschlussgröße von ca. 60 kDa und kann sich ungehindert in der Zelle verteilen (HAASEN et al., 1999). Als Beispiel eines cytosolisch lokalisierten Proteins wurde RanBPla aus der Ackerschmalwand (Arabidopsis thaliana) gewählt. Es besitzt eine Kernexportsequenz (NES-Nuclear export sequence) und zeigt fusioniert an das GFP eine strikte Lokalisierung im Cytoplasma (HAASEN et al., 1999). Mit 494 Aminosäuren und einer Größe von 52 kDa liegt es unterhalb der Kernporenausschlussgröße. Ein Kontrollkonstrukt der BZI-1-vergleichbaren Größe stellt das CHS-GFP dar. Es besitzt keine lokalisierende Sequenz und liegt gleichverteilt in den 
beiden Kompartimenten vor (HAASEN et al., 1999). Als weiteres Kontrollkonstrukt mit der vergleichbaren Größe und rein cytoplasmatischer Lokalisierung wurde das GFP$\mathrm{CHS}(+\mathrm{NES})$ gewählt. Dieses enthält das in der Größe vergleichbare CHS-Protein in Cterminaler Fusion an dem GFP mit zusätzlich angehängter Kernexportsequenz des HIV-1 Proteins Rev. Das 488 Aminosäuren große Kontrollkonstrukt zeigt ebenfalls eine rein cytosolische Lokalisierung (HAASEN et al., 1999). Die verwendeten Kontrollkonstrukte sind in Abbildung D-16 schematisch aufgeführt.

\author{
GFP $\quad: 260 \mathrm{AS}$ \\ RanBPla : 234 AS \\ CHS $\quad: 477$ AS \\ CHS+NES : 488 AS
}

$\begin{array}{ll}\mathrm{BD} 1 & : 452 \mathrm{AS} \\ \Delta \mathrm{N} & : 380 \mathrm{AS} \\ \Delta \mathrm{D} 1 & : 399 \mathrm{AS} \\ \Delta \mathrm{N} \Delta \mathrm{DD} 1 & : 327 \mathrm{AS} \\ \Delta \mathrm{D} 2 & : 436 \mathrm{AS} \\ \triangle \mathrm{N} \triangle \mathrm{D} 2 & : 364 \mathrm{AS} \\ \triangle \mathrm{BD} & : 431 \mathrm{AS} \\ \triangle \mathrm{N} \triangle \mathrm{BD} & : 359 \mathrm{AS} \\ \mathrm{N1} 2 & : 243 \mathrm{AS}\end{array}$
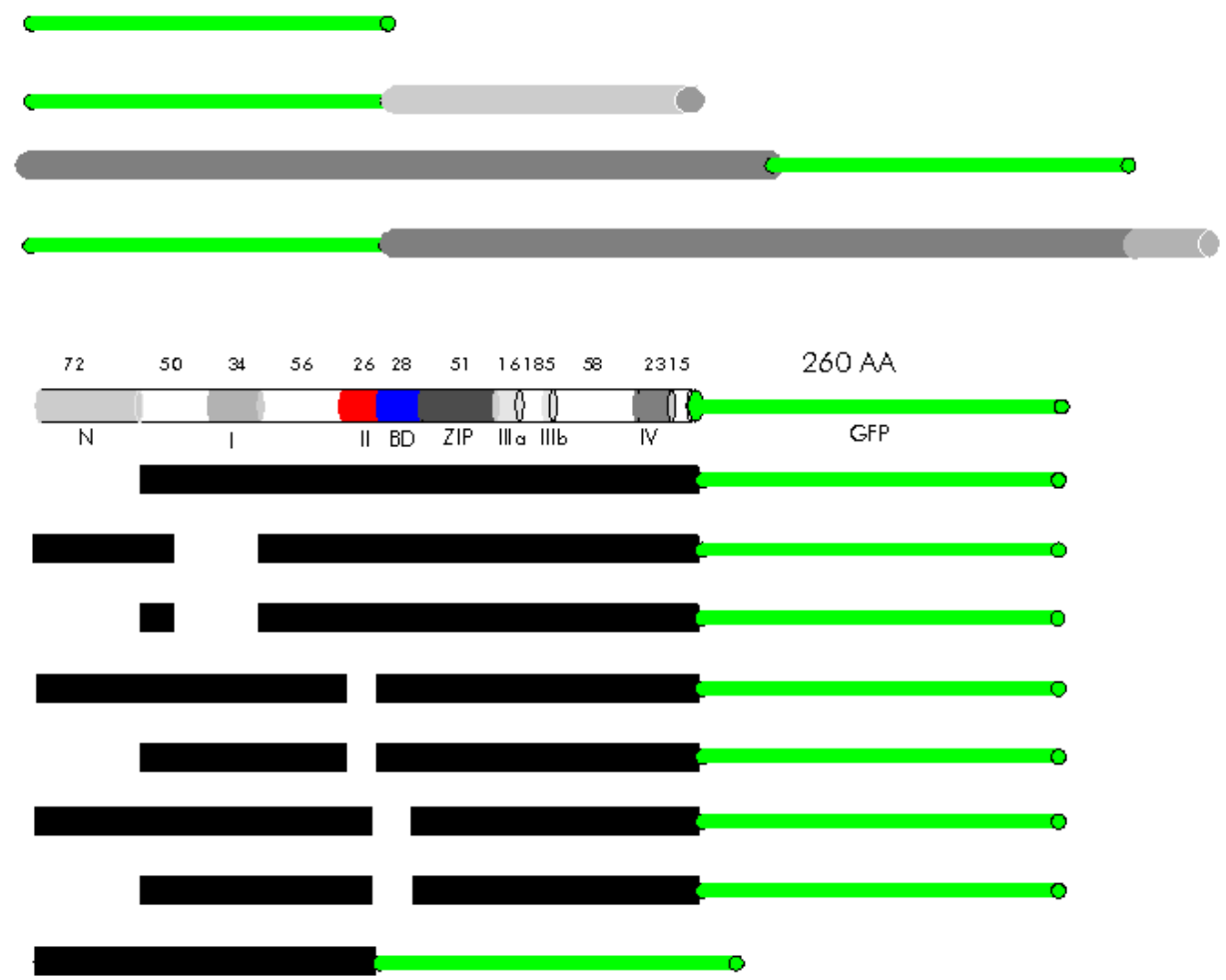

Abb. D - 16: Größen der konstruierten BZI1-GFP-Fusionen und Kontrollen.

Die Abbildung zeigt die Kontrollkonstrukte und die Deletionsderivate, fusioniert an das GFP-Protein in den relativen Größen. Die Zahlen hinter den Bezeichnungen geben die Größe der Proteine (ohne fusioniertes GFP) in Aminosäuren an (AA). Domänen des BZI-1 :N: Domäne N, I: Domäne 1, II: Domäne 2, Bas.: basische Domäne, Illa+b: Domäne 3 und IV: Domäne 4, $\Delta$ : Deletion. BZI-1: N.t.BZI-1, GFP: Grün fluoreszierendes Protein, RanBP1a: A.t.RanBP1a, CHS: N.t. Chalkonsynthase, NES: Nuclear-export-sequence von HIV-Rev. Die schwarzen Balken symbolisieren die noch vorhandenen Bereiche des BZI-1. 
Die im Folgenden beschrieben Konstrukte stellen die zur Analyse verwandten BZI-1Konstrukte dar, die in der Übersicht Abbildung D-16 zu entnehmen sind. Die Tabelle D-2 zeigt die Größen der Fusionsproteine mit den entsprechenden Molekulargewichten.

\begin{tabular}{|c|c|c|c|}
\hline Konstrukt & $\begin{array}{c}\text { Größe } \\
\text { [Aminosäuren] }\end{array}$ & $\begin{array}{c}\text { Molekulargewicht } \\
{[\mathrm{kDa}]}\end{array}$ & $\begin{array}{l}\text { deletierter Bereich } \\
\text { [Pos. AS-Sequenz] }\end{array}$ \\
\hline BZI-1-GFP & 712 & 75,6 & - \\
\hline BZI-1- $\Delta$ N-GFP & 640 & 68 & $1-72$ \\
\hline BZI-1- $\Delta \mathrm{D} 1$-GFP & 659 & 70 & $111-164$ \\
\hline BZI-1- $\Delta \mathrm{N} \Delta \mathrm{D} 1$-GFP & 587 & 62,5 & $1-72,111-164$ \\
\hline BZI-1-DD2-GFP & 728 & 74 & $235-251$ \\
\hline BZI-1- $\Delta \mathrm{N} \Delta \mathrm{D} 2-\mathrm{GFP}$ & 624 & 66 & $1-72,235-251$ \\
\hline BZI-1- $\triangle B D-G F P$ & 691 & 72,6 & $253-274$ \\
\hline BZI-1- $\Delta \mathrm{N} \Delta \mathrm{BD}-\mathrm{GFP}$ & 619 & 65 & $1-72,253-274$ \\
\hline N-1-2-GFP & 503 & 52,4 & $253-465$ \\
\hline
\end{tabular}

Tab. D - 2: Übersicht über die Größen und Molekularmassen der BZI-1-GFP-Fusionsproteine.

Die Konstrukte bezeichnen die C-terminalen GFP-Fusionen an die BZI-1-Derivate. Die Angabe der Größe erfolgt in [Aminosäuren]; die der Molekulargewichte in errechneten Kilodalton $[\mathrm{kDa}]$. Als deletierter Bereich werden die eingefügten Deletionen mit der Position in der Aminosäuresequenz angegeben. Bei Doppelmutanten entsprechend zwei Stellen.

Durch eine in silico-Analyse zeigte sich eine putative Kernlokalisierungssequenz im Bereich der basischen Domäne (AS 258-272).

\section{$4 \mid 2$ Zelluläre Verteilung der GFP-Fusionsproteine}

Die Verteilung der GFP-Fusionsproteine in den Tabakmesophyll-Protoplasten wurde mit Hilfe des Fluoreszenzmikroskops und eines konfokalen Laserscanning-Mikroskopes detektiert und aufgezeichnet. Die Überlagerung und Verrechnung der Bilder erfolgte durch das Programm ZLS 510 release 2.01. Die Aufnahmen sind zusammengesetzt aus:

1. der bei $488 \mathrm{~nm}$ im Fluoreszenzbereich angeregten und bei 505 - $550 \mathrm{~nm}$ detektierten Fluoreszenz;

2. der bei $560 \mathrm{~nm}$ detektierten Fluoreszenz;

3. der Durchlichtaufnahme und

4. der Überlagerung.

Zum Größenvergleich ist in jeder Abbildung ein $10 \mu \mathrm{m}$ Maßstab eingefügt. 


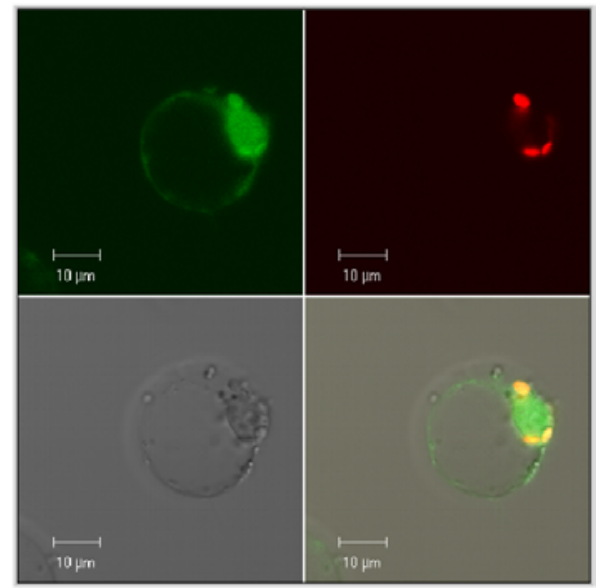

Abb. D - 17: Verteilung des Grün-Fluoreszierenden-Proteins in Protoplasten.

LSM (Laserścanning-mikroskopische)-Aufnahme von Mesophyll-Protoplasten mit GFP (Grün-fluoreszierendes Protein). links oben: 488 nm Anregung / 505-550 nm Detektion; rechts oben: 560 nm Detektion; links unten: Durchlicht; rechts unten: Überlagerung; Größenmaßstab: $10 \mu \mathrm{m}$.

In der Abbildung 17 zeigt sich die relative Gleichverteilung des GFP-Proteins in den Tabak-Mesophyll-Protoplasten.

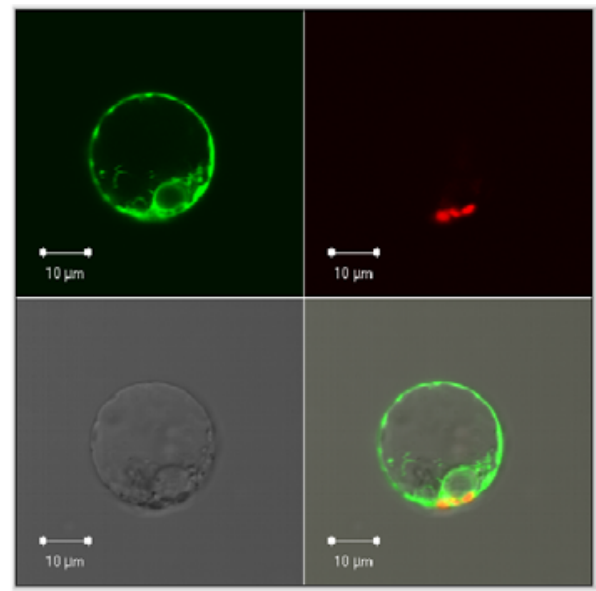

Abb. D - 18: Verteilung des RanBP1a-GFP in Protoplasten.

LSM-Aufnahme von Mesophyll-Protoplasten mit N-terminaler Fusion des GFPan des RanBindeprotein la. links oben: 488 $\mathrm{nm}$ Anregung / 505-550 nm Detektion; rechts oben: 560 nm Detektion; links unten: Durchlicht; rechts unten: Überlagerung; Größenmaßstab: $10 \mu \mathrm{m}$.

In der Abbildung D-18 wird die exklusive Verteilung des RanBPla-GFP-Proteins im Cytoplasma deutlich. Das Konstrukt CHS+NES-GFP zeigt die gleiche cytosolische Verteilung und wird nicht gesondert abgebildet. 


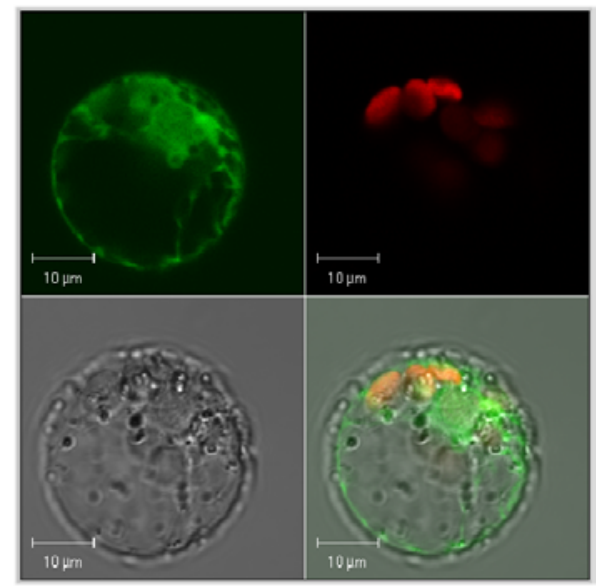

Abb. D - 19: Verteilung des CHS-GFP in Protoplasten.

LSM-Aufnahme von Mesophyll-Protoplasten mit Fusion des GFP an den C-Terminus der Chalkonsynthase (CHS). links oben: 488 nm Anregung / 505-550 nm Detektion; rechts oben: 560 nm Detektion; links unten: Durchlicht; rechts unten: Überlagerung; Größenmaßstab: $10 \mu \mathrm{m}$.

Wie aus der Abbildung D-19 hervorgeht, ist die an das GFP-fusionierte Chalkonsynthase unreguliert, sowohl im Cytoplasma als auch im Kern verteilt. Unter den hier vorgegebenen Versuchsbedingungen mit den Tabakmesophyll-Protoplasten zeigte sich die kompartimentäre Gleichverteilung eines, der Größe des BZI-1 entsprechenden Proteins ohne Lokalisierungssequenzen. 
a Fluoreszenzmikroskopische Aufnahme:
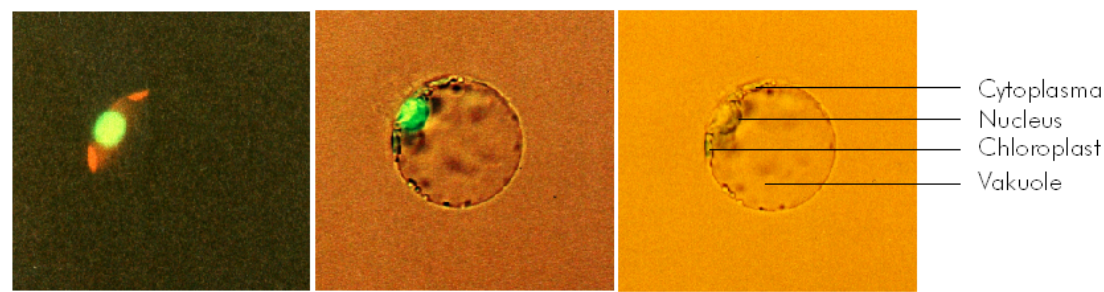

b LSM Aufnahmen :

C
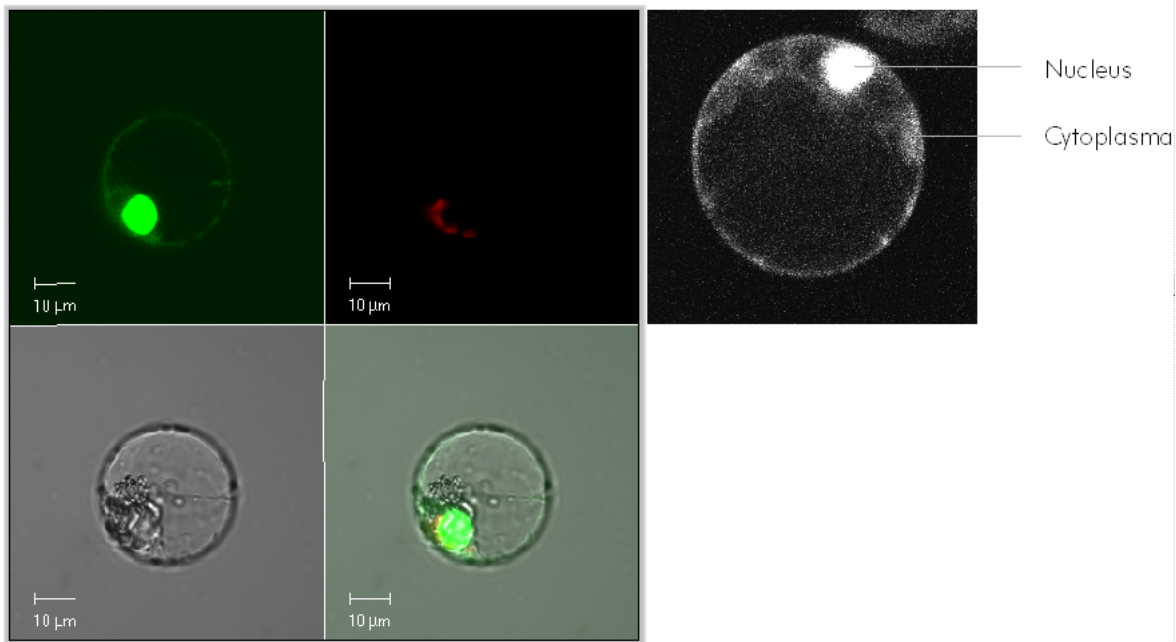

Abb. D - 20: Verteilung des BZI-1-GFP in Protoplasten.

Aufnahme von Mesophyll-Protoplasten mit C-terminaler Fusion des GFP an den Transkriptionsfaktor BZI-1.

a. Lichtmikroskopische Aufnahmen: links: 488 nm: Anregung / 550 nm Detektion, Dunkelfeld; Mitte: Anregung/Hellfeld, rechts: Hellfeld. b. konfokale Schichtaufnahme: S/W zur Quantifizierung c. konfokale LSM (Laserscanningmikroskop)Aufnahme: links oben: 488 nm Anregung / 505-550 nm Detektion; rechts oben: 560 nm Detektion; links unten: Durchlicht; rechts unten: Überlagerung; Größenmaßstab: $10 \mu \mathrm{m}$.

Abbildung D-20 zeigt die Lokalisierung der BZI-1-GFP-Fusion in den MesophyllProtoplasten. Durch lichtmikroskopische Aufnahmen (Abb. D-20 a) mit zusätzlich zuschaltbarer Fluoreszenzanregung wird die vorwiegende Verteilung des BZI-1Fusionsproteins im Kern deutlich. Da die Aussagekraft im Lichtmikroskop durch die geringe Lichtstärke sehr begrenzt ist und die Autofluoreszenz nur sehr schwer von der GFPFluoreszenz abzugrenzen war, wurden die weiteren Analysen am Laserscanning-Mikroskop durchgeführt. Abbildung D-20 b zeigt eine semi-quantitativ auswertbare Schichtaufnahme eines Protoplasten. Durch Quantifizierungen entsprechender Aufnahmen (TINA ${ }^{\circledR}$ ) konnte gezeigt werden, dass sich der Großteil des Fusionsproteins, etwa 80 \%, im Kern befinden. Das restliche Protein, ca. 20 \%, ist im Cytosol lokalisiert. Die mit den Kontrollkonstrukten vergleichbaren LSM-Aufnahmen sind in Abbildung D-20 c zu sehen. Es konnten durch Induktionsversuche mit Auxin (1 mM), Cryptogein (100 mM) und Licht (12 h) keine Veränderungen der Lokalisation des GFP-Fusionsproteins nachgewiesen werden. 


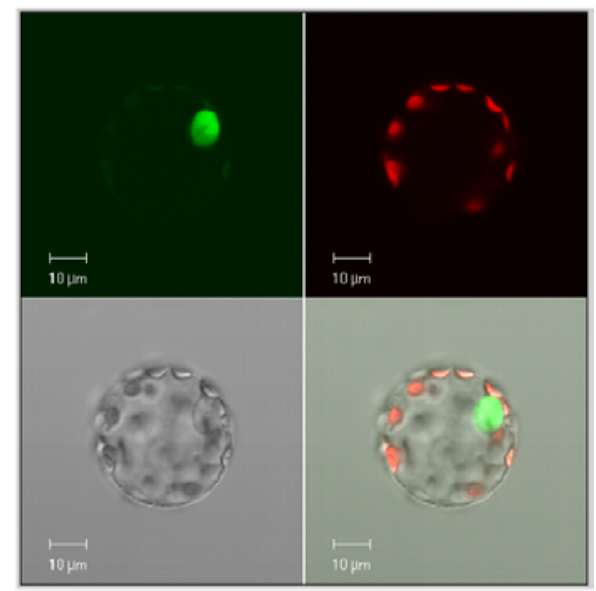

Abb. D - 21: Verteilung des BZI-1- $\triangle$ N-GFP in Protoplasten.

LSM-Aufnahme von Mesophyll-Protoplasten mit Fusion des GFP an das BZI-1 mit deletiertem N-Terminus. links oben: $488 \mathrm{~nm}$ Anregung / 505-550 nm Detektion; rechts oben: 560 nm Detektion; links unten: Durchlicht; rechts unten: Überlagerung; Größenmaßstab: $10 \mu \mathrm{m}$.

In der Abbildung D-21 ist die nukleäre Lokalisation des $\Delta \mathrm{N}$-BZI-1-Fusionsproteins zu erkennen. Durch die Deletion des N-Terminus beschränkt sich das Vorkommen des Fusionsproteins ausschließlich auf den Kern.

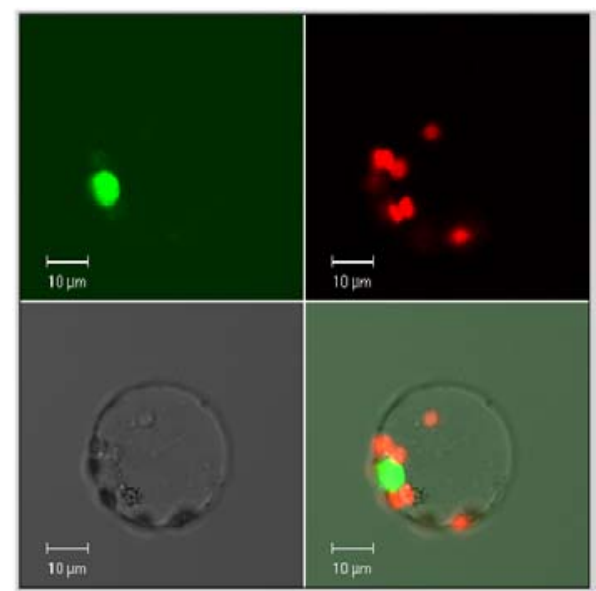

Abbildung D - 22: Verteilung des BZI-1- $\triangle$ D1-GFP in Protoplasten.

LSM-Aufnahme von Mesophyll-Protoplasten mit Fusion des GFP an das BZI-1 mit deletierter Domäne 1. links oben: 488 $\mathrm{nm}$ Anregung / 505-550 nm Detektion; rechts oben: $560 \mathrm{~nm}$ Detektion; links unten: Durchlicht; rechts unten: Überlagerung; Größenmaßstab: $10 \mu \mathrm{m}$.

In der oben aufgeführten Abbildung D-22 ist die Verteilung des $\Delta$ D1-BZI-1-GFP-Proteins im Kern erkennbar. Die von der GFP-Fusion ausgestrahlte Fluoreszenz beschränkt sich auf den Zellkern. Durch die Deletion der Domäne 1 wird die im kompletten Protein noch sichtbare Retention im Cytoplasma aufgehoben. Für die Doppeldeletionsmutante $\Delta \mathrm{N} \Delta \mathrm{D} 1$ BZI-1-GFP zeigte sich das gleiche Bild. 


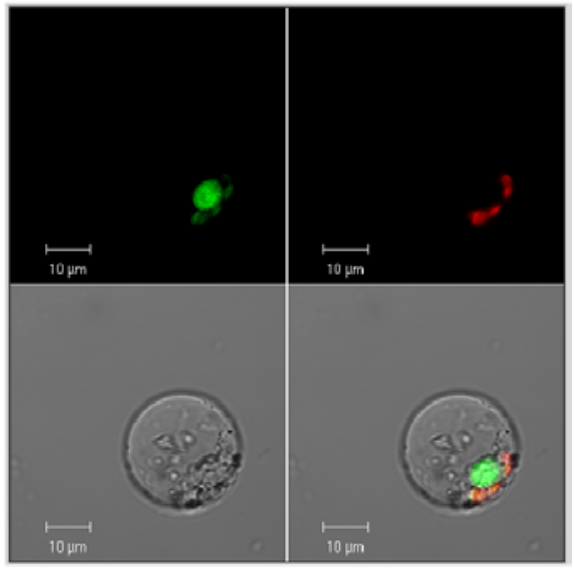

Abbildung D - 23: Verteilung des BZI-1- $\triangle$ D2-GFP in Protoplasten.

LSM-Aufnahme von Mesophyll-Protoplasten mit Fusion des GFP an das BZI-1 mit deletierter Domäne 2. links oben: 488 $\mathrm{nm}$ Anregung/505-550 nm Detektion; rechts oben: $560 \mathrm{~nm}$ Detektion; links unten: Durchlicht; rechts unten: Überlagerung; Größenmaßstab: $10 \mu \mathrm{m}$.

Die vom $\triangle \mathrm{D} 2$-BZI-1-GFP-Fusionsprotein ausgehende Fluoreszenz ist auch hier wieder, wie in den vorausgegangenen Deletionsderivaten rein auf den Kern beschränkt (Abbildung D-23). Die Doppeldeletionsmutante verhält sich auch hier, wie die jeweiligen Einfachmutanten. Die Domäne 2 besitzt somit eine Funktion im Rahmen der Translokation des kompletten Proteins.

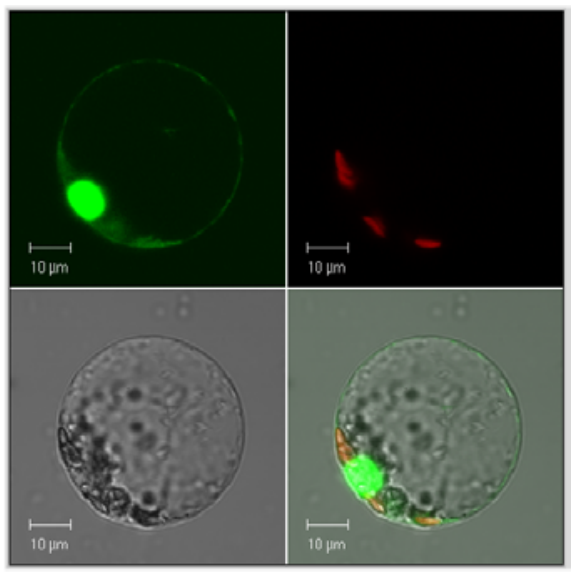

Abbildung D - 24: Verteilung des BZI-1- $\triangle$ BD-GFP in Protoplasten.

LSM-Aufnahme von Mesophyll-Protoplasten mit Fusion des GFP an das BZI-1 mit deletierter basischer Domäne. links oben: 488 nm Anregung / 505-550 nm Detektion; rechts oben: 560 nm Detektion; links unten: Durchlicht; rechts unten: Überlagerung; Größenmaßstab: $10 \mu \mathrm{m}$.

In Abbildung D-24 wird die Verteilung des $\triangle$ BD-BZI-1-GFP-Proteins erkennbar. Diese ist mit der Gleichverteilung des GFP (Abb. D-17) auf die Kompartimente vergleichbar. Aufgrund der Größe des Proteins von 72,6 kDa kann eine Diffusion in den Kern ausgeschlossen werden. Durch die Deletion der putativen Kernlokalisierungssequenz fehlt dem Protein die aktive Steverung in den Kern. Durch Dimerisierung mit anderen Faktoren 
ist es jedoch weiterhin möglich das Protein in den Kern zu schleppen. Damit ist der putativen Kernlokalisierungssequenz in der basischen Domäne die Funktion des Kerntransportes nachgewiesen. Die Doppeldeletionsmutante verhielt sich vergleichbar (ohne Abbildung).

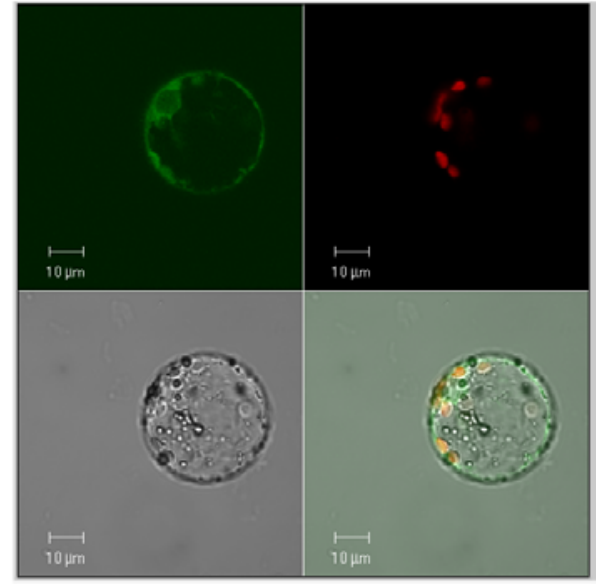

Abbildung D - 25: Verteilung des N-1-2-GFP in Protoplasten.

LSM-Aufnahme von Mesophyll-Protoplasten mit Fusion des GFP an den N-terminalen Bereich des BZI-1. links oben: 488 nm Anregung / 505-550 nm Detektion; rechts oben: 560 nm Detektion; links unten: Durchlicht; rechts unten: Überlagerung; Größenmaßstab: $10 \mu \mathrm{m}$.

Die Abbildung D-25 zeigt die cytosolische Verteilung des N-1-2-GFP-Proteins. Im Bereich des Nukleus zeigt sich eine abgeschwächte Fluoreszenz, vergleichbar mit der rein cytosolischen Verteilung des RanBPla-GFP-Proteins. Da aufgrund der Größe des N-1-2GFP-Proteins $(52,4 \mathrm{kDa})$ eine Diffusion in den Kern nicht ausgeschlossen ist, lässt sich durch dieses Konstrukt der N-terminalen Hälfte des Proteins die Funktion einer gesteuerten cytoplasmatischen Lokalisierung zuweisen. Diese kann auf einer Retention oder einem gesteverten Kernexport beruhen. In jedem Fall wird diese Lokalisierung durch eine Interaktion mit einem anderen Protein oder Proteinkomplex mit diesem Bereich des BZI-1Proteins gesteuert. 


\begin{tabular}{l|c|c} 
Fusionsprotein & Cytoplasma & Kern \\
\hline BZI-1-GFP & + - & + \\
\hline BZI-1- $\Delta$ N-GFP & - & ++ \\
\hline BZI-1- $\Delta$ D1-GFP & - & ++ \\
\hline BZI-1- $\Delta$ N $\Delta$ D1-GFP & - & ++ \\
\hline BZI-1- $\Delta$ D2-GFP & - & ++ \\
\hline BZI-1- $\Delta$ N $\Delta$ D2-GFP & - & ++ \\
\hline BZI-1- $\Delta$ BD-GFP & + & + \\
\hline BZI-1- $\Delta$ N $\Delta$ BD-GFP & + & + \\
\hline N-1-2-GFP & ++ & -
\end{tabular}

Tab. D-3: Zusammenfassung der Verteilung der Fusionsproteine in den Tabakmesophyll-Protoplasten Tabellarische Übersicht über die Verteilung; -: kein Vorkommen, +/-: geringes Vorkommen, +: Vorkommen, ++: starkes bis ausschließliches Vorkommen.

Wie der Zusammenfassung in Tabelle D-3 zu entnehmen ist, lässt sich der NLS im Bereich der basischen Domäne die Steuerung des Proteins in den Kern nachweisen. Diese Aufgabe kann durch Dimerbildung mit anderen Transkriptionsfaktoren (BZI-2, -3 und -4) ersetzt werden. Eine geringe Retention des Transkriptionsfaktors BZI-1 im Cytosol kann nachgewiesen werden. Diese Retention beruht nicht auf der Größe des Transkriptionsfaktors sondern ist Teil einer aktiven Regulation. Der vollständige N-Terminus bis zur basischen Domäne ist für die Retention des Proteins im Cytoplasma nötig. Wie die oben gezeigten Deletionsderivate N, D1 und D2 gezeigt haben, ist das komplette Vorhandensein des N-Terminus für die vollständige Interaktion nötig. 


\section{5 | Analyse der Interaktion zwischen Domäne 1 und ANK1}

Durch einen Hefe-"two-hybrid"-Analyse konnte ein 352 Aminosäuren-großes Protein (37,3 kDa) aus Nicotiana tabacum identifiziert werden. Dieses Protein interagiert spezifisch mit dem Bereich der Domäne 1 und den angrenzenden Bereichen des BZI-1-Proteins. Die im Hefe-System gezeigte Interaktion (K. HORVAY, 2000) sollte insbesondere in planta weiter charakterisiert werden. Zum weiteren Nachweis der Interaktion wurde die DNABindeeigenschaft des BZI-1 in Abhängigkeit zum ANK1-Protein analysiert und die Expression des ANK1 nach Pathogenbefall untersucht. Weitergehende Untersuchungen befassten sich mit der zellulären Lokalisation eines GFP-Fusionsproteins.

\section{5| 1 In-vitro Nachweis der Interaktion zwischen BZI-1 und ANK1}

Durch die vorausgegangenen Ergebisse wurde gezeigt, dass BZI-1- $\Delta \mathrm{N}$ an die G/C-Box bindet. Durch die Bindung des ANK1-Proteins an das BZI-1-Protein sollte ein Einfluss auf den im nativen Gel nachzuweisenden Komplex sichtbar werden. Für die Gelretardationsanalyse (EMSA) wurden die Ansätze mit in vitro translatiertem ANK1-Protein versetzt. Das in vitro-Translatat wurde freundlicherweise von A. Strathmann zur Verfügung gestellt.

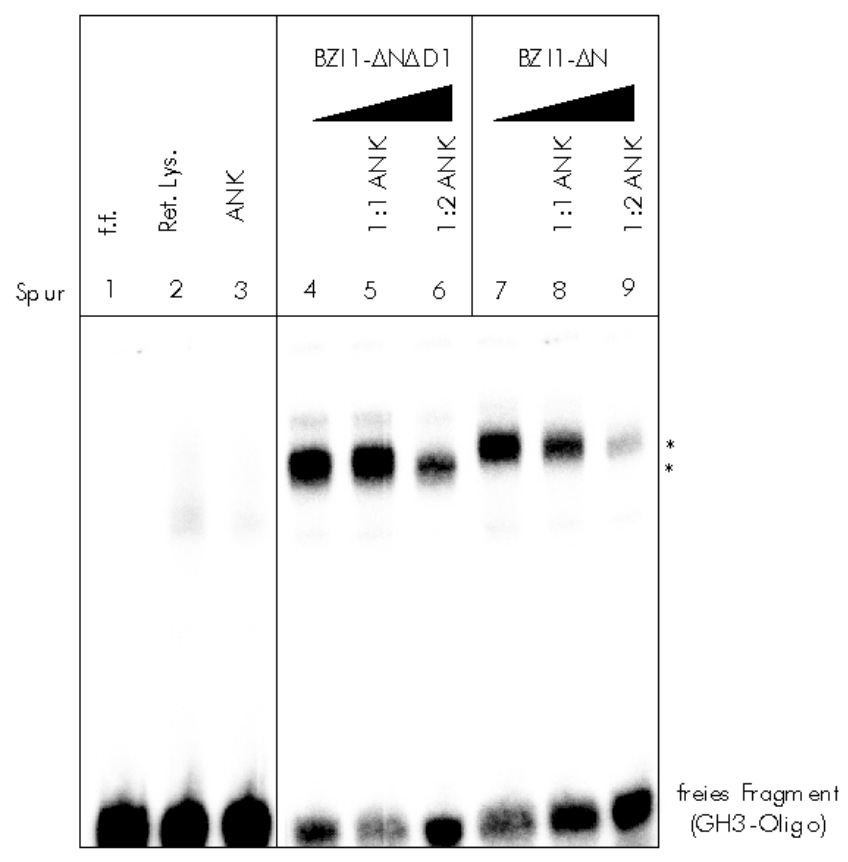

Abb. D - 26: Inhibierung der BZI-1 DNA-Bindeaktivität durch ANK1-Protein.

Eingesetzt wurden $0,2 \mu \mathrm{g} \mathrm{HIS}{ }^{\circledR}-\mathrm{BZI}-1-\Delta \mathrm{N} \Delta \mathrm{D} 1$ und $\mathrm{HIS}^{\circledR}-\mathrm{BZI}-1-\Delta \mathrm{N}$. Die Proben wurden mit dem Volumenverhältnis $1: 1$ oder 1:2 mit in vitro translatiertem ANK1-Protein versetzt und mit Retikulocytenlysat auf das gleiche Endvolumen abgeglichen $(6 \mu \mathrm{l})$. Das Sternchen bezeichnet die spezifische Bindeaktivität an da GH3-Oligo. Spur1: freies Fragment; Spur 2: Reticulocytenlysat, Spur 3: i.v. ANK1; Spur 4-6: rekombinantes His ${ }^{\circledR} B Z I-1-\Delta N \Delta D 1$ (4. ohne ANK1, 5. 1:1 mit ANK1, 6. 1:2 mit ANK1), Spur 7-9: rekombinantes HIS ${ }^{\circledR}$-BZI-1- $\Delta N$ (7. ohne ANK1, 8. 1:1 mit ANK1, 9. 1:2 mit ANK1). 
Wie aus Abbildung D-26 ersichtlich, besitzt das in vitro-translatierte ANK keine eigenständige DNA-Bindeeigenschaft an die G/C-Box.

Durch eine Interaktion des in vitro-translatierten ANK 1 -Proteins mit dem BZI-1 -Protein zeigt sich keine zusätzliche, stärker retardierte Bande. Eine in ihrer Mobilität eingeschränkte Bande würde auf eine Vergrößerung des DNA-bindenden Komplexes hinweisen. Die Menge des bindenden Komplexes nimmt hingegen durch die Zugabe des ANK1-Proteins ab. Diese Ergebnisse belegen eine Interaktion zwischen dem ANK1-Protein und BZI-1. Die DNA-Bindefähigkeit des BZI-1 wird durch diese Interaktion herabgesetzt. Durch die vergleichenden Versuche mit den rekombinant hergestellten BZI-1-Deletionderivaten lässt sich die Interaktion der Domäne 1 und der umgebenden Bereiche mit ANK1 nachweisen. Die Aussagen dieser in-vitro-Analyse bestätigen die im Hefe-System gewonnen Ergebnisse. Der durch die Deletion betroffene Bereich der Domäne 1 reicht nicht vollständig zur Unterbindung der Komplexbildung aus. 


\section{5|2 Transkriptionelle Regulation der ANK1-Expression nach Elicitierung}

Die Expression des ANK1-Gens ist ubiquitär und gewebe-unabhängig in der Pflanze. Um einen Einfluss unterschiedlicher Stimuli auf die Transkription des ANK1-Gens zu untersuchen, wurden Northern-Blot-Analysen vorgenommen. Es wurde Blattgewebe von Wildtyp-Tabakpflanzen und unterschiedlichen transgenen Linien getestet. An diesen wurden Pathogeninduktionen mit Pseudomonas syringae pv. pisi und dem pilzlichen Elicitor Cryptogein an Blattgewebe durchgeführt.

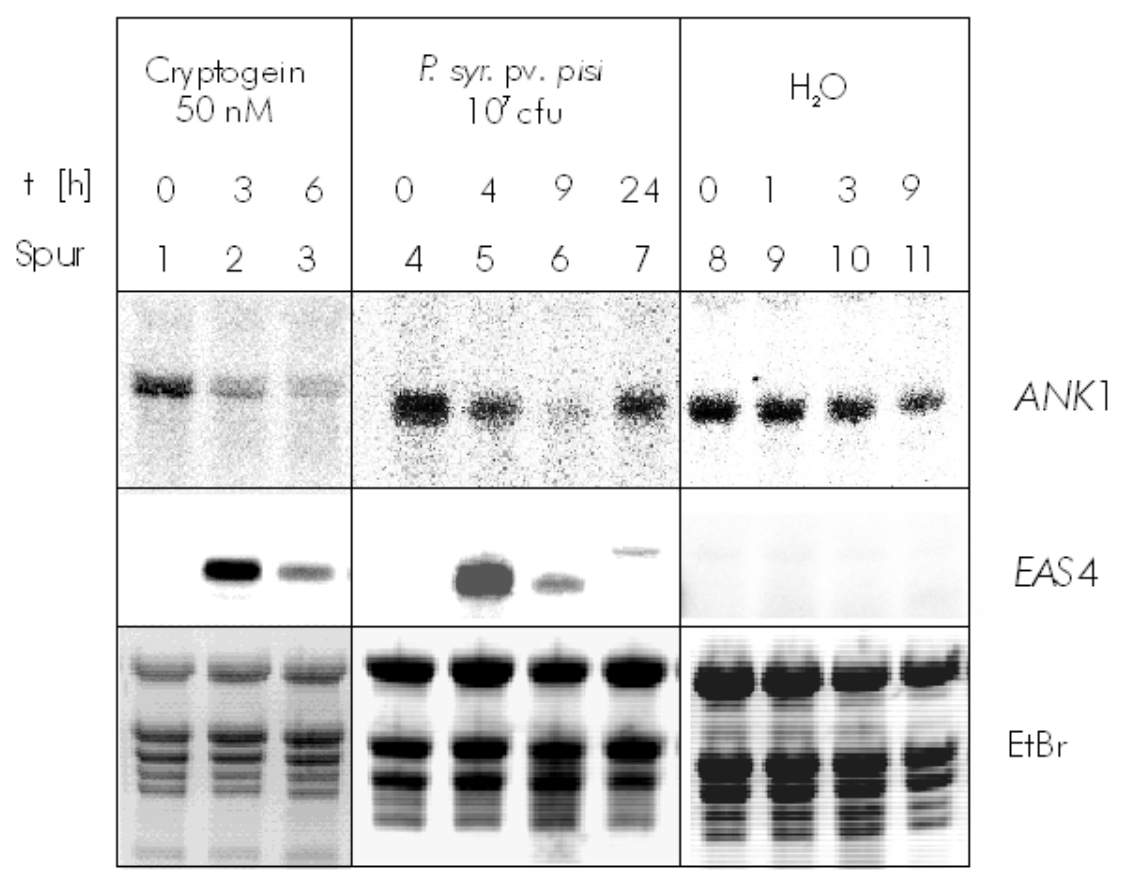

Abb. D - 27: Verringerung der ANK1-Transskriptmenge nach Elicitierung.

Northern-Blot-Analyse der ANK1-Expression. Aufgetragen wurden je $8 \mu \mathrm{g}$ der, zu den angegebenen Zeitpunkten [Stunden nach Inokulation] nach Stimulus isolierten Blatt-RNA. Als Pathogenstimulus wurde Spur 1-3: Cryptogein (50

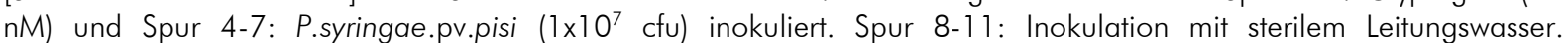
Hybridisierungssonden: ank - ANK1-Gen; eas4 - Sesquiterpenecyclase-Gen (5-epi aristolochen synthase). EłBr Ethidiumbromid gefärbtes Gel.

Die Abbildung D-27 zeigt die Analyse der Expression des ANK1-Gens nach Elicitierung und Pathogenbefall. Durch die Expression der Sesquiterpenecyclase (eas4) ca. 3 - $4 \mathrm{~h}$ nach der Inokulation lässt sich das Auslösen der pflanzlichen Pathogenantwort molekular nachweisen. Die Expressionsstärke des ANK1-Gens sinkt nach Infektion innerhalb von $9 \mathrm{~h}$ stark ab. Nach 24 h ist das ursprüngliche Ausgangsniveau der Transkription wieder erreicht. Durch die Ergebnisse der parallelen Inokulation von sterilem Leitungswasser kann die Pathogenspezifität dieser Regulation belegt werden. 
Um zu zeigen, dass die Expression des ANK1-Gens unabhängig von BZI-1 ist, wurden unterschiedliche BZI-1-exprimierende transgene Linien (Kap. D|6) mit Pseudomonaden inokuliert und die Expression des ANK1-Gens analysiert.

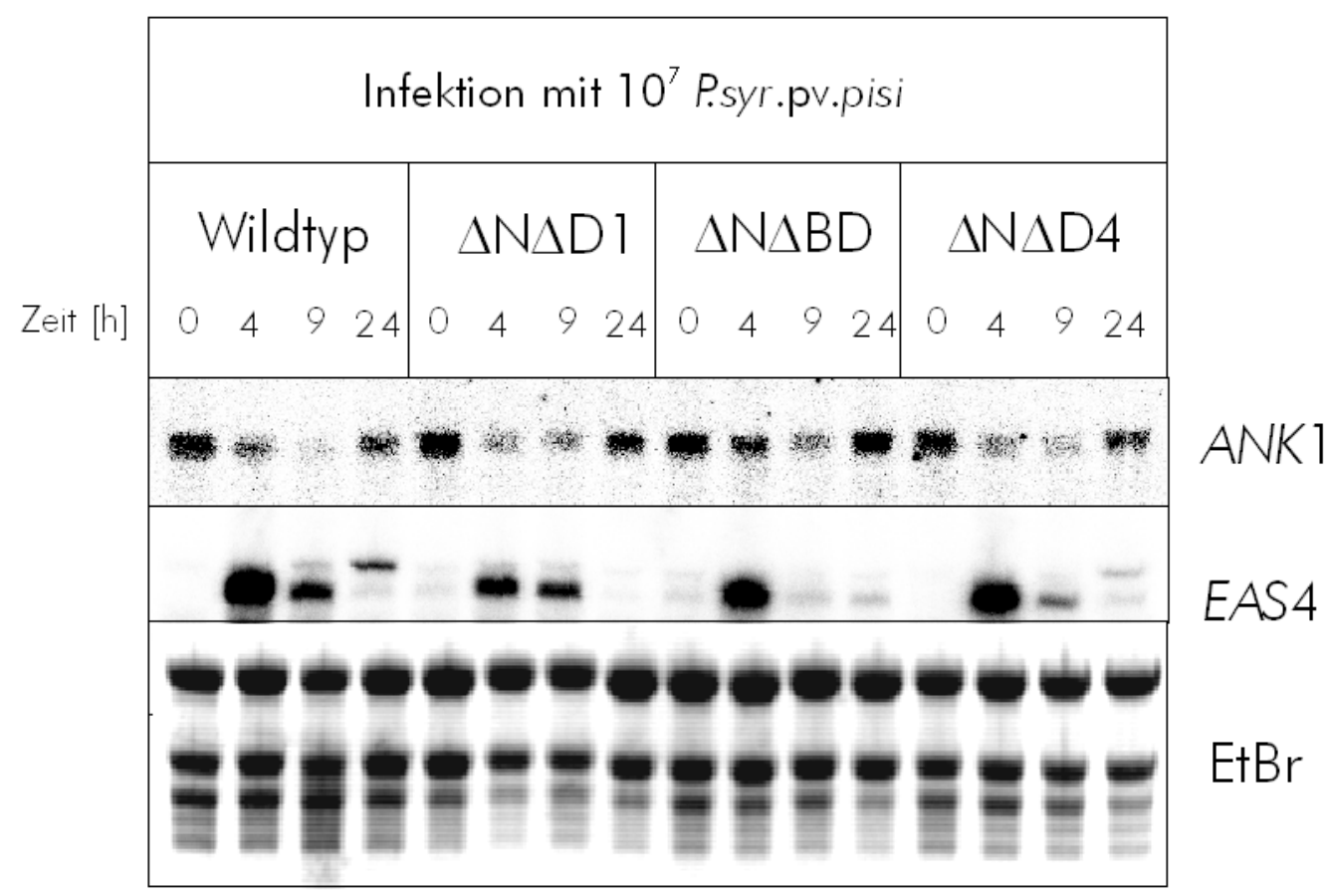

Abb. D - 28: Die ANK1-Expression ist unabhängig von BZI-1.

Pathogeninduktion von Blattgewebe der Linien Wildtyp, HA-BZI-1- $\Delta \mathrm{N} \Delta \mathrm{D}$ 1, BZI-1- $\Delta \mathrm{N} \Delta \mathrm{BD}$ und HA-BZI-1 $\Delta \mathrm{N} \Delta \mathrm{D} 4 \mathrm{mit} 1 \mathrm{x}$ $10^{7}$ cfu Pseudomonas syringae pv. pisi. Hybridisierungssonden: ank: ANK1-Gen; eas4: Sesquiterpenecyclase-Gen (5-epi aristolochen synthase); eas3: Pathogen-unbeeinflusstes Mitglied der Genfamilie.

In allen untersuchten Linien variierte die Expression des ANK1-Gens im normalen Rahmen der Abweichung (Zeitpunkt 0). Durch die Expression des Markergens eas4 zeigt sich die ausgelöste Pathogenantwort in allen untersuchten Pflanzen. Es zeigen sich keine Unterschiede im Verlauf der ANK1-Expression nach Pathogengabe zwischen den unterschiedlichen Pflanzenlinien. Die Abnahme der Expression nach Pathogenbefall ist mit der zuvor gezeigten Verringerung der ANK1-Expression durch Cryptogein-Inokulation zu vergleichen. Aus den vorgelegten Ergebnissen wird deutlich, dass die Expression des ANK1-Gens unabhängig von BZI-1 ist und die ANK1-Expression im Rahmen der Pathogenantwort negativ reguliert wird. 


\section{5|3 Lokalisation des ANK1-GFP-Fusionsproteins}

Nach der Ermittlung der vollständigen Sequenz des ANK1-Gens erfolgte die Konstruktion der C-terminalen GFP-Fusion (AS-Sequenz: s. G|3, DNA-Sequenz: s. G|4). Das ANK1-GFPKonstrukt (Abbildung D-29a) wurde in Tabakmesophyll-Protoplasten transient exprimiert und die Lokalisierung detektiert. Das ANK1-GFP-Fusionsprotein besitzt eine berechnete Größe von 64,6 kDa und liegt damit im Bereich der Kernporenausschlussgröße.
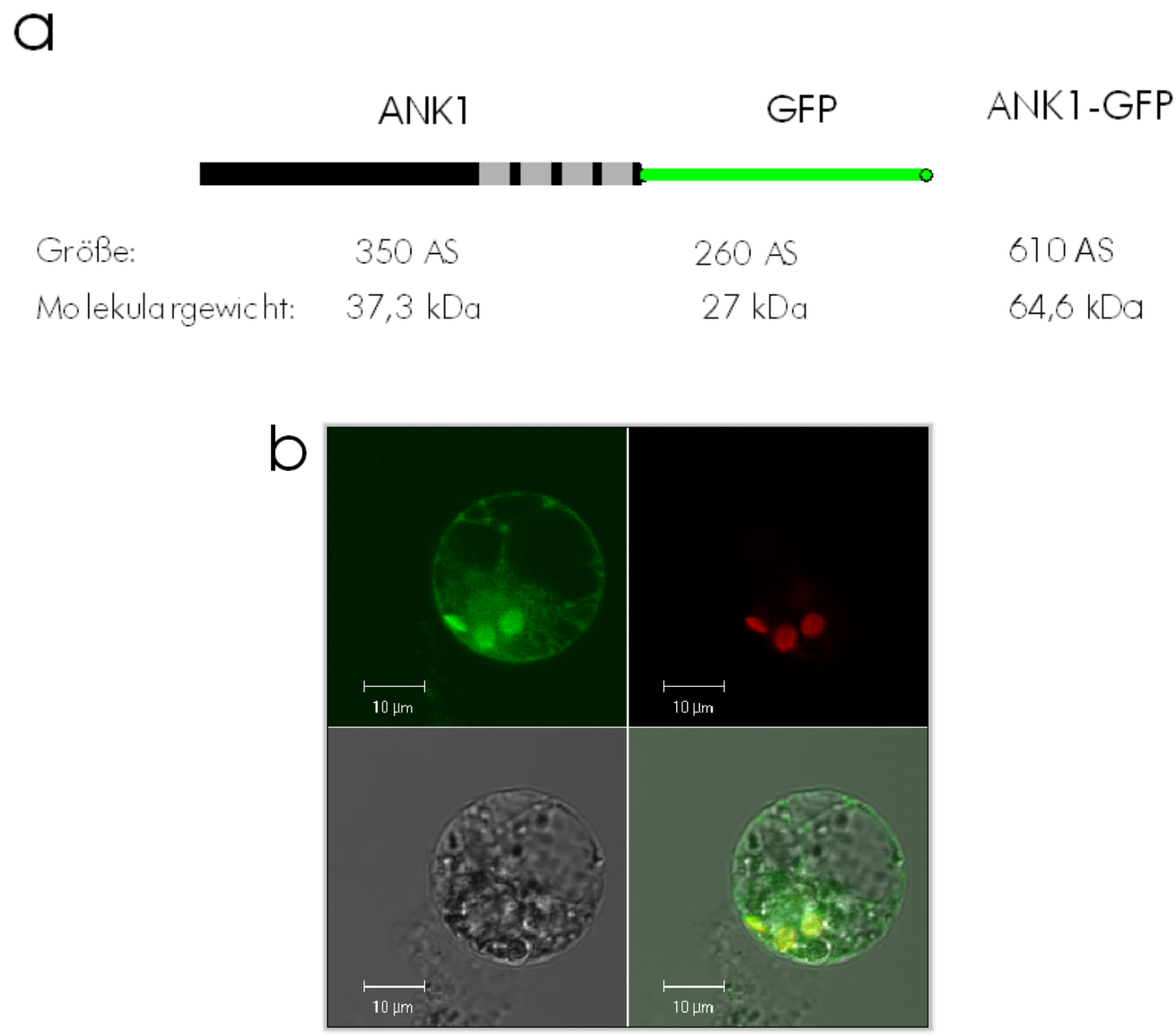

Abb. D - 29: ANK-GFP-Fusionsprotein/Lokalisierung des ANK1-GFP in Protoplasten.

a. ANK-GFP-Konstrukt zur Lokalisierung des ANK1-Proteins in Tabakmesophyllprotoplasten ANK1: N.t.ANK1, GFP:

Grünfluoreszierendes Protein, grau hervorgehoben: Ankyrin-repeats b. LSM-Aufnahme von Mesophyllprotoplasten mit Fusion des GFP(grünluoreszierenden Proteins) an das ANK-Protein. links oben: $488 \mathrm{~nm}$ Anregung/505-550 nm Detektion; rechts oben: 560 nm Detektion; links unten: Durchlicht; rechts unten: Überlagerung; Größenmaßstab: $10 \mu \mathrm{m}$

In der Abbildung des ANK1-GFP (Abbildung D-29b) ist die ubiquitäre Verteilung des Proteins zu erkennen. In vielen transformierten Zellen zeigte sich durch die Expression der ANK-GFP-Fusion oder des unfusionierten ANK1-Proteins ein cytotoxischer Effekt. Es konnten keine, im Vergleich zu anderen Transformationsereignissen, stark exprimierenden Protoplasten detektiert werden. Viele durch GFP markierte Protoplasten zeigten zerstörte Membranen oder eine starke Autofluoreszenz in der Vakuole. 


\section{6 | Funktionale Analyse der BZI-1-Domänen in planta}

Zur Aufklärung der Domänenfunktionen in planta wurden eine Reihe von BZI-1 Deletionsmutanten transgen in Tabakpflanzen exprimiert. Die Konstrukte standen unter der Kontrolle des CaMV (CauliflowerMosaikVirus)-35S-Promotors. Der gewählte Ansatz basierte auf dem Prinzip der transdominanten Suppression. Durch die Expression eines BZI-1-Deletionsderivates im Bereich der Domäne $N$ wird die transaktivierende Funktion von BZI-1-Homodimeren und BZI-1-interagierenden bZIP-Proteinen (BZI-2, -3, -4) durch die Bindung an cis-Elemente unterdrückt. Die regulatorische Funktion des $\Delta \mathrm{N}-\mathrm{BZZ}-1$ Derivates spiegelt sich in phänotypischen Auffälligkeiten wieder. Der von mir gewählte Ansatz bestand in der Expression von BZI-1-Doppeldeletionsderivaten. Diese Derivate besaßen alle eine Deletion im N-Terminus und eine zusätzliche Deletion in den Bereichen der zu charakterisierenden Domäne. Durch das Entfernen einer funktionell wichtigen Domäne sollte so der transdominante Effekt der Domäne $\mathrm{N}$ revertiert werden. Durch die Zuordnung der Effekte zu einzelnen funktionalen Bereichen lässł sich ein Rückschluss auf die Beteiligung der einzelnen Domänen in unterschiedlichen Funktionsbereichen nachweisen. Die analysierten Signalprozesse bezogen sich auf die Blütenmorphologie und -fertilität, die Auxinsignalperzeption und die Pathogenantwort.

\section{6|1 Expression von BZI-1-Deletionsderivaten in transgenen Tabak-Pflanzen}

Zur Analyse der Domänenfunktionen in vivo wurden BZI-1-Deletionsderivateexprimierende Pflanzen hergestellt. Die hergestellten und transgen exprimierten BZI-1Doppeldeletionsderivate sind zur Orientierung schematisch in Abbildung D-30 dargestellt.

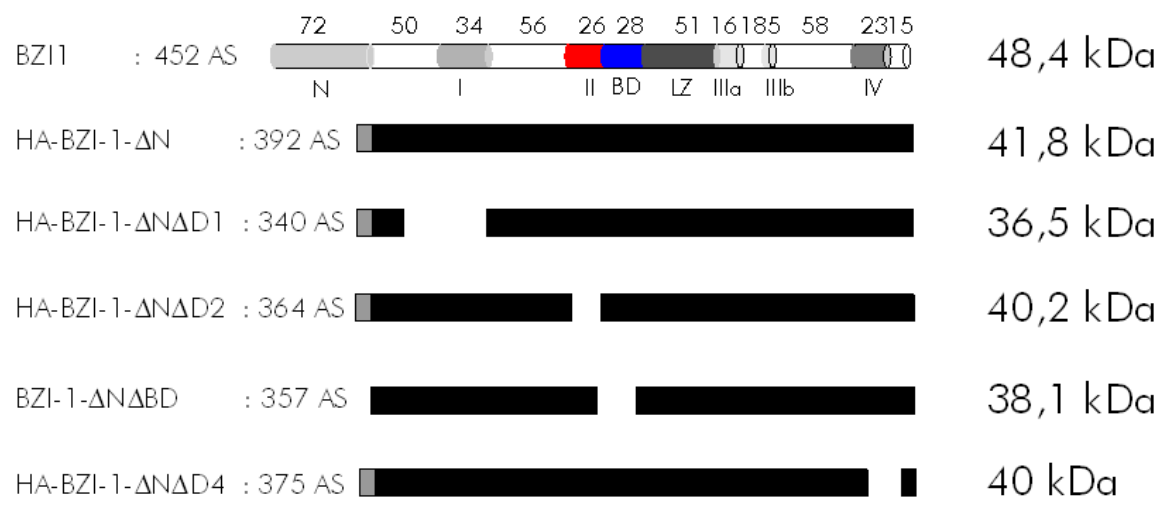

Abbildung D - 30: Schematische Übersicht der transgen exprimierten BZI-1 -Derivate.

Zum Vergleich der Größen sind die Deletionsderivate schematisch aufgeführt. Das BZI-1-Protein zeigt im Größenverhältnis die anteiligen Proteindomänen mit der Anzahl der Aminosäuren. Die schwarzen Balken entsprechen den vorhandenen Proteinanteilen, das grave Rechteck symbolisiert den N-terminalen HA-tag. AS-Aminosäuren, kDAMolekulargewicht in KiloDalton. BZI-1: N.t.BZI-1, N: Domäne N, I, D1: Domäne 1, II D2: Domäne 2, BD: basische Domäne, Illa +b: Domäne 3, IV, D4: Domäne 4, $\Delta$ : Deletion. 
Zur Übersicht sind die getesten und für die weiteren Versuche eingesetzten transgenen Linien in der Tabelle D-4 aufgeführt.

\begin{tabular}{|c|c|c|c|c|c|c|}
\hline Konstrukt & $\begin{array}{c}\text { Größe } \\
{[A S]}\end{array}$ & $\begin{array}{l}M G \\
{[k D a]}\end{array}$ & $\begin{array}{l}\text { deletierter Bereich } \\
\text { [pos. AS-Sequenz] }\end{array}$ & $\begin{array}{l}\text { Getestete } \\
\text { Linien }\end{array}$ & $\begin{array}{l}\text { Positiv } \\
\text { getestet }\end{array}$ & $\begin{array}{l}\text { Verwendete } \\
\text { Linien }\end{array}$ \\
\hline BZI- 1 & 452 & 48 & - & T.Heinekamp & & 8. BZI-1\#3 \\
\hline HA-BZI- $1-\Delta N$ & 392 & 42 & $1-72$ & T.Heinekamp & & 8.HA $\triangle \mathrm{N} \# 5$ \\
\hline HA-BZI- $1-\Delta \mathrm{N} \Delta \mathrm{D} 1$ & 340 & 36,5 & $1-72,111-164$ & 30 & 10 & $\begin{array}{l}8 . \Delta \mathrm{N} \Delta \mathrm{D} 1 \# \mathrm{C} \\
8 . \Delta \mathrm{N} \Delta \mathrm{D} 1 \# \mathrm{X}\end{array}$ \\
\hline HA-BZI- $1-\Delta N \Delta D 2$ & 364 & 40 & $1-72,235-251$ & 20 & 8 & $\begin{array}{l}\text { p. } \Delta \mathrm{N} \Delta \mathrm{D} 2 \# 2 \\
15 . \Delta \mathrm{N} \Delta \mathrm{D} 2 \# 1\end{array}$ \\
\hline $\mathrm{BZI}-1-\Delta \mathrm{N} \Delta \mathrm{BD}$ & 357 & 38 & $1-72,253-274$ & 13 & 2 & $15 . \Delta \mathrm{N} \Delta \mathrm{BD} \# 1$ \\
\hline HA-BZI- $1-\Delta \mathrm{N} \Delta \mathrm{D} 4$ & 375 & 40 & $1-72,441-456$ & 12 & 4 & $\begin{array}{l}\text { 8. } \Delta \mathrm{N} \Delta \mathrm{D} 4 \# \mathrm{C} \\
\text { p. } \Delta \mathrm{N} \Delta \mathrm{D} 4 \# 1\end{array}$ \\
\hline
\end{tabular}

Tab. D - 4: Übersicht der transgenen Linien.

Konstrukt: Bezeichnung der transformierten Konstrukte; HA: HA-tag; AS: Größe der Proteine in Aminosäuren; MG: Molekulargewicht der Proteine in Kilodalton; Getestet Linien: Anzahl der getesteten unabhängigen Transformanden; Positiv getestet: Immunologisch nachweisbares Transgen; Verwendete Linien: Hochexpremierende Linien für weitere Versuche ausgewählt.

Die Überexpressionslinie und die transdominant supprimierte, BZI-1- $\Delta \mathrm{N}$-exprimierende Linie wurde als Kontrolle verwendet und von T. Heinekamp hergestellt und getestet. Zur Analyse der in vivo Proteininteraktion wurde das HA-BZI-1- $\Delta$ N $\Delta$ DI in den Pflanzen exprimiert. Das HA-BZI-1- $\Delta \mathrm{N} \Delta \mathrm{D} 2-$ Konstrukt wird zur weiteren Analyse der Domäne 2 verwendet. Durch die Expression des BZI-1- $\Delta \mathrm{N} \Delta \mathrm{BD}$-Transgens erfolgt ein weiterer transdominant supprimierender Ansatz zur Untersuchung der DNA-Bindung des BZI-1. Durch die Expression des HA-BZI-1- $-\Delta \mathrm{N} \Delta \mathrm{D} 4$ soll die Funktion der Phosphorylierung und damit die Bedeutung des BZI-1 in der Pathogenantwort aufgeklärt werden. Wie der Tabelle oben zu entnehmen ist, besitzen einige Deletionsderivate N-terminal einen HA-tag (influenza hemagglutinin, 12 Aminosäuren) zum zusätzlichen Immunonachweis mit einem HA-Antikörper. Die Expression des Transgens wurde auf Transkriptebene mit Hilfe der BZI1-Sonde detektiert. Für die weiteren Analysen wurden die Linien mit immunologisch gut detektierbarem Transgen ausgewählt. Zum Vergleich der Expressionsstärken werden die exemplarisch ausgewählten Linien in Abbildung D-31 a auf Transkript- und Abbildung D$31 \mathrm{~b}$ auf Proteinebene dargestellt. 


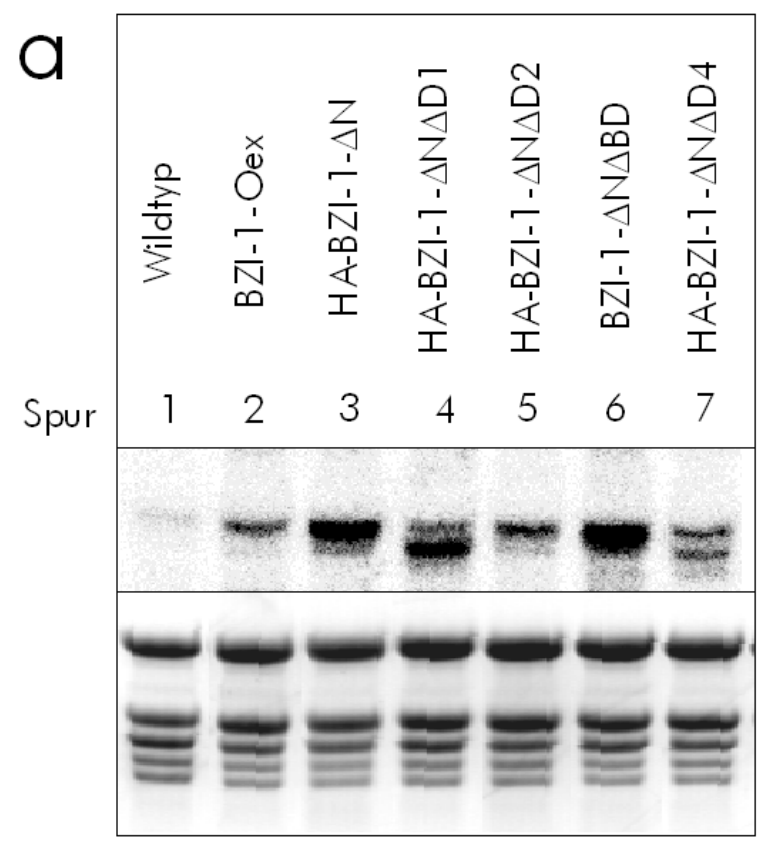

$B Z \mid-1$

$\mathrm{EtBr}$

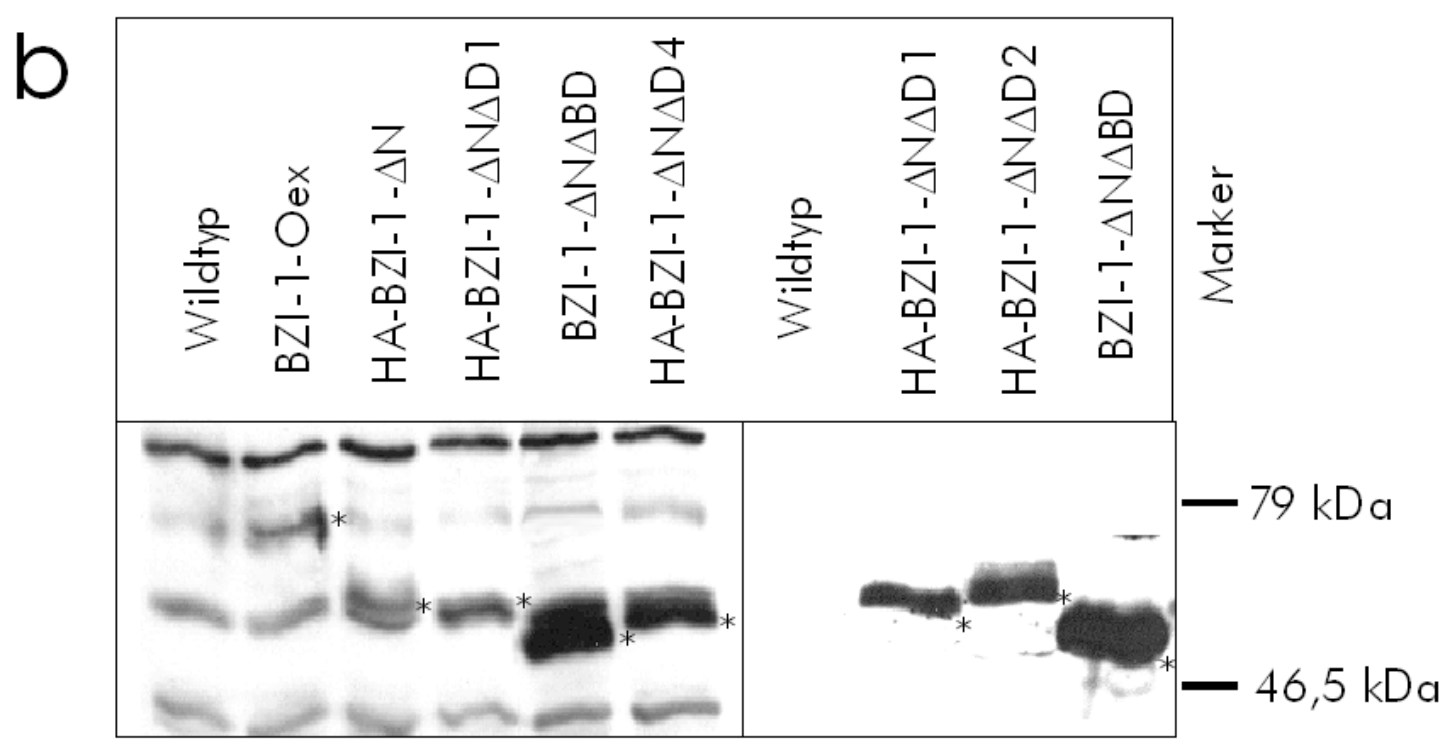

Abbildung D - 31 : Detektion der Expression von BZI-1-Derivaten in den transgenen Pflanzen.

a. Detektion der Transkription mit Hilfe der N.t.BZI-1 Hybridisierungssonde b. Immunologische Detektion von denaturierten Blatt-Proteinextrakten von transgenen Linien (8\% PAGE-Gel). Die Sternchen bezeichnen die BZI-1 -Derivate. Immunodetektion mit primärem AK: $\alpha$-BZI-1 1:1250; sekundärer AK $\alpha$-KaninchenHRP 1:5000. Wildtyp: Linie 8; BZI-1: 8.BZI-1\#3; HA-BZI-1- $\Delta \mathrm{N}$ : 8.HA- $\Delta \mathrm{N} \# 5$; HA-BZI-1- $\Delta \mathrm{N} \Delta \mathrm{D} 1$ : 8. $\Delta \mathrm{N} \Delta \mathrm{D} 1$ 1\#C; HA-BZI-1- $\Delta \mathrm{N} \Delta \mathrm{D} 2$ : p. $\Delta \mathrm{N} \Delta \mathrm{D} 2 \# 2 ;$ BZI-1$\Delta \mathrm{N} \Delta \mathrm{BD}: 15 . \Delta \mathrm{N} \Delta \mathrm{BD} \# 1 ; \mathrm{HA}-\mathrm{BZI}-1-\Delta \mathrm{N} \Delta \mathrm{D} 4$ : 8. $\Delta \mathrm{N} \Delta \mathrm{D} 4 \# \mathrm{C}$; Marker: Prestained.

Die das Transgen stark exprimierenden BZI-1- $\Delta \mathrm{N} \Delta \mathrm{BD}$ - und BZI-1- $\Delta \mathrm{N} \Delta \mathrm{D} 4$-Pflanzen entstammen jeweils den Linien 15. $\mathrm{N} \triangle \mathrm{BD} \# 1$ und 8. $\mathrm{N} \triangle \mathrm{D} 4 \# \mathrm{C}$. Aufgrund der Hintergrundbande im Bereich von ca. $50 \mathrm{kDa}$ ist die Detektion der weniger stark exprimierten Derivate schwieriger. 
Des Weiteren wurden im Rahmen der vorausgegangenen Diplomarbeit BZI-1-antisenseKonstrukt-exprimierende Linien hergestellt (KUHLMANN, 1998). Die Linien wurden auf RNAEbene analysiert und die Linie \# 1 für weitere Versuche verwendet. Diese Pflanzenlinie zeigte phänotypisch die gleichen Effekte wie die auf Proteinebene transdominant supprimierten $\Delta \mathrm{N}$-BZI-1-exprimierenden Pflanzen. Für künftige Analysen stehen noch Tetracyclin-induzierbare Pflanzenlinien jeden Konstruktes, die als positiv getestet wurden zur Verfügung.

\section{$6 \mid 2$ Zelluläre Lokalisierung der BZI-1-Deletionsderivate in den Pflanzen}

Um die zelluläre Verteilung der transgenen Deletionsderivate zu analysieren wurden Kernextrakte aus dem Blattgewebe der transgenen Pflanzen immunologisch getestet. Es wurden Pflanzen am Ende der Dunkelphase und in der Mitte der Lichtphase geerntet. Abbildung D-32 zeigt den Immunonachweis mit Hilfe des BZI-1-Antikörpers. Zur Kontrolle wurden die Kernextrakte und cytosolischen Extrakte mit Hilfe des HMG-Antikörpers immunologisch auf ihre Reinheit getestet.

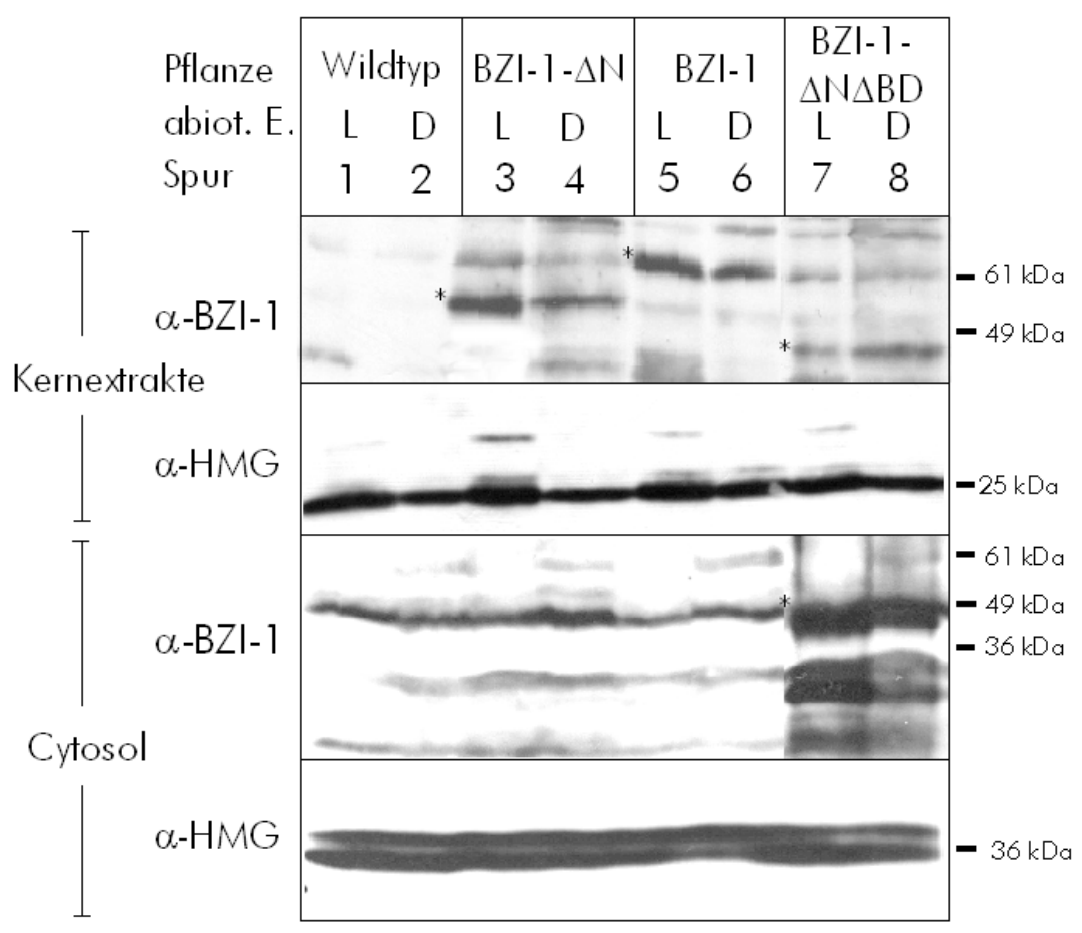

Abb. D - 32: Zelluläre Lokalisierung der BZI-1-Derivate in planta.

PAGE-Gel mit denaturierten Blatt-Kern- und Cytosol-Proteinextrakten. Die Sternchen bezeichnen die BZI-1-Derivate. Immunodetektion mit primärem AK: $\alpha$-BZI-1 1:1250; Kontrollen der Extrakte $\alpha$-HMG (High Mobility Group) 1:1250; sekundärer AK $\alpha$-KaninchenHRP 1:5000. Obere Teilabbildungen: Kernextrakte, untere: cytosolische Extrakte. abiot. E.: abiotischer Einfluss: L-Lichtphase; D-Dunkelphase. Spur 1/2: Wildtyp- Linie 8; Spur 3/4: HA-BZI-1- $\Delta N$ : 8.HA- $\Delta N \# 5$; Spur 5/6: BZI-1 - 8.BZI-1\#3; Spur 7/8: BZI-1- $\Delta N \Delta B D$ : 15. $\Delta N \Delta B D \# 1$. 
Aus der Abbildung D-32 geht hervor, dass es einen geringen nachweisbaren lichtabhängigen Unterschied bei der zellulären Verteilung des BZI-1-Proteins gibt. Im Wildtyp liegt die Menge des endogenen BZI-1-Proteins sowohl im Kern als auch im Cytosol unterhalb der Nachweisgrenze des Antikörpers. Das transgen exprimierte $\Delta \mathrm{N}$ Derivat zeigt eine hauptsächliche Lokalisierung im Kern, wobei eine sehr geringe Akkumulation im Kern während der Lichtphase zu verzeichnen ist. Durch die Überexpression des BZI-1-Proteins zeigt sich die Lokalisierung im Kern. Hier ist auch eine lichtabhängige Akkumulation im Nucleus in sehr geringem Umfang zu verzeichnen. Durch die Deletion der basischen Domäne mit der NLS ist der größte Teil des transgen exprimierten Proteins im Cytosol nachweisbar. Die Kernlokalisierung kann somit auch in planta auf die NLS im Bereich der basischen Domäne zurückgeführt werden. Zur Kontrolle wurden die analog hergestellten Membranen mit dem Antikörper gegen das kernlokalisierte HMG-Protein gegengetestet. Der, gegen das Arabidopsis thaliana - HMGProtein hergestellte Antikörper detektiert in den Kernextrakten ein Protein vergleichbarer Größe (204 AS, ca. 24 kDa). Für Tabak wurde bisher nur die Expression von HMG-gus Reportergenkonstrukten beschrieben (GUPTA et al., 1998/1999). Dieser Gegentest belegt die Reinheit der Extrakte. In der Abbildung D-32 wird durch die Größe der nachweisbaren Proteine der Unterschied zwischen der nucleären und cytosolischen Fraktion deutlich. Durch die HMG-Immunodetektion lässt sich zeigen, dass die Extrakte keine Kontamination durch die jeweils andere Fraktion enthalten.

\section{6|3 Veränderungen in den Pflanzen durch die Expression von BZI-1-Derivaten}

Die Expression des transdominant negativ wirkenden Deletionsderivates BZI-1- $\Delta \mathrm{N}$ bewirkt eine Reihe von phänotypischen Veränderungen der Pflanzen. Diese phänotypischen Effekte lassen sich in drei Bereiche einordnen. Zum einen der Einfluss von BZI-1 auf entwicklungsbiologische Prozesse, wie die Blütenbildung und Pollenreifung. Zum zweiten Effekte auf Wuchs, Blattmorphologie und hormonstimulierte Wurzelbildung. Diese weisen auf eine veränderte Auxinsignalverarbeitung hin. Als dritter Effekt konnte eine veränderte Pathogenresponsivität nachgewiesen werden. 


\section{6|3|1 Veränderung der Blütengröße}

Die im Bereich der BZI-1-Funktion beeinflussten Pflanzenlinien zeigen eine veränderte Größe der Blüten. Die Petalen, Stamina und das Pistill sind um 25 \% reduziert. Dieser Phänotyp war nicht nur durch die Expression der transdominant negativ wirkenden Derivate zu erkennen, sondern ebenso bei einer durch BZI-1 Antisense-Expression reprimierten Linie (8.anti\#1). Es wurden zur statistischen Erhebung insgesamt die Blüten von 20 unabhängigen BZI-1-Derivat exprimierende Linien ausgezählt. Die Abweichungen in den Größen der transformierten Ursprungslinien lagen jeweils im Rahmen der üblichen Standardabweichung $(\approx 0,09)$. Die einzelnen Werte der Messungen sind der Tabelle im Anhang zu entnehmen. Die $\Delta \mathrm{N}$-Linien zeigten alle eine Reduzierung der Blütengröße. Die zur Messung herangezogene Linie 8.anti\#1 zeigte die gleiche Reduzierung der Blütengröße wie die transdominant supprimierten Linien. Die $\Delta \mathrm{N} \Delta \mathrm{D} 1$ 1-Linien zeigten eine Revertierung des Phänotyps zu den Wildtyp-Blüten. In der hoch exprimierenden Linien p. $\Delta \mathrm{N} \Delta \mathrm{D} 2 \# 2$ zeigte sich eine Verkürzung der Blüten vergleichbar den $\Delta \mathrm{N}-\mathrm{BZZ}-1$ exprimierenden Linien. Dies deutet darauf hin, dass der Domäne 2 in diesem Funktionszusammenhang keine Bedeutung zufällt. Durch die Expression des $\Delta \mathrm{N} \Delta \mathrm{BD}$ Deletionsderivates zeigte sich ein leicht veränderter Blütenphänotyp. Die Blüten waren zwar ebenso kleiner, jedoch waren sie leicht "bauchiger" als Blüten der $\Delta \mathrm{N}$-BZI-1-DerivatExprimierer. Die Länge der Stamina entsprach den Wildtyp-Stamina. Dieses Konstrukt stellt durch seine Deletion der DNA-bindenden Domäne eine Variante der transdominanten Suppression dar. Die BZI-1- $\Delta \mathrm{N} \Delta \mathrm{D} 4$-Doppeldeletionsderivate exprimierenden Linien zeigen in den 3 untersuchten hochexprimierenden Linien eine Revertierung zum Wildtyp. Zur Übersicht sind einige exemplarische Blüten in Abbildung D-33 aufgeführt. 


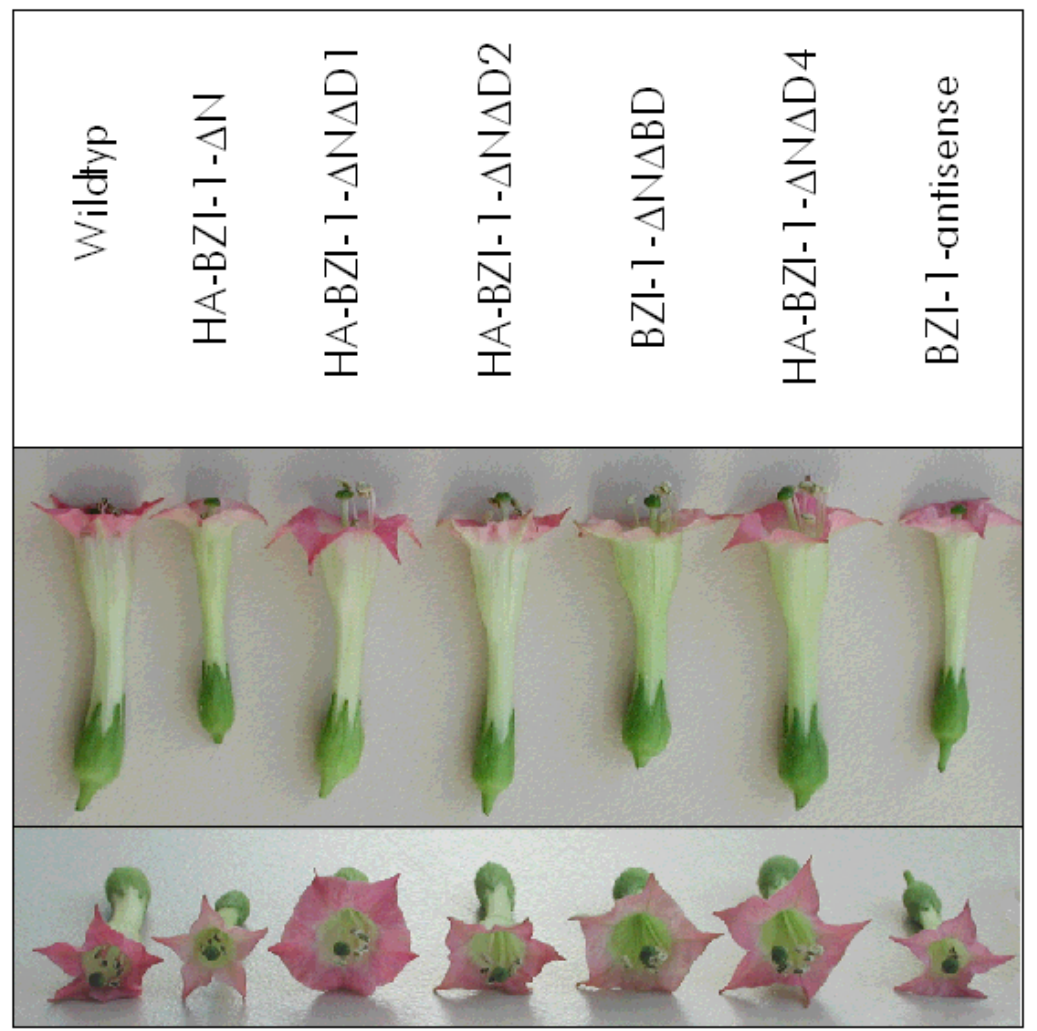

Abb. D-33 Größenvergleich voll expandierter Blüten der transgenen Linien.

Abgebildet sind die vollständig ausgebildeten Blüten der BZI-1-Deletionsderivat-exprimierenden Linien von der Seite und in Aufsicht. (Wildtyp: Linie 8; HA-BZI-1- $\Delta$ N: 8.HA-BZI-1 $\Delta$ N\#4; HA-BZI-1- $\Delta$ N $\Delta$ D 1: 8.HA $\Delta N \Delta D$ D \#C; HA-BZI-1- $\Delta$ N $\Delta$ D2: p.HA $\Delta N \Delta \mathrm{D} 2 \# 2$; BZI-1- $\Delta \mathrm{N} \Delta \mathrm{BD}$ : 15. $\Delta \mathrm{N} \Delta \mathrm{BD} \# 1$; HA-BZI-1- $\Delta \mathrm{N} \Delta \mathrm{D} 4$ : 8.HA $\Delta \mathrm{N} \Delta \mathrm{D} 4 \#$ C; BZI-1-antisense: 8-anti\# 1).

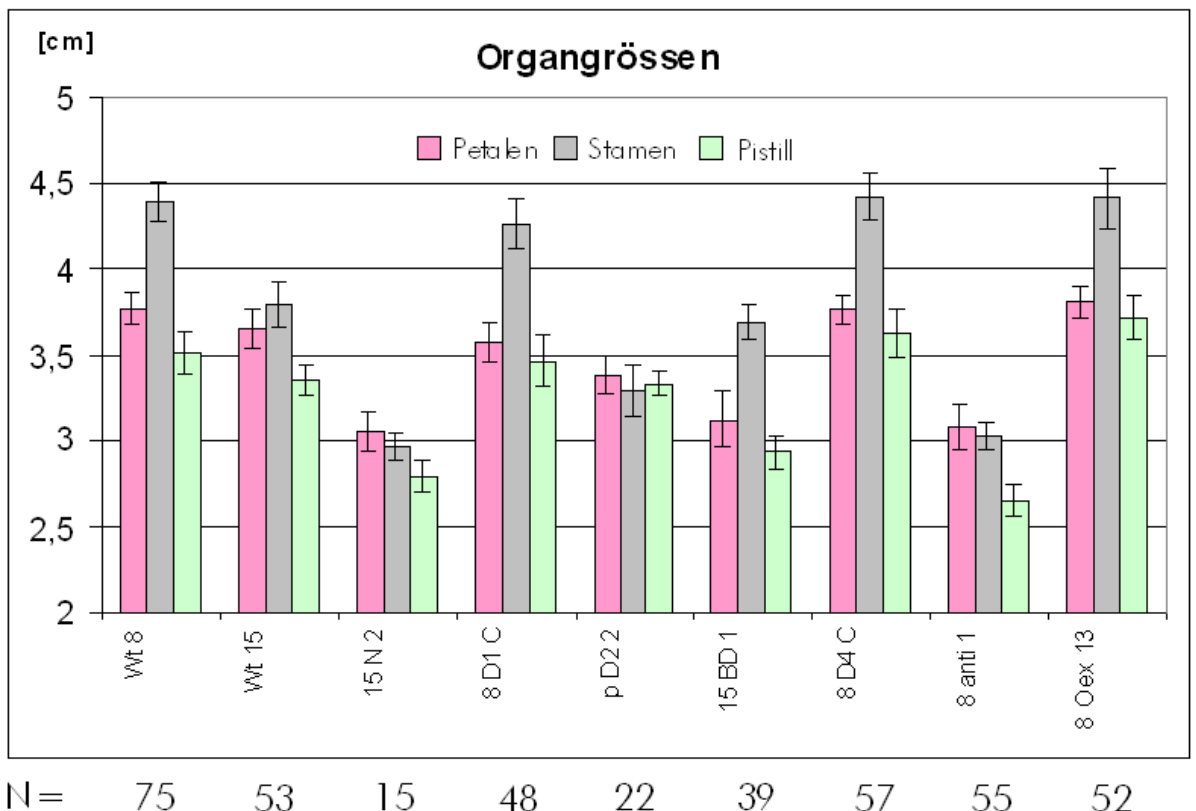

Abb. D-34: Statistische Auswertung der Blüten-Organgrößen.

Die Balken repräsentieren die Mittelwerte der gemessenen Organgrößen (Petalen-rosa, Stamina-grau und Pistill-grün) in Zentimetern mit den Standardabweichungen. (W+8: Wildtyp 8 = Wildtyp p; W+15: Wildtyp 15; 15 N 2: 15. HA-BZI-1$\Delta \mathrm{N \# 2} 8 \mathrm{D} 1 \mathrm{C}$ : 8.HA-BZI-1 $\Delta \mathrm{N} \Delta \mathrm{D} 1$ \#C; p D2 2: p.HA-BZI-1 $\Delta \mathrm{N} \Delta \mathrm{D} 2 \# 2 ; 15$ BD 1: 15.BZI-1 $\Delta \mathrm{N} \Delta \mathrm{BD} \# 1 ; 8$ D4 C: $8 . \mathrm{HA}-$ BZI-1 $\Delta$ N $\Delta$ D4\#C, 8 anti 1: 8.BZI-1-antisense\# 1; 8.Oex 13: 8-BZI-1Oex\#13); N: Stichprobenanzahl der ausgezählten Blüten. 
Die ermittelten Werte werden beispielhaft von einigen Linien graphisch aufgetragen. Aus den ermittelten Daten geht hervor, dass die Domäne 1 zur Ausbildung der normalen Blütengröße wichtig ist. Der transdominante Effekt der N-terminalen Deletion kann sich phänotypisch durch Einführung der zusätzlichen Deletion im Bereich der Domäne 1 nicht auswirken. Das N-terminal mutierte Protein wird durch die zusätzliche Mutation unfunktional. Der Domäne 2 kann in diesem Zusammenhang keine funktionale Wichtigkeit nachgewiesen werden. Die DNA-Bindung des BZI-1 ist zur Ausbildung des Phänotyps ebenfalls bedeutend. Dieses wird durch die Ausprägung des abgewandelten, jedoch ähnlichen BZI-1- $\Delta$ N-Blütenbildes deutlich. Der Domäne 4 kommt ebenfalls eine wichtige Funktion in diesem Bereich zu. Bei einer zusätzlichen Deletion zeigt sich ebenfalls die Wiederherstellung der Wildtyp-Blütenmorphologie.

\section{$6|3| 2$ Veränderung der Pollenmorphologie}

Die Reifung von Pollen ist ein wichtiger Vorgang bei der Reproduktion der Pflanze. Dieser Prozess ist von der Versorgung der Pollen als sogenanntes "sink"-Gewebe mit Zuckern abhängig. Wie in der Arbeit von ROITSCH et al., 2000 gezeigt werden konnte, ist diese Versorgung durch das Vorhandensein einer extrazellulären Invertase im Tapetum gewährleistet. Das Tapetum stellt die Nährschicht der Pollenmutterzellen im Pollensack dar, in der die Sucrose extrazellulär gespalten wird und von den Zellen durch einen Hexosetransporter aufgenommen werden kann. In Tabak (Nicotiana tabacum) konnte durch eine Verringerung der Menge dieser Invertase (NIN88) die Unterversorgung der Pollen mit folgender männlicher Sterilität der Pflanze nachgewiesen werden (GOETZ et al., 2000). Missgebildete Pollen konnten auch in den transdominant supprimierten $\Delta \mathrm{N}$-Linien nachgewiesen werden. Er korrelierte mit einer verringerten Expresssion des NIN88-Gens in den Antheren (HEINEKAMP, 2002). Um die Funktion der einzelnen Domänen in diesem Funktionszusammenhang zu charakterisieren wurden die Pollen der Doppeldeletionsderivat-exprimierenden Linien lichtmikroskopisch untersucht. Das Ergebnis ist in Abbildung D-35 zu sehen. 

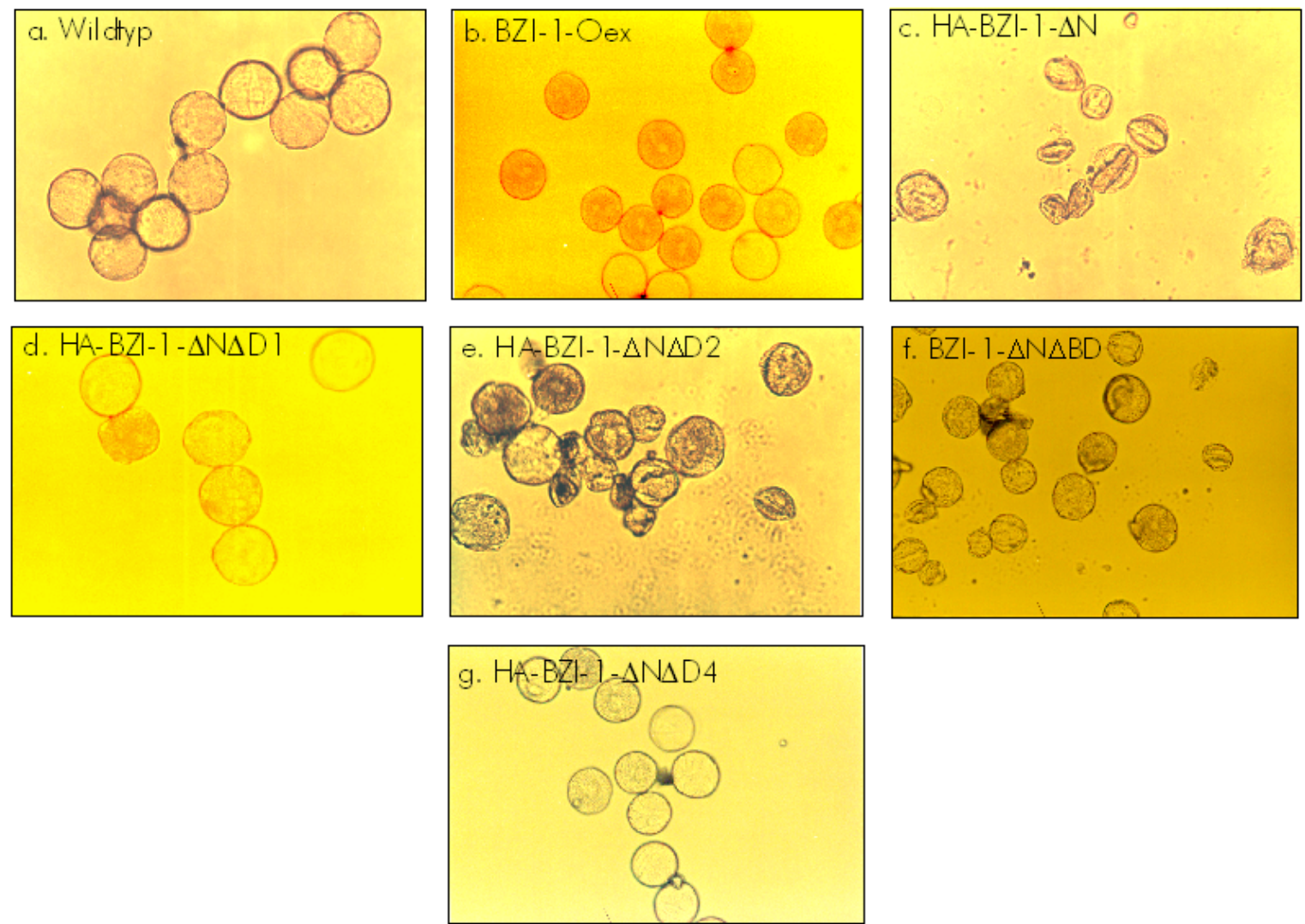

Abb. D - 35: Pollen der transgenen BZI-1 -Derivat-exprimierenden Linien.

Hellfeld-Aufnahmen der Pollen im Lichtmikroskop; a. Wildtyp: Linie 8; b. BZI-1: 8.BZI-1-Oex\#3; c. BZI-1 $\Delta$ N: 8.HA-BZI$1-\Delta \mathrm{N} \# 5$; d. BZI-1 $\Delta \mathrm{N} \Delta \mathrm{D} 1$ : 8. $\Delta \mathrm{N} \Delta \mathrm{D} 1$ 1\# ; e. BZI-1- $\Delta \mathrm{N} \Delta \mathrm{D} 2$ 2: p. $\Delta \mathrm{N} \Delta \mathrm{D} 2 \# 2 ;$ f. BZI-1- $\Delta \mathrm{N} \Delta \mathrm{BD}$ : $15 . \Delta \mathrm{N} \Delta \mathrm{BD} \# 1$; g. BZI-1$\Delta \mathrm{N} \Delta \mathrm{D} 4:$ p. $\Delta \mathrm{N} \Delta \mathrm{D} 4 \# 1$.

Die Abbildung D-35 zeigt die Pollenkörner in Durchlichtaufnahmen. Sowohl im Wildtyp als auch in der überexprimierenden Linie (8.BZI-1\#13) zeigen sich nur vitale, runde Pollenkörner. In der transdominanten Linie 8.HA $\triangle \mathrm{N} \# 5$ sind fast alle Pollen missgebildet und zeigen den vergleichbaren Phänotyp der NIN-88-antisense Pflanzen. Eine zusätzliche Deletion der Domäne 1 zeigt eine Revertierung der transdominanten Suppresion zu vitalen Pollen (Linie 8. $\Delta \mathrm{N} \Delta \mathrm{D} 1 \# \mathrm{X}$ ). Durch die Deletion der Domäne 2 wird der Phänotyp nicht revertiert. Es zeigen sich weiterhin viele missgebildete Pollen. Zur Analyse wurde die stark exprimierende Linie p. $\Delta \mathrm{N} \Delta \mathrm{D} 2 \# 2$ verwendet, die ebenfalls die verkürzten Blüten zeigte. Durch die Deletion der basischen Domäne tritt erneut ein transdominanter negativer Effekt bei der Pollenbildung auf. Die Pollen der Linie 15. $\mathrm{N} \triangle \mathrm{BD} \# 1$ zeigen ebenfalls einige missgebildete Pollen. Die Ausprägung der Missbildung hier ist jedoch nicht so stark wie durch die Entfernung des N-Terminus. Die zusätzliche Deletion der Domäne 4 führt auch in diesem Fall (Linie p. $\Delta \mathrm{N} \Delta \mathrm{D} 4 \# 1)$ zur Revertierung des Phänotyps, wodurch die Beteiligung an der Regulation gezeigt werden kann. Der transdominante Effekt kann wieder aufgehoben werden und es können sich vitale Pollen entwickeln. 


\section{6|3|3 Veränderte Expression von BZI-4 im Blütengewebe}

Um genauer zu charakterisieren, ob neben den phänotypischen Erscheinungen auch die Expression von mit BZI-1 interagierenden Faktoren betroffen ist, wurde eine Northern-BlotAnalyse durchgeführt. Eine mengenmäßige Veränderung von interagierenden Faktoren kann eine Beeinflussung der Homo- oder Heterodimerbildung bewirken. Die BZI-1 interagierenden bZIP-Transkriptionsfaktoren BZI-3 und -4 wurden im Hefe-"two-hybrid"system isoliert (STRATHMANN et al., 2002). BZI-4 zeigt eine Stamen-spezifische Expression. Für die BZI-4 verwandten Faktoren BZIP1 und BZIP2 aus Löwenmäulchen (Antirrhinum majus) konnte bisher eine G/C-Box-Spezifität nachgewiesen werden. Die Expression des weiterhin untersuchten Faktors BZI-3/TBZF (KUSANO et al., 1998) ist ubiquitär und gewebeunabhängig reguliert. Sie zeigt einen Anstieg durch Kälte und andere Stressoren. Wie aus den Northern Blot-Analysen in Abbildung D-36 hervorgeht, ist in den untersuchten transgenen Linien die Expression des interagierenden Faktors BZI-3 unverändert. Die Expression des interagierenden Faktors BZI-4 zeigt eine Stamen-spezifische Veränderung in den transgenen Linien. Durch eine Überexpression des BZI-1 zeigt sich eine verstärkte Expression des BZI-4. In den transdominant supprimierten Linien $\triangle \mathrm{N}$-BZI-1 und der BZI-1antisense Linie zeigt sich hingegen eine Abnahme der BZI-4-Expression. Durch die zusätzliche Deletion der Domänen 1 und 2 bleibt die Expression gleich beziehungsweise nimmt leicht zu. Die Expression des Deletionderivates zeigt im Gegenzug die verringerte Expression. Belegt wird dieser Einfluss auch zusätzlich durch die Abnahme der BZI-4Expression bei gleichzeitiger Abnahme der BZI-1 -Expression (antisense-Konstrukt). Dass die zusätzlichen Deletionen der Domänen 1 und 2 hier die Wildtyp-Situation auf molekularer Ebene wiederherstellen, zeigt die Wichtigkeit dieser Domänen und somit die essentielle Bedeutung des Faktors in diesem Funktionszusammenhang. 


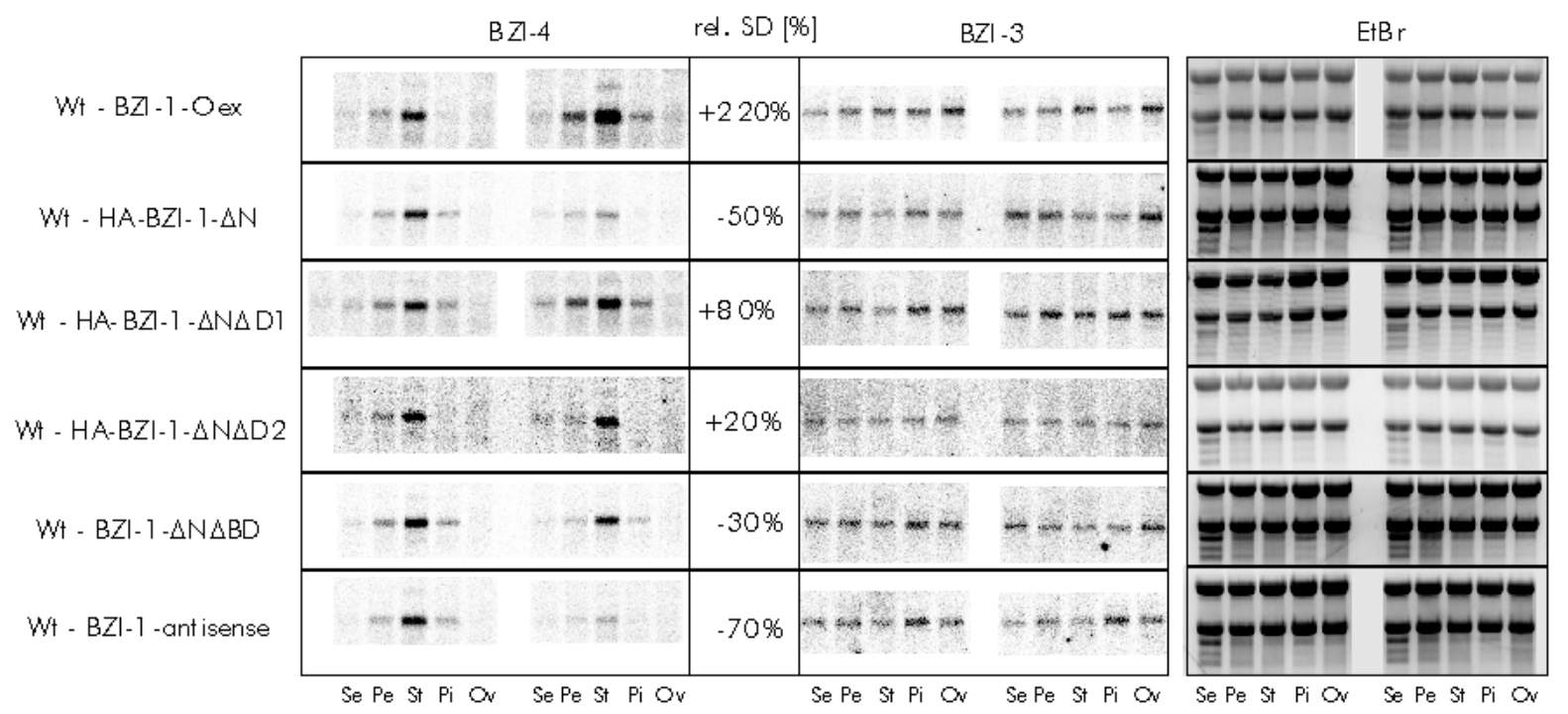

Abb. D - 36: BZI-4-Expression im Blütengewebe von BZI-1-Derivat-exprimierenden Pflanzen.

Hybridisierung von Blütengewebe-RNA mit Sonden gegen BZI-1-interagierende bZIP-Faktoren. Analysiertes Gewebe: SeSepalen; Pe-Petalen; St-Stamina; Pi-Pistill; Ov-Ovar. Sonden: BZI-4: Nt.BZI-4; BZI-3: Nt.BZI-3; EtBr: Ethidiumbromidgel. Untersuchte Linien: Wt: Linie 8; BZI-1c: 8.BZI-1Oex\#13; BZI-1 $\Delta \mathrm{N}$ : 8.HA-BZI-1- $\Delta \mathrm{N} \# 5$; BZI-1 $\Delta \mathrm{N} \Delta \mathrm{D} 1$ : 8. $\Delta \mathrm{N} \Delta \mathrm{D} 1 \# \mathrm{X}$; BZI-1- $\Delta \mathrm{N} \Delta \mathrm{D} 2$ 2: p. $\Delta \mathrm{N} \Delta \mathrm{D} 2 \# 2 ; \quad \mathrm{BZI}-1-\Delta \mathrm{N} \Delta \mathrm{BD}$ : 15. $\Delta \mathrm{N} \Delta \mathrm{BD} \# 1$; BZl-1-antisense: 8.anti\#1. rel. SD (\%)-relative Strahlungsdichte der Banden abgeglichen auf das Wildtypsignal in Prozent.

\section{6|3|4 Veränderung im vegetativen Wuchs}

Durch die Expression des transdominant negativ wirkenden Deletionsderivates $\Delta \mathrm{N}$-BZI-1 zeigt sich ein veränderter vegetativer Wuchs der Pflanzen. Die Blätter sind im Vergleich zum Wildtyp kleiner, leicht nach links verdrillt und die Pflanzen haben einen gestauchten Wuchs (HEINEKAMP et al., 2002). Des Weiteren bilden sich vermehrt Seitensprosse in den Blattachsen, was auf einen Bruch der apikalen Dominanz hinweist. Diese phänotypischen Merkmale sind vergleichbar mit anderen transgenen Pflanzen, die einen Defekt im AuxinSignalweg oder einen veränderten Auxingehalt besitzen. 

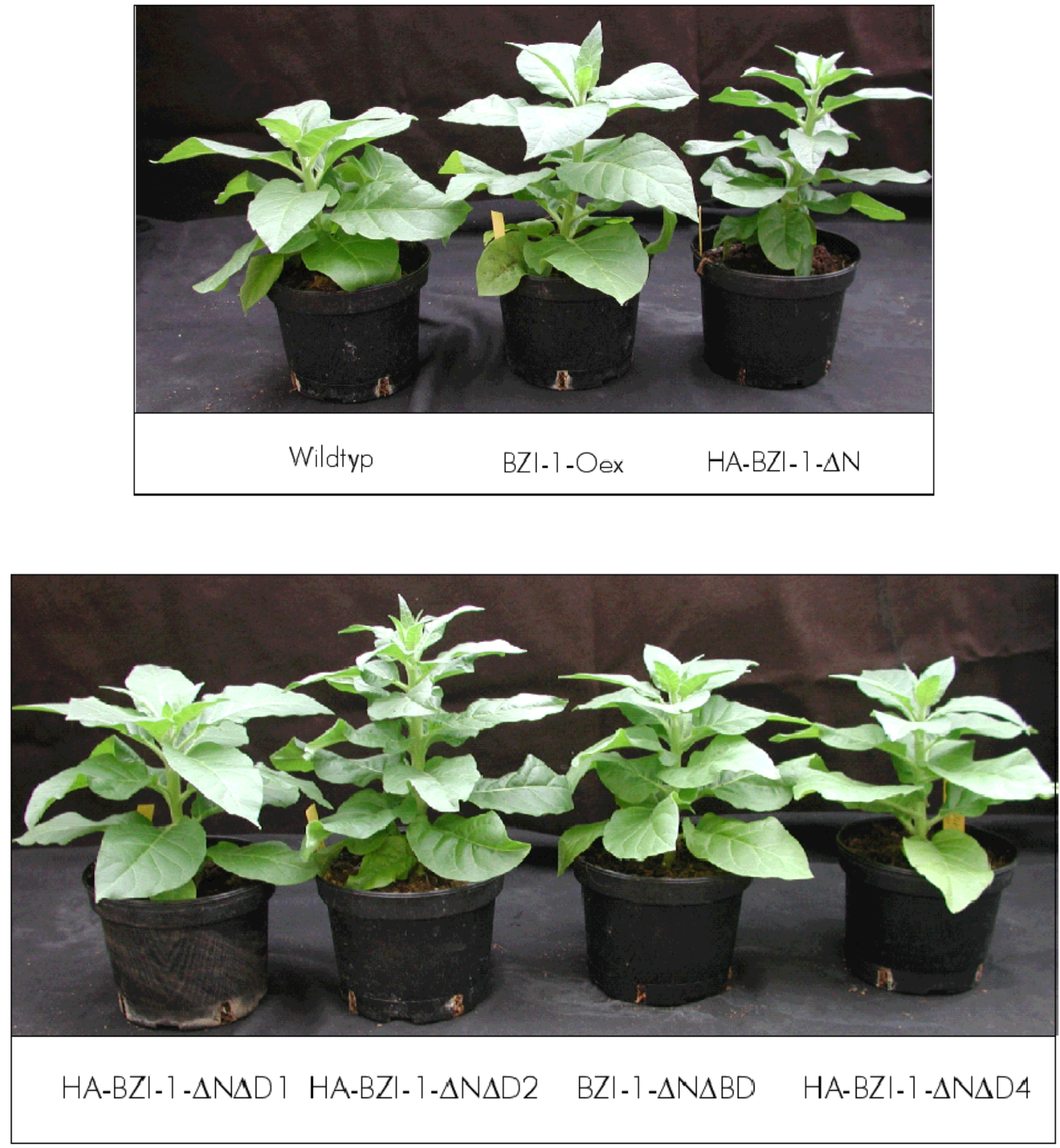

Abb. D - 37: Verändertes Wachstum der transgenen Pflanzen.

Seitenansicht der in Erdkultur angezogenen transgenen Pflanzen. Wt: Linie 8; BZI-1-Oex: 8.BZI-1Oex\#13; HA-BZI-1 $\Delta$ N: 8.HA-BZI-1- $\Delta \mathrm{N} \# 5$; HA-BZI-1 $\Delta \mathrm{N} \Delta \mathrm{D} 1$ 1: 8. $\Delta \mathrm{N} \Delta \mathrm{D} 1 \# \mathrm{X} ; \mathrm{HA}-\mathrm{BZI}-1-\Delta \mathrm{N} \Delta \mathrm{D} 2$ : p. $\Delta \mathrm{N} \Delta \mathrm{D} 2 \# 2 ; \mathrm{BZI}-1-\Delta \mathrm{N} \Delta \mathrm{BD}: 15 . \Delta \mathrm{N} \Delta \mathrm{BD} \# 1$; HA-BZI-1- $\Delta \mathrm{N} \Delta \mathrm{D} 4$ : p. $\Delta \mathrm{N} \Delta \mathrm{D} 4 \# 1$.

In Abbildung D-37 lässt sich der Unterschied im Wuchs der aufgeführten Pflanzen erkennen. Während es bei der ektopischen Überexpression des Transkriptionsfaktors (Linie 8.BZI-1 \# 13) zu keiner Veränderung im Wuchs kommt, zeigt die in der Funktion des BZI-1 gestörte Pflanze HA-BZI-1- $\Delta \mathrm{N}$ (8.HA $\Delta \mathrm{N} \# 5)$ die Merkmale einer gestörten AuxinSignalverarbeitung (HEINEKAMP et al., zur Veröffentlichung eingereicht). Im unteren Teilbild sind exemplarisch die BZI-1-Doppelderivate-exprimierenden Linien abgebildet. Hier weist ausschließlich die Linie $\Delta \mathrm{N} \Delta \mathrm{D} 2-\mathrm{BZI}-1$ (p. $\Delta \mathrm{N} \Delta \mathrm{D} 2 \# 2)$ den gestauchten Wuchs, die typische Blattform und -farbe der veränderten Auxinantwort auf. Die anderen transgenen Linien 
$(\Delta \mathrm{N} \Delta \mathrm{D} 1$-Linie: 8. $\Delta \mathrm{N} \Delta \mathrm{D} 1 \# \mathrm{X}$ und $\Delta \mathrm{N} \Delta \mathrm{D} 4$ Linie: p. $\Delta \mathrm{N} \Delta \mathrm{D} 4 \# 1)$ zeigen ein dem Wildtyp vergleichbares Wachstum. Die transdominante Funktion des BZI-1- $\Delta \mathrm{N}$ wird durch die zusätzlichen Deletionen ausgeschaltet. Die im Bereich der DNA-Bindung transdominant supprimierend wirkenden Linie BZI-1- $\Delta \mathrm{N} \Delta \mathrm{BD}$ (Linie 15. $\Delta \mathrm{N} \Delta \mathrm{BD} \# 1$ ) weist die vergleichbare Wildtypmorphologie auf. Die Unterdrückung der DNA-Bindefähigkeit des Proteins scheint somit keinen Effekt auf das morphologische Erscheinungsbild der Pflanze zu haben.

\section{6|3|5 Veränderung der auxinstimulierten Wurzelbildung}

Um die Einbindung des BZI-1 in die Auxin-Signaltransduktion genauer zu untersuchen wurden Blattexplantate des Wildtyps, der transgenen Überexpressionslinie und der transdominant supprimierten Linie BZI-1- $\Delta \mathrm{N}$ auf Medien mit unterschiedlichen Hormongehalten (Auxin / Cytokinin) ausgebracht. Durch den hohen Auxingehalt wird die Wurzelbildung stimuliert. Es zeigte sich bei der transdominant supprimierten Linien auf dem Medium mit hohem Auxingehalt eine geringe Wurzelbildung und z.T. ein Absterben des Gewebes (HEINEKAMP, 2002). Zum Test der unterschiedlichen Linien wurden Explantate auf auxinhaltige Medien ausgebracht und die Wurzelbildung analysiert (Abbildung D-38).

Die ausgebrachten Wildtyp-Pflanzen-Explantate zeigen eine normale Kallusbildung, mit daraus folgender Wurzelbildung auf dem auxinhaltigen Medium. Die Explantate der BZI-1 $\Delta \mathrm{N}$-Linie (8.HA $\Delta \mathrm{N} \# 5)$ zeigen keine Wurzel- und Kallusbildung. Das Gewebe dieser Linien verbräunt sich nach einigen Wochen und stirbt ab. Die BZI-1- $\Delta N \Delta D$ 1Doppeldeletionsderivat-exprimierenden Explantate zeigen eine sehr geringe Kallusbildung und nur vereinzelte Wurzelauswüchse. Die Verbräunung ist nicht so massiv wie bei der schon erwähnten BZI-1- $\Delta \mathrm{N}$-Linie. Die Explantate der BZI-1- $\Delta \mathrm{N} \Delta \mathrm{D} 2$-exprimierenden Linie zeigen eine leichte Kallusbildung und keine Wurzelbildung. Das Gewebe entspricht mit leichten Abweichungen dem Gewebe der BZI-1- $\Delta$ N-Pflanzen. Die Explantate der BZI-1$\Delta \mathrm{N} \Delta \mathrm{BD}$-exprimierenden Linie zeigen eine normale Kallusbildung und ein kräftiges Wurzelwachstum. Die BZI-1- $\Delta \mathrm{N} \Delta \mathrm{D} 4$-exprimierenden Explantate zeigen das gleiche Erscheinungsbild wie der Wildtyp. Hier bilden sich normale Kalli und es kommt zu normalem Wurzelwachstum. Durch die vorliegenden Ergebnisse zeigt sich die Unabhängigkeit des BZI-1- $\Delta \mathrm{N}$-ausgelösten Effektes von der Domäne 2. Die Domänen 1 und 4 sind für die molekulare Wirkung von BZI-1- $\Delta \mathrm{N}$ wichtig, wobei sich die partielle Beteiligung der Domäne 1 in der abgeschwächten Hormonantwort wiederspiegelt. Die Deletion der DNA-bindenden Domäne führt zu einer leicht verstärkten Hormonantwort. 
a

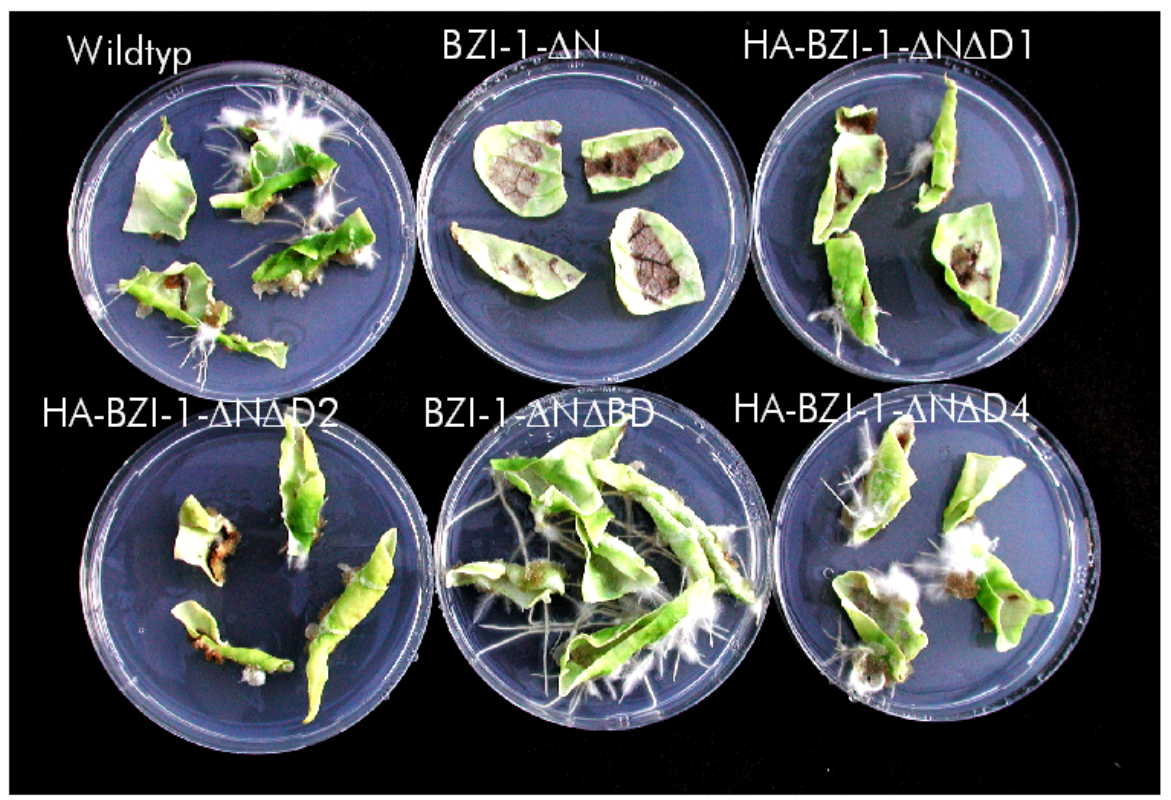

NAA $2 \mathrm{mg} /$ Kinetin 0,2 mg

b.

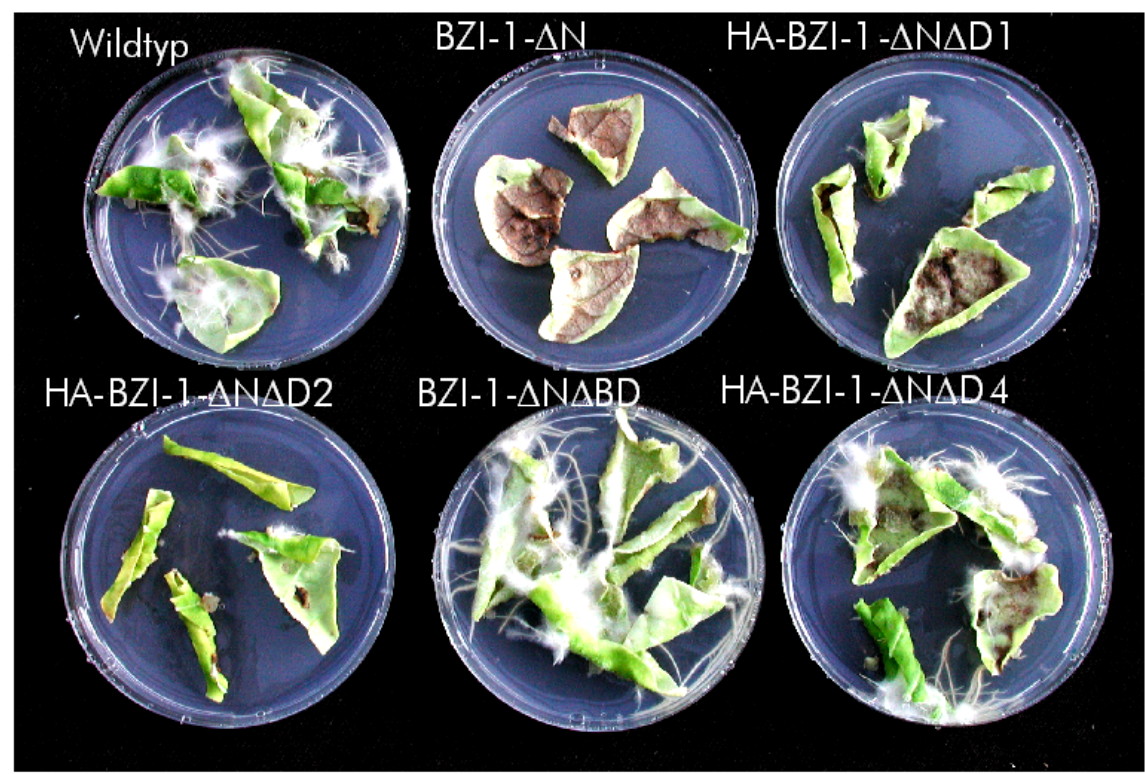

NAA $2 \mathrm{mg} /$ Kinetin 0,02 mg

Abb. D - 38: Veränderte Wurzelbildung nach Hormonstimulation mit Auxin.

Blattexplantate auf MS-Hormonmedien nach 8 Wochen Inkubation. Hormongehalt der Platten: a. NAA (Auxin) $2 \mathrm{mg} / \mathrm{l}$; Kinetin 0,2 mg/l; b. NAA (Auxin) $2 \mathrm{mg} / \mathrm{l}$; Kinetin 0,02 mg/l; Wt: Linie 8; HA-BZI-1 $\triangle \mathrm{N}$ : 8.HA-BZI-1- $\triangle \mathrm{NA} 5$; HA-BZI-

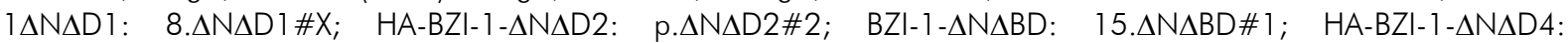
p. $\triangle \mathrm{N} \Delta \mathrm{D} 4 \# 1$. 
6|3 |6 Veränderung der Pathogenantwort durch Expression von BZI- 1 -Deletionsderivaten Um den Einfluss des Transkriptionsfaktors BZI-1 auf die Signaltransduktion während der Pathogenantwort zu charakterisieren, wurde die Reaktion der transgenen Pflanzen auf unterschiedliche pathogene Stimuli getestet. Zum Einen wurde, als Beispiel einer inkompatiblen Reaktion, die Infektion mit dem Bakterienstamm Pseudomonas syringae pv. pisi analysiert und zum Anderen die phänotypische, sowie molekulare Reaktion der transgenen Pflanzenlinien nach Infektion der Pflanzen durch den Tabakmosaikvirus (TMV) untersucht.

Der Bakterientiter wurden dreimal mit ähnlichen Ergebnissen durchgeführt. Abgebildet ist eine exemplarische Titration (s. G|7).

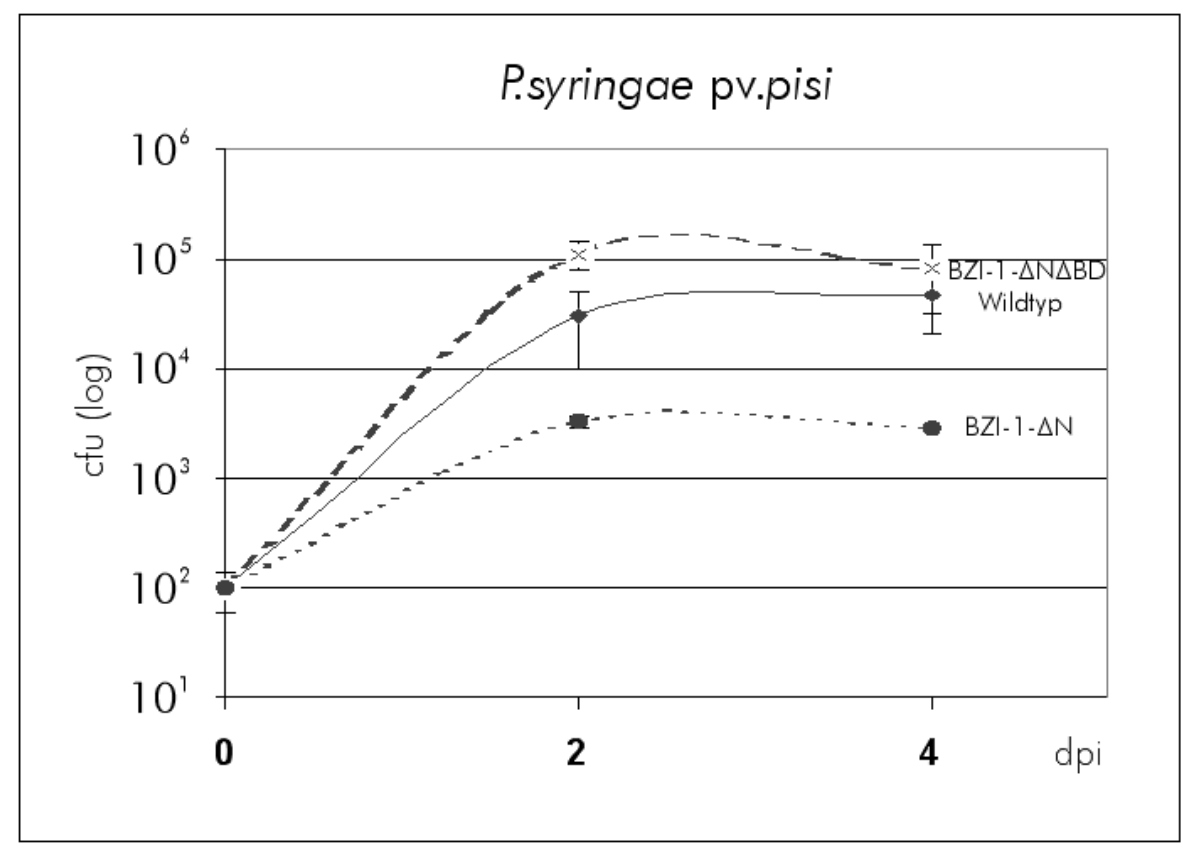

Abb. D - 39: Wachstum der Pseudomonaden in transgenen Pflanzen.

Logarithmisch aufgetragenes Wachstum der Pseudomonaden im Blattgewebe. dpi-Tage nach der Infektion (days post infection). Wachstum von Pseudomonas syringae pv. pisi in Wildtyp: Linie 8; BZI-1- $\Delta$ N: 8.HA-BZI-1- $-\Delta N \# 5 ; B Z I-1-\Delta N-$ $\Delta \mathrm{BD}$ : 15. $\triangle \mathrm{N} \Delta \mathrm{BD} \# 1$; dpi: days post infection-Tage nach Infektion.

In der oben aufgeführten Abbildung ist die Vermehrung der Bakterien, bezogen auf eine Infektionsstelle graphisch aufgetragen. Ein Messpunkt stellt den Mittelwert von 4 Messwerten á 5 Infektionsstellen dar. Die Inokulation wurde mit einer Menge von 100 cfu Pseudomonaden pro Infektionsstelle durchgeführt. Das Bakterienwachstums in der WildtypPflanze zeigt den repräsentativen Verlauf einer inkompatiblen Reaktion zwischen Bakterien und Pflanze. Die Bakterien vermehren sich innerhalb der ersten zwei Tage auf einen Wert von ca. 30.000 Bakterien pro Infektionsstelle. Im weiteren Verlauf der Infektion stagniert 
das bakterielle Wachstum. In der BZI-1- $\Delta \mathrm{N}$-exprimierenden Pflanzenlinie war die Bakterienpopulation nur auf ein Zehntel im Vergleich zum Wildtyp angestiegen. In der BZI-1 überexprimierenden Linie zeigt sich ein dem Wildtyp entsprechendes Bakterienwachstum (s. G|7). In der BZI-1- $\Delta \mathrm{N} \Delta \mathrm{BD}$-exprimierenden Linie zeigt sich in den beiden aufgeführten Versuchen ein leicht verstärktes Bakterienwachstum und eine Stagnation auf einem höheren Niveau.

Die bakterielle Vermehrung wird auf pflanzlich transkriptioneller Ebene, durch das Fehlen der Aktivierungsdomäne des $\Delta \mathrm{N}$-BZI-1-Proteins, unterdrückt. Durch die Deletion im Bereich der DNA-Bindedomäne wird die bakterielle Ausbreitung unbeeinflusst gelassen oder sogar gefördert. Die Überexpression des Proteins besitzł keinen Einfluss auf die bakterielle Ausbreitung.

Zur weiteren Analyse der Pathogeninteraktion der transgenen Pflanzen und der Funktion der einzelnen Domänen des BZI-1 wurden TMV-Infektionen der einzelnen transgenen Linien analysiert. In Datenbankanalysen konnte ein zu ANK1 identisches Protein $\mathrm{Hbp}-1$ (van der Heijden) gefunden werden. Das als $\mathrm{Hbp}-1$ bezeichnete Protein wurde in einer Hefe-"two-hybrid"-Analyse als RNA-Pflanzenvirus-Helicase-Domäne-bindendend identifiziert. Zur Charakterisierung der Domänenfunktionen in diesem Zusammenhang wurden die Pflanzen nach der TMV-Infektion phänotypisch und molekular analysiert. Den isolierten, getiterten TMV-Virus stellte freundlicherweise U. Fischer zur Verfügung.

Die untersuchten Pflanzen entstammen dem Kultivar Xanthi nc und enthalten das $\mathrm{N}$ Resistenzgen. Durch das N-Resistenzgenprodukt kann der Virus erkannt und die Pflanzenabwehr vermittelt werden. In den TMV-infizierten Wildtyp-Pflanzen zeigten sich nach 3 - 4 Tagen die Ausbildung 3 - 5 mm großer Läsionen (Abbildung D-40). Die Läsionen besaßen dunkle Ränder um einen helleren Innenhof und waren voneinander abgegrenzt. Die Ausbildung dieser Läsionen ist ein apoptotischer Vorgang (PCD, Programmierter Zelltod; programmed cell death) und wird als HR (ㅂypersensitive Reaktion) bezeichnet. Das restliche Gewebe zeigte eine leichte Vergilbung. Die Ausbreitung der Läsionen war auf das behandelte Blatt beschränkt. In diesen NN-Pflanzen vermittelt das NGenprodukt die Erkennung des Virus und die Einleitung der Pflanzenantwort. Es kommt zur Induktion der Pflanzenabwehr und Ausbildung der HR. Die Ausbreitung des Virus wird durch diesen Vorgang eingegrenzt. 

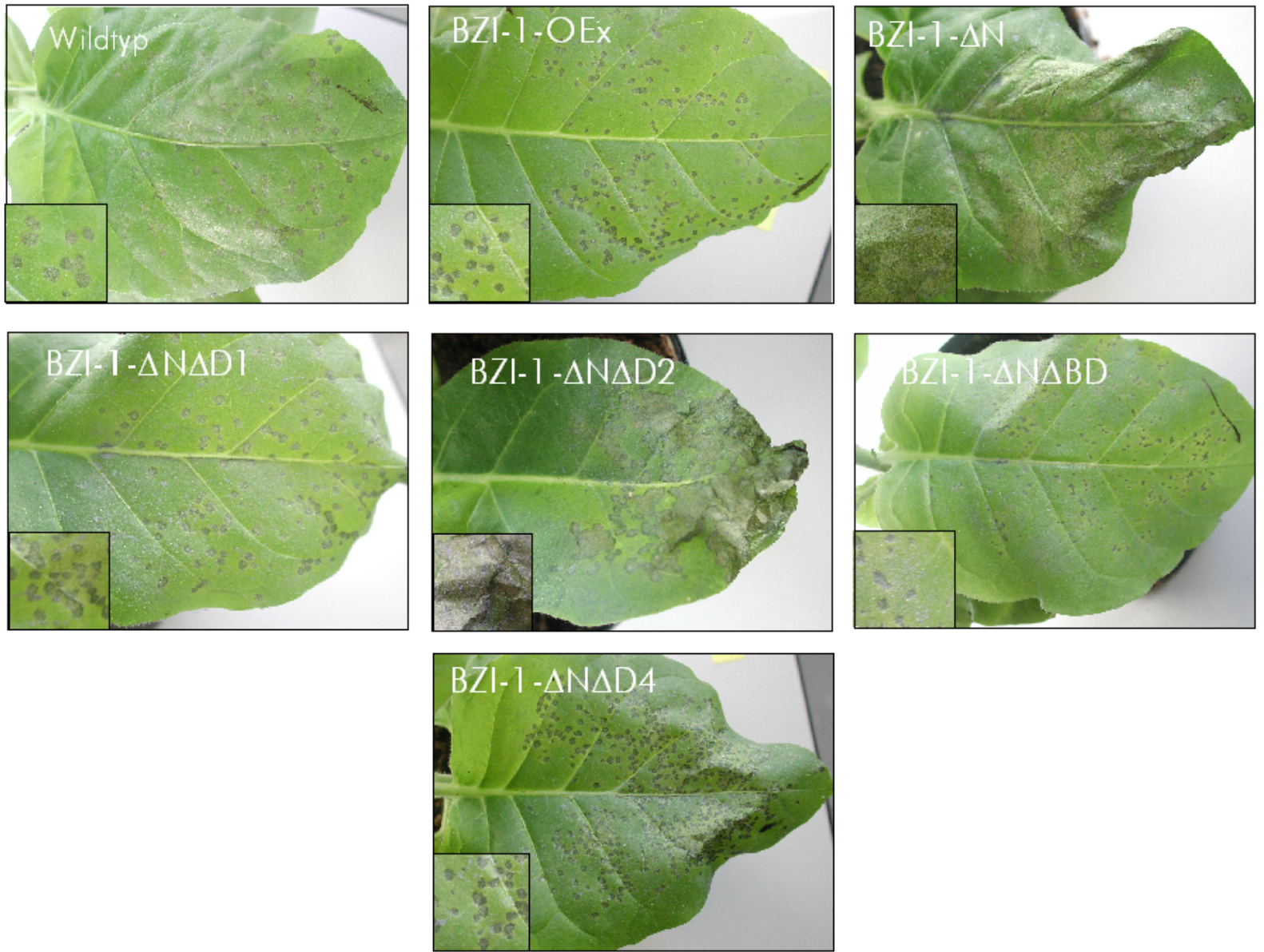

Abb. D - 40: Läsionsbildung nach TMV-Infektion.

Bildung von HR (Hypersensitiven Reaktionen) nach der TMV-Infektion an der TMV-Applikationsstelle. Wt: Linie 8; BZI-1OEx: 8.BZI-1Oex\#13; BZI-1 $\Delta$ N: 8.HA-BZI-1- $\Delta$ N\#5; BZI-1 $\Delta$ N $\Delta$ D1: 8. $\Delta$ N $\Delta$ D1 \#X; BZI-1- $\Delta N \Delta D 2$ : p. $\Delta$ N $\Delta$ D2\#2; BZI-1 $\Delta \mathrm{N} \Delta \mathrm{BD}: 15 . \Delta \mathrm{N} \Delta \mathrm{BD} \# 1$; BZI-1 $-\Delta \mathrm{N} \Delta \mathrm{D} 4$ : p. $\Delta \mathrm{N} \Delta \mathrm{D} 4 \# 1$ Aufnahmen :6 Tage nach Infektion.

In der BZI-1 überexprimierenden Linie zeigten sich ebenfalls voneinander abgegrenzte Läsionen. In der Größe entsprachen sie den Läsionen der Wildtyp-Pflanzen. Das umgebende Gewebe hatte eine grünliche Färbung. Die Ausbreitung der Viren war deutlich eingegrenzt. In der das BZI-1- $\Delta \mathrm{N}$-Derivat-exprimierenden Linie zeigte sich zu Beginn der Infektion eine Aufhellung des gesamten TMV-behandelten Gewebes. Im weiteren Verlauf verfärbte sich das komplette TMV-behandelte Blatt nekrotisch schwarz. Es besaß eine ausgetrocknete, papierartige Konsistenz. Die einzelnen Läsionen waren nicht voneinander abgrenzbar, sondern die initialen Infektionsorte nur durch dunklere Färbungen erkennbar. Die Ausbildung der HR war nicht mehr lokal auf die Infektionsorte begrenzt. In der BZI-1 $\Delta \mathrm{N} \Delta \mathrm{D} 1$-exprimierenden Linie zeigte sich ein intermediärer Phänotyp. Die Pflanzenantworł entsprach zu Beginn der Abwehrreaktion einer Wildtyppflanze mit der Ausbildung vereinzelter Läsionen (Abbildung D-40). Die Läsionen weiteten sich im fortschreitenden Verlauf der Infektion weiter aus. Die Ausweitung der HR belief sich im späteren Zeitraum 
der Infektion (>7 Tage) auf das gesamte, infizierte Blatt. Somit war der Phänotyp der BZI1- $\Delta \mathrm{N}$-exprimierenden Linien vergleichbar. Das Blatt war schwarz-bräunlich verfärbt, komplett ausgetrocknet und abgestorben.

Die BZI-1- $\Delta \mathrm{N} \Delta \mathrm{D} 2$-exprimierende Pflanze zeigt ebenfalls eine starke Ausweitung der Nekrose auf das gesamte Blatt. Die einzelnen HRs sind nicht mehr voneinander abgrenzbar und das gesamte Blattgewebe schwarz-braun verfärbt. Die ausgeprägte Abwehrreaktion entspricht der der BZI-1- $\Delta \mathrm{N}$-exprimierenden Pflanze in Aussehen und im gleichen zeitlichen Verlauf.

In der, durch die Deletion der DNA-Bindedomäne transdominant supprimierend wirkenden Pflanzenlinie BZI-1- $\triangle \mathrm{N} \Delta \mathrm{BD}$ zeigt sich der entgegengesetzte Effekt. Hier sind in verringertem Maß hypersensitive Reaktionen zu erkennen. Das infizierte Gewebe zeigł eine verstärkte Vergilbung und in einigen Bereichen kleine Läsionen. Es treten erst sehr spät im Infektionsverlauf deutlich differenzierbare Läsionen auf. Durch das Erscheinungsbild der schwach ausgeprägten lokalen Antwort scheint die Pflanzenabwehr unterdrückł zu sein.

In der BZI-1- $\Delta \mathrm{N} \Delta \mathrm{D} 4$-exprimierenden Pflanzenlinie zeigt sich die Ausbildung abgegrenzter Läsionen und eine zusätzliche Vergilbung des umgebenden Gewebes. Diese Pathogenantwort entspricht der der Wildtyp-Pflanze. Durch die zusätzliche Deletion der Domäne 4 lässt sich der Effekt des BZI-1- $\Delta$ N-Proteins ausschalten. Hieraus kann eine Funktion in der Signaltransduktion der Pflanzenabwehr abgeleitet werden.

Eine lokale Infektion einer Pflanze löst in systemischen Geweben die Ausbildung einer SAR aus. Um die Auswirkungen des BZI-1-beeinflussten Effektes weiter zu untersuchen, wurde die Ausbildung der systemisch erworbenen Resistenz (SAR) durch die TMV-Induktion molekular analysiert. Als Markergen für die SAR wurde die PR-Genexpression nach 6 Tagen analysiert (GUO et al., 2000). 


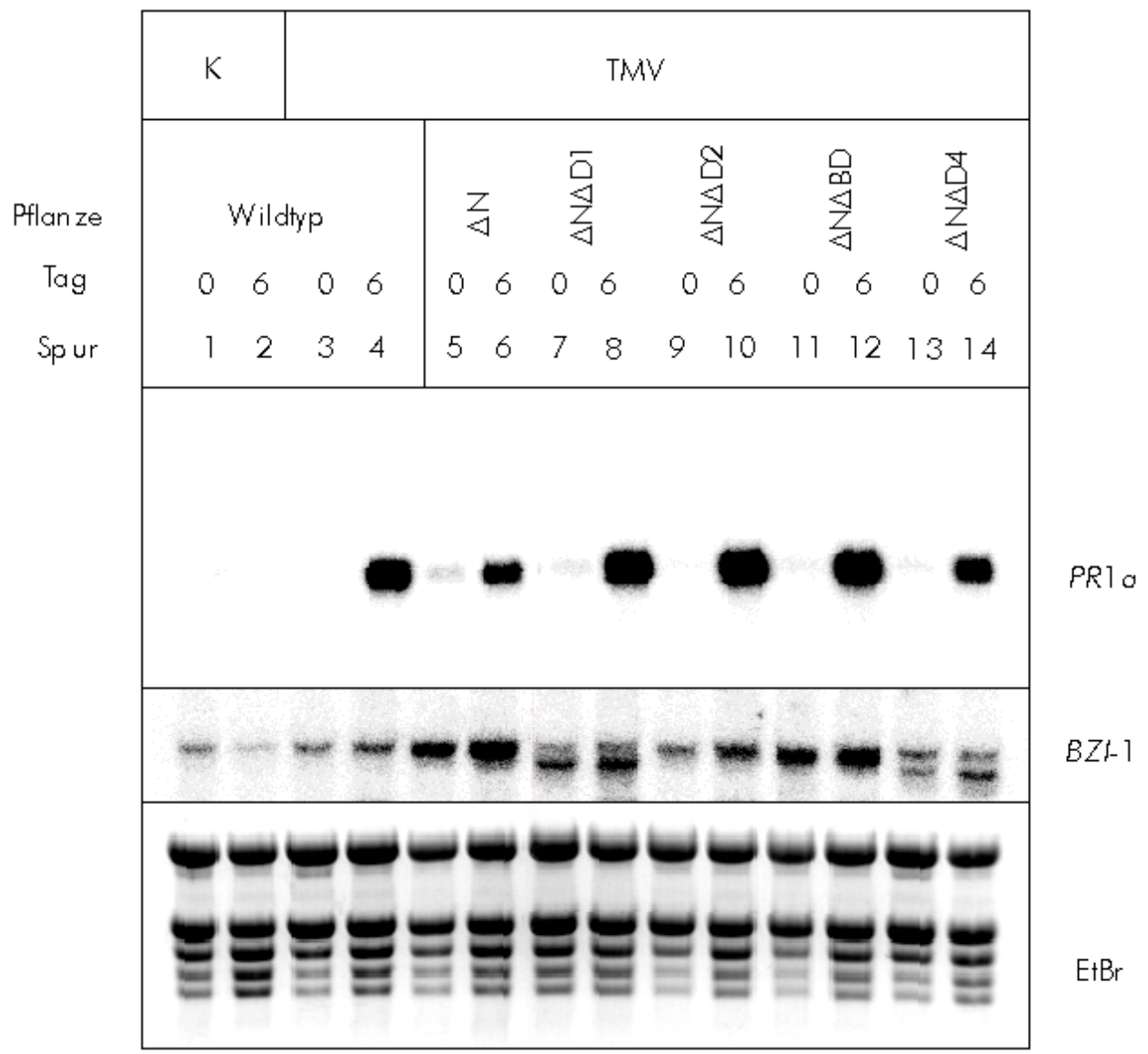

Abb. D - 41 : Molekulare Analyse der SAR in den BZI-1-Derivat-exprimierenden Linien.

Hybridisierung von Blatt-RNA 0 und 6 Tage nach TMV-Infektion mit PRla: N.t.PRla und BZI-1 : N.t.BZI-1; EtBr: Ethidiumbromidgel. K- Puffer behandele Kontrolle; TMV-TMV-Infektion. Spur 1-4 Wildtyp: Linie 8 (1/2: Kontrolle; 3/4: TMV); Spur5/6: BZI-1 $\Delta$ N: 8.HA-BZI-1- $\Delta$ N\#5; Spur7/8: BZI-1 $\Delta N \Delta D 1$ : 8. $\Delta N \Delta D 1 \#$; Spur9/10: BZI-1- $\Delta N \Delta D 2$ : p. $\Delta$ N $\Delta$ D2\#2; Spur1 1/12: BZI-1- $\Delta \mathrm{N} \Delta \mathrm{BD}$ : 15. $\Delta \mathrm{N} \Delta \mathrm{BD} \# 1$; Spur 13/14: BZI-1- $-\Delta \mathrm{N} \Delta \mathrm{D} 4$ : p. $\Delta \mathrm{N} \Delta \mathrm{D} 4 \# 1$.

Die Abbildung D-41 zeigt die molekularen Auswirkungen der TMV-Infektion auf die PR laExpression in den unterschiedlichen BZI-1-Deletionsderivat exprimierenden Linien. Durch die Behandlung und Verwundung mit Carborundum ist keine PRla-Expression und somit keine SAR detektierbar. 6 Tage nach der Pathogeninfektion zeigt sich deutlich die Expression der PRla-RNA. Diese spiegelt die Etablierung der SAR in der Pflanze wieder. Die isolierte RNA der BZI-1- $\Delta \mathrm{N}$-exprimierenden Pflanze zeigt im Vergleich zum Wildtyp eine Reduzierung der PRla-Transkriptmenge nach TMV-Infektion um ca. die Hälfte. Vergleichbares ist ebenso in der $\Delta \mathrm{N} \Delta \mathrm{D} 4$-BZI-1-Derivat-exprimierenden Linie zu erkennen. In den BZI-1- $\Delta \mathrm{N} \Delta \mathrm{D} 1$ 1-, BZI-1- $\Delta \mathrm{N} \Delta \mathrm{D} 2$ - und BZI-1- $\Delta \mathrm{N} \Delta \mathrm{BD}$-exprimierenden Linien zeigt sich die dem Wildtyp vergleichbare Menge des PR 1a-Transkriptes. Die supprimierende Wirkung des $\Delta \mathrm{N}$-Derivates wird durch die Deletionen der Domänen 1 und 2 eliminiert. Durch die Expression des nicht mehr DNA-bindenden Derivates zeigt sich ebenfalls die, dem Wildtyp vergleichbare Auslösung der SAR. Die Detektion des BZI-1-Transkriptes zeigt in den 
Wildtyp-Pflanzen die Expression des endogenen BZI-1-Gens. In den transgenen Linien wird zusätzlich zu der Expression des endogenen BZI-1 die Expression der transgenen Deletionsderivate sichtbar. Durch die zusätzlich eingefügten Deletionen werden vor allem die Deletionsderivate $\Delta \mathrm{N} \Delta \mathrm{D} 1-\mathrm{BZI}-1$ und $\Delta \mathrm{N} \Delta \mathrm{D} 4-\mathrm{BZI}-1$ sichtbar. Die anderen Deletionderivate überlagern aufgrund des 3'-untranslatierten Bereiches die endogene BZI1-RNA-Bande. In allen transgenen Linien wird die verstärkte Expression des Transgens nach TMV-Induktion sichtbar. Die verstärkte Expression beruht auf dem pathogenregulierten as- 7 -Element im verwendeten CaMV35S-Promotor. 


\section{E | Diskussion}

Die wesentlichen Eigenschaften eines Transkriptionsfaktors sind seine Fähigkeit spezifisch an DNA zu binden und die Transkription zu regulieren. Neben diesen fundamentalen Eigenschaften werden jedoch für eine spezifische Signalvermittlung weitere Eigenschaften benötigt. So muss der Faktor, möglicherweise reguliert, im Zellkern vorkommen, mit anderen Proteinen interagieren können oder posttranslational modifiziert werden. Für den im Rahmen dieser Arbeit untersuchten Transkriptionsfaktor N.t.BZI-1 konnten durch den Aminosäuresequenz-Vergleich mit verwandten Faktoren die konservierten Domänen definiert werden. Da Transkriptionsfaktoren modular aufgebaut sind (PTASHNE et al., 1989) ist es wahrscheinlich, dass die konservierten Domänen Modulen entsprechen, durch die bestimmte Funktionen vermittelt werden. Durch die Analyse von Deletionsderivaten des Transkriptionsfaktors BZI-1 in vitro und in vivo wurde so diesen Domänen eine Funktion zugewiesen.

\section{1 | Expression von BZI-1-Deletionsderivaten in transgenen Pflanzen: Charakterisierung der konservierten BZI-1-Domänen}

Wie aus den vorangegangenen Studien bekannt, traten in den BZI-1- $\Delta \mathrm{N}$ - exprimierenden Pflanzen phänotypische Veränderungen auf (HEINEKAMP et al., 2002). Diese phänotypischen Effekte beruhen möglicherweise auf der Bildung von BZI-1- $\Delta \mathrm{N}-$ Homodimeren und inaktiven BZI-1/ BZI-1- $\Delta \mathrm{N}$-Heterodimeren. Durch die Deletion des N-Terminus im BZI-1Protein erfolgt so nach der Bindung an ein cis-Element die Blockierung der Transkription von Zielgenen. Die erhöhte Affinität des BZI-1- $\Delta$ N-Derivates gegenüber dem BZI-1Gesamtprotein belegten die EMSA-Studien. Die Menge an funktionalem, endogenem BZI1 ist in diesen BZI-1- $\Delta \mathrm{N}$-exprimierenden Pflanzen somit herabgesetzt.

Die transaktivierende Wirkung des N-terminalen Bereichs von BZI-1 konnte durch unterschiedliche Methoden nachgewiesen werden. Erstmals konnte eine transaktivierende Wirkung der Domäne N von BZI-1 im Hefe-"two-hybrid"-System gezeigt werden (HEINEKAMP et al., 2002). Vergleichbare Ergebnisse waren auch von dem BZI-1-verwandten Transkriptionsfaktor BLZ1 aus Gerste bekannt. Im Hefe-System konnte den 203 N- 
terminalen Aminosäuren von BLZ1 85\% der aktivierenden Eigenschaften nachgewiesen werden (VICENTE-CARBAJOSA et al., 1998).

Reportergenanalysen, in denen BZI-1 transient in Tabak-Protoplasten exprimiert wurde, zeigten eine leichte Aktivierung, die durch die Deletion der Domäne $N$ verlorenging (HEINEKAMP, 2002). Vergleichbare Reportergenanalysen mit dem Transkriptionsfaktor CPRF2 aus Petersilie zeigten eine entsprechende schwache Aktivierung (SPRENGER-HAUSSELS \& WEISHAAR, 2000).

Des Weiteren können durch die Interaktion des BZI-1- $\Delta \mathrm{N}$ mit BZI-2, BZI-3/TBZF und BZI-4 ebenfalls inaktive Heterodimere gebildet werden, wodurch ebenfalls die Transkription von Zielgenen reduziert wird. Die Expression des BZI-1- $\Delta \mathrm{N}$-Derivates führt somit zU einem dominant negativen Effekt auf die BZI-1-Zielgenexpression.

Die Analyse der Funktionen der unterschiedlichen Domänen wurde, basierend auf diesen BZI-1- $\Delta \mathrm{N}$-exprimierenden Pflanzen, durchgeführt. So wurde untersucht, ob die zusätzliche Deletion einer Domäne zum Ausfall des aufgetretenen Phänotyps führt. Durch diese Revertierung zum Wildtyp-Phänotyp in den einzelnen funktionalen Zusammenhängen kann man auf eine Beteiligung der Domänen schließen. Untersucht wurden in diesem Zusammenhang die Blütengröße, die Pollenbildung, die Auxin- und die Pathogenantwort der Pflanzen.

Durch die zusätzliche Deletion einer weiteren Domäne des BZI-1 kann möglicherweise eine Änderung der Konformation oder Stabilität des Proteins herbeigeführt werden, was zu einem totalen Ausfall der nachweisbaren Eigenschaften des Proteins führen kann. In solch einem Fall kann eine Revertierung zu dem Wildtyp-Phänotypen eine Funktion der zusätzlichen Domäne suggerieren, welche nicht gegeben ist.

Der Nachweis der Expression der transgenen Proteine konnte in jedem Fall geführt werden. Durch die Western-Blot-Analyse wurde ersichtlich, dass die Stabilität der transgen eingebrachten Proteine nicht beeinflusst war. Es waren immunologisch keine nachweisbaren Abbauprodukte vorhanden.

Ein funktionaler Nachweis der transgenen Proteine konnte für BZI-1- $\Delta N, B Z I-1-\Delta N \Delta D 1$ in Bezug auf die DNA-Bindung durch die in vitro DNA-Bindestudien geführt werden. Dies zeigte die verstärkte Bindung der BZI-1- $\Delta \mathrm{N}$ und $\mathrm{BZI}-1-\Delta \mathrm{N} \Delta \mathrm{D} 1$-Derivate im Vergleich zum BZI- 1 .

Durch die komplette Deletion der einzelnen Domänen erfolgt nur eine funktionale Grobkartierung der jeweiligen vermittelten Funktion. Zur direkten Zurückführung der 
Funktion auf einzelne Aminosäuren oder Sequenzen wäre eine Punktmutation im jeweiligen Bereich zur genaveren Charakterisierung angebracht. Eine solche Punktmutation könnte zwar eine Konformationsänderung ebenfalls nicht ausschließen, jedoch die Wahrscheinlichkeit dafür verringern. Die Analyse dieser Vielzahl von Konstrukten in planta ist allerdings überaus aufwendig. Durch die Expression des BZI-1$\Delta \mathrm{N} \Delta \mathrm{D} 2$-Derivates und dem BZI-1-DN entprechenden Phänotyp.

Für die Analyse der Domänenfunktionen von BZI-1 in der Pflanze wurden die Pflanzenlinien, die unterschiedliche BZI-1-Deletionsderivate exprimieren durch Agrobakterien-vermittelten Gentransfer hergestellt. Die Expression der Deletionsderivate steht unter der Kontrolle des modifizierten 35S-Promotors (GATZ et al., 1992). Hierdurch sollte eine konstitutive, Gewebe-unabhängige, gleichmäßige Expression der Transgene gewährleistet werden. Bei der Analyse der transgenen Linien zeigten sich dennoch relativ große Schwankungen zwischen den unterschiedlichen unabhängigen Transformanten. Diese beruhen wahrscheinlich auf Positionseffekten durch den jeweiligen Insertionsort der T-DNA in das Genom der Pflanze. Verwendet wurden für die in planta-Studien jeweils die das Transgen am stärksten exprimierenden Linien, deren Expression auf RNA- und ProteinEbene ähnlich stark war. Für die Doppeldeletionsmutante im Bereich der basischen Domäne konnte leider nur mit einer hochexprimierenden Linie gearbeitet werden, da alle weiteren, getesten Linien das Transgen in weit geringerem Maße exprimierten. Durch die Deletion der basischen Domäne ist die Funktion der DNA-Bindung nicht mehr möglich. Da die basische Domäne neben der DNA-Bindung ebenso die Funktion einer Kernlokalisierung vermittelt, sind die in planta phänotypisch auftretenden Effekte sehr schwierig zu differenzieren. So kann in jedem funktionalen Zusammenhang, neben der Unterdrückung der DNA-Bindung durch eine cytosolisch lokalisierte Homo- oder Heterodimerbildung, die Kernlokalisation unterschiedlicher Faktoren modifiziert werden, was zu den unterschiedlichen sichtbaren Phänotypen führen kann. Ein sowohl von der BZI1- $\Delta \mathrm{N}$-exprimierenden Pflanze als auch von der BZI-1-überexprimierenden Pflanze abweichender phänotypischer Effekt war ausschließlich in der BZI-1- $\Delta N \Delta B D$ exprimierenden Linie nachweisbar. Die phänotypischen Effekte bezüglich Wuchs, Blütenbildung oder Pathogenantwort der weiteren, BZI-1-Doppeldeletionsderivateexprimierenden Pflanzen korrelierten mit der nachweisbaren Expression der transgenen Proteine in jedem Fall. 
Durch die zusätzliche Deletion der Domänen 1 und 4 konnten in den untersuchten transgenen Pflanzen die phänotypischen Auswirkungen der Domäne-N-Deletion in Bezug auf die Auxin-Antwort, Pollenbildung und Blütenentwicklung zum Wildtyp-phänotypen revertiert werden.

Die transgenen BZI-1- $\Delta \mathrm{N} \Delta \mathrm{D} 2$-Derivat exprimierenden Pflanzen entsprachen phänotypisch den BZI-1- $\Delta$ N-Derivat exprimierenden Pflanzen. Diese zusätzlich eingefügte Deletion besitzt somit keine funktionalen Auswirkungen auf die Wirkung des BZI-1- $\Delta$ N-Proteins.

So lässt sich eine Bedeutung der Domänen 1, der basischen Domäne und Domäne 4 in allen Funktionszusammenhängen, gestütz† durch die weiteren in vitro-Analysen, nachweisen.

\section{2 | Die basische Domäne von BZI-1 vermittelt die Spezifität, die Domäne N moduliert die Bindung an ein G/C-Box-Promotorelement des auxinresponsiven GH3-Gens}

Die DNA-Bindung von Transkriptionsfaktoren kann durch unterschiedliche Methoden nachgewiesen werden. Dies kann einerseits durch den in vitro-Nachweis der Bindung durch eine EMSA geschehen, oder anderseits in planta durch Unterschiede in der Expression von Zielgenen in transgen modifizierten Pflanzen detektiert werden. Ergänzend sind Mutationen im Promotorbereich und eine Analyse der Reportergen-Expression in transgenen Pflanzen und Chromatin-Immuno-Präzipitations-Analysen möglich.

Die Bindung von bZIP-Faktoren an DNA wird durch die basische Domäne vermittelt (VARAGONA et al., 1994). Das rekombinant hergestellte BZI-1-Deletionsderivat, ohne die basische Domäne ist nicht mehr in der Lage an DNA zu binden. Immunologisch waren die zur EMSA eingesetzten rekombinanten Proteinen in den gleichen Mengen nachweisbar.

Durch die Aminosäuresequenz dieser Domäne wird die DNA-Bindespezifität für das entsprechende cis-Element festgelegt. Als Konsensussequenz für bZIPTranskriptionsfaktoren konnte das ACGT-Kernmotiv festgelegt werden (FOSTER et al., 1994), welches jedoch in Einzelfällen auch abweichen kann (DE PATER et al., 1994). Neben dem Kernmotiv sind auch die umgebenden Nucleotide für die Spezifität eines Faktors von entscheidender Wichtigkeit (IZAWA et al.,1992). Für den BZI-1 nah verwandten Transkriptionsfaktor CPRF2 aus Petersilie (Petroselinum crispum) konnte gezeigt werden, dass er in vitro die G- und die C-Box bindet (KIRCHER et al., 1998; WELLMER et al., 1999). 
Für BZI-1- $\Delta \mathrm{N}$ konnte im Vorfeld bereits die Bindung an ein breites Spektrum verwandter cis-Elemente gezeigt werden (DRÖGE-LASER et al., 1997). Diese Bindung an die G- und CBox-Elemente durch eine Kompetitions-Analyse bestätigt. Eine Regulation der G-Boxenthaltenden Promotoren in planta wurde aufgrund der in vitro-Isolation (DRÖGE-LASER et al., 1997) des Faktors BZI-1 postuliert, konnte jedoch in vivo nicht nachgewiesen werden (HEINEKAMP et al., 2002). Untersucht wurden hier insbesondere Gene des Phenylpropanstoffwechsels (Chalkonsynthase, CHS und Phenylammoniumlyase, PAL) deren Promotoren G-Box-Elemente mit regulatorischen Eigenschaften trugen. Die Expression dieser Gene konnte durch negativ regulierende BZI-1- $\Delta \mathrm{N}$-Derivate oder überaktivierende VP16-BZI-1-Derivate weder gewebespezifisch noch Pathogen-stimuliert beeinflusst werden. Aufgrund des veränderten vegetativen Wuchses in den BZI-1- $\Delta \mathrm{N}$ exprimierenden Pflanzen konnte ein direkter oder indirekter Einfluss auf Auxin-induzierte Gene vermutet werden. Da sich die Auxin-mengen in den untersuchten Pflanzen nicht voneinander unterschieden (HEINEKAMP et al., 2002), wurde eine Beteiligung von BZI-1 an der Auxin-Signalverarbeitung angenommen. Durch die verringerte Wurzelbildung von Blattexplantaten auf Auxinhaltigen Medien der BZI-1- $\Delta \mathrm{N}$-exprimierenden Pflanzen zeigt sich ein reproduzierbarer Effekt von BZI-1 in der Auxin-Signaltransduktion. Die Explantate der Pflanze mit nicht mehr DNA-bindendem BZI-1- $\Delta \mathrm{N} \Delta \mathrm{BD}$-Derivat zeigten keine Veränderung, beziehungsweise eine gering verstärkte Wurzelbildung. Als putatives Zielgen konnte so das N.t.-GH3-Gen identifiziert werden (ROUX et al., 1997). Im gut analysierten Promotorbereich des vergleichbaren Sojabohnen (Glycine max) - GH3-Gens (LIU et al., 1997) konnte so die G/C-Box als putative BZI-1-Bindestelle innerhalb des Fragmentes El (LIU et al., 1997) gefunden werden.

Die Auxin-Responsivität des GH3-Gens wird durch die Auxin-responsiven Promotorfragmente D1, D4 und E1 unabhängig voneinander vermittelt (ULMASOV et al., 1995, LIU et al., 1997). BZI-1- $-\Delta N$ bindet, wie durch die EMSA-Analyse belegt, an die G/C-Box im Bereich des Fragmentes E1. Diese in vitro nachgewiesene Bindung legt somit, beispielhaft am GH3-Gen gezeigt, die Vermutung nahe, dass durch die Expression des BZI-1- $\Delta \mathrm{N}$ Derivates der Auxin-insensitive Phänotyp molekular hervorgerufen wird. Ein ähnlicher repressiver Mechanismus konnte bereits durch ein G-Box-bindendes Protein (SGBF-2) an das E1-Promotorfragment gezeigt werden (LIU et al., 1997).

Wie aus den Ergebnissen der in vitro DNA-Bindestudien ersichtlich, ist BZI-1- $\Delta \mathrm{N}$ als Homodimer in der Lage an die chimäre G/C-Box zu binden. Die Bindung ist spezifisch 
und korreliert mit der Menge an eingesetztem Transkriptionsfaktor. Aus dem Kompetitionsvergleich mit den anderen ACGT-Kernmotiv-enthaltenden cis-Elementen geht hervor, dass die Bindung von BZI-1- $\Delta \mathrm{N}$ an die chimäre G/C-Box eine vergleichbar hohe Affinität besitzł wie die Bindung an die G-oder C-Box. Da Transkriptionsfaktoren einen modularen Aufbau besitzten (PTASHNE et al., 1988) ist davon auszugehen, dass das "Modul" der basische Domäne die spezifische Bindung an die G/C-Box vermittelt. Dieses gilt demnach ebenso für BZI-1. Wie aus den in vitro Bindestudien ersichtlich, bindet das Gesamt-BZI-1, beim Einsatz der gleichen immunologisch nachweisbaren Menge, jedoch nur mit einer sehr geringen Affinität an die G/C-Box im Vergleich zum BZl-1- $\Delta N$. Die geringe Affinität des Gesamt-BZI-1 zur G/C-Box weist auf eine regulatorische Funktion der Domäne $\mathrm{N}$ in Bezug auf die DNA-Bindung hin.

Diese Verringerung der Bindeeigenschaft kann möglicherweise auf einer sterischen Hinderung der DNA-Zugänglichkeit beruhen. Es ist aber auch möglich, dass die Nterminale Domäne sterisch die Homodimer-Bildung von BZI-1 einschränkt und hierdurch die DNA-Bindefähigkeit moduliert wird. Beide Mechanismen könnten in planta durch eine posttranslationale Modifikation aufgehoben werden.

Diese Daten aus der in vitro-Analyse entspechen auch der Beobachtung, dass die BZI-1OEx-Pflanzen keine phänotypischen Abweichungen im vegetativen Wuchs von der Wildtyppflanze zeigen (HEINEKAMP et al., 2002).

Zusammen mit den Ergebnissen aus den in planta-Expressionsstudien ist hier ein direkter Einfluss des BZI-1- $\Delta$ N-Derivates auf ein Auxin-responsives Zielgen nachweisbar. Ob diese Regulation durch das BZI-1-Homodimer oder ein Heterodimer (z.B. BZI-1/-3) ausgelöst wird, ist weiter zu untersuchen. Für den BZI-3/TBZF-Faktor konnte eine Auxin-stimulierte transkriptionelle Aktivierung gezeigt werden (YANG et al., 2001). Eine solche Regulation legt eine Beteiligung eines Heterodimers an der Auxin-Signalverarbeitung nah.

Die vorliegenden Ergebnisse weisen die Beteiligung des BZI-1-Trankriptionsfaktors auf die Auxin-Signalverarbeitung auf molekularer Ebene nach. Dieser Mechanismus könnte Teil einer Regulation von Auxin-sensitiven Genen sein, wobei die Expression dieser Gene nach Pathogenbefall gesenkt wird. Diese Regulation wäre verständlich, da für die Pathogenabwehr die begrenzten Ressourcen der Pflanze von Wachstumsprozessen in die Abwehrprozesse umgeleitet werden müssen. Eine entsprechende Regulation konnte bereits für Signalwege von Mitogen-aktivierten Proteinkinasen gezeigt werden (TENA et al., 2001). 
In der BZI-1- $\Delta \mathrm{N} \Delta \mathrm{BD}$-Derivat-exprimierenden Pflanze wird die Auxin-Signalperzeption nicht beeinflusst. Dies spiegelt sich in dem Wildtyp-ähnlichen vegetativen Wuchs der Pflanze und dem Verhalten der Explantate auf den Hormonmedien wieder. Das transgen eingebrachte BZI-1- $\Delta \mathrm{N} \Delta \mathrm{BD}$-Protein ist nur eingeschränkt in der Lage in den Kern zu gelangen und ebenfalls nicht DNA-bindefähig. Ein vergleichbarer BZI-1- $\Delta \mathrm{N}$-ausgelöster Mechanismus ist für dieses Derivat somit nicht möglich.

Um den Zusammenhang zwischen BZI-1- $\Delta$ N-DNA-Bindung und Regulation der GH3Expression abzusichern, sollte im Weiteren eine genavere Promotor-Analyse des GH3Gens erfolgen, um die G/C-Box als cis-Element auch im Tabak-Promotorkontext nachzuweisen. Eine direkte Bindung des transgen eingebrachten Proteins sollte durch eine Chromatin-Immunopräzipitation künftig nachweisbar sein. Durch diese Methode könnte auch die DNA-Bindung von BZI-1 unter unterschiedlichen Stimuli in planta fixiert und der regulatorische Mechanismus aufgeklärt werden. 


\section{3| Die Domänen N, 1, 2 und die basische Domäne sind an der Regulation des Kerntransportes von BZI-1 beteiligt}

Eine mittlerweile häufig angewendete Methode zur Lokalisierung von Proteinen innerhalb der Pflanzenzelle ist der mikroskopische Nachweis von GFP-Fusionsproteinen (HAASEN et al., 1999). Durch die GFP-Fusion und transiente Expression der BZI-1-Deletionsderivate in den Tabak-Mesophyll-Protoplasten lässt sich die Verteilung des BZI-1-Proteins detektieren. Durch die C-terminale Fusion des GFP-Proteins an das zu untersuchende Protein wird das Molekulargewicht des Fusionsproteins erhöht, was eine veränderte Lokalisation zur Folge haben kann. Zusätzlich scheint das GFP-Protein selbst eine verstärkte Stabilität im Kern zu besitzten. Um Aussagen über die Verteilung des BZI-1 machen zu können, wurden Konstrukte vergleichbarer Größe mit bekannter Lokalisation als Kontrollen verwendet.

Durch die Deletion der Domänen N, 1, 2 und der basischen Domäne, sowie den in den transgenen Pflanzen exprimierten Doppeldeletionsderivaten BZI-1- $\Delta N \Delta \mathrm{D} 1, \mathrm{BZI}-1-\Delta \mathrm{N} \Delta \mathrm{D} 2$ und BZI-1- $-\Delta N \Delta B D$, sollte eine Zuweisung einer Funktion im Rahmen des Kernimportes oder eventuell Kernexportes nachzuweisen sein.

Für das BZI-1-GFP-Fusionsprotein war eine vorwiegende Lokalisierung im Kern nachweisbar. Durch eine semiquantitative Auswertung von LSM-Aufnahmen lässt sich die Menge des im Kern vorkommenden Proteins auf ca. 80\% der Gesamtmenge festlegen. Diese nachweisbare nukleäre Verteilung des Proteins kann unter Umständen durch die Überexpression in dem transienten System beeinflusst sein. Mögliche regulatorische Mechanismen, die eine Retardation des endogenen BZI-1 bewirken, können so außer Kraft gesetzt sein.

Durch die Analyse der aufgrund des Molekulargewichtes vergleichbaren Proteine kann man auf einen aktiven Transport von BZI- 1 in den Kern schließen. So müssen Proteine mit einer Größe von mehr als 60 kDa aktiv in den Kern transportiert werden (RHEE et al., 2000). Eine Translokation in den Kern erfolgt durch zwei Schritte. Der erste Schritt besteht in der Bindung des zu transportierenden Proteins über eine als NLS bezeichnete Erkennungssequenz an Importrezeptoren. Diese Bindung kann auch durch zusätzliche Adaptorproteine vermittelt werden. Im zweiten Schritt erfolgt die energieabhängige Einschleusung des Proteins durch den Kernporenkomplex (MERKLE, 2001).

Wie aus den Analysen des BZI-1-ABD-GFP-Fusionsproteins ersichtlich, lässt sich dieses fluoreszenz-mikroskopisch verstärkt im Cytosol nachweisen. Das weiterhin im Kern 
nachweisbare BZI-1-ABD-GFP-Fusionsprotein bildet im Cytosol möglicherweise Heterodimere mit anderen bZIP-Transkriptionsfaktoren. Hierdurch erhielte das Dimer eine NLS und das BZI-1-ABD-GFP könnte in den Kern eingeschleppt werden.

In den BZI-1- $\Delta$ N $\Delta$ BD-Derivat-exprimierenden Pflanzen zeigt die Immunodetektion eine fast ausschließliche Verteilung des nachgewiesenen BZI-1- $\Delta \mathrm{N} \Delta \mathrm{BD}$-Proteins im Cytoplasma. Wie aus den oben genannten Ergebnissen deutlich wird, wirkt die basischen Domäne des Transkriptionsfaktors BZI-1 nicht nur als DNA-Bindedomäne, sondern besitz† unabhängig die Funktion einer NLS (Nukleus-Lokalisierungs-Sequenz). Vergleichbares konnte für den verwandten Faktor OPAQUE-2 gezeigt werden (VARAGONA \& RAIKHEL, 1994). OPAQUE2 besitzt neben der NLS A im N-terminalen Bereich die funktional charakterisierte NLS B als zweigeteilte (bipartite) NLS. Diese NLS B besteht aus zwei Teilen mit basischen Aminosäuren. Der erste Teil besteht aus zwei basischen Aminosäuren und ist durch eine "Spacer"-Region von 10 Aminosäuren von einem weiteren Bereich abgeteilt, der sich durch 5 Aminosäuren, von denen mindestens 3 basisch sind, auszeichnet. Zusammengefasst wird dies mit einer allgemeinen Sequenz $\left[K R(X)_{10}\left(B_{3} X_{2}\right)\right]$ (DINGWALL \& LASKEY, 1991), wobei B eine basische Aminosäure darstellt. Die vergleichbare Sequenz findet sich im BZI-1-Protein im Bereich von 259-279 AS (KRVRRMLSNRESARRSRRRK) wieder. Durch die eingefügte Deletion im BZI-1 - $\Delta$ N $\Delta B$ D-Protein wird diese komplette Sequenz, bis auf die letzten beiden Aminosäuren entfernt. Durch die Bindung dieser Domäne an NBP (Nucleare-BindeProteine) als cytosolischer Rezeptorer (HICKS \& RAIKHEL, 1995) und anschließender Verbindung an den Kernporenkomplex über ein IMPORTIN $\alpha$-homologes Protein wird im Anschluss der zweite ATP-abhängige Schritt der Translokation eingeleitet. Vergleichbares konnte für die funktional identische NLS von OPAQUE2 gezeigt werden (SMITH et al., 1997). Durch die Deletionen der Domänen $N, 1$ und 2 zeigt sich ein rein nukleäres Vorkommen der BZI-1-GFP-Fusionsproteine. Diese veränderte Lokalisierung kann entweder in der Deletionen-bedingten verringerten Größe der Proteine und damit erhöhten Mobilität, oder einer verringerten Retention der Proteine begründet sein.

Die Verteilung des N-1-2-GFP-Konstruktes entspricht dem cytosolischen RanBPla-GFPFusionsprotein. Das aufgrund der Größe vergleichbare CHS-GFP-Fusionprotein ohne Lokalisierungsequenzen zeigt eine freie Verteilung im Kern und Cytosol (auch HAASEN et al., 1999). Somit weist das größtenteils cytosolisch lokalisierte N-1-2-GFP-Konstrukt auf eine aktive Retention hin. Diese aktive Retention des BZI-1 wird folglich möglicherweise durch Protein-Interaktionen in dem Bereich der Domäne 1 und Umgebung bewirkt. 
Eine Retardation durch diesen Bereich der Domäne 1 kann durch die Bildung eines inhibitorischen Komplexes, durch Maskierung der Kernimportsequenz oder einer Adhäsion an das Cytoskelett vermittelt werden. Eine Funktion und Beteiligung des in diesem Bereich interagierenden ANK1-Proteins (K. HORVAY, 2001) innerhalb eines solchen Komplexes ist ebenfalls möglich.

Ein vergleichbarer Mechanismus der Retardation im Cytoplasma wird auch für die lichtregulierte, phytochromabhängige Translokation des verwandten Transkriptionsfaktors CPRF2 aus Petersilie (Petroselinum crispum) vermutet (KIRCHER et al., 1999). Durch die Analyse von GFP-Fusionsproteinen und in situ-immuno-Detektionen konnte eine vergleichbare von Domäne $N, 1$ und 2 abhängige Verteilung nachgewiesen werden. Dem spekulativen Modell für die Regulation von CPRF2 entspechend, soll der Transkriptionsfaktor Phyłochrom-abhägig phosphoryliert werden und nach Auflösung einer intra- oder intermolekularen Interaktion in den Kern transportiert werden. Eine intramolekulare Interaktion kann für BZI-1 aufgrund der Ergebnisse aus dem Hefe-"twohybrid"-System ausgeschlossen werden (A. STRATHMANN, 1999).

Eine Veränderung des zellulären Vorkommens der BZI-1-GFP-Fusionsproteine nach Stimulation der Protoplasten durch Auxin, Elicitierung mit dem pilzlichen Elicitor Cryptogein oder Belichtung konnte nicht nachgewiesen werden. Diese Methode stellt aufgrund des aufarbeitungsbedingten physiologischen Stresses der Protoplasten ein begrenztes System zur Analyse der Einflüsse von Umweltstimuli dar. Künftig sollte zur Analyse von Stressbeeinflussten Stimuli auf die transgene Expression von GFP-Fusionen in planta übergegangen werden. Auf diese Weise könnten eine durch Stimuli veränderte Lokalisation von BZI-1-GFP-Derivaten direkt analysiert werden.

Zur Untersuchung der Regulation des Kernimportes in der Pflanze wurden Kernextrakte aus Blattgewebe analysiert. Wie aus den immunologischen Detektionen des BZI-1-Proteins in den Kernextrakte ersichlich, lässt sich das endogene BZI-1 nur sehr schwach in den Kernextrakten der Wildtyp-Pflanze nachweisen. Es zeigt sich jedoch die primäre Lokalisierung des transgen exprimierten BZI-1 und des BZI-1- $\Delta$ N-Derivates in den Kernfraktionen der transgenen Pflanzen. Die Lokalisierung ist unabhängig von dem Belichtungszustand der Blätter. Eine lichtabhängige Translokation, wie sie für CPRF2 gezeigt werden konnte (KIRCHER et al., 1999), ist hier nicht nachweisbar. Dieser Unterschied zwischen BZI-1 und CPRF2 liegt möglicherweise in den strukturellen Unterschieden im Bereich zwischen den Domänen $N$ und 1 begründet. So besitz† BZI-1 in diesem Bereich 
eine Extension um 34 Aminosäuren, die möglicherweise eine regulatorische, lichtunabhängige Funktion vermittelt.

\section{4 | Die Domänen N, 1, 4 und die basische Domäne von BZI-1 sind in Prozesse der Blütenbildung und Pollenentwicklung eingebunden}

Ein regulatorischer Einfluss des Transkriptionsfaktors BZI-1 lässt sich zusätzlich im gewebespezifischen Kontext der Blüte nachweisen. Dieser Einfluss zeigł sich einerseits durch die morphologische Veränderung der Blüte und der Pollen, anderseits auf molekularer Ebene, durch die veränderte Expression des interagierenden Faktors BZI-4 im Stamengewebe.

Durch die Expression des Derivates BZI-1- $\Delta \mathrm{N}$ in transgenen Pflanzen zeigt sich morphologisch eine starke Verkürzung der Blüten im Vergleich zu den Wildtyp-Pflanzen. Diese Verkürzung betrifft die Petalen, die Stamina und das Pistill. Ein vergleichbarer Phänotyp tritt in der untersuchten BZI-1-antisense-Pflanzenlinie auf. Eine Herabsetzung der endogenen BZI-1 Menge durch Bildung von unfunktionalen Heterodimeren (BZI-1$\Delta$ N/BZI-1) oder eines Antisense-Ansatzes (antisense: WEINTRAUB, 1990) führt demzufolge zU der Ausbildung der verkleinerten Blüten und Missbildung von Pollen.

In den untersuchten BZI-1-Überexpressions-Linien tritt der Wildtyp-Phänotyp bezüglich der Blütengröße und Pollenbildung auf. Eine Erhöhung der Menge des Transkriptionsfaktors führt dementsprechend zu keiner phänotypischen Veränderung.

Die Versorgung der Pollen wird durch eine extrazelluläre Invertase gewährleistet. Durch die Spaltung der Saccharose zu Hexosen können diese durch Hexosetransporter von "sink"Geweben aufgenommen werden (ROITSCH et al., 1999). Für diverse Invertasen konnte, neben der entwicklungsspezifischen Expression im Tapetum (Nährschicht der Pollen) eine positive transkriptionelle Regulation durch eine Vielzahl von Stimuli gezeigt werden. Zu diesen Stimuli zählen Cytokinine, Brassinisteroide, Verwundung, Elicitierung und Pathogeninfektionen. Eine Gemeinsamkeit dieser Stimuli ist das Benötigen von Kohlenhydraten in dem jeweiligen Gewebe. Pflanzliches Gewebe mit solchen Eigenschaften wird auch als "sink"-Gewebe bezeichnet. Wie GOETZ et al., 2001 durch einen Antisense-Ansatz zeigen konnten, führt die Verringerung der Menge einer antherenspezifischen Invertase (NIN88) zu der vergleichbaren Pollenmorphologie. Durch 
eine gewebespezifische Verringerung der Invertasemenge kann es somit zu einer Unterversorgung der Pollen mit Hexosen aus dem Tapetum kommen, was möglicherweise die sichtbare Missbildung der Pollen erklärt.

In den BZI-1- $\Delta$ N-Derivat-exprimierenden Pflanzen konnte eine verringerte Expression der Invertase NIN88 nachgewiesen werden (HEINEKAMP et al., 2002). Diese korreliert mit der nachgewiesenen Missbildung der Pollen.

Ein direkter Einfluss durch die DNA-Bindung von BZI-1 an NIN88-Promotorelemente kann vermuten werden, da sich im Bereich von -301 bp vom Start-ATG eine halbseitige G-Box (AACGTG) im NIN88-Promotor befindet.

Der mit BZI-1 interagierende Faktor BZI-4 wird gewebespezifisch in Stamina exprimiert (STRATHMANN et al., 2001). Durch die gewebespezifische Expression von BZI-4 kann so möglicherweise die vermehrte Bildung von BZI-1/BZI-4-Heterodimeren entstehen. Durch die BZI-1/BZI-4-Heterodimere kann aufgrund der für BZI-1 belegten und für BZI-4 vermuteten G/C-Box-Spezifität (STRATHMANN, unveröffentlicht) eine Zielgenexpression postuliert werden. Die Expression von BZI-4 wird, wie aus den aufgeführten Daten ersichtlich, zusätzlich durch BZI-1 reguliert. Da der Promotorbereich des BZI-4-Gens noch nicht näher charakterisiert ist, lässt sich hier keine nähere Aussage über die direkte Beteiligung von cis-Elementen treffen. Durch die erhaltenen Ergebnisse und den nachgewiesenen Einfluss auf die Expression des NIN88-Gens durch BZI-1 lässt sich eine gewebespezifische Regulation durch das folgende Modell beschreiben. Unter Beteiligung eines gewebespezifischen Faktors im Stamengewebe bindet BZI-1 in den Promotorbereichen von BZI-4 und NIN88, wodurch die Expression reguliert wird. Ob BZI4 an der Regulation des NIN88-Gens beteiligt ist, bleibt weiterhin zu analysieren. Des Weiteren ist durch eine Promotoranalyse von BZI-4 und NIN88 zu klären, ob der Einfluss von BZI-1 als Homo- oder Heterodimer direkt oder möglicherweise doch indirekt erfolgt. Die Beteiligung von BZI-1 lässt sich aus den erhaltenen Ergebnissen in dem folgenden Modell zusammenfassen: 


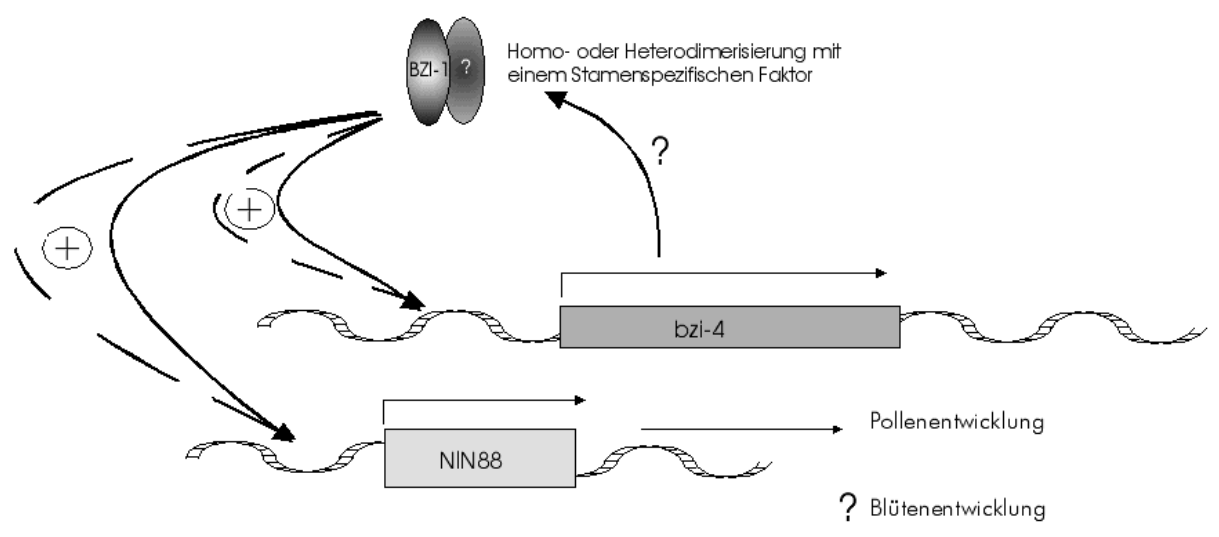

Mod. E - 1: BZI-1-vermittelte gewebespezifische Regulation von putativen Zielgenen.

BZI-1: N.t.BZI-1; ?: Heterodimerisierender Transkriptionsfaktor, stamenspezifisch; bzi-4: N.t.BZI-4-gen; NIN88: NIN88-, Invertase-Gen, Pfeil: direkte Wirkung, unterbrochener Pfeil: indirekte Wirkung

Durch die Expression des BZI-1- $\Delta \mathrm{N} \Delta \mathrm{BD}$-Derivates zeigt sich ein weiterer veränderter Blüten-Phänotyp. Die Petalen der Blüten sind vergleichbar verkürzt, jedoch besitzł die Blüte einen bauchigeren Habitus. Ebenso fällt auf, dass die Länge der Stamina in der BZI-1$\Delta \mathrm{N} \Delta \mathrm{BD}$-exprimierenden Linie eher dem Wildtyp entspricht und nur wenige Pollen eine Missbildung aufweisen. Die Auswirkungen des BZI-1- $\Delta$ N $\Delta B D$-Derivates können, im Vergleich zu dem BZI-1- $\Delta \mathrm{N}$-Derivat auf der cytosolischen Lokalisierung des transgenen Proteins und möglichen Seiteneffekten beruhen. Inwiefern die Blütengröße und die Pollenunterversorgung durch den gleichen Mechanismus beeinflusst werden, lässt sich nicht aussagen.

Die regulatorische Beteiligung der Domänen 1 und 4 in diesem funktionalen Zusammenhang zeigt sich in der Revertierung der Blütengröße und Pollenbildung zum Wildtyp, bei zusätzlicher Deletion der Domänen innerhalb des BZI-1- $\Delta \mathrm{N}$-Derivates. Die mechanistische Wirkung dieser Domänen in diesem Zusammenhang ist noch weiter aufzuklären. Für die vollständige Funktion des Faktors in der Blütenentwicklung und Pollenversorgung ist das Vorhandensein dieser Domänen notwendig.

Durch die Expression das BZI-1- $\Delta$ N $\Delta$ D2-Derivates zeigt sich ebenfalls eine Verkürzung der Blüten und eine Missbildung der Pollen. Dies deutet auf den durch die Deletion der Domäne $\mathrm{N}$ ausgelösten Effekt hin und zeigt, dass die Domäne 2 keinen Einfluss auf diesen Zusammenhang besitzt. Für die Domäne 2 kann somit in diesem Zusammenhang keine Funktion nachgewiesen werden. 


\section{5 | BZI-1 ist durch Phosphorylierungsereignisse an der basischen Domäne und der Domäne 4 in Signalprozesse der Pathogenabwehr eingebunden}

Aufgrund der Phosphorylierung von rekombinantem BZI-1- $\Delta \mathrm{N}$ durch elicitierte SojaZellextrakte und der verstärkten DNA-Bindung nach Phosphorylierung des BZI-1- $\Delta \mathrm{N}$ Derivates (DRÖGE-LASER et al., 1997) konnte eine Beteiligung des Transkriptionsfaktors BZI-1 in pathogenstimulierten Signaltransduktionsprozessen vermutet werden. Durch die deutliche Steigerung der BZI-1-Transkriptmenge nach Pathogenbefall zeigt sich ein weiterer Hinweis auf die Beteiligung dieses Faktors in Bereichen der Pflanzenabwehr (HEINEKAMP et al., 2002).

Wie aus den gezeigten Ergebnisse ersichtlich, erfolgt eine Phosphorylierung des BZI-1- $\Delta \mathrm{N}$ Proteins nach Pathogen-Stimulus. Diese Kinaseaktivität ist transient und unabhängig von dem untersuchten Gewebe. Sie erfolgt sowohl in Suspensionskulturzellen, als auch in Blattgewebe. Eine entsprechende Kinaseaktivität konnten durch Auxin- oder LichtStimulation nicht nachgewiesen werden.

Die durch Sojabohnen-Extrakte ausgelöste Phosphorylierung war serinspezifisch (DRÖGELASER et al., 1997). Für das hochhomologe CPRF-2 aus Petersilie (Petroselinum crispum) konnte ein lichtreguliertes Phosphorylierungsereignis ebenfalls als serinspezifisch identifiziert werden (WELLMER et al., 1999). Anhand dieser Ergenisse ist davon auszugehen, dass es sich bei der von mir detektierten Kinaseaktivität ebenfalls um ein Serin-spezifische Phosphorylierung handelt.

Die phosphorylierten Bereiche konnten für BZI-1 durch die proteolytischen Spaltungen und die Analyse des BZI- $\Delta \mathrm{N} \Delta \mathrm{BD}$-Derivates auf den Bereich der basischen Domäne und des Cterminalen Bereiches der Domäne 4 eingegrenzt werden. Im verwandten CPRF2 konnte das Phosphorylierungsereignis auf die zweite, C-terminale Hälfte des Proteins (196-401 Aminosäuren; vergleichbar BZI-1: 246-450 Aminosäuren) eingegrenz† werden. Hervorgerufen wurde diese nachweisbare Phosphorylierung durch die Aktivierung eine 40 kDa große Kinase nach Licht-Stimulus.

Für BZI-1 konnte auch die Interaktion mit einer Calcium-abhängigen Kinase im Hefe"two-Hybrid"-System nachgewiesen werden (CDPK, Lamb, unveröffentlicht). Für Calciumabhängige Protein-Kinasen konnte eine Beteiligung an der Pathogenantwort in Tabak nachgewiesen werden (NtCDPK2 und NtCDPK3, ROMEIS et al., 2000, 2001). 
Die Phosphorylierung im Bereich der basischen Domäne weist auf eine Modifikation der DNA-Bindefähigkeit hin. Eine Verstärkung von DNA-Bindeeigenschaften durch Phosphorylierung konnte bereits von DRÖGE-LASER et al., 1997 gezeigt werden. Die zusätzliche Phosphorylierung in der Domäne 4 führt möglicherweise zu sterischen Veränderungen von BZI-1, wodurch Protein-Interaktionen verändert werden können. Für eine direkte molekulare Wirkung gibt es aber bislang keine weiteren Hinweise.

Eine Beteiligung von BZI- 1 in der Pathogenantwort der Pflanze zeigt sich weiterhin direkt durch die veränderte Resistenz und Ausprägung von Reaktionen der BZI-1- $\Delta \mathrm{N}$ exprimierenden Pflanze auf Pathogene. Untersucht wurde das Wachstum des avirulenten Bakterienstammes Pseudomonas syringae pv. pisi in den transgenen Pflanzen. Wie aus dem Wachstum der Bakterien in der Wildtyp-Pflanze und der vergleichbaren BZI-1Überexpressions-Pflanze ersichtlich, zeigt sich eine typische inkompatible Reaktion der Pflanze auf die Pseudomonaden. Im Vergleich zu der Wildtyp-Pflanze war das bakterielle Wachstum in den BZI-1- $\Delta \mathrm{N}$-Derivat-exprimierenden Pflanzen um das 10-fache eingeschränkt. Dies belegt den starken Einfluss des DNA-bindenden BZI-1- $\Delta$ N-Derivates in der Signalverarbeitung bei der Pathogenabwehr. Durch die Expression des BZI-1- $\Delta \mathrm{N}$ Derivats wird, wie aus den vorliegenden Ergebnissen ersichtlich, der Pflanze durch die verstärkte Abwehr eine erhöhte Resistenz vermittelt.

Ein vergleichbares Ergebnis zeigte die lokale Reaktion der Pflanzen auf die virale Infektion mit dem Tabak-Mosaik-Virus. Die untersuchten Pflanzen besitzen das N-Gen und zeigen nach TMV-Applikation eine lokale Abwehr der Viren (MURPHY et al., 1999). Sichtbar wird diese Abwehr durch die Ausprägung der hypersensitiven Reaktion. Durch die Expression des BZI-1- $\Delta$ N-Derivates zeigt sich eine räumlich nicht begrenzte Läsionsbildung und somit Ausweitung der hypersensitiven Reaktion.

Ein vergleichbarer Phänotyp von sich unbegrenz† ausweitenden Läsionen nach Pathogenbefall konnte in Arabidopsis thaliana-Pflanzen mit mutiertem LSD1-Gen beobachtet werden (AVIV et al., 2002). Bei LSDI handelt es sich um ein Zink-Finger-Protein mit Ähnlichkeit zu einem GATA-1 Transkriptionsfaktor (DIETRICH et al., 1997). Funktional scheint es sich um einen negativen Regulator eines Apoptose-Signals zu handeln. Die Anhäufung von reaktiven Saverstoff-Spezien (ROS) ist in Isdl-Pflanzen in den Infektionsbereichen verstärkt zu detektieren. LSD1 wirkt in der Pathogen-induzierten Signalkette unterhalb der SA-Anhäufung negativ auf die Auslösung des induzierten 
Zelltodes. Die räumliche Begrenzung des programmierten Zelltodes wird auf diese Weise unterlaufen.

Die sichtbare Ausweitung der Läsionen in den BZI-1- $\Delta \mathrm{N}$-exprimierenden Pflanzen könnte auf einem ähnlichen Mechanismus beruhen. Dieser könnte einerseits direkt durch ein verstärktes Auftreten der ROS in den BZI-1- $\Delta \mathrm{N}$-exprimierenden Pflanzen bedingt sein. Dies kann zu einer schnelleren Überschreitung eines Schwellenwertes führen, wodurch ein Signal zur Auslösung des programmierten Zelltodes verstärkt propagiert wird und sich die HR unbegrenzt ausweiten kann.

Ein weiterer denkbarer Mechanismus ist die Interaktion von BZI-1- $\Delta \mathrm{N}$ mit einem LSD1ähnlichen Faktor in Tabak. Hierdurch könnte der den Isdl-Mutanten ähnliche Phänotyp ausgelöst werden.

Die Überexpression des BZI-1-Derivates führt, ebenso wie in den anderen untersuchten Funktionszusammenhängen, nach TMV-Infektion nicht zu einer Abweichung vom WildtypPhänotyp. Durch die verstärkte DNA-Bindeaffinität des BZI-1- $\Delta \mathrm{N}$-Derivates gegenüber dem Gesamt-BZI-1 kann es zu einer Deregulation von unterschiedlichen Genen kommen, was direkt oder indirekt zur Ausprägung des oben genannten Phänotyps führt.

In den transgenen Pflanzen, die das BZI-1-Derivat ohne DNA-bindende Domäne exprimieren, zeigt sich eine leicht verringerte Ausprägung der hypersensitiven Reaktionen im Vergleich zur Wildtyp-Pflanze. Die Läsionen sind etwas kleiner und es zeigt sich partiell eine leichte Vergilbung des Gewebes. Diese geringere Reaktion entspricht auch den durch die Bestimmung des Bakterienwachstums erhaltenen Ergebnissen. Hier deuteten sich leichte Veränderungen innerhalb des Bakterienwachstums zugunsten der Bakterien an. Die BZI-1- $\Delta \mathrm{N} \Delta \mathrm{BD}$-Derivat-exprimierenden Pflanzen zeigen somit eine leicht verringerte Resistenz. In diesen Pflanzen kann die Signaltransduktion durch das BZI-1- $\Delta \mathrm{N} \Delta \mathrm{BD}$-Derivat auf unterschiedlichste Weise beeinflusst werden. So kann neben der nicht mehr vorhandenen DNA-Bindefähigkeit auch die Veränderung der zellulären Lokalisation des transgen exprimierten Proteins zu einer veränderten Ausprägung der Pathogenantwort führen. Die cytosolische Lokalisierung des BZI-1- $\Delta \mathrm{N} \Delta \mathrm{BD}$ kann möglicherweise zu einer komplett unterschiedlichen Interaktionen mit Proteinen und auf der Ebene der Heterodimer-Bildung führen, welches zur Ausprägung dieses Phänotyps führt.

Durch die Auswertung der lokalen Pathogenantwort nach TMV-Infektion zeigte sich in den transgenen Pflanzen ebenfalls die Beteiligung der Domänen 1 und 4 bei der Ausprägung des BZI-1- $\Delta \mathrm{N}$-bedingten Phänotyps. Die zusätzlich eingebrachten einzelnen Deletionen 
dieser Domänen in den transgen exprimierten Proteinen zeigten eine dem Wildtyp vergleichbare Ausbildung einer typischen HR-Bildung. Die Bedeutung der Domänen 1 und 4 für die Ausbildung des Phänotyps und damit für die funktionale Beteiligung innerhalb der Signalprozesse während der Pathogenantwort ist hierdurch zusätzlich belegt.

Zur weiteren Bestätigung der Beteiligung der Domäne 4 an den pathogenspezifischen Signalprozessen kann künftig noch die Bestimmung des bakteriellen Wachstums in den BZI-1- $\Delta$ N $\Delta$ D4 exprimierenden Pflanzen im Vergleich zu den BZI-1- $\Delta$ N-exprimierenden Pflanzen analysiert werden.

Die Beteiligung der Domäne 4 in diesem Zusammenhang in Verbindung mit der Pathogen-stimulierten, nachgewiesenen Phosphorylierung legt die Vermutung nahe, dass in dem Doppeldeletionsderivat BZI-1- $\Delta \mathrm{N} \Delta \mathrm{D} 4$ eine Phosphorylierung des Proteins nicht mehr erfolgen kann. Dies hat zur Folge, dass es in die weitere Signalverarbeitung, die zur Ausprägung ausgeweiteter Läsionen führt, nicht mehr einfließen kann.

Der Domäne 2 kann in dem hier untersuchten Funktionszusammenhang der lokalen Pathogenantwort keine Beteiligung nachgewiesen werden. Die TMV-Infektion in der BZI-1$\Delta \mathrm{N} \Delta \mathrm{D} 2$-exprimierenden Pflanze führt zu einer Ausweitung der Läsionen, wie sie auch in der TMV-infizierten BZI-1- $\Delta \mathrm{N}$-exprimierenden Linie zu beobachten war.

Die BZI-1- $\Delta \mathrm{N} \Delta \mathrm{D} 1$-exprimierenden Pflanzen zeigten eine sichtbare Pathogenantwort, die in ihrer Intensität zwischen der der BZI-1- $\Delta$ N-Derivat-exprimierenden Pflanzen und der der Wildtyp-Pflanzen lag. So war die Ausprägung der HR der BZI-1- $\Delta$ N-Derivatexprimierenden Pflanzen 6 Tage nach TMV-Infektion noch mit der HR der Wildtyp-Pflanzen vergleichbar. Wenige Tage später jedoch zeigte sich eine leichte Ausweitung der Läsionen. Für die Domäne 1, die eine $\alpha$-helicalen Struktur besitzt, konnte im Hefe-"two-hybrid"System eine Interaktion mit dem ANK1-Protein mit dem Bereich der Aminosäuren 73-241 von BZI-1 nachgewiesen werden (K. HORVAY, 2001). Durch die Deletion dieser Domäne wird die Interaktionsfähigkeit zwischen BZI-1 und ANK1 um ca. die Hälfte gesenkt (K. HORVAY, 2001). Die herabgesetzte Interaktion mit dem ANK1-Protein korreliert mit der partiellen Ausweitung der nekrotischen Bereiche in der BZI-1- $\Delta \mathrm{N} \Delta \mathrm{D} 1$-exprimierenden Pflanzenlinie.

Eine weitere Funktion dieser Interaktion wird im folgenden Kapitel E | 6 diskutiert.

Durch die Revertierung der lokalen Pflanzenantwort zum Wildtyp-Phänotypen zeigł sich eine Beteiligung der Domäne 4 und partiell der Domäne 1. 
Um den Einfluss der BZI-1-Deletionsderivate auf die Etablierung der SAR zu analysieren wurde die Expression des PR la-Gens 7 Tage nach der TMV-Infektion analysiert.

Die Expression dieses Gens dient als Marker für die Etablierung der SAR (Systemisch erworbenen Resistenz, GUO et al., 2000). Untersucht wurden die transgenen Linien, welche die unterschiedlichen BZI-1-Deletionsderivate exprimieren. Es zeigte sich eine Verringerung $\operatorname{der} P R 1 a$-Expression in BZI-1- $\Delta \mathrm{N}$-exprimierenden Linie. Dies weist auf den Einfluss von BZI-1 auf die Etablierung de SAR hin. Um die Funktionalität der einzelnen Domänen in diesem Zusammenhang zu testen, wurde die PRla-Expression der BZI-1Doppeldeletionsderivate-exprimierenden Linien getestet. Wie sich zeigte, führt die zusätzliche Deletion der Domänen 1, 2 und der basischen Domäne zu einer dem Wildtyp vergleichbaren PRla-Expression in den transgenen Pflanzen. Die zusätzliche Deletion der Domäne 4 führt zu einer BZI-1- $\Delta \mathrm{N}$ vergleichbaren Verringerung der PR la-Genexpression. Die Domäne 4 scheint in diesem funktionalen Zusammenhang der SAR-Entwicklung keine weitere Funktion zu besitzen. Dieses Resultat entspricht auch der Vorstellung, dass eine schnelle posttranslationale Modifikation, wie es eine Phosphorylierung darstellt, eine Veränderung von Bindeaffinitäten beeinflusst. Langfristige, komplexe Genregulationen werden hingegen häufig durch eine, auf transkriptioneller oder translationeller Ebene veränderte Proteinmenge beeinflusst. Diese transkriptionelle Aktivierung des BZI-1-Gens ist zudem nachweisbar.

Durch die zusätzlich eingefügten Doppeldeletionen in den Bereichen der Domäne 1 und 2 von BZI-1 zeigt sich eine Wildtyp-ähnliche Entwicklung der SAR. Die PRla-Genexpression entspricht dem vergleichbaren Niveau der Wildtypexpression. Hierdurch zeigt sich die potentielle Wichtigkeit der Domänen für die Funktion der transgenen Proteine in der Etablierung der SAR, beziehungsweise der PRla-Genexpression. Die Wirkung des BZI-1$\Delta \mathrm{N}$-Proteins wird durch die zusätzlichen Deletionen aufgehoben. Der hierfür verantwortliche Mechanismus kann in einer nicht mehr ermöglichten Interaktion des BZI-1 in diesem Bereich mit einem weiteren Protein liegen. Durch die Überexpression des BZI-1$\Delta \mathrm{N}$-Derivates wird möglicherweise über diese Interaktion ein SAR-propagierendes Signal unterdrückt. Dieses Protein stellt möglicherweise das ANK1-Protein dar, dessen direkte Funktion in diesem Zusammenhang bislang nicht weiter aufgeklärt ist.

Durch die zusätzliche Deletion der basischen Domäne zeigł sich kein Effekt auf die Etablierung der SAR. Somit scheint es sich bei der verringerten SAR der BZIÜberexpressions-Linie um einen Gendosis-Effekt der massiven Überexpression in diesem 
funktionalen Zusammenhang zu handeln. Der gleiche Effekt zeigt sich entsprechend in den BZI- $1-\Delta \mathrm{N}$ und BZI-1- $\Delta \mathrm{N} \Delta \mathrm{D} 4$-exprimierenden Linien. Somit konkurrieren die transgenen BZI-1-Proteine möglicherweise mit endogenen Faktoren um ACGT-Kernmotive vor SARspezifischen Genen und es kommt zu einer Abschwächung der natürlichen SARAusprägung. Die durch die Northern-Analyse erhaltenen Daten sollten in jedem Fall durch die Analyse von Zweitinfektionen an den Pflanzen belegt werden. Erst durch die phänotypischen Auswirkungen auf die ausgebildete SAR lässt sich ein verlässlicher Schluss auf die Beteiligung von BZI-1 an der Etablierung der SAR ziehen.

Durch die Interaktion zwischen BZI-1 und ANK1 stellt sich möglicherweise eine wichtiger Schritt in der Auslösung einer Pathogenantwort der Pflanze dar.

\section{6 | Der Bereich der $\alpha$-helicalen Domäne 1 von BZI-1 interagiert mit dem} ANK1-Protein

Durch einen Hefe-"two-hybrid"-Screen konnte mit dem Aminosäure-Bereich 73-241 des BZI-1-Proteins das interagierende Protein ANK1 identifiziert werden (K.HORVAY, 2001). Der interagierende Bereich enthält die Domäne 1. Durch die Analyse des Köderproteins mit der Deletion im Bereich der Domäne 1 wird die Interaktion nicht vollständig unterbunden. Die Domäne $\mathrm{N}$ und die Domäne 2 sind den Hefe-Daten entsprechend, an der Interaktion nicht beteiligt (K. HORVAY, 2001). Das isolierte Protein besitzt als strukturelle Besonderheit einen vierfachen Ankyrinrepeat. Ankyrinrepeats konnten in Proteinen in unterschiedlichsten Funktionszusammenhängen gefunden werden. Sehr häufig vermitteln sie Protein-ProteinInteraktionen (SEDGWICK \& SMERDON, 1999).

Die BZI-1-ANK1-Interaktion konnte durch die DNA-Bindeanalysen von BZI-1- $\Delta \mathrm{N}$ mit dem ANK 1-Protein zusätzlich bestätigł werden. Protein-Interaktionen mit Transkriptionsfaktoren können eine Veränderung der Migration des Komplexes im Gel hervorrufen. Falls die Interaktion das DNA-Bindeverhalten in der EMSA beeinflusst, spiegelte sich dieses in einer Abnahme des detektierbaren Komplexes wieder. In dem untersuchten in vitro-System unterdrückte die Interaktion mit ANK1 die DNA-Bindefähigkeit von BZI-1. Dies deutet entweder auf eine sterische Hinderung der basischen Domäne zum DNA-Zugang hin oder auf eine Unterdrückung der Dimer-Bildung des bZIP-Transkriptionsfaktors durch die Interaktion. 
Durch die Analyse des His ${ }^{\circledR}$-BZI-1- $-\Delta \mathrm{N} \Delta \mathrm{D} 1$-Derivates in Bezug auf die Beeinflussung der DNA-Bindung durch die Interaktion, zeigte sich ein im Vergleich zum His ${ }^{\circledR}$-BZI-1- $\Delta \mathrm{N}$ schwächerer Einfluss des ANK1-Proteins auf die DNA-Bindefähigkeit. Zur vergleichbaren Verminderung des Komplexes wurde ca. die doppelte Menge des ANK1-Protein benötigt. Dieses Verhältnis spiegelt die im Hefe-System detektierte Interaktion des ANK1-Proteins mit diesem Bereich des BZI-1-Proteins wieder. Das ANK1-Protein interagiert mit dem BZI-1 im Bereich der Domäne 1. Durch die Deletion der Domäne 1 lässt sich die Interaktion jedoch nicht vollständig inhibieren.

In der genetischen Modellpflanze Arabidopsis thaliana wurden mit unterschiedlichen Methoden hoch homologe Proteine isoliert. Die als AKR2 (Acc.-Nr.: AAD10949), ARP2 (Acc.-Nr.: CAB54873) und AFT (Acc.-Nr.: AAC33264) bezeichneten Proteine sind identisch und liegen auf dem 4. Chromosom. Isoliert wurde AKR2 als GF14 $\lambda$-Proteininteragierendes Protein im Hefe-"two-hybrid"-System. GF14 $\lambda$ gehört der Familie der 14-33-Proteine an (ZHANG et al., 1995). Für 14-3-3-Proteine konnte in Pflanzen unter anderem eine Beteiligung in der Pathogenantwort (SEEHAUS \& TENHAKEN, 1998) und eine Interaktion mit bZIP-Proteinen (GBF, LU et al. 1992) gezeigt werden. Die nachgewiesenen Interaktionen in Arabidopsis deuten auf eine Beteiligung der genannten Ankyrinprotein-Familie im funktionalen Kontext der BZI-Regulation in Tabak hin.

Dem AKR2-Protein konnte zusätzlich eine Interaktion mit einer Ascorbatperoxidase (APX3) und strukturell einer $\mathrm{N}$-terminalen PEST-Domäne nachgewiesen werden (YAN et al., 2002). Als PEST-Domänen werden Prolin, Glutamat, Serin und Threonin-reiche Domänen bezeichnet, die als proteolytisches Signal zum Abbau von kurzlebigen Proteinen dienen. Eine vergleichbare Domäne besitzt das ANK1 -Protein nicht.

Das Protein AtPhos43 konnte auf dem Chromosom 2 lokalisiert werden. Aufgrund der hohen Homologie zu den oben genannten Proteinen scheint es sich um ein zweites Mitglied einer kleinen Genfamilie zu handeln. Bei AtPhos43 konnte 4 Minuten nach Elicitorbehandlung eine Phosphorylierung nachgewiesen werden (PECK et al., 2001). Der Vergleich der Proteine auf Aminosäureebene (Alignment) ist dem Anhang G|5 zu entnehmen. Über den Online veröffentlichten zu ANK1 identischen Faktor N.t.HBP1 (Acc.Nr.: AAK 18619.1, VAN DER HEIJDEN \& BOL) sind noch keine weiteren Daten veröffentlicht. Aufgrund der Homologien zu AKR2 und AtPhos43 und deren Einbindung in die Pathogenantwort der Pflanze (YAN et al., 2002; PECK et al., 2001) wurde die Interaktion des 
ANK1-Proteins mit dem BZI-1 funktionell insbesondere in Bezug auf die Pathogenantwort untersucht.

Durch die Induktion mit dem pilzlichen Elicitor Cryptogein und dem bakteriellen Pathogen Pseudomonas syringae pv. pisi kommt es zu einer transient verringerten Transkription des ANK1-Gens im Blattgewebe der Pflanze. Diese Regulation auf transkriptioneller Ebene deutet zusätzlich auf eine Beteiligung des Proteins in der Pathogenantwort der Pflanze. Mit Hilfe der GFP-Fusionen konnte gezeigt werden, dass das untersuchte Protein hauptsächlich cytosolisch lokalisiert ist.

In der TMV-infizierten Wildtyp-Pflanze zeigen die nach außen bräunlich-abgegrenzten Nekrosen eine "typische" N-Gen-vermittelten HR. Während es in den BZI-1- $\Delta \mathrm{N}$ exprimierenden Pflanzen zu einer Ausbreitung der Nekrosen kommt, weist die BZI-1$\Delta \mathrm{N} \Delta \mathrm{D} 1$-exprimierende Pflanze in den ersten Tagen nach TMV-Infektion eine wildtypähnliche HR-Bildung auf. Erst in den folgenden Tagen entwickelt sich die Ausbreitung der Läsionen über das gesamte infizierte Blatt. Diese bereits weiter oben diskutierten Ergebnisse stützen zusätzlich die Wichtigkeit der Domäne 1 in planta für die korrekte Ausbildung der Pflanzenantwort.

Überdies hinaus deuten die Regulation des ANK1-Proteins und die Auswirkungen der Deletionsderivate auf ein Zusammenwirken des ANK1-Proteins mit dem BZI-1 hin. Möglicherweise werden zur Etablierung der Pathogenantwort zwei wichtige regulatorische Komplexe durch ANK1 beeinflusst.

Dem Modell von YAN et al., 2002 folgend könnte ANK1 an der Bildung eines Komplexes mit einer Peroxidase beteiligt sein. Dieser Komplex könnte durch einen Pathogen-Stimulus zur Reduzierung des ANK1-Proteins. Diese Reduzierung führt zu einem Zerfall dieses Komplexes, wodurch eine Peroxidase inaktiviert wird. Durch diese Inaktivierung kommt es zu einer Anhäufung von $\mathrm{H}_{2} \mathrm{O}_{2}$ und einer Ausprägung der HR (vergleiche YAN et al., 2002). Ob eine ATPhos43 vergleichbare Elicitor-abhängige Phosphorylierung (PECK et al., 2001) des ANK1 zur Auflösung des Komplexes beiträgt bleibł zu klären. Durch die negative Regulation der ANK1-Menge nach Pathogenbefall kann es zur veränderten Bildung eines weiteren Komplexes mit dem Transkriptionsfaktor BZI-1 kommen. Durch diesen Komplex kann eventuell die Heterodimerisierung mit den kleinen bZIP-Transkriptionsfaktoren (BZI-2, -3 und -4) gestevert werden. Durch die Modifizierung und Reduzierung der Menge des ANK1-Proteins wird möglicherweise die Bildung von BZI-1-Homodimeren präferiert. Ein 
entsprechend aktiviertes Homodimer oder neu gebildetes Heterodimer könnte an der Aktivierung von Genen beteiligt sein, die an der Ausbildung der HR beteiligt sind.

Ein Zusammenhang ist an dieser Stelle möglicherweise durch die Ausprägung des Auxininsensitiven vegetativen Phänotyps in Verbindung zu der lokalen Pathogenantwort zu sehen. So besitzen die Blätter als infiziertes Gewebe eine zum Wildtyp veränderte Struktur. Dieses deutet auf die Deregulation von Genen durch das transgen eingebrachte BZI-1DN-Derivat hin. Durch diese Deregulation kann, möglicherweise als sekundärer Effekt eine Eingrenzung der Läsionsbildung in diesen Pflanzen nicht mehr stattfinden. Ein vergleichbarer Einfluss zeigte sich durch die veränderte Expression einer anionischen Peroxidase (CEVI-1; MAYDA et al., 2000), die mit einer Auxin-Insensitivität korreliert.

Ein entsprechendes "Umschalten" und eine gegenseitige Hemmung zwischen dem Auxinvermittelten-Signaltransduktionsweg mit einem direkten Effekt auf die GH3-Expression und der Signalverarbeitung von oxidativem Stress konnte in der Regulation von Mitogenaktivierten Protein Kinasen nachgewiesen werden (TENA et al., 2001).

Aus den aufgeführten Daten lässt sich das folgende Modell entwickeln: 


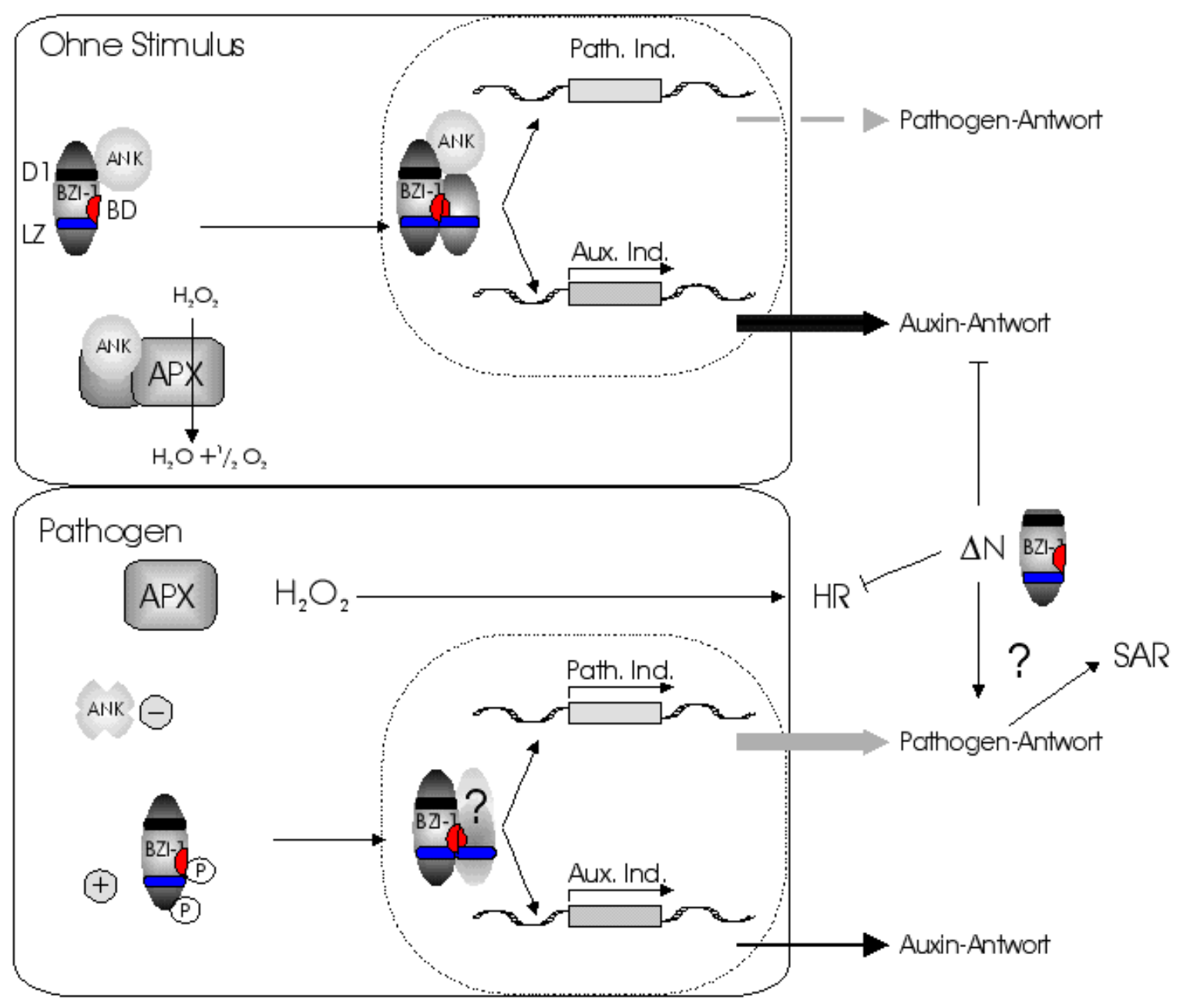

Mod. E - 2: Beteiligung von BZI-1 und ANK1 an der Ausprägung der Pathogenantwort.

Pathogen: TMV oder Pseudomonas; APX: Ascorbatperoxidase, oder allg. Peroxidase; ANK: N.t.ANK1, BZI-1: N.t.BZI-1; die transkriptionelle Aktivierung erfolgt in jedem Fall als Homo- oder Heterodimer; P: Phosphorylierungsereignis, HR: Hypersensitive Reaktion, SAR: Systemisch erworbene Resistenz, + : verstärkte Expression, - : verringerte Expression, Path. Ind.: Pathogen induzierbares Gen, Aux. Ind.: Auxin induzierbares Gen., D1: Domäne 1, BD: basische Domäne, LZ: Leucinzipper 


\section{8 | Ausblick}

Zum weiteren Verständnis der molekularen Wirkweise und DNA-Bindung von BZI-1 in planta ist die Aufklärung von Promotorstrukturen der putativen Zielgene wie GH3, BZI-4 oder der NIN88-Invertase unerlässlich. Des Weiteren sollte eine Charakterisierung der Regulation dieser Gene durch BZI-1 unter den unterschiedlichen gewebe- und umweltbedingten Einflüssen analysiert werden.

Um die Relevanz der nachgewiesenen DNA-Bindespezifitäten von BZI-1 unter entwicklungsbiologischen oder Pathogen-stimulierten Einflüssen in planta zu untersuchen bietet sich die Methode der Chomatin-Immuno-Präzipitationsanalyse (ChIP) an. Dies stellt eine effiziente Methode dar, die BZI-1-Protein-Bindung an die spezifischen cis-Elemente zu charakterisieren.

Ein zukünftiges Forschungsfeld sollte die Aufklärung der Funktion der Interaktion von der Domäne 1 von BZI-1 und ANK1 sein. Hierfür können die Auswirkungen der durch ANK1Überexpression oder RNAi-modulierten ANK1-Expression in transgene Tabakpflanzen analysiert werden. Hierdurch kann die Beteiligung von ANK1 in der Pathogenbeeinflussten Signaltransduktion in Bezug auf die hypersensitive Reaktion und die SAR genaver spezifiziert werden. Weiterhin sollte in diesem Zusammenhang eine mögliche Interaktion von ANK1 mit entsprechenden anionischen Peroxidasen aus Tabak untersucht werden, wie sie entsprechend für AKR2 in Arabidopsis schon gezeigt werden konnte. Für einen Nachweis der Interaktion von BZI-1 und ANK1 in planta würde sich eine Immunopräzipitation des Komplexes anbieten.

Die Einbindung von BZI-1 in die Pathogen-stimulierte Signaltransduktion kann durch die Identifizierung der pathogenaktivierten Kinase weiter analysiert werden. Durch die entdeckte CDPK (LAMB, unveröffentlicht) bietet sich hier eine weitere Möglichkeit diesen Bereich der Signalkaskade zu entschlüsseln. 


\section{F | Literaturverzeichnis}

1 Abel S., Oeller P.W. and Theologis A.: Early auxin-induced genes encode short-lived nuclear proteins. Proc. Natl. Acad. Sci. 91 (1), 326-30 (1994)

$2 \mid$ Abel S. and Theologis A.: Transient transformation of Arabidopsis leaf protoplasts: a versatile expression system to study gene expression. Plant J. 5(3), 421 -427 (1996)

3| Agrios G.N.: Plant Pathology Academic Press, London (1988)

4| Armstrong G.A., Weisshaar B. and Hahlbrock K.: Homodimeric and hetrodimeric leucinezipper proteins and nuclear factors from parsley recognize diverse promoter elements with ACGT core. Plant Cell 4, 525-553 (1992)

5| Aviv D.H., Rustérucci C., Holt B. F., Dietrich R.A., Parker J.E. and Dangl J.L.: Runaway cell death, but not basal disease resistance, in Isd 1 is SA- and NIMI/NPR I-independent. Plant J 29 (3) 381-391 (2002)

6| Blumwald E., Aharon G.S. and Lam B.C.-H.: Early signal transduction pathways in plant-pathogen interactions. Trend Plant Sci 3, 342-436 (1998)

7| Bolton, E.T., McCarthy, B.J.: A general method for isolation of RNA complementary to DNA. Proc. Natl. Acad. Sci. 48, 1390-1397 (1962)

8| Bradford M.M.: A rapid and sensitiv method for the quantification of microgram quantities of protein utilizing the prinziple of protein dye binding. Anal Biochem. 72, 248254 (1976)

9| Bradley D.J., Kjellbom P. and Lamb C.J.: Elicitor- and wound-induced oxidative crosslinking of a proline-rich plant cell wall protein: a novel, rapid defense response. Cell 70(1), $21-30$ (1992)

10| Bullock W.O., Fernandez J.M. and Short J.M.: XL-1-Blue: A high effiviency plasmid transforming recA-Escherichia coli strain with beta galactosidase selection. Biotechniques 5, 376-379 (1987)

11 Church G.M. and Gilbert W.: Genomic sequencing. PNAS 81 (7), 1991-1995 (1984)

12| Cubitt A.B., Heim R., Adams S.R., Boyd A.E., Gross L.A. and Tsien R.Y.: Understanding, improving and using greenfluorescent proteins. Trens Biochem. Sci. 20(1 1), 448-455 (1995)

13| Cutt J.R., Dixon D.C., Carr J.P. and Klessig: Isolation and nucleotide sequence of cDNA clones for the pathogenesis-related proteins PR $1 a, P R 1 b$ and PR $1 c$ of Nicotiana tabacum cv Xanthi nc by TMV infection. Nucl. Acids Res. 16, 9861 (1988)

14| Delaney T.P., Uknes S., Vernooii B., Friedrich L., Weymann K., Negrotto D., Gaffney T., Gut-Rella M., Kessmann H., Ward E. and Ryals J.: A central role of salicylic acid in plant desease resistance. Science 266, 1247-1250, (1994) 
15| De Pater S., Pham K., Memelink J., and Kijne J.: Binding specificy and tissue-specific expression pattern of the Arabidopsis bZIP transcription factor TGA2. Mol. Gen. Genet 250, 237-239 (1994)

16| Dingwall C. and Laskey R.A.: Nuclear targetting sequences--a consensus? Trends Biochem. Sci.16(12), 478-481 (1991)

17| Dixon R.H., Dey P.M., Lamb C.J.: Phytoalexins: enzymology and molecular biology Adv. Enzymol. Relat. Areas Mol. Biol. 55, 1-236 (1983)

18| Dixon R.H. and Harrison: Activation, structure and organisation of genes involved in microbial defense in plants. Adv. Genet. 28, 165-234 (1990)

19| Dower W.J., Miller J.F. and Ragsdale C.W.: High efficiency transformation of E.coli by high voltage electroporation. Nucl. Acid Res. 16(13), 6127-6145 (1988)

20| Drews G.N., Beals T.P., Bui A.Q. and Goldberg R.B.: Regional and cell-specific gene expression patterns during petal development. Plant Cell 4, 1383-1404 (1992)

21 | Dröge-Laser W. Kaiser A., Lindsay W.P., Halkier B.A., Loake G.J., Doerner P., Dixon R.A. and Lamb C.: Rapid stimulation of a soybean protein-serine kinase that phosphorylates a novel bZIP DNA-binding protein, G/HBF-, during the induction of early transcription-dependent defenses. EMBO 16 (4), 726-738 (1997)

22| Durner J., Shah J. and Klessig D.F.: Salicylic acid and disease resistance in plants. Trends Plant Sci. 2, 266-274 (1997)

23| Ebel J. and Mithöfer A.: Early events in the elicitation of plant defence. Planta 206, 336-348 (1998)

24| Ebel J. and Scheel D.: Signals in host-parasite interactions. In: Carroll G.C., Tudynski P. (eds) The Mycota V, part A. Plant relationships. Springer Berlin Heidelberg, 183-205 (1997)

25| Eick A.: Der Transkriptionsfaktor N.t.G/HBF-1 aus Tabak: cDNA-Klonierung und genomische Analyse. Diplomarbeit, Universität Göttingen. (1999)

26| Facchini P.J. and Chapell J.: Gene family for an elicitor-induced sesquiterpene cyclase in tobacco. Proc. Natl. Acad. Sci. 89, 11088-1 1092 (1992)

27| Feinberg A.P. and Vogelstein B.: A technique for radiolabelling DNA restriction endonuclease fragments to high specific activity. Anal. Biochem. 132, 6-13 (1983)

28| Feldbrügge M., Hahlbrock K.and Weisshaar B.: The transcriptional regulator CPRF1: expression analysis and gene structure. Mol. Gen. Genet. 251, 619-627 (1996)

29| Finnie C., Borch J. and Collinge D.B.: 14-3-3 proteins: eucaryotic regulatory proteins with many functions. Plant Mol. Biol. 40, 545-554 (1999) 
30| Foster R., Takeshi I. and Chua N.-H.: Plant bZIP proteins gather at ACGT elements. FASEB J. 8, 192-200 (1994)

$31 \mid$ Frye C.A., Tony D. and Imes R.W.: Negative regulation og defense responsees in plants by a conserved MAPKK Kinase. Proc. Natl. Acad. Sci. 98 (1) 373-378 (2001)

32| Gatz C., Frohberg C. and Wendenburg R.: Stringent repression and homogeneous de-repression by tetracycline of a modified CaMV 35S promoter in intact transgenic tobacco plants. Plant J. 2(3), 397-404 (1992)

33| Goetz M., Godt D.E. and Roitsch T.: Tissue-specific induction of the mRNA for an extracellular invertase isoenzyme of tomato by brassinosteroide suggests a role for steroid hormones in assimilate partioning. Plant J. 22(6), 512-522 (2000)

34| Goetz M., Godt D.E., Guivarc'h A., Kahmann U., Chriqui D. and Roitsch T.: Induction of male sterility in plants by metabolic engeneering of the carbohydrate supply. Proc. Natl. Acad. Sci. 98 (1 1), 6522-6527 (2001)

35| Greenwald I.S., Sternberg P.W. and Horvitz H.R.: The lin- 12 locus specifies cell fates in Caenorhabditis elegans.Cell 43(3.2), 567-581 (1985)

36| Guilfoyle T.J.: Auxin regulated geneexpression and gravitropism in plants.ASGSB Bull. $8(2), 39-45$ (2001)

37| Guo A., Gaza S. and Klessig D.F.: Activation of a diverse set of genes during the tobacco resistance response to TMV is independent of salicylic acid; induction of a subset is also ethylene independent. Plant Journal 21 (5), 409-418 (2000)

38| Gupta R., webster C.I. and Gray J.C.: Characterisation and promoter analysis of the Arabidopsis gene encoding high-mobility-group protein HMG-I/Y. Plant Mol. Biol. 36(6), 897-907 (1998)

39| Gupta R. and Gray J.C.: Characterization of a single-copy Arabidopsis gene encoding a protein showing limited similarity to the $\mathrm{N}$-terminus of the mammalian clathrinassembley protein AP180. DNA Res. 6 (1), $51-55$ (1999)

40| Haasen D., Köhler C.,Neuhaus G. and Merkle T.: Nuclear export of proteins in plants: AtXPO1 is the export receptor for leucine-rich nuclear export signals in Arabidopsis thaliana. Plant J. 20 (6), 695-705 (1999)

41 | Hammond-Kosack K.E. and Jones J.D.G.: Resistance gene-dependent plant defense responses. Plant Cell 8, 1773-1791 (1996)

42 Hanahan D.: Studies on transformation of Escherichia coli with plasmids. J. Mol. Biol. $166,557-580$ (1983) 
43| Hatton D., Sablowski R., Yung M.H., Smith C., Schuch W. and Bevan M.: Two classes of sequences contribute to tissue-specific expression of a PAL2 promoter in transgenic tobacco. Plant J. 7(6), 859-8761995

44| Harter K., Kircher S., Frohnmeyer H., Krenz M., Nagy F. and Schäfer E.: LightRegulated Modification and Nuclear Translocation of Cytosolic G-Box Binding Factors in Parsley. Plant Cell 6, 545-559 (1994)

45| Heinekamp T.: Funktionelle Analyse des pflanzlichen bZIP-Transkriptionsfaktors G/HBF-1. Diplomarbeit, Universität Bielefeld (1997)

46| Hicks and Raikhel.: Nuclear localisation signal binduíng proteins in higher plant nuclei. Proc. Natl. Acad. Sci.92(3), 734-738 (1995)

47| Hokema A., HirschP.R., Hooykaas P.J.J. and Schilperoort R.A.: A binary plant vectorstrategy based on separation of vir and T-region of the Agrobacterium tumefaciens Ti-plasmid. Nature 303, 179-180 (1983)

48| Horvay K.: Isolierung und Analyse von Proteininteraktionspartnern des bZIPTranskriptionsfaktors BZI-1 aus Nicotiana tabacum. Diplomarbeit, Universität Göttingen (2000)

49| Hood J.K. and Silver P.A.: In or out? Regulating nuclear transport. Cur. Op. Cell Biol. $11,241-247$ (1999)

50| Huxford T., Huang D.B., Malek S. and Ghosh G.: The crystal structure of the IkappaBalpha/NF-kappB complex reveals mechanisms of NF-kappaB inactivation. Cell 95(6), 729-731 (1998)

51 Inove H., Nojima H. and Okayama H.: High efficiency transformation of Escherichia coli with plasmids. Gene 96, 23-28 (1990)

52| Izawa T., Foster R. and Chua N.-H.: Plant bZIP protein DNA binding specificy. J. Mol. Biol. 230, $1131-1144$ (1993)

53| Jakoby M., Parcy F., Vicente-Carbajossa J., Tiedemann J., Kroj T., Dröge-Laser W. and Weisshaar B.: - The bZIP Research Group: bZIP transcription factors in Arabidopsis. Trends Plant Sci. 7 (3) 106-111 (2002)

$54 \mid$ Jacobs, M.D., Harrison, S.C.: Structure of an $1 \kappa B \alpha /$ NF- $\kappa B$ complex. Cell 95, 749758 (1998)

55| King E.O., Ward M.K.and Raney D.E.: Two simple media for the demonstration of phycocyanin and fluorescin. J. Lab. Clin. Med. 44, $301-307$ (1954)

56| Kircher S., Ledger S., Hayashi H., Weisshaar B., Schäfer E. and Frohnmeyer H.: CPRF4a, a novel plant bZIP protein of the CPRF family: comparative analysis of lightdependent expression, post-transriptional regulation, nuclear import and heterodimerisation. Mol. Gen. Genet. 257, 595-605 (1998) 
57| Kircher S., Wellmer F., Nick P., Rügner A., Schäfer E. and Harter K.: Nuclear Import of the Parsley bZIP Transcription Factor CPRF2 is Regulated by Phytochrome Photoreceptors. J. Cell Biol. 144 (2) 201-211 (1999)

58| Klessig D.F. and Malamy J.: The salicylic acid signal in plants. Plant Mol. Biol. 26, 1439-1458 (1994)

59| Klimczak, L.J., Schindler U. and Cashmore A.R.: DNA-binding activity of the Arabidopsis G-box binding factor GBFl is stimulated ba phosphorylation by caseinkinase II from broccoli. Plant Cell 4, 87-98 (1995)

60| Knoche H. and Duvick J.P.: The role of fungal toxins in plant disease. Brit Mycol. Soc. Symp. Ser. 13, 158-192 (1987)

61| Kuhlmann M.: Funktionelle Charakterisierung des pflanzlichen bZIPTranskriptionsfaktors G/HBF-1 in transgenen Tabakpgflanzen. Diplomarbeit Universität Bielefeld (1997)

62| Kusano T., Sugawara K., Harada M. and Berberich T.: Molecular cloning and partial characterisation of a tobacco cDNA encoding a small bZIP protein. Biochem. Biophys. Acta 1395, $171-175$ (1998)

63| Kombrink E. and Somssich I.E.: Pathogenesis-related proteins and plant defense. In: The Mycota (Part A) 107-128, Springer-Verlag, Berlin (1997)

64| Kyhse-Andersen, J.: Electroblotting of multiple gels: A simple apparatus without buffer tank for rapid transfer of proteins from polyacrylamide to nitrocellulose. J. Biochem. Biophys. Meth. 10, 203-209 (1984)

65| Lam E., Kato N. and Lawton M.: Programmed cell death, mitochondria and the plant hypersensitive response. Nature 411, 848-853 (2001)

66| Lamb C. and Dixon R.A.: The oxidative burst in plant disease resistance. Annu. Rev. Plant Physiol. Plant Mol. Biol. 48, 251-275 (1997)

67| Landschulz W.H., Johnson P.F. and McKnight S.L.: The leucine zipper: a hypothetical structure common to a new class of DNA binding proteins. Science 240, 1759-1764 (1988)

68| Leborgne-Castel N., Jelitto-Van Dooren E.P., Crofts A.J. and Deneke J.: Overexpression of BiP in tobacco alleviates endoplasmic reticulum stress. Plant Cell 11 459-470 (1999)

69| Le Gouill C., Parent J.-L., Rola-Pleszczynski M. and Stankova J.: Analysis of recombinant plasmids by a modified alkaline lysis method. Anal. biochem. 219, 164 (1994)

70| Leyser O.: Auxin signalling: the beginning, the middle and the end. Cur. Op. Plant Biol. 4, 382-386 (2001) 
71 Liu X. and Lam E.: Two binding sites for the plant transkription factor ASF-1 can respond to auxin treatments in transgenic tobacco. J. Biol. Chem. 269, 668-675 (1994) Liu Z.-B., Ulmasov T., Shi X., Hagen G. and Guilfoyle T.J.: Soybean GH3 promotor contains multiple auxin-inducible-elements. Plant Cell \&, 645-657 (1994)

72| Liu Z.-B., Hagen G. and Guilfoyle T.J.: A G-Box-Binding Protein from Soybean Binds to the E1 Auxin-Response Element in the Soybean GH3 Promoter and Contains a ProlineRich Repression Domain. Plant Physiol. 115, 397-407 (1997)

73| Lu G., DeLisle A.J., De Vetten N.C. and Ferl R.J.: Brain proteins in plants: an Arabidopsis homolog to neurotransmitter pathway activators is part of a DNA binding complex. Proc. Natl. Acad. Sci. 89 (23), $11490-11494$ (1992)

74| Lux S.E., John K.M. and Bennett V.: Analysis of cDNA for human erythrocyte ankyrin indicates a repeated structure with homology to tissue-differentiation and cell-cycle control proteins. Nature 344(6261), 36-42 (1990)

75| Macdonald H.: Auxin perception and signal transduction. Physiol. Plant. 100, 423430 (1997)

76| Martin G.B. Brommonschenkel S.H., Chunwongse J., Frary A., Ganal M.W., Spivey R, Wu T., Earle E.D. and Tanksley S.D.: Map-based cloning of a protein kinase gene confering disease resistance in tomato. Science 262 (5138), 1432-1436 (1993)

77| Martinez-Garcia J.-F., Moyano E., Alcocer M. J.C. and Martin C.: Two bZIP proteins from Anthirrhinum flowers preferentially bind a hybrid C-box/G-box motif and helg to define a new sub-family of bZIP transcription factors. Plant J 13 (4) 489-505 (1998)

78| Mayda E., Mauch-Mani B and Vera P.: Arabidopsis dth9 Mutation Identifies a Gene Involved in Regulating Disease Susceptibility without Affecting Salicylic Acid-Dependent Responses. Plant Cell 12, 21 19-2128 (2000) a

79| Mayda E., Marqués C., Conejero V. and Vera P.: Expression of a pathogen-Induced Gene Can Be Mimicked By Auxin Insensivity. Mol Plant Mirob. Int. 13 (1), 23-31 (2000) b

80| McKnight S.L.: Molecular zippers in gene regulation. Sci. Am. 264, 54-64 ( 1991)

$81 \mid$ Merkle T.: Nuclear import and export of proteins in plants: a tool for regulation of signalling. Planta 213, 499-517 (2001)

82| Murphy A.M., Chivasa S., Singh D.P. and Carr J.P.: Salicylic acid-induced resistance to viruses and other pathogenes: a parting of the ways? Trends Plant sci. 4 (4), 155-160 (1999)

83| Mullis K.B. and Faloona F.A.: Specific synthesis of DNA in vitro via a polymerasecatalyzed chain reaction. Methods Enzymol. 155, 335-350. (1987) 
84 Murashige T. and Skoog F.: A revised medium for rapid growth and bioassays with tobacco tissue culture. Plant Physiol. 15, 473-497 (1962)

85| Nakase M., Aoki N., Matsuda T. and Adachi T.: Characterisation of a novel rice bZIP protein which binds to the alpha-globulin promoter. Plant Mol. Biol. 33(3), 513-522 (1997)

86| Niggeweg, R. (1999): Salizylsäure- und Auxin-induzierte Genexpression in Nicotiana tabacum: Funktionelle Bedeutung der TGA-Faktoren der Subklasse II. Dissertation, Universität Bielefeld.

87| Niggeweg R., Thurow C., Weigel R., Pfitzner U. and Gatz C.: Tobacco TGA factors differ with respect to interaction with NPR1, activation potential and DNA-binding properties.

Plant Mol Biol. 2000 Mar;42(5):775-788 (2000)

88| Nuhse T.S., Peck S.C. Hirt H. and Boller T.: Microbial elicitors induce activation and dual phosphorylation of the Arabidopsis thaliana MAPK 6.J. Biol. Chem. 275(11), 7521 7526 (2000)

89| Oliver S.G., Van der Aart G.J., Agostoni-Carbone M.L. and Aigle M.: The complete DNA sequence of yeat chromosome III. Nature 357 (6373), 38-46 (1992)

90| Paiva N.L., Edwards R., Sun Y.J., Hrazdina G. and Dixon R.A.: Stress responses in alfalfa (Medicago sativa L.) 11. Molecular cloning and expression of alfalfa isoflavone reductase, a key enzyme of isoflavonoid phytoalexin. Plant Mol. Biol. 17(4), 653-667 (1991)

91 Palme K. and Gälweiler L.: PIN-pointing the molecular basis of auxin transport. Cur. Op. Plant sci. 2, 375-381 (1999)

92| Peck S.C., Nuhse T.S. Hess D., Iglesias A. Meins F. and Boller T.: Directed Proteomics Identifies a Plant-Specific Protein Rapidly Phosphorylated in Response to Bacterial and Fungal Elicitors. Plant Cell 13 1467-1475 (2001)

93| Perlmann D.C. and Halvorson H.O.: Improved resolution of DNA fragments in polysaccharid-supplemented agarose gels. Analytical Biochem. 163, 247-256 (1987)

94 Pieterse C.M.J. and Van Loon L.C.: salicylic acid-independent plant defence pathways. Trends Plant Sci. 4(2), 52-58 (1999)

95| Pinna L.A.: Proteinkinase CK2. Int. J. Biochem. Cell Biol. 29(4), 551 -554 (1997)

96| Ptashne M.: How gene activators work. Sci.Am. 260(1), 40-47 (1989)

97| Prat S., Willmitzer L. and Sánchez-Serrano J.J.: Nuclear proteins binding to a cauliflower mosaic virus 35S truncated promoter. Mol. Gen. Genet. 217, 209-214 (1989) 
98| Pysh L.D., Aukermann M.J. and Schmidt R.J.: OHPl: a maize basic domain/leucine zipper protein that interacts with Opaque2. Plant Cell 5: 227-236., 1993

99| Qin X. F., Holuigue L., Horvat D.M. and Chua N.H.: Immediate early transcription activation by salicylic acid via the cauliflower mosaic virus as-1 element. Plant Cell 6, 863-874 (1994)

100| Reed J.W.: Roles and activities of Aux/IAA proteins in Arabidopsis. Trends Plant Sci. 6(9), 420-425 (2001)

101| Rhee Y., Gurel F., Gafni Y., Dingwall C. and Citovski V.: A genetic system für detection of protein nuclear import and export. Nature Biotech 18, 433-437 (2000)

102| Riechmann J.L. and Ratcliffe O.J.: A genomic perspective on plant transcription factors. Cur. Opin. Plant Biol. 3, 423-434 (2000)

103| Roitsch T.: Source-sink regulation by sugar and stress. Curr. Op. Plant Biol. 2(3), 198-206 (1999)

104 | Roitsch T., Ehneeß R., Goetz M., Hause B., Hofmann M. and Sinha A.K.: Regulation and function of extracellular invertase from higher plants in relation to assimilate partitioning, stress responses and sugar signalling. Aust. J. Plant Physiol. 27, 815-825 (2000)

105| Romeis T., Piedras P., Zhang S., Klessig D.F., Hirt H. and Jones J.D.G.: Rapid Avr9and Cf-9-Dependent Activation of MAP Kinases in Tobacco Cell Cultures and Leaves: Convergence of Resistance gene, Elicitor, Wound, and Salicylate Responses. Plant Cell 11, 273-287 (1999)

106| Romeis T., Ludwig A.A., Martin R. and Jones J.D.G.: Calcium-dependent protein kinase play an essential role in a plant defence response. EMBO J. 20 (20), 5556-5567 (2001)

107| Rook F., WeisbeckP P. and Smeekens S.: The light-regulated Arabidopsis bZIP transcription factor ATB2 encodes a protein with an unusually long leucine zipper domain. Plant Mol Biol. 37, 171-178 (1998)

108| Ross F.A.: Virology 14, 329-358 (1961)

109| Roux C. and Perrot-Rechenmann C.: Isolation by differential display and characerization of a tobacco auxin-responsive cDNA Nt-gh3, related to GH3. FEBS Letter $419,131-136$ (1997)

$110 \mid$ Rugner A., Frohnmeyer H., Nake C., Wellmer F., Kircher S., Schäfer E. and Harter K.: Isolation and characterization of four novel parsley proteins that interact with the transcriptional regulators CPRF1 and CPRF2. Mol Genet Genomics. 265(6):964-976 (2001) 
111 Ryals J.A., Neuenschwader U.H., Willits M.G., Molina A., Steiner H.-Y. and Hunt M.D.: Systemic acquired resistance. Plant Cell 8, 1809-1819 (1996)

112| Sakai T., Takahashi Y. and Nagata T.: The Identification of DNA Binding Factors Specific for as-1-like Sequences in Auxin-Responsive Regions of parA, parB and parC. Plant Cell Physiol. 39(7), 731 -739 (1998)

113| Sambrook J., Fritsch E.F. and Maniatis T.: Molecular cloning: A Laboratory Manual $2^{\text {nd }}$ edition Cold Spring Harbour Laboratory Press, New York (1989)

$114 \mid$ Sanger F., Nickler S. and Coulson A.R.: DNA-Sequencing with chain-terminating inhibitors. Proc. Natl. Acad. Sic. USA 74, 5463-5467 (1977)

115 | Schindler U., Beckmann H. and Cashmore A.R.: TGA1 and G-box binding factors: Two distinct classes of Arabidopsis leucine zippers proteins compete for the G-box-like element TGACGTGG. Plant Cell 4, 1309-1319 (1992)

$116 \mid$ Schwechheimer C. and Bevan M.: The regulation of transcription factor activity in plants. Trends Plant Sci. 3, 378-383 (1998)

$117 \mid$ Schwechheimer C., Zourelidou M. and Bevan M.: Plant Transkription Factor Studies. Annu. Rev. Plant. Physiol. Plant Mol. Biol. 49, 127-150 (1998)

118| Seehaus K. and Tenhaken R.: Cloning of genes by mRNA differential display induced during the hypersensitive reaction of soybean after inoculation with Pseudomonas syringae pv. glycinea. Plant Mol. Biol. 38(6), 1225-1234 (1998)

119 Sedgwick S.G. and Smerdon S.J.: The ankyrin repeat: a diversity of interactions on a common strucural framework. Trends Biochem. Sci. 24(8), 311 -316 (1999)

120| Shulaev V., Léon J. and Raskin I.: Is salicylic acid a translocated signal of systemic acquired resistance in tobacco? Plant Cell 7, $1691-1701$ (1995)

$121 \mid$ Smith H.M.S., Hicks G.R. and Raikhel N.V.: Importin $\alpha$ from Arabidopsis thaliana Is a Nuclear Import Receptor That Recognizes Three Classes of Import Signals. Plant. Phys. $114,411-417$ (1997)

122| Sprenger-Haussels M. and Weisshaar B.: Transactivation properties of parsley proline-rich bZIP transcription factors. Plant J. 22(1) 1-8 (2000)

123| Stintzi A., Heitz T., Prasad V., Wiedemann-Merdinoglu S., Kauffmann S., Geoffroy P., Legrand M. and Fritig B.: Plant 'pathogenesis-related'proteins and their role in defense against pathogens. Biochimie 75(8), 687-706 (1993)

124 Strathmann A.: Identifizierung von Protein-Interaktionspartnern des -bZIPTranskripitionsfaktors G/HBF-1 mit Hilfe des Hefe-"two-Hybrid"-Systems. Diplomarbeit Universität Göttingen (1999) 
125| Strathmann A., Kuhlmann M., Heinekamp T. and Dröge-Laser W.: BZI- 1 specifically heterodimerises with the tobacco bZIP transcription factors BZI-2, BZI3/TBZF and BZI-4, and is functionally involved in flower development. Plant J. 28 (4), 397-408 (2002)

126| Studier F.W.and Moffat B.A.: Use of bacteriophage T7 RNA polymerase to direct selective high-level expression of cloned benes. J. Mol. Biol. 189, 113-130 (1986)

127| Sutherland M-W.: The generation of oxygen radicals during host plant responses to infection. Physiol. Mol. Plant Pathol. 39, 79-94 (1991)

128| Tena G., Asai T., Chiu W.-L. and Sheen J.: Plant mitogen-activated protein kinase signaling cascades. Cur. Op. Plant Biol. 4, 392-400 (2001)

129| Terzaghi, W.B., Betekap R.L. and Cashmore A.R.: Intracellular localisation of GBF proteins and blue light-induced import of GBF2 fusion proteins into the nucleus of cultured Arabidopsis and soybean cells. Plant J. 11 (5), 967-982 (1997)

130| Ulmasov T., Liu Z.-B., Hagen G. and Guilfoyle T.J.: Composite structure of Auxin Response Elements. Plant Cell 7, 1611-1623 (1995)

131 Varagona M.J. and Raikhel N.V.: The basic domain in the bZIP regulatory protein Opaque2 serve two independent functions: DNA binding and nuclear localisation. Plant Journal 5 (2) 207-214 (1994)

132| Vettore A.L., Yunes J.A. Cord Neto G., Da Silva M.J., Arruda P. and Leite A.: The molecular and functional characterisation of an Opaque2 homologue gene from Coix and a new classification of plant bZIP proteins. Plant. Mol. Biol. 36 (2), 249-263 (1998)

133| Vicente-Carbajosa J., Onate L., Lara P., Diaz I. and Carbonero P., Barley: BLZ1: a bZIP transcriptional activator that interacts with endosperm-specific gene promoters. Plant J. 13 (5), 629-640 (1998)

134 Vogeli U. and Chappell J.: Inhibition of a plant sesquiterpene cyclase by mevinolin. Arch Biochem. Biophys. 288(1), 157-162 (1991)

135| Walker L. and Estelle M.: Molecular mechanisms of auxin action. Cur. Op. Plant Biol. 1, 434-439 (1998)

136| Ward E.R., Uknes S.J., Williams S.C., Dincher S.S., Wiederhold D.L., Alexander D.C., Ahl-Goy P., Métraux J.-P. and Ryals J.A.: Coordinate gene activity in response to agents that induce systemic acquired resistance. Plant Cell 3, 1085-1094 (1991)

137| Weisshaar B., Armstrong G.A., Block A., daCosta e Silva O. and Hahlbrock K.: Light-inducible and constitutivley expressed DNA-binding proteins recognizing a plant promotor element with functional relevance in light response. EMBO J. 10(7), 1777-1786 (1991) 
138| Wellmer F., Kircher S., Rügner A., Frohnmeyer H., Schäfer E. and Harter K.: Phosphorylation of the Parsley bZIP Transcription Factor CPRF2 is Regulated by Light. J Biol. Chem. 274 (41) 29476-29482 (1999)

139| Weintraub H.M.: Anti-Sense-DNA und -RNA: komplementäre Codes mit Sinn. Spektrum der Wissenschaften 3, 70-77, (1990)

140| Wharton K.A., Johansen K.M., XU T. and Artavanis-Tsakonas S.: Nucleotide sequence from the neurogenic locus notch implies a gene product that shares homology with proteins containing EGF-like repeats. Cell 43(3.2), 567-581 (1985)

$141 \mid$ Yalpani N., Silvermann P., Wilson T.M., Kleier D.A. and Raskin I.: Salicylic acid is a systemic signal and an inducer of pathogenesis-related proteins in virus-infected tobacco. Plant Cell 3(8) 809-818 (1991)

142 Yan J., Wang J. and Zhang H.: An ankyrin repeat-containing protein plays a role in both disease resistance and antioxidation metabolism. Plant Journal 29 (2), 193-202 (2002)

143| Yang D., Wu L., Hwang Y.S., Chen L. and Huang N.: Expression of the REB transcriptional activator in rice grains improves the yield of recombinant proteins whose genes are controlled by a Reb-responsive promoter. Proc. Natl. Acad. Sci. 98(29), 11438 $11443(2001)$

$144 \mid$ Yang S.H., Berberich T., Sano H. and Kusano T.: Specific association of transcripts of tbzF and tbz 17, tobacco genes encoding basic region leucine zipper-type transcriptional activators, with guard cells of senescing leaves and/or flowers. Plant Physiol. 127 (1), 23$32(2001)$

145 Yin S., Mei L., Newmann J. Back K. and Chappell J.: Regulation of Sesquiterpene Cyclase Gene expression. Plant Pysiol. 115, 437-451 (1997)

146| Yucel I., Xiao YX., Hutcheson SW: Influence of Pseudomonas syringae culture conditions on initiation of the hypersensitive response of culture tobacco cells. Appl. Environ. Microbiol. 1989. Jul. 55(7):1724-9

147| Zhang B., Chen W., Foley R.C., Büttner M. and Singh K.B.: Interactions between distinct types of DNA binding proteins enhance binding to ocs element promoter sequences. Plant Cell 7, $2241-2252$ (1995)

148| Zhang S. and Klessig D.F.: Resistancegene N-mediated de novo synthesis and activation of tobacco mitogen activated protein-kinase by tobacco mosaic virus infektion. Proc. Natl. Acad. Sic. 95(13), 7433-7438 (1991)

149| Zhang S. and Klessig D.F.: The tobacco wound-activated mitogen-activated protein kinase is encoded by SIPK. Proc. Natl. Acad. Sic. 95(12) 7225-7230 (1998)

150| Zhou J.-M., Trifa Y., Silva H., Pontier D., Lam E., Shah J. and Klessig D.F.: NPR1 differentially interacts with members of the TGA/OBF family of transcription factors that bind an element of the PR-1 gene requiered for induction by salicylic acid. Mol. Plant Microbe Interact. 13 (2), 191-202 (2000) 


\section{G | Anhang}

\section{1 | Aminosäuresequenz BZI-1}

LOCUS AAL27150 450 aa linear PLN 07-NOV-2001

DEFINITION bZIP transcription factor [Nicotiana tabacum].

ACCESSION AAL27150

PID $\quad$ g16797791

VERSION AAL27150.1 GI:16797791

DBSOURCE accession AY061648.1

SOURCE common tobacco.

ORGANISM Nicotiana tabacum Eukaryota; Viridiplantae; Streptophyta; Embryophyta; Tracheophyta; Spermatophyta; Magnoliophyta; eudicotyledons; core eudicots; Asteridae; euasterids I; Solanales; Solanaceae; Nicotiana.

AUTHORS Heinekamp,T., Kuhlmann,M., Lenk,A., Strathmann,A. and Droege-Laser,W.

TITLE The tobacco bZIP transcription factor BZI- 1 binds to G-box promoter cis-elements of phenylpropanoid pathway genes in vitro, but it is not involved in their regulation in vivo

JOURNAL Unpublished

University of Goettingen, Albrecht-von-Haller-Institut, Untere Karspuele 2, Goettingen 37073,

Germany

FEATURES

Location/Qualifiers

source

$1 . .450$

/organism ="Nicotiana tabacum"

$/ d b \_x r e f=" t a x o n: 4097 "$

Protein $\quad 1 . .450$

/product="bZIP transcription factor"

CDS $\quad 1 . .450$

/gene="BZI-1"

ORIGIN

/coded by="AY061648.1:1..1353"

1 mervfsmedd igdhfwstpp tadlgvdspt aaaavsyskm mnrsssewaf qrflqeataa

61 gtstssppqp ptmtasssss shqndvveik denlsipnln pstalnskpa ssfglapppn

121 iavdseeyqa flksqlhlac aavaltrgks Inpqdsgsta hdkgsetasa aqsgshvstl

181 gsgqevakiq dkdaggpvgi pslppvqkkp vvqvrsttsg ssreqsddde aegeaettqg

241 mdpadakrvr rmlsnresar rsrrrkqahl teletqvsql rvenssllkr Itdisqkyne

301 aavdnrvlka dvetlrtkvk maeetvkrvt glnplfaams eissmvmpsy sgspsdtsad

361 aavpvqddpk hhyyqqppnn Impthdpriq ngmvdvppie nveqnpataa vggnkmgrtt

421 smqrvasleh lqkrirgevs scgtagrgeq 


\section{2 | DNA Sequenz BZI-1}

LOCUS AY061648 1425 bp mRNA linear PLN 07-NOV-2001

DEFINITION Nicotiana tabacum bZIP transcription factor (BZI-1) mRNA, complete cds.

ACCESSION AY061648

VERSION AY061648.1 GI:16797790

KEYWORDS

SOURCE common tobacco.

ORGANISM Nicotiana tabacum Eukaryota; Viridiplantae; Streptophyta; Embryophyta; Tracheophyta; Spermatophyta; Magnoliophyła; eudicotyledons; core eudicots; Asteridae; evasterids I; Solanales; Solanaceae; Nicotiana.

REFERENCE 1 (bases 1 to 1425)

AUTHORS Heinekamp,T., Kuhlmann,M., Lenk,A., Strathmann,A. and Droege-Laser,W.

TITLE The tobacco bZIP transcription factor BZI-1 binds to G-box promoter cis-elements of phenylpropanoid pathway genes in vitro, but it is not involved in their regulation in vivo

1 atggagcggg tettctccat ggaggatgac attggcgacc acttctggtc gacgecgecg 61 acggeggact taggegttga Hecccaacc gctgecgecg ccgtctccta ctcaaagatg 121 atgaatcgaa getcttccga atgggetttc cagcgcttcc tccaagaagc caccgecgec

181 ggtacctcca cttcatctcc cccccagcca cctacaatga cggegtcttc ctcgtcatct

241 tcgcaccaaa acgacgtcgt ggagatcaag gatgagaatc tttctattcc taatttaaat

301 cccagtacgg cgttgaattc gaagecggeg tcgtcgtttg gectcgcacc tccgccgaat

361 attgccgttg attccgaaga gtatcaagca ttcctcaaaa gecaactcca tttggettgc

421 gccgccgttg ctttgactcg cggcaagagt ttaaaccetc aggattcagg ctctacagct

481 cacgacaaag gatcagagac tgctagtgca gctcaatcag gatctcacgt ctccacttta

541 ggatctggtc aggaagtgge aaaaattcaa gataaggatg ctggtggacc agttggaatt

601 ccctccttgc ecceggtgca aaagaaacct gtggtgcagg tgaggtcaac aaccagtggt

661 tcatctagag agcaatctga tgatgatgaa getgaaggag aagcagaaac aactcaagge

721 atggatccag ctgatgcaaa acgtgtaagg agaatgcttt caaatagaga atcagccaga

781 cgttcaagga gaagaaagca ggcccatctg acagaactcg agacacaggt ttctcaactc

841 agagtagaaa actcctctct actgaaacgt ctgactgaca taagccagaa atacaatgaa

901 gcagcggttg ataatcgagt cttgaaagca gatgttgaga cattaagaac gaaggtaaag

961 atggctgaag aaactgttaa aagagttact gggttaaatc cgttattcca agctatgtca

1021 gagatttcct caatggtaat gccatcctac tctggtagtc cttcagacac atcggcagac

1081 getgctgtac ctgtgcaaga tgatccaaaa catcactact accaacagec gecaaataat

1141 cttatgccaa cccatgatcc tagaatccaa aatggtatgg tagatgittcc tccaatagaa

1201 aatgtagagc agaatcctgc aacggcagca gitggggggga acaagatggg tagaacaact

1261 tcaatgcagc gggttgctag cttggagcat ctgcagaagc gcatccgtgg tgaagtgagt

1321 tcctgtggaa ctcaaggcag gggagagcaa taaacacggt taaagccacc agctgcaccg

1381 aagattltgc acagcatgtt gataaaatca tactgttcca attcc

\section{3 | Aminosäuresequenz ANK1}

1 msegekvlpt asadeksgas enkkssesss teapsgeart tstaaagagl qnpfdfsams

61 gllndpsike laeqiakdpa fnqmaeqlak tfqgaavees vpnfdsqqyy stmqqvmqnp

121 gfmtmaerlg nalmadpsms gmleslsnpa qkeqieerma rikedpslkp ileeiesggp

181 aammrywndq etlkkigeam gfaaggegat ssaipgtdet eeanedesvv hqcasvgdae

241 glkaaltaga dkdeedsegr talhfacgyg evkcaqille agakvdaldk nkntalhyaa

301 gygrkecval llengaavtl qnldgktpid vaklnnqqev Ikllekdvfl 


\section{4 | DNA-Sequenz ANK1}

1 ctctttttct Htttctttt ttgtctgtac ccccaaatct cctcctatct ttcaacttta

61 ctcttacccc aacacaactc Htgtagtca tgtctgaggg agagaaagtt ttgcctactg

121 catcagcaga tgagaagtct ggggcatctg agaataaaaa atcttctgag tcttcctcca

181 cagaagcacc atcaggagag gcgagaacaa cctctacgge tgcggctgga gctgggcttc

241 aaaatccctt tgatttctca gccatgtctg gactacttaa tgacccaagt atcaaagaac

301 tagcggagca gatagcgaaa gatcctgcat ttaatcagat ggcggagcag cttcagaaga

361 cctttcaagg tgctgcagtc gaagagagcg tccccaactt tgatagccaa caatactatt

421 ccacaatgca acaggttatg caaaatcctc aatttatgac aatggctgag cggcttggta

481 atgcgittgat gcaggatcca tccatgtctg gcatgcttga gagtttgtca aaccctgctc

541 agaaggagca aattgaagaa cgaatggcac gcatcaaaga agacccatcg ctgaaaccga

601 tttggaaga gatagagagc gggggaccag ctgcaatgat gaggtattgg aatgatcaag

661 aaacactgaa gaaaattggt gaagcaatgg gttttgctgc tgggggagag ggtgctacct

721 cttccgcaat acctgggacc gatgaaaccg aagaggctaa tgaagatgaa tctgttgttc

781 accagtgtgc tagtgttggt gatgcagagg gcttgaaggc tgcactaact gctggtgctg

841 ataaagacga agaagactca gaaggaagga cggcattgca ttttgcttgt ggatatggcg

901 aggtgaagtg tgctcagatt cttctggaag ctggggcaaa ggttgatgec ttggacaaga

961 ataagaatac tgctcttcac tatgctgctg gatatggtag gaaggagtgt gtcgcgctgc

1021 tgctagagaa tggagccgct gtaactctcc aaaacttgga tggtaagaca ccgatcgatg

1081 tggccaaact caacaaccag caggaggtcc tgaagctgct cgagaaagat gtgtttctgt

1141 gaactgggga gggatgtcac agggtttat tgtcgagcca cagtattttg aggaactaag

1201 gggtcttatt catggttgat ttgcttctta agttatcttt gctggtgtat catttatagt

1261 tttggtgttt ttctaagaat tgcctgttca aaagatcctg Httttttt gtaaaaaaaa

1321 aaaaaaaaaa a 


\section{5 | Homolgievergleich des ANK1}

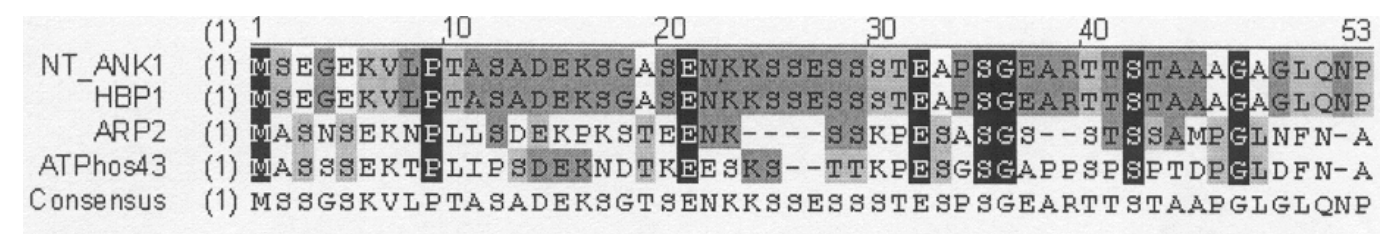

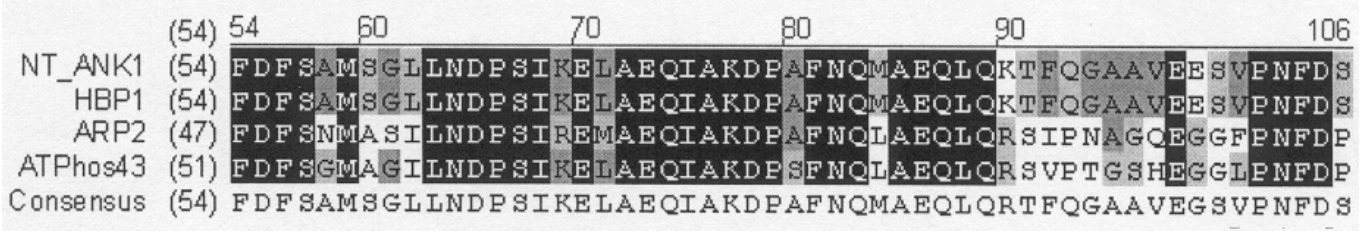

NT_ANK1 (107) $\frac{107}{\text { QQYYSTMQQVMQNECFMTMAERL GNA LMQDE SMSGMLESI SNEA QREQIEERM }}$ HBP1 (107) QQYYSTMQQVMQN OFMTMA ERI GNA LMOD E SMSGMLE SL SNE A QRE QIEERM ARP2 (100) QQYVNTMQQVMHNE E FTMA EKL GTA LVQD E OMSE F LDAF SNPE TAE HF TERM

ATPhos43 (104) QQYMOTMQQVMENE E FRTMAERL GNA LVQDE CMSP F LEAI GNPAASEQF AERM

Consensus (107) QQYYSTMQQVMQNP QFMTMAER L GNA LVQD SMSPMLE SI INPAQKEQIEERM
(160) 160
170
180
190
200
212

NT_ANK1 (160) ARIKEDESLKEILEEIE SGGEAAMMRYWNDQETLKRIGEAMGFAAGG-EGAT S HBP1 (160) AR IKED S LKP I LEIE SGGPAAMMRYWND QETLKR I GEAMGFAAGG-EGAT S ARP2 (153) ARMKED F EL KP I LDE ID A GGE SAMMKYWND E EVLKRL GEAMGMPVA GL P D OTV

ATPhos43 (157) AOMKEDE LRPI IAEID AGGESAMNKYWNDKDVLAKLGEAMGIAVG- - AD CTV

Consensus (160) ARMKEDP SLRPILEEIE SGGP SAMMRYWNDQEVLKKLGEAMGFAVGG EGQTV Ank-repeat 1

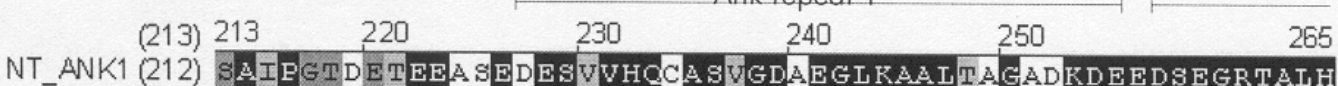

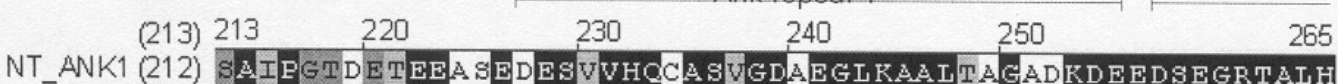

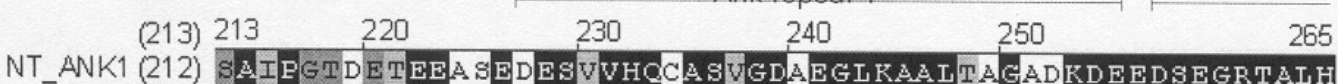
HBP1 (212) SAIPGTDETEEANEDESVVHCCA SVGDAEGLKAALTAGADKDEEDSEGRTALH ARP2 (206) SAEA--EVAEEGEEEESIVHCTA SIGDVEGLKAALASGGNKDEEDSEGRTALH

ATPhos43 (208) AAEE- - EEAEEGEEEESIVHOTASIGDVEGLKAA LA.SGGNKDEEDSEGRTALH

Consensus (213) SAIPGTEETEEGEEEESVVHQTASVGDVEGLKA.AT SGGNRDEEDSEGRTALH

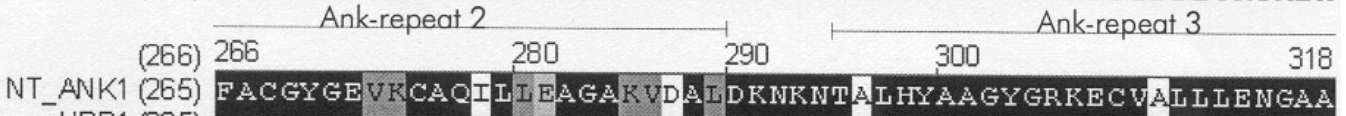
HBP1 (265) FACGYGEVKCAOI L LEAGA KVDAIDKNKNTA LHYAAGYGRKECVAIL L ENGAA ARP2 (257) FACGYGEL KCA QVI I DAGA SUNA VD KNKNT L HYAAGYGR E CVSL L LENGAA

ATPhos43 (259) FACGYGEVRCA VVIIDAGANANAIDKNKNTP L HYAAGYGR KECVSL LLENGAA

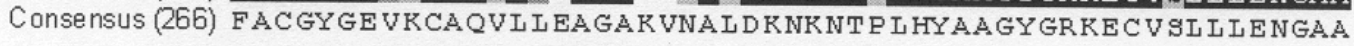

\section{G - 5 : Homologievergleich des ANK1 zu verwandten Proteinen.}

ANK1: N.t.ANK1-Ankyrinrepeat enthaltendes Protein, HBP1: N.t. HBP1 (Helicase Binde Protein, ANK1 identisch), ARP2: A.t. ARP2 (identisch zu AFT ZHANG et al., 1995 und AKR2 Yan et al., 2001), AtPhos43: A.t.Atphos43 (Peck et al., 2001); schwarz unterlegte Felder: identische Aminosäuren, grau unterlegte Felder: ähnliche Aminosäuren. 


\section{6 | Ausgemessene Blütenorgane}

\begin{tabular}{|c|c|c|c|c|c|c|c|}
\hline $\begin{array}{l}\text { limakammer } \\
\text { Lirie }\end{array}$ & Petalen & Filament & Sternpel & $\Pi$ & Stabw(P) & Stabw(F) & Stabw(S) \\
\hline chss & 3,77 & 4,39 & 3,51 & 75 & 0,09 & 0,12 & 0,12 \\
\hline chs 15 & 3,64 & 38 & 3,35 & 55 & 0,12 & 0,13 & 0,09 \\
\hline $8 \mathrm{GHc} 2$ & 3,51 & 4,24 & 3,46 & 14 & 0,09 & 0,17 & 0,09 \\
\hline $8 \mathrm{GHc} 3$ & 3,71 & 4,36 & 3,58 & 17 & 0,09 & 0,12 & 0,15 \\
\hline $8 \mathrm{GHc} 6$ & 3,68 & 4,44 & 3,72 & 19 & 0,08 & 0,07 & 0,08 \\
\hline $8 \mathrm{GHc} 7$ & 3,58 & 42 & 3,42 & 20 & 0,05 & 0,08 & 0,12 \\
\hline $8 \mathrm{GHc} 13$ & 38 & 4,41 & 3,72 & 52 & 0,09 & 0,17 & 0,13 \\
\hline $15 \mathrm{HAN} 2$ & 3,05 & 2,95 & 2,79 & 15 & 0,12 & 0,09 & 0,09 \\
\hline 8 HAN 4 & 3,15 & 3,03 & 2,84 & 40 & 0,09 & 0,09 & 0,11 \\
\hline 8 HAN 5 & 3,07 & 2,92 & 2,70 & 30 & 0,09 & 0,09 & 0,09 \\
\hline 8 anti 1 & 3,08 & 3,03 & 2,65 & 55 & 0,13 & 0,08 & 0,09 \\
\hline 15 anti 3 & 3,58 & 4,28 & 3,22 & 5 & 0,04 & 0,07 & 0,07 \\
\hline $8 \mathrm{D} 1 \mathrm{C}$ & 3,57 & 4,26 & 3,46 & 48 & 0,12 & 0,14 & 0,15 \\
\hline $8 \mathrm{D} 1 \mathrm{x}$ & 3,49 & 4,24 & 3,39 & 15 & 0,06 & 0,17 & 0,1 \\
\hline p D2 S1 & 3,76 & 4,00 & 3,33 & 22 & 0,11 & 0,15 & 0,07 \\
\hline pD2 2 & 3,38 & 3,29 & 2,73 & 49 & 0,08 & 0,11 & 0,13 \\
\hline $15 \mathrm{D} 21$ & 3,62 & 4,06 & 3,48 & 40 & 0,09 & 0,12 & 0,1 \\
\hline 15D24 & 3,57 & 4,07 & 3,45 & 35 & 0,09 & 0,12 & 0,07 \\
\hline $15 \mathrm{BD} 1$ & 3,11 & 3,69 & 2,94 & 44 & 0,15 & 0,10 & 0,1 \\
\hline $8 \mathrm{HABD} \mathrm{A}$ & 3,60 & 4,21 & 3,40 & 27 & 0,09 & 0,10 & 0,07 \\
\hline $8 \mathrm{HABD} \mathrm{G}$ & 3,79 & 4,03 & 39 & 23 & 0,17 & 0,23 & 0,14 \\
\hline pD4 1 & 3,76 & 4,42 & 3,56 & 25 & 0,06 & 0,07 & 0,08 \\
\hline $8 \mathrm{D} 4 \mathrm{~B}$ & 3,55 & 4,31 & 3,52 & 35 & 0,09 & 0,08 & 0,1 \\
\hline $8 \mathrm{D} 4 \mathrm{C}$ & 3,76 & 4,42 & 3,62 & 57 & 0,09 & 0,14 & 0,14 \\
\hline
\end{tabular}

G - 6-1: Ausgemessene Blütenorgane der BZI-1-Derivat-exprimierenden Pflanzenlinien.

Mittelwerte der Messungen: chs8/chs15: Wildtyp; GHc: BZI-1-Überexpressionsplanzen; HAN: Deletion der Domäne N mit HA-tag; anti: BZI-1-antisense RNA-exprimierende Pflanzen; D1: Deletion der Domäne N und D1; D2: Deletion der Domäne N und D2; BD: Deletion der Domäne Nun BD; D4: deletion der Domäne N und D4, n: Anzahl der ausgemessenen Blüten; Stabw: Standardabweichung, P:Petalen, F: Filament, S: Stempel. 


\section{Blütenlängen}

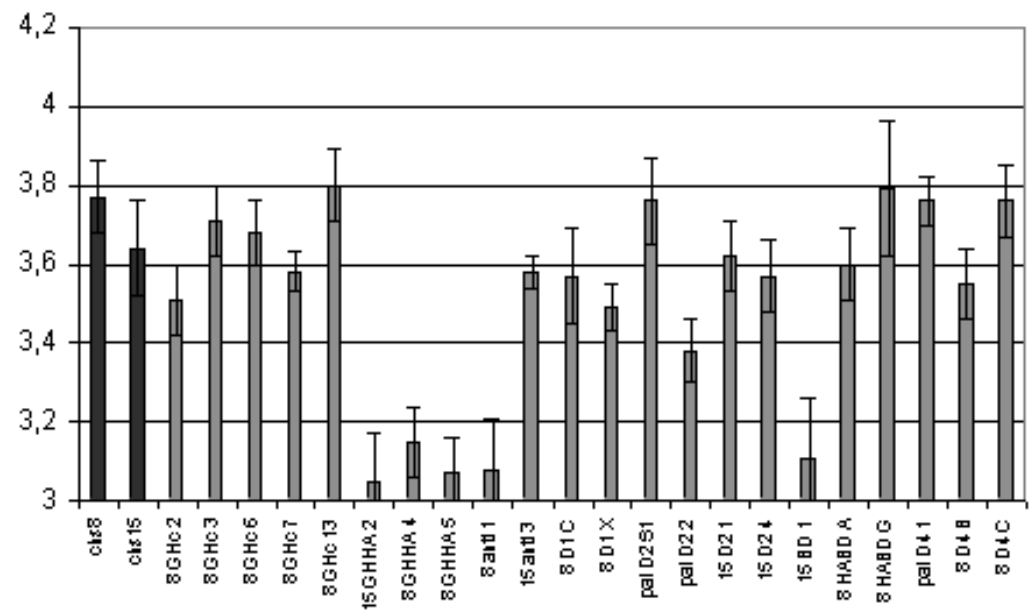

Stempellängen

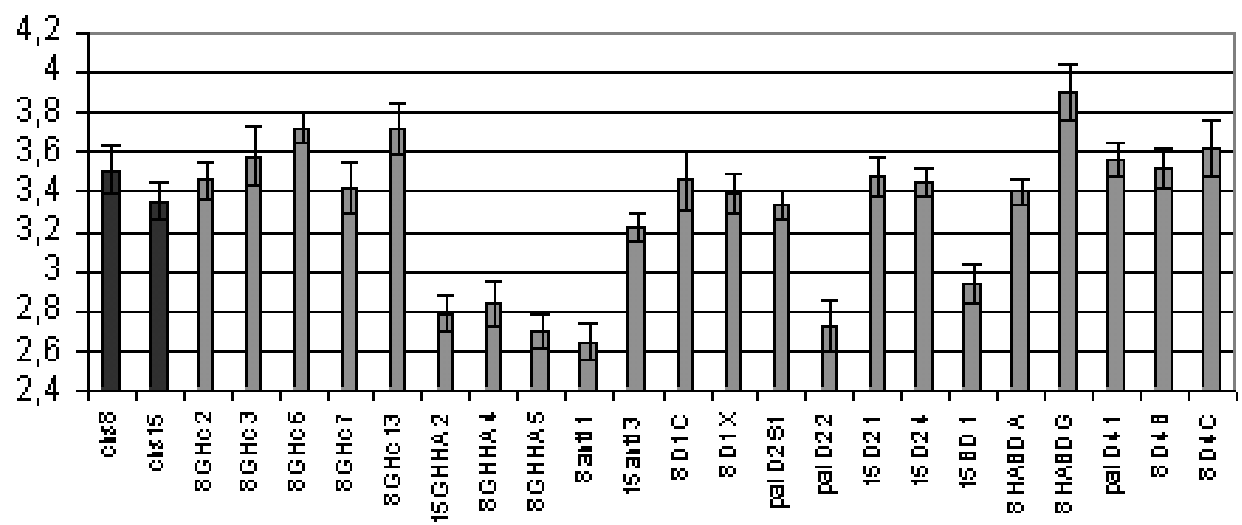

Filam entlängen

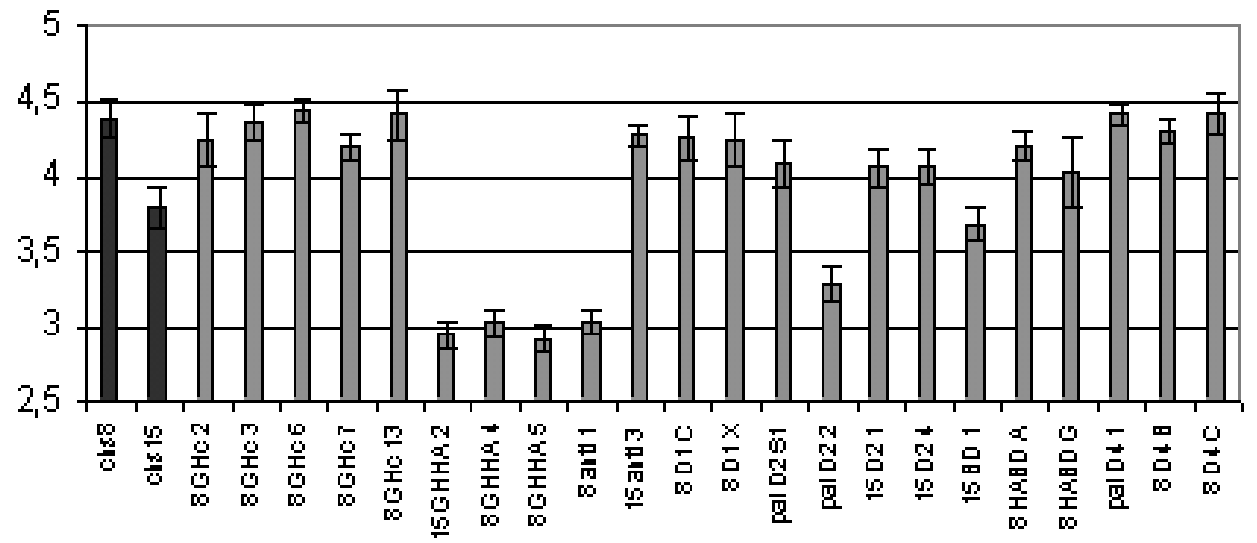

G - 6-2: Graphische Auftragung der Organgrößen.

Blütenlängen, Filamentlängen und Stempellängen; Größen in cm. 


\section{7 | Detektion des Bakterienwachstums}

extrapolierte Mittelwerte
\begin{tabular}{|l|c|c|c|}
\hline P.s.pisi & 0 & 2 & 4 \\
\hline WT & 101 & 30533 & 45333 \\
\hline BZI1 $\Delta$ BD & 101 & 112267 & 82750 \\
\hline BZI1 $\Delta$ N & 101 & 3250 & 2850 \\
\hline
\end{tabular}

Standardabweichung

\begin{tabular}{|l|c|c|c|}
\hline P.s.pisi & 0 & 2 & 4 \\
\hline WT & 40,8 & 20619 & 24962 \\
\hline BZI1 $\Delta$ BD & 40,8 & 33427 & 50684 \\
\hline BZI1 $\Delta$ N & 40,8 & 350 & 150 \\
\hline
\end{tabular}

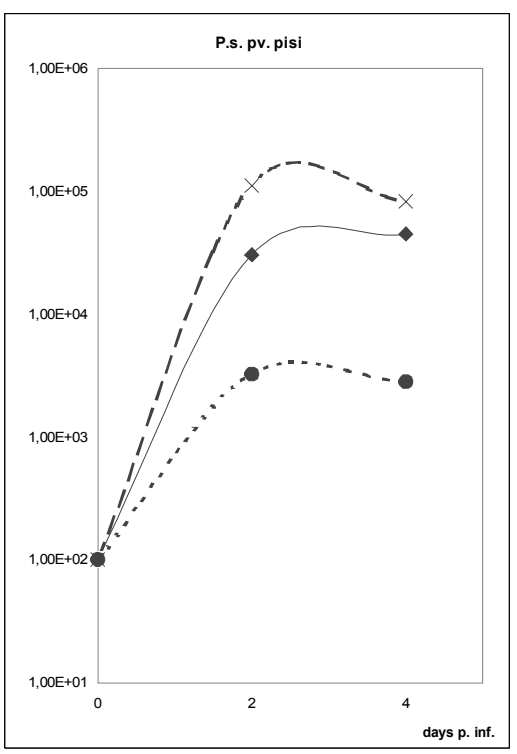

extrapolierte Mittelwerte

\begin{tabular}{|l|c|c|c|}
\hline P.s.pisi & 0 & 2 & 4 \\
\hline Wt & 800 & 11333 & 4867 \\
\hline BZI1Oex & 735 & 13533 & 11667 \\
\hline$\Delta \mathrm{N}$ & 490 & 2600 & 3640 \\
\hline$\Delta \mathrm{BD}$ & 660 & 24800 & 49600 \\
\hline
\end{tabular}

Standardabweichung
\begin{tabular}{|l|c|c|c|}
\hline P.s.pisi & 0 & 2 & 4 \\
\hline Wt & 422 & 4694 & 2457 \\
\hline BZI1Oex & 159 & 4177 & 6430 \\
\hline$\Delta \mathrm{N}$ & 290 & 909 & 640 \\
\hline$\Delta \mathrm{BD}$ & 278 & 6082 & 14755 \\
\hline
\end{tabular}

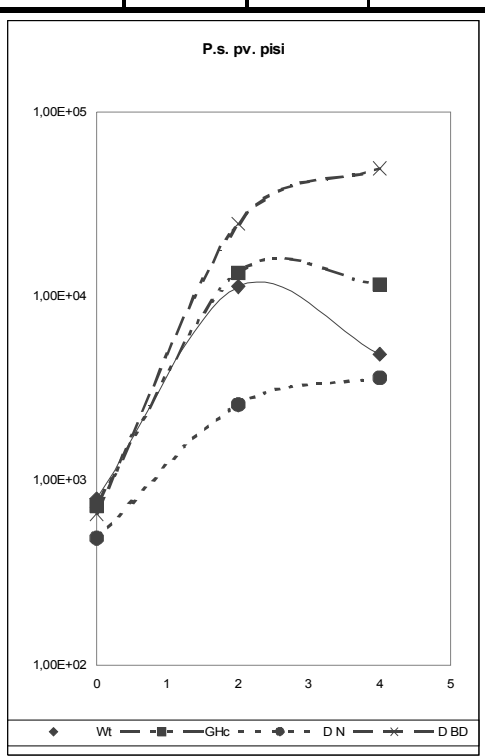

extrapolierte Mittelwerte

\begin{tabular}{|l|c|c|c|}
\hline P.pisi & 0 & 2 & 4 \\
\hline $\mathrm{Wt}$ & 44 & 1211 & 6054 \\
\hline$\Delta \mathrm{DN}$ & 100 & 61 & 315 \\
\hline$\Delta \mathrm{BD}$ & 102 & 2207 & 17467 \\
\hline
\end{tabular}

Standardabweichung

\begin{tabular}{|l|c|c|c|}
\hline P.pisi & 0 & 2 & 4 \\
\hline $\mathrm{Wt}$ & 23 & 297 & 5999 \\
\hline$\Delta \mathrm{DN}$ & 6 & 25 & 199 \\
\hline$\Delta \mathrm{BD}$ & 8 & 1436 & 9795 \\
\hline
\end{tabular}

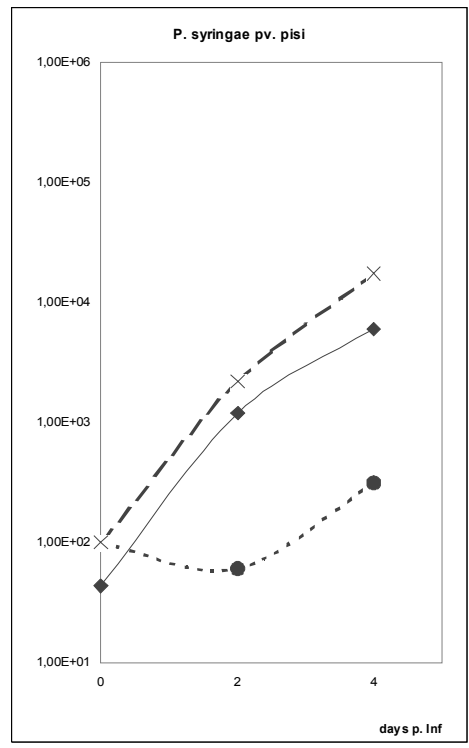

extrapolierte Mittelwerte

\begin{tabular}{|l|c|c|c|}
\hline P.tab & 0 & 2 & 4 \\
\hline $\mathrm{Wt}$ & 375 & 30850 & 330000 \\
\hline$\Delta \mathrm{DN}$ & 240 & 3350 & 5850 \\
\hline$\Delta \mathrm{BD}$ & 98 & 190000 & 750500 \\
\hline
\end{tabular}

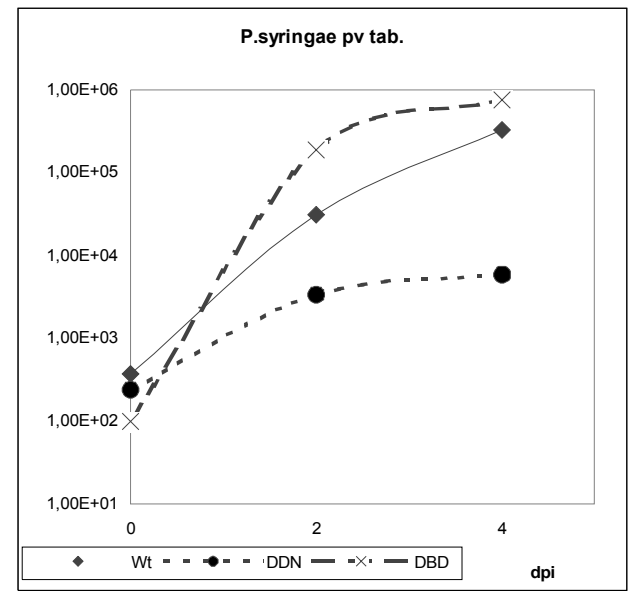

extrapolierte Mittelwerte

\begin{tabular}{|l|c|c|c|}
\hline P.tab & 0 & 2 & 4 \\
\hline $\mathrm{Wt}$ & 54 & 2868 & 12531 \\
\hline$\Delta \mathrm{DN}$ & 25 & 347 & 509 \\
\hline$\Delta \mathrm{BD}$ & 9 & 100325 & 58103 \\
\hline
\end{tabular}

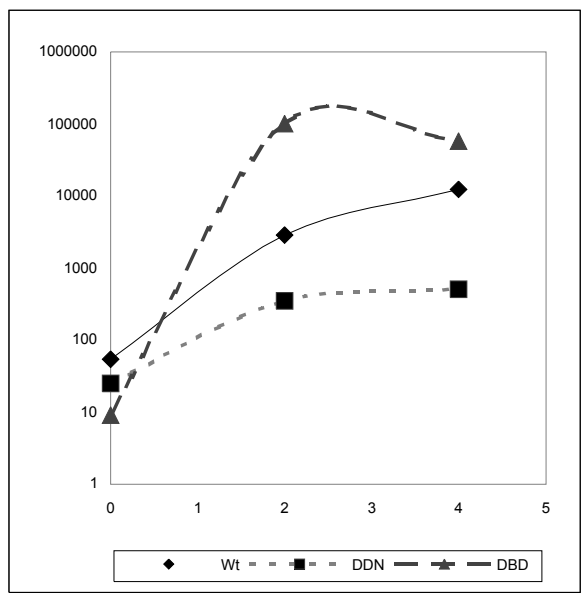

[cfu] reisoliert nach 0, 2 und 4 Tagen Inkubation

G - 7: Detektion des Bakterienwachstums in den transgenen Linien. 


\section{8 |Abkürzungen}

\begin{tabular}{|c|c|}
\hline 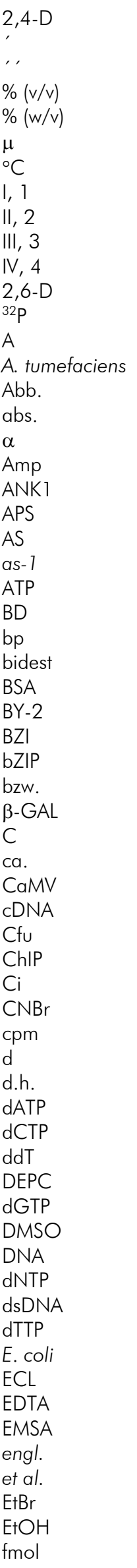 & 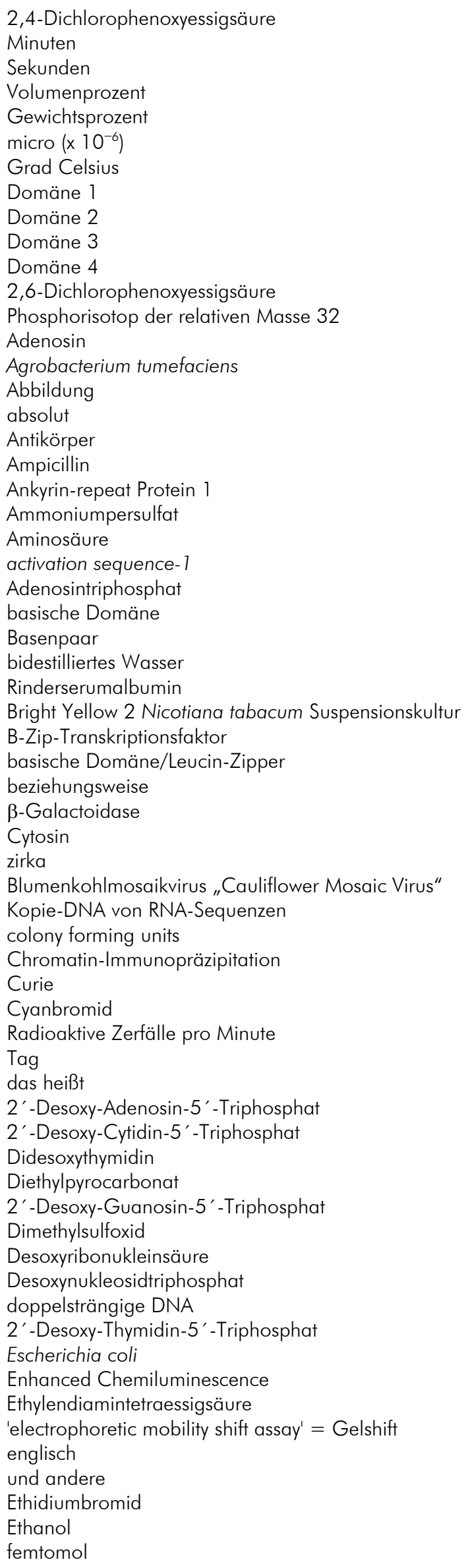 \\
\hline
\end{tabular}




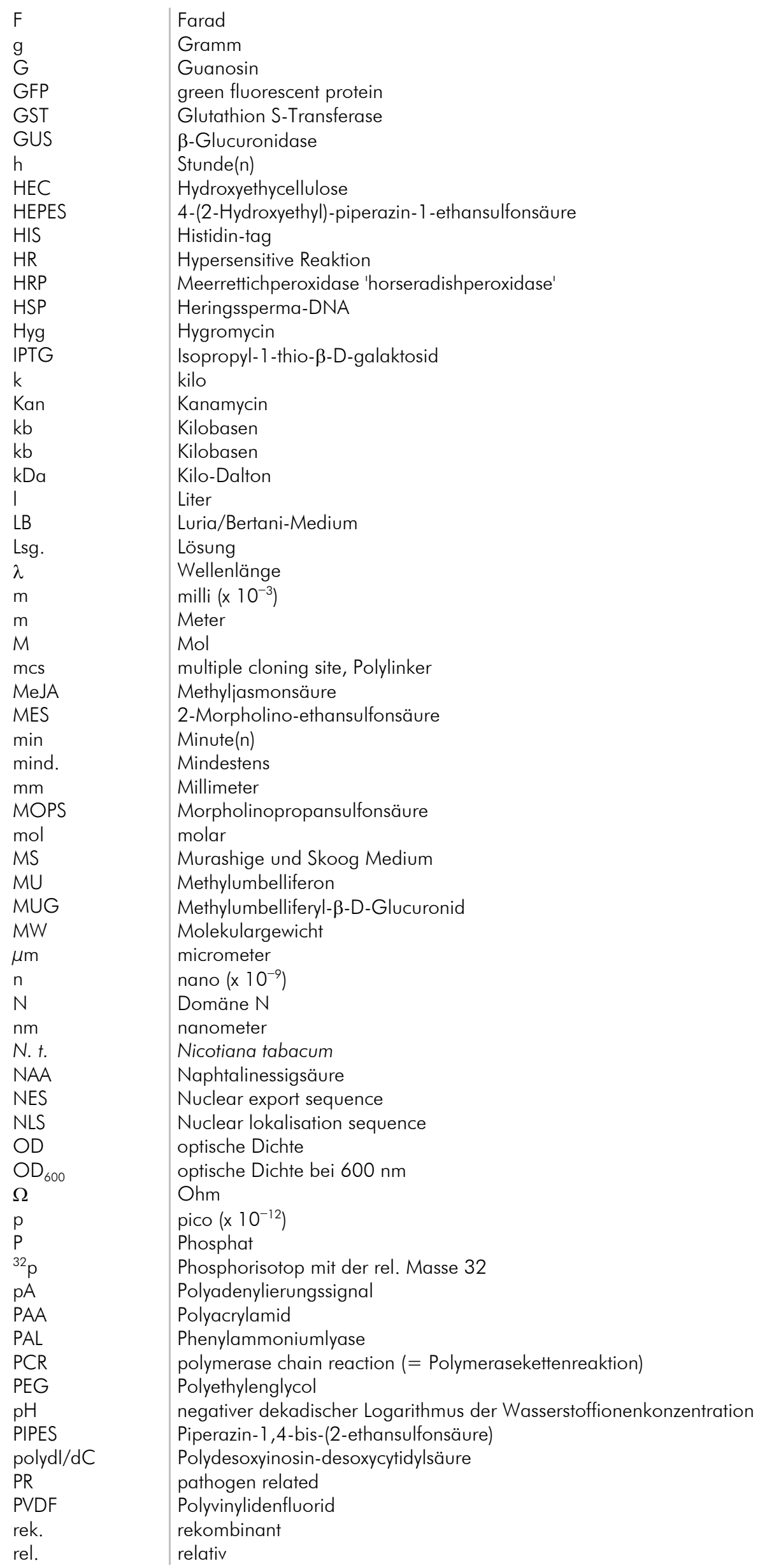




\begin{tabular}{l|l} 
Rif & Rifampicin \\
RNA & Ribonukleinsäure \\
Rnase A & Ribonuklease A \\
ROS & reactive oxygen species \\
rpm & rounds per minute \\
RT & Raumtemperatur \\
s & Sekunde \\
s.o. & siehe oben \\
s.U. & siehe unten \\
SA & Salizylsäure \\
SAR & systemic acquired resistence \\
SDS & Natriumdodecylsulfat \\
sec & Sekunden \\
SNN & Samsun NN, Tabakkultivar \\
SSC & standard saline citrat buffer \\
sSDNA & Einzelstrang-DNA \\
T & Thymin \\
Tab. & Tabelle \\
TAPS & N-[Tris-(hydroxymethyl)-methyl]-3-aminopropansulfonsäure \\
Taq & Thermus aquaticus \\
TEMED & N,N,N',N'-Tetramethylethylendiamin \\
Tris & Tris(hydroxymethyl)aminomethan \\
U & Unit (=Einheit) der Enzymaktivität \\
U.a. & unter anderem \\
U.U. & unter Umständen \\
UORF & upstream open reading frame \\
UTR & untranslated region \\
Ü.N. & über Nacht \\
UV & Ultraviolettes Licht \\
V & Volt \\
Vol & Volumen \\
Vol & Volumen \\
Wt & Wildtyp \\
WNV & zeight per volumen \\
X-Gal & \\
ZIP & zum Beispiel \\
z.B. &
\end{tabular}

\begin{tabular}{l|l|l|l|l|l}
$\begin{array}{l}\text { Symbole für } \\
\text { Aminosäuren }\end{array}$ & Abkürzung & Aminosäure & $\begin{array}{l}\text { Symbole für } \\
\text { Aminosäuren }\end{array}$ & Abkürzung & Aminosäure \\
\hline A & Ala & Alanin & M & Met & Methionin \\
B & Asx & Asparagin oder Asparaginsäure & N & Asn & Asparagin \\
C & Cys & Cystein & P & Pro & Prolin \\
D & Asp & Asparaginsäure & Q & Gln & Glutamin \\
E & Glu & Glutaminsäure & R & Arg & Arginin \\
F & Phe & Phenylalanin & S & Ser & Serin \\
G & Gly & Glycin & T & Thr & Threonin \\
H & His & Histidin & V & Val & Valin \\
I & Ile & Isoleucin & W & Trp & Tryptophan \\
K & Lys & Lysin & Y & Tyr & Tyrosin \\
L & Leu & Leucin & Z & Glx & Glutamin oder Glutaminsäure
\end{tabular}


An dieser Stelle möchte ich mich ganz herzlich bei allen Menschen bedanken, die mir bei dem Entstehen dieser Arbeit zur Seite gestanden haben:

Vielen Dank Frau Professorin Christiane Gatz für die Möglichkeit diese Arbeit anzufertigen, die Aufnahme in die Arbeitsgruppe und Begutachtung der Arbeit.

Mein besonderer Dank geht an Herrn Doktor Wolfgang Dröge-Laser für die hervorragende Betreuung dieser Arbeit. Es hat Spaß gemacht mit dir zu arbeiten und mich in wissenschaftlichen Sichtweisen ein großes Stück weiter gebracht.

Ein weiterer Dank geht an Thorsten Heinekamp für die Zusammenarbeit bei der Erforschung von BZI-1 seit Anbeginn der Laborarbeit. Wird schon komisch ohne dich im Labor...

Dankeschön auch an Anne Strathmann für die Interaktion.

Und einen Dank natürlich auch an alle Mitglieder der AG WDL besonders natürlich an Ute, die mir jederzeit hilfreich zur Seite stand.

Und einen weiteren Dank auch alle Mitglieder der AG GATZ für wichtige Tipps und Hinweise in jeder Lebens- und Laborlage.

Ein weitere Dank geht an meine Freunde Thorsten\&Steffi, Thomas\& Anke, Axel, Alex und Ingo\&Andrea für die Unterstützung in allen Lebenslagen.

Bedanken möchte ich mich auch besonders bei meiner Familie, die mir den Weg zu dieser Doktorarbeit durch ihre Unterstützung und liebevolle Mithilfe überhaupt erst ermöglicht hat.

Und das allergrößte Dankeschön geht natürlich an dich, mein liebe Frau Alexandra für alles $(-)$. 


\section{LEBENSLAUF}

Name

Adresse

Familienstand

Ehefrau

Eltern

Geburtsort

Geburtsdatum

Staatsangehörigkeit

Konfession

Schulbildung

Zivildienst

Studium

Promotion

Rosdorf, 11. März 2002
Markus Kuhlmann

Obere Str. 10

37124 Rosdorf / Göttingen

Tel: 0551-5078270

e-mail:mkuhlma2@gwdg.de

verheiratet (seit Juni 2000)

Alexandra Kuhlmann, geb. Czeko

Paul und Ingeburg Kuhlmann

Herford

22. Juni 1970

deutsch

evangelisch

1976 - 1980: $\quad$ Besuch der Grundschule Altensenne

1980 - 1989: $\quad$ Besuch des FriedrichsGymnasium in Herford

1989: Abschluss Abitur

$1990-1991: \quad \quad K r e i s k r a n k e n h a u s$ Herford

WS 1991 -WS 1997: Universität Bielefeld mit externer Diplomarbeit an der Georg-August-Universität in Göttingen "Funktionale Charakterisierung des pflanzlichen bZIPTranskriptionsfaktors G/HBF-1

19. Januar 1998: Diplom seit Juni 1998 Albrecht-von-HallerInstitut der G-A-Universität in Göttingen

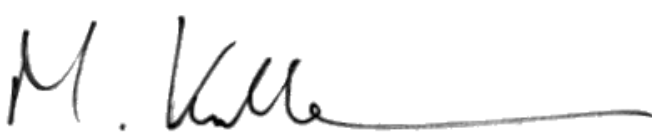

Markus Kuhlmann 